Classification canceled June 12, 1957

Other copies of this report may bear the number NRL-O-2982.

\section{LEGAL NOTICE}

This report was prepared as an account of Government sponsored work. Neither the United States, nor the Commission, nor any person acting on behalf of the Commission:

A. Makes any warranty or representation, express or implied, with respect to the accuracy, completeness, or usefulness of the information contained in this report, or that the use of any information, apparatus, method, or process disclosed in this report may not'infringe privately owned rights; or

B. Assumes any liabilities with respect to the use of, or for damages resulting from the use of any information, apparatus, method, or process disclosed in this report.

- As used in the above, "person acting on behalf of the Commission" includes any employee or contractor of the Commission to the extent that such employee or contractor prepares, handles or distributes, or provides access to, any information pursuant to his employment or contract with the Commission.

Printed in U.S.A., price $\$ 4.00$. Available from the Office of Technical Services, Department - of Commerce, Washington 25, D. C. 


\section{DISCLAIMER}

This report was prepared as an account of work sponsored by an agency of the United States Government. Neither the United States Government nor any agency Thereof, nor any of their employees, makes any warranty, express or implied, or assumes any legal liability or responsibility for the accuracy, completeness, or usefulness of any information, apparatus, product, or process disclosed, or represents that its use would not infringe privately owned rights. Reference herein to any specific commercial product, process, or service by trade name, trademark, manufacturer, or otherwise does not necessarily constitute or imply its endorsement, recommendation, or favoring by the United States Government or any agency thereof. The views and opinions of authors expressed herein do not necessarily state or reflect those of the United States Government or any agency thereof. 


\section{DISCLAIMER}

Portions of this document may be illegible in electronic image products. Images are produced from the best available original document. 


\title{
Liquid Thermal Diffusion
}

\author{
Edited by
}

PHILIP H. ABELSON

Department of Terrestrial Magnetism

Carnegie Institution of Washington

\section{NATHAN ROSEN}

Department of Physics

University of North Carolina

\section{JOHN I. HOOVER}

Nucleonics Division, Naval Research Laboratory, Washington, D. C.

$$
\begin{aligned}
& \text { Exparsion and Revision } \\
& \text { of MMEs - } 1 x-1 \\
& \text { Declassified } 2 / 12 / 57
\end{aligned}
$$

Issuance Date: August 1958

Naval Research Laboratory

Physics Special Research Division

Washington, D. C.

Sept. 10, 1946 


\section{CONTRIBUTING AUTHORS}

J. B. Bidwell

W. N. Blatt

G. Y. Brokaw

M. Drott

F. J. Gradishar

P. N. Kokulis

H. M. Moseley

R. E. Ruskin

J. H. Tayman

W. E. Whybrew 


\section{REPORT PREFACE}

The primary problem, other than finding circumstances under which a controlled chain reaction could be sustained, that faced scientists engaged in this country's atomic energy program in early 1940 was the development of methods for separating uranium isotopes on a large scale. Time would not permit a gradual development of individual separation processes, followed by the full exploitation of the best method. Consequently it was necessary to launch a number of separation projects simultaneously. This report is concerned with the liquid thermal diffusion method for the separation of isotopes.

Work on the liquid thermal diffusion method was initiated after P. H. Abelson and R. Gunn of the Naval Research Laboratory recommended this process to L. J. Briggs in September 1940. The work was carried out successfully at the Naval Research Laboratory through the pilot-plant stage by the spring of 1943 ; subsequently a second, larger pilot plant was constructed at the Philadelphia Navy Yard. A full-scale plant (S-50) was constructed and put into operation during the late summer of 1944.

Part I of this report discusses the experimental aspects of the liquid thermal diffusion method, and Part II discusses the theoretical aspects of the process as they were applied to the design, development, and performance criteria. 


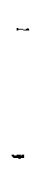




\section{CONTENTS}

PART I. EXPERIMENTAL ASPECTS

\section{CHAPTER 1}

Introduction

\section{CHAPTER 2}

A Survey of the Literature Relevant to Liquid Thermal

Diffusion to 1940 . $\quad$. . . . . . .

CHAPTER 3

History of Liquid Thermal Diffusion from 1940 to 1945

CHAPTER 4

Water Solution Work .

CHAPTER 5

The Column

CHAPTER 6

Experimental Column Studies

\section{CHAPTER 7}

Engineering and Operation

CHAPTER 8

The Pyramid

PART II. THEORETICAL ASPECTS

CHAPTER 9

The Column 
CHAPTER 10

Approach to Equilibrium by a Single Column _ . . $\quad 116$

CHAPTER 11

Effect of Circulation . $\quad . \quad$. $\quad . \quad$. $\quad . \quad$. 137

CHAPTER 12

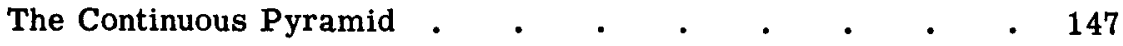

CHAPTER 13

Performance Criteria $\quad$. $\quad . \quad$. $\quad . \quad$. $\quad 155$

CHAPTER 14

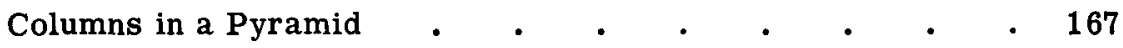

CHAPTER 15

Design and Performance of Small Pyramids $\quad$ • $\quad$ • $\quad$ - $\quad$ - 181

CHAPTER 16

Approximate Treatment of Small Pyramids Approaching

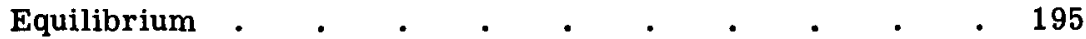

CHAPTER 17

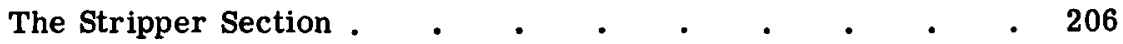

CHAPTER 18

Nonuniform Columns in Parallel Operation $\quad$ - $\quad$ - $\quad$ - 212

APPENDIX A

Critical Temperature Measurement of Uranium Hexafluoride $\quad 223$

APPENDIX B

Pressure-Temperature-Volume Characteristics of Uranium

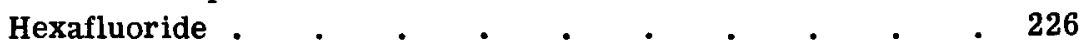

APPENDIX C

Viscosity of Liquid Uranium Hexafluoride $\quad$ - $\quad$ - $\quad$ - 230 


\section{APPENDIX D}

Measurement of Diffusion Coefficient of Uranium

Hexafluoride . . . . . • . . . • 232

\section{APPENDLX E}

Corrosion of Nickel by Uranium Hexafluoride at High Temperatures

Bibliography (1940 to 1946)

Index 
Part I

EXPERIMENTAL ASPECTS 


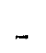

$-$ 


\section{Chapter 1}

\section{INTRODUCTION}

The discovery of uranium fission opened up vast new possibilities for useful applications. Among these was the energy-yielding chain reaction. Since only one uranium isotope $\left(U^{235}\right)$ takes part in this process, it was thought likely that it might be necessary to obtain some separation of the isotopes of uranium in order to liberate energy. Representatives of the Navy were interested in the possible application of atomic energy to submarine propulsion. To attain the small weights and small volume necessary for submarine installations, an energy source built up either of separated uranium or of uranium plus heavy water seemed essential. Accordingly, as early as May 1939, the Naval Research Laboratory (NRL) supported a number of research projects to investigate the separation of uranium isotopes. Some of the aspects of the work carried out by the Navy on the liquid thermal diffusion method of isotope separation are discussed in this report. This chapter deals briefly with the subject of liquid thermal diffusion from four points of view: (1) the role of the method in the production of the atomic bomb, (2) scientific applications of the process, (3) an elementary picture of thermal diffusion, and (4) an outline of some of the more simple theory governing the phenomena.

\section{ROLE OF LIQUID THERMAL DIFFUSION IN THE PRODUCTION OF THE ATOMIC BOMB}

Since preliminary studies of liquid thermal diffusion carried on at the Carnegie Institution of Washington in 1940 showed sufficient promise, a program of study of this method of isotope separation was supported by the Navy through a contract with the Institution. The work was expanded and later transferred to NRL in Washington, D. C. When emphasis was shifted from the energy aspect to the bomb aspect of nuclear fission and the Manhattan Engineer District of the Corps of Engineers was created, isotope studies were still continued at NRL 
with a view toward useful energy production. The liquid thermal diffusion method of separation was brought to a state of practical usefulness early in 1943.

The main part of the research and development work on the method was conducted at NRL by a group of one to six men. In addition to investigating liquid thermal diffusion, this group developed the first practical method of producing uranium hexafluoride, invented the fluorine conditioning technique, and studied many of the chemical and physical properties of uranium hexafluoride, including corrosive effects, vapor pressure, viscosity, critical phenomena, electric conductivity, and self-diffusion.

In the summer of 1943 , a small pilot plant at NRL shipped $236 \mathrm{lb}$ of uranium hexafluoride with partial isotopic separation to the Metallurgical Laboratory in Chicago. This material was of particular value at that time because the electromagnetic devices then being studied at Berkeley were the only other sources of separated uranium. Later, starting in January 1944, a large pilot plant was erected at the naval base in Philadelphia.

In June 1944, responsible officials of the Manhattan District concluded that liquid thermal diffusion could be employed effectively in the atomic bomb program. Accordingly, the efforts of the liquid thermal diffusion group were integrated into the common effort that led to the atomic bomb. The resulting S-50 plant was constructed in the extremely short time of four months, largely through the efforts of Lt. Col. M. C. Fox, Corps of Engineers. This unit served mainly as a feeder for the electromagnetic method. For this purpose, optimum over-all results were obtainable when normal uranium containing 0.715 per cent of $U^{235}$ was enhanced to 0.86 per cent of $U^{235}$. This comparatively modest change was effective for two reasons:

1. The output of a given electromagnetic unit was increased by 20 per cent.

2. Simultaneously, the purity of the output was improved some 20 per cent. The method has been credited with shortening the war by eight days. This was accomplished by the expenditure of $\$ 20,000,000$ for the construction and operation, or about 1 per cent of the total cost, of the Manhattan Project.

Among the outstanding characteristics of the equipment was simplicity, leading to relatively low installation cost and speedy construction. Principal drawbacks were the relatively long relaxation times and the high heat consumption of the plant.

\section{SCIENTIFIC APPLICATIONS OF LIQUID THERMAL DIFFUSION}

The studies described herein were pursued for the purpose of developing a separation method to be used in World War II. Hence, the 


\section{INTRODUCTION}

accuracy obtained and required was only that necessary to give practical answers. Purely by accident, some results of general scientific interest were achieved.

Most of the work is, in no sense, complete from the scientific point of view. This material is presented because it is of historic interest and because it serves as a starting point for further work.

Although the method has been titled liquid thermal diffusion, it should be noted that, in many of the experiments and much of the plant operation, part of the process fluid was at temperatures above critical. Strictly speaking, therefore, the method was a combination of gaseous and liquid diffusion on these occasions. The results of the work suggest that studies of other substances in the gaseous state under high pressure might be of considerable interest.

From the viewpoint of future research, liquid thermal diffusion is of some importance. It is a method applicable to many elements other than uranium and can be used either with pure liquid compounds of the element to be studied or with solutions of the compound in water or other solvents.

For instance, a small column can produce sufficient separation of isotopes in an aqueous solution to aid in the assignment of neutron cross sections of the isotopes of a given element. In the case of radioactive isotopes of unknown mass, the column can be used as a tool in the assignment of mass numbers. Conversely, radioactive isotopes can be used in the study of column properties.

Studies involving liquid thermal diffusion give promise of aiding in the elucidation of the liquid state. The method can be used to separate ions dissolved in water or to separate mixtures of organic materials.

There need be no limitation on hot- and cold-wall temperatures. A small useful installation can, for instance, operate with a hot wall at $0^{\circ} \mathrm{C}$ and a cold wall at $-70^{\circ} \mathrm{C}$. Many valuable results can be obtained in runs lasting a few hours using small columns costing only several cents an hour to operate.

Equipment for some of the studies suggested above can be built for a few hundred dollars. This equipment is extremely simple to operate and requires no delicate adjustments or specialized knowledge.

\section{THERMAL DIF FUSION}

A description of the phenomenon of liquid thermal diffusion is in order at this point.

If a substance, in the for $m$ of a liquid or a gas, consisting of two kinds of molecules (e.g., an aqueous solution of a salt, a mixture of two gases, or a liquid consisting of a chemical compound in which one of the elements is present as two different isotopes) is put into a box- 
shaped container having a pair of opposite walls kept at different temperatures, it is found that the substance, which at the beginning is a homogeneous mixture of the two kinds of molecules, after a while becomes, in general, somewhat inhomogeneous. In the material close to the hotter wall there is an excess of one kind of molecule, whereas near the cold wall another kind of molecule is present in excess. Thermal diffusion may then be thought of as a process in which one kind of molecule tends to move in the direction of rising temperature and another kind of molecule tends to move in the direction of falling temperature.

The extent of the separation brought about by the thermal diffusion process is, however, very limited. This is because the molecules of the substance are in a continuous state of chaotic motion (associated with their thermal energy) so that the two kinds of molecules tend to mix. This is the phenomenon of ordinary diffusion (as distinct from thermal diffusion), and it acts to bring about uniformity in the composition of the substance. The greater the inhomogeneity in the distribution of the molecular species, the faster ordinary diffusion takes place. It then follows that, as one kind of molecule collects near the hot wall and the other near the cold wall, the rate of remixing of the molecules increases until, finally, a condition of equilibrium is reached at which the separation process due to thermal diffusion is just balanced by the remixing process due to ordinary diffusion.

At equilibrium the separation produced is, in general, small; the composition of the substance near the hot wall differs very little from that near the cold wall. It is therefore not practical to try to separate isotopes in a mixture by the simple process of thermal diffusion described above. The method that is actually used, although based on the phenomenon of thermal diffusion, involves an additional phenomenon. The walls of the container, which are kept at the two different temperatures, are vertical and close together. The density of the fluid near the hot wall is decreased, whereas that near the cold wall is increased, and convection sets in, causing the fluid near the hot wall to rise and that near the cold wall to descend. This causes two streams of fluid to flow past each other and, at the same time, exchange molecules of the two species because of the thermal diffusion. The stream near the hot wall catches the molecules moving toward that wall by thermal diffusion and carries them upward, whereas near the cold wall molecules of the other kind are carried down by the convection flow there. The result is that one kind of molecule accumulates near the top of the container whereas the other kind collects near the bottom. Under suitable conditions, this method of countercurrents is much more effective in bringing about separation of the constituents of the fluid than that of the unaided phenomenon of thermal diffusion. It is 


\section{INTRODUCTION}

this combination of thermal diffusion and convection that is utilized in the apparatus to be described.

Although this process can be carried out both in liquids and in gases, it has been found that, for the separation of the uranium isotopes in uranium hexafluoride, the fluid under high pressure produces the most satisfactory yield.

\section{INTRODUCTORY THEORY OF THE COLUMN}

The apparatus used in the work, referred to hereafter as a "column" (see Fig. 7.2), was in the form of three long vertical coaxial cylinders, two of which bounded the space in which the working fluid was kept.

The length of the column used varied in different experiments from 12 to $48 \mathrm{ft}$, the latter being the length finally adopted. The annular space in which the working fluid was kept had a diameter of about $4.25 \mathrm{~cm}$, and the spacing between its walls was of the order of $0.025 \mathrm{~cm}$. The inner, or hot, wall was maintained at a temperature that varied in different experiments from about 150 to about $320^{\circ} \mathrm{C}$, and the outer, or cold, wall was kept at a temperature near $70^{\circ} \mathrm{C}$. When a column is filled with uranium hexafluoride, the process or working fluid, and kept under the conditions described, isotope separation takes place. The fluid at the top of the column gradually becomes richer in the light isotope, $\mathrm{U}^{235}$, whereas that at the bottom of the column acquires relatively more $\mathrm{U}^{238}$.

The separation process can be described quantitatively by introducing the concept of the separation factor. Let us denote by $c$ the concentration of the light isotope, i.e., the fraction of the molecules containing atoms of $\mathrm{U}^{235}$. Then $1-\mathrm{C}$ is the concentration of the heavy isotope. If $c_{T}$ denotes the value of $c$ at the top of the column and $c_{B}$ that at the bottom of the column, the separation factor $S$ is defined by the relation

$$
S=\frac{c_{T} /\left(1-c_{T}\right)}{c_{B} /\left(1-c_{B}\right)}=\frac{c_{T}\left(1-c_{B}\right)}{c_{B}\left(1-c_{T}\right)}
$$

This separation factor plays a fundamental role in the theory of the behavior of the column. To give some idea of the orders of magnitude involved in a typical case, a separation factor $S=1.4$ was obtained in five days, whereas the limiting or equilibrium value obtained after the column had been run for a much longer period was $S_{e}=1.6$. In a few columns, separation factors were much higher, going up to $\mathrm{s}_{\mathrm{e}}=2.5$.

It was pointed out above that one constituent in the column, in this case the lighter one, moves toward the hot wall, whereas the heavier 
one moves toward the cold wall, owing to thermal diffusion, and that at the same time the fluid near the hot wall moves upward, whereas that near the cold wall moves downward, owing to convection. The light constituent therefore accumulates near the top and the heavy one near the bottom. There are, however, factors working to bring about a remixing. The ordinary diffusion process is active: as the concentration up the column begins to vary with the height, ordinary diffusion in the vertical direction sets in, tending to make the concentration more uniform. In addition, mixing takes place between the two streams because of the ordinary diffusion in a horizontal direction from one to the other. Mixing is also caused by local irregularities in the temperature and flow distribution (known as parasitic convection), agitation of the fluid by mechanical vibrations, and other factors.

By taking these various effects into account, the behavior of the column can be described approximately by the following differential equation:

$$
\frac{\mathrm{M}}{\mathrm{L}} \frac{\partial \mathrm{c}}{\partial \mathrm{t}}=-\frac{\partial \tau}{\partial \mathrm{z}}
$$

where $c$, as before, is the concentration of the light constituent; $t$ is the time; $\mathrm{z}$ is the distance measured from the bottom of the column; $M$ is the holdup mass, i.e., the mass of the material in the column; and $\mathrm{L}$ is the length of the column, so that $\mathrm{M} / \mathrm{L}$ is the holdup mass per unit length. The quantity $\tau$ is the net rate of transport of the light constituent and is given by

$$
\tau=\mathrm{Pc}+\mathrm{Hc}(1-\mathrm{c})-\mathrm{K} \frac{\partial \mathrm{c}}{\partial \mathrm{z}}
$$

where $\mathbf{P}$ is the product rate, i.e., the rate at which material is withdrawn from the top of the column; $\mathrm{Pc}$ is the corresponding rate for the light constituent; and $H$ and $K$ are constants. The constant $H$ is associated with the separative process in the column, and $\mathrm{K}$ is associated with the remixing processes.

For the case of small concentrations ( $c \ll 1$ ), it is not too difficult to investigate the problem involving dependence on the time, i.e., when the column is set into operation and approaches equilibrium. If $c \ll 1$, the differential equation, obtained by substituting Eq. 3 with $\mathrm{P}=0$ in Eq. 2, is found to be

$$
\mathrm{X} \alpha^{2} \frac{\partial \mathrm{c}}{\partial \mathrm{t}}=\frac{\partial^{2} \mathrm{c}}{\partial \mathrm{z}^{2}}-\alpha \frac{\partial \mathrm{c}}{\partial \mathrm{z}}
$$


where $\mathrm{X}$, the "time constant" of the column, is given by

$$
\mathbf{X}=\frac{\mathbf{M}}{\mathrm{HY}}
$$

with

$$
\mathrm{Y}=\alpha \mathrm{L}
$$

and

$$
\alpha=\frac{\mathrm{H}}{\mathrm{K}}
$$

If the column is in a steady state

$$
\tau=\text { constant }=\mathbf{P} \mathbf{c}_{\mathbf{T}}
$$

since, in this case, the upward rate of transport of the light constituent must equal the rate at which it is removed from the column. In particular, if no product is being removed $(\mathrm{P}=0)$, equilibrium exists. If $\mathrm{S}$ is defined as before, i.e.,

$$
\mathbf{S}=\frac{\mathbf{c}_{\mathrm{T}}\left(1-\mathbf{c}_{\mathrm{B}}\right)}{\mathrm{c}_{\mathrm{B}}\left(1-\mathrm{c}_{\mathrm{T}}\right)}
$$

it follows that (using the symbol $S_{e}$ to denote the value at equilibrium)

$$
\mathrm{S}_{\mathrm{e}}=\mathrm{e}^{\mathrm{Y}}
$$

If product is being removed $(P>0)$, matters can be simplified by considering the case in which $c$ is very small compared with unity, which is the case of greatest interest at present. Then it is found that

$$
\mathbf{S}=\frac{1+\nu}{\nu+\mathbf{e}^{-(1+\nu) \mathrm{Y}}}
$$

where

$$
\nu=\mathbf{P} / \mathbf{H}
$$

In the problem of approach to equilibrium, with the column either closed at both ends or attached to a storage chamber at one end or the 


\section{LIQUID THERMAL DIF FUSION}

other, or both, the solution of the equation is expressible in the form: $S$ is a certain function of $t / X$ and certain constants associated with the column and the storage chamber. In a number of cases the function can be represented in the form

$$
S=S_{e}-\sum_{n=1}^{\infty} A_{n} e^{-k_{n}(t / X)}
$$

where $A_{n}$ and $k_{n}$ are constant coefficients and $S_{e}$ is the equilibrium value of the separation factor. After a sufficiently long time, all but the first term in the series can be neglected and can be written as

$$
S=S_{e}-A_{1} e^{-k_{1} t / X}
$$

which is of a convenient form.

This equation states that separation in a column approaches an equilibrium value in the familiar exponential manner. 


\title{
Chapter 2
}

\section{A SURVEY OF THE LITERATURE RELEVANT TO LIQUID THERMAL DIFFUSION TO 1940}

\author{
H. M. Moseley
}

To provide the background for the liquid thermal diffusion method of isotope separation, this chapter surveys the status of experiment and theory as it existed in early 1840. Although this report is devoted primarily to the liquid case, experimental work on both gaseous and liquid thermal diffusion will be described because of the similarities between the two processes. Since much less is known about liquids than about gases, analogies to the gas case are of value in planning liquid experiments. The basic process in thermal diffusion is the separation that occurs when a mixture is subjected simultaneously to two different temperatures. The diffusion column merely magnifies the simple ef fect. In the gas case, this simple basic process appears to be understood. For a review of gaseous thermal diffusion, the reader is referred to the work of Jones and Furry.' The basic process in the case of liquids is not understood. For the case of pure substances, almost nothing is known. However, a considerable amount of experimental work and theoretical study has been devoted to a special case of llquid thermal diffusion, the soret effect.

\section{THE SORET EFFECT}

If a temperature gradient is maintained in an originally homogeneous salt solution, it is found that, after a time, a concentration gradient will also exist. This phenomenon was first observed by Ludwig; ${ }^{2}$ however, it became customary to refer to it as the Soret ${ }^{3-b}$ effect, after its second discoverer.

Ludwig placed a solution of $\mathrm{Na}_{2} \mathrm{SO}_{4}$ in a $U$ tube, one limb of which was kept at $100^{\circ} \mathrm{C}$ and the other at $0^{\circ} \mathrm{C}$. After two days he observed solid crystals in the cold $1 \mathrm{imb}$, whereas the concentration in the hot limb had decreased by a factor of $1 / 2$. 
The technique used by Soret was slightly different. A vertical tube of $30 \mathrm{~cm}$ length and $2 \mathrm{~cm}$ diameter was filled with the solution to be investigated, e.g., copper sulfate. The upper end was then heated to, and maintained at, $80^{\circ} \mathrm{C}$, whereas the lower end was held at $20^{\circ} \mathrm{C}$. After a few months, small samples of the solution taken from both ends were analyzed and yielded the following typical results:

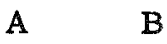

$\begin{array}{lll}\text { Copper sulfate at cold end, \% } & 17.33 & 29.87 \\ \text { Copper sulfate at hot end, \% } & 14.03 & \mathbf{2 3 . 8 2}\end{array}$

Soret studied solutions of $\mathrm{KNO}_{3}, \mathrm{KCl}, \mathrm{NaCl}, \mathrm{LiCl}$, and $\mathrm{CuSO}_{4}$ in this manner, obtaining a small change in concentration in all cases.

No theoretical explanation of the phenomenon was offered until 1887, when Van't Hoff ${ }^{6}$ attempted to account for it on the basis of his theory of dilute solutions. According to Van't Hoff, equilibrium is obtained when the osmotic pressure is the same everywhere, and, since, according to his well-known theory, the osmotic pressure is given by

$$
\mathbf{p}=\mathbf{c R T}
$$

where $c$ is the molar concentration, $R$ is the universal gas constant, and $T$ is the absolute temperature, this view leads to the equation $\mathrm{cT}=\mathrm{a}$ constant, or

$$
c_{1} / c_{2}=T_{2} / T_{1}
$$

as the criterion for equilibrium. When this equation is applied to the data given by Soret, it is found that the ratio of the concentrations should equal 1.205. In the two examples cited above, the values found are (A) 1.235 and (B) 1.254, which are of the correct order of magnitude. Equation 2 proved to be approximately true for $\mathrm{CuSO}_{4}, \mathrm{NaCl}$, $\mathrm{KCl}$, and $\mathrm{LiCl}$.

Using apparatus similar to that employed by Soret, Berchem ${ }^{7}$ investigated aqueous solutions of $\mathrm{HCl}$ and $\mathrm{NH}_{3}$. Shortly thereafter, Arrhenius ${ }^{8,9}$ extended the investigation to more dilute solutions, employing a tube $15 \mathrm{~cm}$ long, the top maintained at $67^{\circ} \mathrm{C}$ and the bottom at $27^{\circ} \mathrm{C}$. Accordingly to the Van't Hoff theory, the equilibrium ratio of the concentrations should equal 1.133. The results given in Table 2.1 (for times of 89 to 90 days) are typical of the data of Arrhenius. Concentration ratios both below and above the theoretical value were obtained. The data of Arrhenius served to indicate that the Soret effect is not completely accounted for by Eq. 2 . Since these data indicate that the effect depends on the substance being investigated and 
its concentration as well as on the temperature difference, they not only demonstrated the incorrectness of the theory but also showed the need for more experimental work.

Abegg, ${ }^{10}$ in a paper dealing mainly with demonstration experiments, discussed the effect of the shape of the apparatus on the time required to obtain substantially equilibrium separation. In his apparatus, in which (1) the interfacial area of hot and cold surfaces was as large as practical and (2) the volume of the cold mass was small in comparison with that of the hot, Abegg obtained crystals of $\mathrm{CuSO}_{4}$ at the cold side after $2 \mathrm{hr}$, as compared with Arrhenius' experimental time of 90 days.

Table 2.1-SORET EFFECT

\begin{tabular}{ll}
\hline \multicolumn{1}{c}{ Solution } & $\mathrm{c}_{27} / \mathrm{c}_{67}$ \\
\hline $0.02 \mathrm{~N} \mathrm{NaOH}$ & 1.087 \\
$0.1 \mathrm{~N} \mathrm{NaOH}$ & 1.123 \\
$1.0 \mathrm{~N} \mathrm{NaOH}$ & 1.167 \\
$0.1 \mathrm{~N} 1 / 2 \mathrm{CuSO}_{4}$ & 1.088 \\
$1.0 \mathrm{~N}^{2} \mathrm{CuSO}$ & 1.456 \\
$1.0 \mathrm{~N} \mathrm{NaCl}$ & 1.049 \\
\hline
\end{tabular}

For the most part, however, little additional experimental work was reported until almost 20 years after the publication of the results of Arrhenius. In 1914 , Wereide ${ }^{11,12}$ reported results on $\mathrm{NaCl}, \mathrm{NaOH}$, and $\mathrm{CuSO}_{4}$; in addition, he extended the investigation to solutions of organic compounds (antipyrine, glycerol, acetic acid, acetone, and alcohol) and nonelectrolytes. Using a small cell of rectangular cross section and $1.5 \mathrm{~cm}$ height in place of the long tube and making his analysis by means of refractive index measurements, he was able to obtain approach-to-equilibrium data without disturbing the system. Wereide proposed a theory based on the change in the rate of ordinary diffusion with the temperature but admitted that his results were not in accord with his theory.

Chipman, ${ }^{13}$ by utilizing the changes in electric conductivity of solutions with change in concentration, was also able to follow the approach to equilibrium. His investigations were, for the most part, concerned with $0.1 \mathrm{~N}$ solutions of about 40 different salts. With the hot temperature at $30^{\circ} \mathrm{C}$ and the cold at $20^{\circ} \mathrm{C}$, he obtained values of the ratio $c_{20} / c_{30}$ randomly distributed between one for $\mathrm{NH}_{4} \mathrm{Cl}$ and three times the theoretical value for $\mathrm{Ba}(\mathrm{OH})_{2}$. No explanation of the discrepancy was offered.

In addition, Chipman investigated 26 solutions of $\mathrm{HCl}$ with concentrations ranging from $0.00002 \mathrm{~N}$ to $13.6 \mathrm{~N}$. He found that the percentage of separation increased steadily as the concentration increased, reached a maximum at about $0.1 \mathrm{~N}$, then fell off for higher concentrations. 
The latest report of experimental work on the Soret effect is that of Tanner, ${ }^{14}$ who, like Wereide, used an optical method of analysis. Tanner investigated solutions of 35 compounds. Porter ${ }^{15}$ attempted to explain some of the results obtained by Tanner by theoretical reasoning different from that of Van't Hoff. By considering a plane being bombarded from opposite directions perpendicular to the plane, he found that the net number of particles passing through the plane is $1 / 6 \mathrm{~d}(\mathrm{cu})$, where $c$ is the concentration of the solvent and $u$ is the average velocity of the particles. Assuming $u$ to be proportional to the square root of the temperature, this yields, at equilibrium

$$
c T^{1 / 2}=a \text { constant }
$$

Like the equation $\mathrm{cT}$ = constant, Eq. 3 agrees with some experimental results and not with others. Consequently, Porter introduced a factor $i$, depending on the ionization, and stated that

$$
\text { ic } T^{1 / 2}=\text { constant }
$$

The presence of the factor i caused the difference in the Soret effect in different cases. Since no further discussion of the $i$ is given, its introduction must be regarded as an ad hoc assumption.

It should also be noted that Eastman, ${ }^{16}$ in applying the first and second laws of thermodynamics to the deduction of equilibrium conditions in nonisothermal systems, has discussed the Soret effect. He arrived at the conclusion that in perfect solutions the Soret effect is entirely the result of irreversible processes and does not represent a thermodynamic equilibrium. In imperfect solutions his work indicates that the Soret effect consists in part of a reversible effect.

In summary, although considerable experimentation is reported in the literature, a satisfactory explanation of the Soret effect has not yet been advanced.

\section{THE THERMAL DIFFUSION (CLUSIUS-DICKEL) COLUMN}

2.1 Note on Theory. The theory of the thermal diffusion column is covered in detail in Chap. 9, references to previous work being given where due. It suffices here to mention those theoretical investigators who were most active in developing the theory during 1939: Furry, Jones, and Onsager, ${ }^{17}$ Waldmann, ${ }^{18,19}$ van der Grinten, ${ }^{20}$ Debye,,${ }^{21}$ and Wirtz. ${ }^{22}$ For the most part, these men dealt with equilibrium conditions and with approximate solutions of the time-dependent differential equation. The exact solution of the time-dependent equation under 
various sets of boundary conditions, for the case in which the concentration of one component is small compared with unity, was later given by Bardeen. ${ }^{23}$

2.2 Experimental Work. In 1938, Clusius and Dickel ${ }^{24}$ ingeniously used convection currents to enhance the normal thermal diffusion process considerably. Their discovery of the fact that the substitution of a horizontal temperature gradient for the vertical gradient increased the separation to an enormous extent made thermal diffusion a method of practical utility for isotope separation.

Shortly after the initial paper of Clusius and Dickel appeared on this subject, describing the "Trennrohr" or separation column only sketchily, a number of investigators, both in the United States and in Europe, began work on the utilization of the thermal diffusion column. Nevertheless, the most comprehensive report on the usefulness of the column and the empirically found laws governing its operation is contained in later papers by Clusius and Dickel。 ${ }^{25-28}$

The column employed by Clusius and Dickel in their preliminary experiments consisted of a glass tube about 1 meter long and of about $1 \mathrm{~cm}$ internal diameter, surmounted by a sphere of about 1 liter capacity. This tube was enclosed in a second tube through which cooling water could be run. An electrically heated chromium-nickel wire, stretched down the center of the tube, served as the hot wall.

A mixture containing 42.5 per cent $\mathrm{CO}_{2}$ and 57.5 per cent $\mathrm{H}_{2}$ was employed to test the operation. The current was adjusted to give a wire temperature of about $500^{\circ} \mathrm{C}$. After $1 \mathrm{hr}, 20 \mathrm{~cm}^{3}$ of gas was drawn off the bottom, the analysis of which showed practically pure $\mathrm{CO}_{2}$ 。 This result was encouraging enough to lead Clusius and Dickel to a further investigation of their Trennrohr.

Their next experiment was with dry air, for which they used a tube of $0.84 \mathrm{~cm}$ radius and $260 \mathrm{~cm}$ length. After $5 \mathrm{hr}$ of operation at a wire temperature of $650^{\circ} \mathrm{C}, 12 \mathrm{~cm}^{3}$ of gas was withdrawn from the bottom of the column; this sample was analyzed as being 43.0 per cent oxygen. Similar results were obtained in various other experiments.

As a final preliminary test to determine whether the method could be used for the separation of isotopes, the $260-\mathrm{cm}$ tube was used to separate the neon isotopes. After an 8-day run, with the wire at $600^{\circ} \mathrm{C}$, a $10-\mathrm{cm}^{3}$ sample yielded the following analysis:

$\begin{array}{lccr} & \mathrm{Ne}^{20} & \mathrm{Ne}^{21} & \mathrm{Ne}^{22} \\ \text { Normal neon, \% } & 90.0 & 0.3 & 9.7 \\ \text { Sample, \% } & 68.4 & 0.6 & 31.0\end{array}$

With these promising preliminary results proving the usefulness of the method, Clusius and Dickel began a lengthy investigation of the 
laws governing the operation of the thermal diffusion column. Their purpose was to determine the dependence of the equilibrium separation and the transport on (1) the radius of the column; (2) the length; (3) the pressure; (4) the mixing ratio of the two species; (5) the temperature difference; and, (6) the time. For ease of analysis, dry $\mathrm{CO}_{2}$-free air was used rather than an isotope mixture.

Rather than a listing of numerical results, a brief summary of their conclusions is given here:

1. Equilibrium separation

(a) Varies approximately as the inverse fourth power of the difference between the radius of the tube and that of the wire in the range $(0.4$ to $1.0 \mathrm{~mm})$ investigated.

(b) Rises to a maximum at a pressure depending, of course, on the values of the other variables, falling off from this maximum at higher pressures approximately as the inverse square of the pressure.

2. Transport

(a) Proportional to the square of the pressure.

(b) Proportional to the fourth power of the tube radius.

(c) Proportional to the square of the temperature difference, so long as this value is small.

(d) Independent of the length of the tube.

3. Approach to equilibrium: Separation is proportional to the square root of the time for comparatively small times.

Finally, using a group of columns connected in series, Clusius and Dickel were able to realize a practically complete separation of the isotopes of chlorine. The product at the heavy end analyzed $99.4 \mathrm{per}$ cent $\mathrm{HCl}^{37}$ and that at the light end analyzed 99.6 per cent $\mathrm{HCl}^{35}$. All tubes had a radius of $0.84 \mathrm{~cm}$ except one, which was $1.28 \mathrm{~cm}$; the hot temperature was approximately $700^{\circ} \mathrm{C}$.

As mentioned above, shortly after the original note by Clusius and Dickel on the thermal diffusion column appeared, several others undertook investigations with it. In most cases the later workers modified the column along the lines introduced by Brewer and Bramley, ${ }^{29-32}$ $i_{.}$e., the hot wire was replaced by an inner tube, so that the material being investigated was contained in the annular space between two concentric cylinders.

Brewer and Bramley, employing a column 1 meter long and using a temperature difference of about $350^{\circ} \mathrm{C}$, studied mixtures of $\mathrm{CH}_{4}$ and $\mathrm{NH}_{3}$. On varying the wall clearance from 0.13 to $2.2 \mathrm{~cm}$, they found that the separation rose sharply with increasing wall spacing, reached a broad maximum at approximately $0.7 \mathrm{~cm}$, and then fell off for larger spacings. The variation of separation with pressure was also studied, and it was found that for the $0.7-\mathrm{cm}$ wall spacing a rather broad maximum occurred at about $20 \mathrm{~cm} \mathrm{Hg}$. 
Brewer and Bramley state that the mechanism of energy flow from the hot to the cold surface consists of a series of swirls in the gas between the surfaces, rather than an over-all convection current up the hot wall and down the cold wall, as assumed by other investigators.

Groth, ${ }^{33}$ using a hot-wire apparatus of $25 \mathrm{~cm}$ length and $0.5-\mathrm{cm}$ wall clearance, studied the separation of the xenon isotopes. His results are positive, but they do not show the quantitative separations since he reports only the difference in atomic weight of samples from the ends of the column. Normal xenon exists as a mixture of nine isotopes. His equilibrium values for the difference in atomic weight of the samples taken from the top and bottom are as follows:

$\begin{array}{cc}\text { Hot temperature } & \begin{array}{c}\text { Change in } \\ \text { atomic weight }\end{array} \\ 1650^{\circ} \mathrm{C} & 0.96 \text { unit } \\ 1200^{\circ} \mathrm{C} & 0.65 \text { unit }\end{array}$

In addition, Groth found a shift in the atomic weight of mercury after a 60-hr run with an apparatus of 2.2 meter length and $0.7-\mathrm{cm}$ wall clearance.

Taylor and Glockler ${ }^{34,35}$ constructed a 40 -ft concentric-tube column with an annular space of $0.9 \mathrm{~cm}$ and employed it to study the possible separation of the carbon isotopes, using $\mathrm{CH}_{4}$. Watson ${ }^{36}$ also studied the separation of the carbon isotopes, obtaining a separation factor of about 2.4 .

Nier and Bardeen, ${ }^{37}$ using a unit $74 \mathrm{ft}$ long, obtained $308 \mathrm{mg}$ of $\mathrm{CH}_{4}$ every $48 \mathrm{hr}$. In this experiment the $\mathrm{C}^{13} / \mathrm{C}^{12}$ ratio was increased 11.3 times.

Korsching and Wirtz ${ }^{38-41}$ investigated the separation of liquid mixtures, e.g., hexane and carbon tetrachloride, and aqueous salt solutions. Using an apparatus of $90 \mathrm{~mm}$ length and $0.25 \mathrm{~mm}$ wall clearance with a temperature difference of $50^{\circ} \mathrm{C}$ and starting with a $50-50 \mathrm{mix}-$ ture of hexane and carbon tetrachloride, they obtained results for a run of one day. On extrapolating these results, they arrived at the

- conclusion that the apparatus would yield an equilibrium separation factor of about 50, with a relaxation time ranging from 500 to 1000 days.

With the same apparatus, the results given in Table 2.2 were obtained for typical salt solutions.

The samples from experiment 4 in Table 2.2 were analyzed spectroscopically by examining the hyperfine structure of the $\mathrm{Zn}$ II line, $\lambda=7479 \mathrm{~A}$, for possible separation of the zinc isotopes. A summary of results is given in Table 2.3 . 
Clusius and Dickel ${ }^{27}$ report the experiments described below, which were carried out in a sheet-iron box $20 \mathrm{~mm}$ by $1 \mathrm{~mm}$ by $150 \mathrm{~cm}$. The top of the box was heated with steam or hot water, whereas the bottom

Table 2.2-THERMAL DIFFUSION SEPARATION OF SOLUTIONS

\begin{tabular}{ccccl}
$\begin{array}{c}\text { Expt. } \\
\text { No. }\end{array}$ & Substance & $\begin{array}{c}\text { Concentration, } \\
\text { mole/liter }\end{array}$ & Time, hr & $\frac{\mathrm{C}_{\text {botom }}}{\mathrm{C}_{\text {top }}}$ \\
\hline 1 & $\mathrm{ZnCl}_{2}$ & 0.1 & 60 & 1.5 \\
2 & $\mathrm{ZnCl}_{2}$ & 0.1 & 72 & 1.75 \\
3 & $\mathrm{ZnSO}_{4}$ & 0.1 & 48 & 4.4 \\
4 & $\mathrm{ZnSO}_{4}$ & 0.4 & 48 & 7.3 \\
5 & $\mathrm{ZnSO}_{4}$ & 0.6 & 48 & 9.5 \\
\hline
\end{tabular}

Table 2.3-ISOTOPE SEPARATION BY LIQUID THERMAL DIFFUSION

\begin{tabular}{lcccc}
\hline & \multicolumn{2}{c}{ Mass-spectro. } \\
\cline { 2 - 6 } & analysis & $\begin{array}{c}\text { Spectro. } \\
\text { analysis }\end{array}$ & \multicolumn{2}{c}{$\begin{array}{c}\text { Concentration } \\
\text { Bottom }\end{array}$} \\
\hline$\frac{\mathrm{Zn}^{64}}{\mathrm{Zn}^{68}}$ & 2.84 & 2.93 & 3.2 & 2.7 \\
$\frac{\mathrm{Zn}^{64}}{\mathrm{Zn}^{66}}$ & 1.85 & 1.89 & 1.95 & 1.7 \\
$\frac{\mathrm{Zn}^{66}}{\mathrm{Zn}^{68}}$ & 1.53 & 1.56 & 1.65 & 1.56 \\
\hline
\end{tabular}

of the box was held at a lower temperature with cold water. Convection was obtained by inclining the box to the vertical, the inclination being adjusted to produce maximum separation.

(a) Liquid Mixtures. An acetone-water mixture, originally 42.2 mole $\%$ acetone, yielded a sample at the bottom, or "heavy" end, containing 6.2 mole \% acetone after operation for $6 \mathrm{hr}$ at a temperature difference of $40^{\circ} \mathrm{C}$. It is noteworthy that water, in spite of its small molecular weight in the monomolecular form, concentrates at the heavy end. This result agrees with the concept of the polymeric structure of water.

(b) Isotope Separation. After a run of $8 \mathrm{hr}$ at a temperature difference of $80^{\circ} \mathrm{C}$, an $\mathrm{H}_{2} \mathrm{O}-\mathrm{D}_{2} \mathrm{O}$ mixture yielded 62.9 per cent $\mathrm{D}_{2} \mathrm{O}$ at the top, or "light" end, and 64.5 per cent $\mathrm{D}_{2} \mathrm{O}$ at the opposite end. The thermal diffusion effect in liquid mixtures of isotopes is demonstrated here for the first time. It is not surprising that the effect is small since the polymerization of water leads to a small value of the ratio $\left(m_{2}-m_{1}\right) /\left(m_{2}+m_{1}\right)$. 


\section{SURVEY OF RELEVANT LITERATURE}

\section{REFERENCES}

1. R. C. Jones and W. H. Furry, Revs. Modern Phys., 18: 151 (1946).

2. Ludwig, Wien. Akad. Ber., 20:539 (1856).

3. Soret, Arch. de Genève, 3: 48 (1879).

4. Soret, Arch. de Genève, 4: 209 (1880).

5. Soret, Ann. chim. et phys., [5]22: 293 (1881).

6. J. H. Van't Hoff, Z. physik. Chem., 1: 487 (1887).

7. Berchem, Compt. rend., 110: 82 (1890).

8. S. A. Arrhenius, K. Vet.-Akad. Forh., 2: 61 (1894).

9. S. A. Arrhenius, Z. physik. Chem., 26: 187 (1898).

10. Abegg, Z. physik. Chem., 26: 161 (1898).

11. Wereide, Ann. phys., 2: 55 (1914).

12. Wereide, Ann. phys., 2: 67 (1914).

13. Chipman, J. Am. Chem. Soc., $48: 2577$ (1926).

14. Tanner, Trans. Faraday Soc., 23: 75 (1927).

15. Porter, Trans. Faraday Soc., 23: 314 (1927).

16. Eastman, J. Am. Chem. Soc., 48: 1482 (1926).

17. W. H. Furry, R. C. Jones, and L. Onsager, Phys. Rev., 55: 1083 (1939).

18. Waldmann, Naturwissenschaften, 27: 230 (1939).

19. Waldmann, Z. Physik., 114: 53 (1939).

20. van der Grinten, Naturwissenschaften, 27: 317 (1939).

21. P. Debye, Ann. Physik., 36: 284 (1939).

22. K. Wirtz, Ann. Physik., 36: 295 (1939).

23. J. Bardeen, Phys. Rev., 57: 35 (1940); 58: 95 (1940).

24. H. Clusius and G. Dickel, Naturwissenschaften, 26: 546 (1938).

25. H. Clusius and G. Dickel, Z. physik. Chem., B44: 397 (1939).

26. H. Clusius and G. Dickel, Z. physik. Chem., B44: 451 (1939).

27. H. Clusius and G. Dickel, Naturwissenschaften, 27: 148 (1939).

28. H. Clusius and G. Dickel, Naturwissenschaften, 27: 487 (1939).

29. A. K. Brewer and A. Bramley, J. Chem. Phys., 7: 553 (1939).

30. A. K. Brewer and A. Bramley, J. Chem. Phys., 7: 972 (1939).

31. A. K. Brewer and A. Bramley, Phys. Rev., 55: 590 (1939).

32. A. K. Brewer and A. Bramley, Science, 90: 165 (1939).

33. Groth, Naturwissenschaften, 27: 260, 584 (1939).

34. Taylor and Glockler, J. Chem. Phys., 7: 851 (1939).

35. Taylor and Glockler, J. Chem. Phys., 8: 843 (1940).

36. Watson, Phys. Rev., 56: 703 (1939).

37. A. O. C. Nier and J. Bardeen, J. Chem. Phys., 9: 690 (1941).

38. Korsching and Wirtz, Naturwissenschaften, 27: 110 (1939).

39. Korsching and Wirtz, Naturwissenschaften, 27: 367 (1939).

40. Korsching and Wirtz, Z. angew. Chem., 52: 499 (1939).

41. Korsching and Wirtz, Z. Elektrochem., 45: 662 (1939). 
Chapter 3

\section{HISTORY OF LIQUID THERMAL DIFFUSION FROM 1940 TO 1945}

In June 1940 the desirability of separating uranium isotopes was very apparent. Although there was some doubt that a nuclear chain reaction might be made to proceed using unseparated uranium, it appeared probable that energy could be obtained from separated isotopes of uranium. The task was clearly enormous. It was certain that either a few kilograms of highly separated material or tons of uranium with a small separation would be required for a chain reaction. The previous rate of separations of light elements was of the order of a fraction of a gram per day. For a heavy element like uranium, the problem of isotope separation would certainly be far more difficult. Of all the methods known at that time, none was understood sufficiently well to permit an immediate engineering development. It was therefore desirable to investigate any method that showed some promise. Liquid thermal diffusion seemed to be such a method.

\section{PRELIMINARY SURVEY OF LIQUID THERMAL DIFFUSION}

It should be clear from Chap. 2 that the knowledge regarding liquid thermal diffusion was far from complete in 1940. A few experiments had been conducted with water solutions and with mixtures of organic liquids. A simple experiment had been conducted with a pure liquid (water), which had given a separation factor of 1.025 . No experiments had been conducted employing heavy elements, and no tests had been made involving uranium in any form. No dependable theory had been evolved covering the phenomena. The dependence of separation on apparatus constants had not even been surveyed, and very little was known regarding behavior as a function of temperature conditions.

Accordingly, in July 1940, an exploratory program was initiated at the Department of Terrestrial Magnetism of the Carnegie Institution of Washington. Work was conducted by P. H. Abelson under the general direction of M. A. Tuve and John A. Fleming, Director of the Depart- 
ment of Terrestrial Magnetism. Their efforts were devoted chiefly to verification of the work of Korsching and Wirt $z^{1-4}$ and an investigation of the effect of apparatus constants and temperature on separation. The general correctness of the German work was verified, and the striking dependence of column behavior on spacing was demonstrated. Temperature conditions and column length were shown to play important roles. Work on a series of potassium salts, $\mathrm{KCl}, \mathrm{KBr}, \mathrm{K}_{2} \mathrm{SO}_{4}$, and $\mathrm{K}_{2} \mathrm{Cr}_{2} \mathrm{O}_{7}$, showed that the isotope separation obtainable in potassium did not vary much with the molecular weight of the substance used. In the case of solutions, it was clear that the primary effect was a separation of solute and solvent. In one experiment where a separation factor of 1.2 was obtained in $\mathrm{K}^{39}$ vs. $\mathrm{K}^{41}$, a simultaneous change in solute concentration at the top of a column of a factor of 14 also occurred.

By extrapolation of this effect, it could be predicted that the solute concentration would rapidly approach zero at the top when greater isotope separations were carried out in an aqueous solution. Studies of aqueous uranium solutions showed further that the compounds used tended to hydrolyze in the column, probably because of changes in $\mathrm{pH}$ occurring during operation of the column. The obvious answer to these difficulties lay in the use of a pure single compound of uranium. Uranium hexafluoride was the only substance then known that seemed to have all the required properties. Unfortunately, this substance had been previously prepared only in quantities of the order of grams. Its physical properties were not well known, and its corrosion characteristics had not been determined.

By September 1940, the work on aqueous solutions had been completed. It seemed worthwhile to expand the research with emphasis on the possible use of $U_{6}$. Ross Gunn, of the Naval Research Laboratory (NRL), was interested in the work, as was Lyman J. Briggs, Director of the National Bureau of Standards (NBS). Both men were then members of the Uranium Committee, with Briggs serving as chairman. An arrangement was made under which NRL made $\$ 2500$ available to the Carnegie Institution of Washington for further studies. It was understood that the Institution would use the money to meet expenses for equipment and to pay Abelson's salary. Because special facilities were available at NBS, the research work was moved there.

\section{PRODUCTION OF URANIUM HEXAFLUORIDE}

The first problem to be solved was the production of $\mathrm{UF}_{6}$. A survey of the possibilities showed that the best method was the fluorination of metallic uranium. The metal was expensive, and fluorine was not commercially available. A method of production was devised employing 
the fluorination of $\mathrm{UF}_{4}$. This substance could be prepared easily and cheaply by ordinary wet-chemical methods. To obtain $\mathrm{UF}_{6}$ from the compound required the addition of two rather than six fluorine atoms. The method was first tried in October 1940 using a fluorine generator at NRL.

Facilities that permitted the production of as much as $800 \mathrm{~g}$ of $\mathrm{UF}_{6}$ per day were then installed in the Chemistry Division at NBS. At that time this installation was the only one in the country capable of producing such amounts. During the major part of 1941 this equipment, together with a similar installation later made at $\mathrm{NRL}$, supplied the research requirements of the various organizations that used $U_{6}$ in isotope separation.

Corrosion studies were made on a number of metals, including nickel and some of its alloys, copper, iron, silver solder, and stainless steel. It was learned that the ability of these substances to withstand attack by $\mathrm{UF}_{6}$ was enhanced by a conditioning process that involved pretreatment with fluorine gas.

\section{INITIAL URANIUM ISOTOPE SEPARATION}

Following the investigation of the chemical properties of $U_{6}$, it was possible to build a liquid thermal diffusion column with some confidence, knowing that the process fluid would not decompose in the column and that the fluid could be handled successfully. Therefore, a column $12 \mathrm{ft}$ long was built and operated with $\mathrm{UF}_{6}$. The runs made on this column in April 1941 showed a small separation about equal to the probable error of the measurement. The decision was then made to build a longer column and use higher temperature differences in an effort to verify the effect. Because special facilities were available at NRL, the work was moved to that site in June 1941. There the work was conducted under the general scientific supervision of Gunn and Rear Adm. H. G. Bowen, Director of the Laboratory. In September 1941, Abelson was joined by John I. Hoover, who was second in command of the experimental work throughout the course of study both at NRL and later at Philadelphia.

Ultimately a high-pressure boiler was obtained, and a 36-ft column was built and installed in January 1942. This column had a spacing of $0.053 \mathrm{~cm}$ and gave a separation of 1.02; its half-time was about one day. A second column, having a spacing of $0.068 \mathrm{~cm}$, gave a separation of 1.014 with a half-time of about one day. These results indicated the need for narrower spacing. In June 1942, a column having a spacing of $0.038 \mathrm{~cm}$ was installed and gave a separation factor of 1.11 with a half-time of about $12 \mathrm{hr}$. With these encouraging results it was a 
simple matter to pursue successfully the question of optimum spacing and to establish that the best value lay close to $0.025 \mathrm{~cm}$.

While the optimum value for spacing was being determined, considerable experience was gained in the operation of liquid thermal diffusion columns employing $\mathrm{UF}_{6}$. It was found that the equipment was easy to operate. By cutting columns apart, it was determined that no great corrosion difficulties were involved. These favorable circumstances led to a decision to increase the scope of the work by building a 14-column pilot plant at NRL. With this equipment NRL hoped to separate small quantities of uranium for experimental purposes and to acquire experience in running a number of columns in series and parallel combinations. It was believed further that, by running a number of columns simultaneously, information might be acquired at a speedier rate. Work on this plant, authorized in July 1942, was substantially complete by November 15 . The plant was placed in successful operation, and in six months it had fulfilled its purpose. During this period, William N. Blatt, Robert E. Ruskin, Edward Drott, Jr., and Waldo E. Whybrew were added to the experimental group; Nathan Rosen carried on the theoretical studies.

\section{VISITS OF MANHATTAN DISTRICT REVIEWING COMMITTEES}

It was the policy of NRL to communicate results to the S-1 Committee, and later to the Manhattan District, as soon as any facts were established. Therefore, in August 1942, Briggs was informed of the new developments regarding the process. This led to a visit by Gen. L. R. Groves and Admiral W. R. Purnell in October. In January 1943, the installation was inspected by a special committee assembled by the Manhattan District. This group consisting of Lyman J. Briggs, H. C. Urey, and E. V. Murphree, with Karl Cohen and W. I. Thompson as advisers. The committee was impressed by the simplicity of the equipment and commented favorably. However, no action was taken.

In an NRL report submitted in January 1943, the advantages of an enriched chain reactor were pointed out, and it was shown that a thermal diffusion plant of purely nominal cost (one to two million dollars) would be adequate to provide the necessary separated isotopes.

During the next six months, improvements were made in column construction. The small pilot plant produced some $236 \mathrm{lb}$ of $\mathrm{UF}_{6}$ having various degrees of isotope separation. The quantity and the isotope separation were greater than that obtained from the gaseous diffusion method up to that time.

In August 1943, another committee was appointed, consisting of Lyman J. Briggs, Harold C. Urey, E. V. Murphree, and W. K. Lewis, 
with Karl Cohen and W. I. Thompson serving as technical advisers. On Sept. 8, 1943, the committee submitted a report to James B. Conant emphasizing the large steam consumption involved in the process if the goal were to be $1 \mathrm{~kg}$ of 90 per cent $\mathrm{U}^{235}$ per day. The magnitude of the proposed steam installation can be judged from the cost $(\$ 70,000,000)$. The thermal diffusion plant itself was estimated to cost $\$ 55,000,000$.

The committee was also concerned with the long equilibrium time required to produce 90 per cent $\mathrm{U}^{235}$. In discussing the use of partially enriched feed for another process, the statement was made: "The possibility of using liquid thermal diffusion for the production of an enriched product such as 3.5 per cent for feed to another type of unit for final enrichment seems inadvisable in view of the large steam consumption and the considerable addition to the time required to reach equilibrium operating conditions." The committee favored "support from the S-1 Committee and the Manhattan District on work directed toward improving the efficiency of the liquid thermal diffusion process."

\section{PHILADELPHIA PILOT PLANT}

NRL decided to continue its isotope studies with the object of providing an alternate method if the magnetic and gaseous diffusion methods failed. Therefore, further work was in the nature of insurance against unforeseen events. A survey of naval establishments indicated that the Naval Boiler and Turbine Laboratory at the Philadelphia Naval Base had a number of unique facilities. Building space was available, cooling water could be obtained easily, and the engineers at the Laboratory had considerable experience with both high-pressure steam and large-scale heavy construction.

Authorization to build a 300-unit pilot plant at Philadelphia was obtained on Nov. 17, 1943, under a project order signed by Rear Adm. Earle Mills, Assistant Chief of the Bureau of Ships. Construction of the installation began about Jan. 1, 1944. The Naval Boiler and Turbine Laboratory was operated under the general direction of Capt. C. A. Bonvillian, and Samuel Wier was assigned by the Naval Boiler and Turbine Laboratory to cooperate with NRL on the construction of the plant. The Naval Boiler and Turbine Laboratory undertook to design, construct, and operate the equipment necessary to supply steam and cooling water for the installation. NRL undertook the design of the columns and the subsidiary equipment necessary for their operation, as well as the operation of the columns. In much of the design, NRL was assisted by Wier. 
In the planning of the Philadelphia plant, a primary aim was to build something that might serve as a model if the Manhattan District should find it desirable to utilize liquid thermal diffusion in their atomic bomb program. Accordingly, the basic unit chosen was a rack consisting of 102 columns, with the thought that, if a large expansion should occur, it would be possible to duplicate the basic unit a large number of times.

\section{THERMAL DIFFUSION PLANT AT OAK RIDGE (S-50)}

In June 1944, the Philadelphia plant was approaching completion. J. R. Oppenheimer learned of the progress and recognized the value that partially separated uranium would have when used in conjunction with the electromagnetic method. At that time the electromagnetic plant was the only unit in operation, and an increase in its production was highly desirable. The potential worth of liquid thermal diffusion as a method of accomplishing this objective was brought to the attention of General Groves by Oppenheimer. Consequently, a reviewing committee that consisted of Richard Tolman, W. K. Lewis, E. V. Murphree, Karl Cohen, and W. I. Thompson visited the Philadelphia installation about June 15, 1944. Their report to General Groves was favorable. The decision was made to build a liquid thermal diffusion plant at Oak Ridge, using steam from a powerhouse built for the gaseous diffusion process. Work on the powerhouse had been completed ahead of the gaseous diffusion plant, so steam was available. On June 26, 1944, General Groves, accompanied by Richard Tolman, W. I. Thompson of the H. K. Ferguson Co., and Lt. Col. M. C. Fox, arrived at NRL for the purpose of obtaining available information concerning work on the thermal diffusion process. Blueprints of the Philadelphia installation were turned over to them. General Groves issued instructions that the Oak Ridge installation was to be built as an exact copy of the Philadelphia plant.

The Oak Ridge installation was constructed with phenomenal speed. Ground was broken for the S-50 plant on July 6, 1944, and the first columns were available for conditioning on September 15. The plant was substantially complete two months later, and the first product was removed Oct. 31, 1944. Considering the magnitude of the task and the wartime conditions prevailing, this accomplishment was certainly record-shattering. It stemmed from perfect teamwork of extremely competent people. As Unit Chief, Lt. Col. Fox coordinated activities and supervised the expediting of materials, which was the crux of the problem. Major Thomas E. Evans, Construction Officer, smoothed the way for C. W. Roberts, Project Manager, and his associates, George Lindquist, General Superintendent, and G. R. Byrd, Mechanical 
Superintendent. Key top personnel of the Ferguson Company included W. I. Thompson, Chief Engineer; Frank Buck, Chief Mechanical Engineer; and W. K. Mitchell, General Manager.

\section{OPERATION AT PHILADELPHIA}

In addition to fulfilling the functions of a pilot plant, the Philadelphia installation shipped more than $5000 \mathrm{Ib}$ of $\mathrm{UF}_{6}$ containing 0.86 per cent $\mathrm{U}^{235}$ to Oak Ridge. A number of process improvement schemes were developed at Philadelphia; among them was the first automatic product withdrawal system. Studies of individual column performance, as well as pyramid feasibility, were likewise made.

Organization at Philadelphia was unique. The Project Officer was Capt. T. A. Solberg, Bureau of Ships. The plant itself was divided into two parts. Steam and water facilities were operated by enlisted personnel at the Naval Boiler and Turbine Laboratory under the direction of Capt. C. A. Bonvillian, with Capt. J. K. McCue, Executive Officer. The process area was the responsibility of NRL. During this period the Laboratory was first under the direction of Rear Adm. A. H. Van Keuren and later under Commodore H. A. Schade. Project officers were Capt. R. H. Gibbs and Capt. J. B. Cochran. Since emphasis was largely on experimental work, it was staffed mainly by technical people. Most of the men, both officers and enlisted men, were naval personnel. They worked under the technical direction of civilian supervisors, P. H. Abelson and John I. Hoover.

Perhaps one of the most important contributions of the Philadelphia plant was its safety program. Following a serious accident on Sept. 2, 1944, Capt. George Lyon (MC), USNR, was assigned to the installation. Through his leadership, an extremely successful safety program was initiated. As a result, no accident involving loss of personnel time was suffered during more than a year of operation. In addition, thorough physical examinations and blood studies were made at frequent intervals. This work demonstrated that the occasional breathing of $\mathrm{UF}_{6}$ fumes produced no permanent changes. Many of Captain Lyon's recommendations were adopted at S-50, which suffered no fatal accident.

\section{OPERATION OF S-50}

To operate S-50, the Fercleve Corporation was formed. This organization was completely owned by the H. K. Ferguson Co. and was established for the purpose of avoiding labor difficulties in operation. The procedure of using the Ferguson Company in this way was adopted to avoid bringing another company into the Clinton Engineer Works, 
both for security reasons and to eliminate friction between construction and operations. Since it was a totally new organization, the Fercleve Corporation was faced with the task of accumulating a staff at a time when few persons of any competence were available. This responsibility fell to Roberts, who built up a very efficient operating organization. The Fercleve Corporation was aided by the assignment of 12 Navy men from the Philadelphia plant during the first two crucial months of operation. In addition, the Manhattan District assigned some 120 technically trained young men of the Special Engineer Detachment to the plant. The Fercleve Corporation was fortunate in securing the services of Malcolm Dole and, later, those of B. F. Dodge, who headed a technical division.

Representing the Manhattan District as Unit Chief until Apr. 1, 1945, Lt. Col. Fox expedited the initiation of successful operation. He was succeeded by Major Evans, who contributed a relentless enthusiasm for improved operating efficiency.

When $\mathrm{K}-25$ came into operation, less steam was available for $\mathrm{S}-50$, and normal operation was terminated Sept. 4, 1945.

\section{REFERENCES}

1. Korsching and Wirtz, Naturwissenschaften, 27: 110 (1939).

2. Korsching and Wirtz, Naturwissenschaften, 27: 367 (1939).

3. Korsching and Wirtz, Z. angew. Chem., 52: 499 (1939).

4. Korsching and Wirtz, Z. Elektrochem., 45: 662 (1939). 


\section{Chapter 4}

\section{WATER SOLUTION WORK}

The early work at the Carnegie Institution and the National Bureau of Standards produced some interesting results on the behavior of water solutions in thermal diffusion columns. This is a field which has been little investigated and which has considerable promise of future interest.

For instance, it is indeed remarkable that Korsching and Wirtz ${ }^{1}$ could produce, in a column $100 \mathrm{~cm}$ long, a separation of $S=1.18$ in the $\mathrm{Zn}^{64}-\mathrm{Zn}^{68}$ isotopes, a result which was essentially verified and extended in the early work using potassium salts. There appear to be obvious ways in which small laboratory-size thermal diffusion columns can be used in research. Hence some description of the early thermal diffusion work may be useful to future investigators in the field.

In addition, this early work was of interest because it pointed out significant variables to be investigated when $\mathrm{UF}_{6}$ was employed in the columns. Although the behavior of water solutions did not appear to parallel exactly that of uranium compounds, those variables that were of greatest importance in the water solution case were found to be similarly important in the uranium studies.

Later it was found that the functional interdependence among separation, temperature, and relaxation time is extremely complex and depends on the spacing employed.

\section{APPARATUS}

The columns consisted of three concentric tubes. In general, the inner tubing served as the hot wall and was heated by radiant energy from an electrical element; the second tube served as the cold wall and was enclosed by a third jacketing tube; cold water flowed between the second and third tubes. The tubes were rigidly soldered together at the top, whereas at the bottom a section of Sylphon bellows was used to take up differential expansion. As a result of this construction, 
WATER SOLUTION WORK

Table 4.1-DESIGN CHARACTERISTICS OF COLUMNS

\begin{tabular}{|c|c|c|c|c|}
\hline $\begin{array}{l}\text { Column } \\
\text { No. }\end{array}$ & $\begin{array}{l}\text { Method of } \\
\text { heating }\end{array}$ & $\begin{array}{c}\text { Wall } \\
\text { spacing, } \mathrm{cm}\end{array}$ & $\begin{array}{c}\text { Hot-wall } \\
\text { diameter, cm }\end{array}$ & Length, $\mathrm{cm}$ \\
\hline 1 & $\begin{array}{l}\text { Radiation from } \\
\text { electrical } \\
\text { resistance }\end{array}$ & 0.20 & 2.6 & 50 \\
\hline 2 & $\begin{array}{l}\text { Radiation from } \\
\text { electrical } \\
\text { resistance }\end{array}$ & 0.080 & 2.6 & 50 \\
\hline 3 & $\begin{array}{l}\text { Radiation from } \\
\text { electrical } \\
\text { resistance }\end{array}$ & 0.080 & 3.9 & 150 \\
\hline 4 & $\begin{array}{l}\text { Radiation from } \\
\text { electrical } \\
\text { resistance }\end{array}$ & 0.0355 & 3.5 & 50 \\
\hline 5 & $\begin{array}{l}\text { Radiation from } \\
\text { electrical } \\
\text { resistance }\end{array}$ & 0.0584 & 3.8 & 50 \\
\hline 6 & $\begin{array}{l}\text { Radiation from } \\
\text { electrical } \\
\text { resistance }\end{array}$ & 0.11 & 3.8 & 50 \\
\hline 7 & Calrod & 0.080 & 3.8 & 60 \\
\hline 8 & Steam & 0.080 & 3.8 & 350 \\
\hline 9 & Steam & 0.057 & 4 & 180 \\
\hline 10 & Steam & 0.11 & 3.1 & 350 \\
\hline 11 & Steam & 0.076 & 3.8 & 350 \\
\hline
\end{tabular}

the bottom of the column had added holdup. In Table 4.1, there is a list of the columns constructed.

\section{RELATION BETWEEN SALT CONCENTRATION AND ISOTOPE SEPARATION}

One of the first facts learned about the thermal diffusion of salt solutions is that the solution tends to become more concentrated at the bottom of the column and more dilute at the top. Later it was found that a relation exists between this change in concentration of a given salt and the isotope separations accompanying the changes in concentration. This relation is illustrated in Table 4.2 , which shows results with solutions of potassium bromide. In Table $4.2, \mathrm{c}_{\mathrm{B}}$ and $\mathrm{c}_{\mathrm{T}}$ are the salt concentrations at the bottom and top of the column, respectively, and $\mathrm{S}$ is the ratio of $\mathrm{K}^{39}$ to $\mathrm{K}^{41}$ divided by that of ordinary potassium. 
Table 4.2-- THERMAL DIFFUSION OF POTASSIUM BROMIDE SOLUTIONS

\begin{tabular}{ccccc}
\hline $\begin{array}{c}\text { Initial } \\
\text { concentration, } \\
\text { moles/liter }\end{array}$ & $c_{\mathrm{B}}$ & $\mathrm{c}_{\mathrm{T}}$ & $\mathrm{c}_{\mathrm{B}} / \mathrm{c}_{\mathrm{T}}$ & $\mathrm{S}$ \\
\hline 2.0 & 2.08 & 1.60 & 1.3 & $1.015 \pm 0.005$ \\
2.0 & 2.21 & 1.05 & 2.1 & $1.045 \pm 0.005$ \\
2.0 & 4.13 & 0.187 & 22.0 & $1.218 \pm 0.005$ \\
\hline
\end{tabular}

The values fit the relation $\mathrm{k} \log \mathrm{S}=\log \mathrm{c}_{\mathrm{B}} / \mathrm{c}_{\mathrm{T}}$, but this may be merely fortuitous.

In the early studies it was convenient to use the concentration change to determine the performance of columns since analysis of the thermal diffusion effects merely required measurement of the densities of sample solutions taken from the columns.

\section{EFFECT OF COLUMN LENGTH}

One of the first relations studied was the dependence of equilibrium separation on column length. The results are summarized in Table 4.3,

Table 4.3-EFFECT OF LENGTH ON COLUMN BEHAVIOR

\begin{tabular}{ccc}
\hline $\begin{array}{c}\text { Apparatus } \\
\text { No. }\end{array}$ & Length, cm & $\mathrm{c}_{\mathrm{B}} / \mathrm{c}_{\mathrm{T}}$ \\
\hline 2 & 50 & 1.43 \\
3 & 150 & 3.01 \\
8 & 350 & 12.5 \\
\hline
\end{tabular}

where $c_{B}$ and $c_{T}$ refer to the concentration of the solution at the bottom and the top of the apparatus, respectively, after the column had been run to equilibrium. These values agree very well with $c_{B} / c_{T}=e^{k L}$.

\section{EFFECT OF TEMPERATURE}

Another study concerned the role that temperature difference plays in salt solution thermal diffusion. The effect of the higher $\Delta T$, as shown in Table 4.4, is indeed remarkable. These values fit the relation $\log \mathrm{c}_{\mathrm{B}} / \mathrm{c}_{\mathrm{T}} \sim(\Delta \mathrm{T})^{2}$ for constant spacing. 
Table 4.4--EFFECT OF TEMPERATURE DIFFERENCE ON COLUMN BEHAVIOR

(Salt, $\mathrm{K}_{2} \mathrm{SO}_{4}, 0.5$ mole/ $/$ iter; length of column, $150 \mathrm{~cm}$; spacing, $0.08 \mathrm{~cm}$ )

\begin{tabular}{rl}
$\Delta \mathrm{T},{ }^{\circ} \mathrm{C}$ & $\mathrm{c}_{\mathrm{B}} / \mathrm{c}_{\mathrm{T}}$ \\
\hline 9 & 1.023 \\
18 & 1.10 \\
30 & 1.31 \\
39 & 1.52 \\
51 & 2.15 \\
78 & 5.5 \\
\hline
\end{tabular}

\section{EFFECT OF SPACING}

Another study demonstrated the crucial dependence of the phenomenon of thermal diffusion on the spacing between the hot and cold walls. The results are given in Table 4.5. These values fit the relation

Table 4.5-EFFECT OF SPACING ON BEHAVIOR

(Length of column, $50 \mathrm{~cm}$; gradient, $375^{\circ} \mathrm{C} / \mathrm{cm}$ )

\begin{tabular}{lll}
$\begin{array}{c}\text { Spacing, } \\
\mathrm{cm}\end{array}$ & $\Delta \mathrm{T},{ }^{\circ} \mathrm{C}$ & $\begin{array}{c}\text { Equilibrium } \\
\mathrm{c}_{\mathrm{B}} / \mathrm{c}_{\mathrm{T}}\end{array}$ \\
\hline 0.2 & 75 & 1.04 \\
0.11 & 40.5 & 1.15 \\
0.08 & 30 & 1.3 \\
0.0584 & 21.8 & 1.6 \\
\hline
\end{tabular}

$\log c_{B} / c_{T} \sim\left(1 / a^{2}\right)$ for temperature gradient constant. Since it has already been shown that $\log c_{B} / c_{T} \sim(\Delta T)^{2}$, by combining the two relations, it can be seen that $\log \mathrm{c}_{\mathrm{B}} / \mathrm{c}_{\mathrm{T}} \sim(\Delta \mathrm{T})^{2} / \mathrm{a}^{4}$. It is interesting to note that, in their studies of gaseous thermal diffusion, Clusius and Dickel found similar relations to hold in a gas.

The theoretical studies show that the $1 / \mathrm{a}^{4}$ relation holds in a region where a $>a_{\text {optimum }}$ corresponding to maximum $Y$. Hence it is infer red

- that the spacings employed in the water studies were considerably wider than optimum. Since this was the case, the dependence on $\Delta \mathrm{T}^{2}$ found above is rather surprising from the theoretical standpoint. It could be due to the presence of complicating factors such as a rapid variation 
in the hydration of the salt or in the association of the water molecules with temperature.

\section{EFFECT OF SALT EMPLOYED}

Some interesting results were obtained when salts of differing weight were used, as shown in Table 4.6. Here $S$, of course, refers to the isotope separation of $K^{41}$ and $K^{39}$. These results were obtained with ap-

Table 4.6 - THERMAL DIFFUSION OF SOLUTIONS OF POTASSIUM SALTS

\begin{tabular}{lccc}
\hline \multicolumn{1}{c}{ Salt } & $\begin{array}{c}\text { Molecular } \\
\text { weight }\end{array}$ & $\mathrm{c}_{\mathrm{B}} / \mathrm{c}_{\mathrm{T}}$ & $\mathrm{S}$ \\
\hline $\mathrm{KCl}$ & 74.56 & 2.0 & $1.045 \pm 0.005$ \\
$\mathrm{KBr}$ & 119.02 & 2.1 & $1.045 \pm 0.005$ \\
$\mathrm{~K}_{2} \mathrm{SO}_{4}$ & 174.26 & 5.5 & $1.034 \pm 0.005$ \\
$\mathrm{~K}_{2} \mathrm{Cr}_{2} \mathrm{O}_{7}$ & 294.22 & 2.5 & $1.035 \pm 0.005$ \\
\hline
\end{tabular}

paratus 3 under the following conditions: power input, $1600 \mathrm{cal} / \mathrm{sec}$; gradient, $625^{\circ} \mathrm{C} / \mathrm{cm}$. It is to be remembered that the molecular weight of these salts in solution is enhanced owing to an unknown degree of hydration.

\section{EQUILIBRIUM TIME}

It will be shown later that theory predicts an exponential approach to equilibrium in liquid diffusion. This relation is applicable when the separation has risen more than halfway to the equilibrium value. Studies of water solutions also showed this behavior to apply. Typical data employing a $\mathrm{K}_{2} \mathrm{SO}_{4}$ solution are given in Table 4.7. The data given in Table 4.7 fit the relation

$$
\log c_{B} / c_{T}=\left(\log c_{B} / c_{T}\right)_{\text {equil. }}\left(1-e^{-R t}\right)
$$

For purposes of this section, it is convenient to use the equation to define $\tau$, relaxation time. The quantity $\tau$ is equal to $1 / B_{0}$. It was found that $\tau$ is sensitive both to spacing and to $\Delta T$.

Typical values are given in Table 4.8. These values of relaxation time are quite different from the much larger ones found by Korsching and Wirtz; ${ }^{1}$ however, this is not surprising in view of the sharp de- 
WATER SOLUTION WORK

Table 4.7-APPROACH TO EQUILIBRIUM

(Length of column, $50 \mathrm{~cm}$; spacing, $0.08 \mathrm{~cm}$; operated at a hot-wall temperature of $87^{\circ} \mathrm{C}$ and a cold-wall temperature of $24.5^{\circ} \mathrm{C}$ )

\begin{tabular}{rl}
\hline Time, min & $\mathrm{c}_{\mathrm{B}} / \mathrm{c}_{\mathrm{T}}$ \\
\hline 10 & 1.15 \\
20 & 1.28 \\
30 & 1.37 \\
120 & 1.43 \\
240 & 1.43 \\
\hline
\end{tabular}

Table 4.8-EFFECT OF SPACING ON RELAXATION TIME (Length of column, $50 \mathrm{~cm}$; gradient, $375^{\circ} \mathrm{C} / \mathrm{cm}$ )

\begin{tabular}{cc}
\hline Spacing, cm & $\begin{array}{c}\text { Relaxation } \\
\text { time, min }\end{array}$ \\
\hline 0.11 & 7 \\
0.08 & 20 \\
0.0584 & 120 \\
\hline
\end{tabular}

pendence of $\tau$ on the spacing. Most of the German work was done with narrower spacing.

\section{PARASITIC EFFECT OF AZIMUTHAL GRADIENTS}

To obtain any desired temperature of the hot wall, the use of Calrod (heater element for electric ranges) appeared feasible. This material can be silver-soldered to an outer casing that can be soft-soldered to the hot wall. However, it was soon found that this means of heating leads to a serious parasitic convection effect, which limits the useful temperature difference between the two walls.

Experiments were carried out using a $\mathrm{K}_{2} \mathrm{SO}_{4}$ solution in apparatus 7 . Results are summarized in Table 4.9. In the first three experiments the heat was applied by means of four Calrods spaced $90 \mathrm{deg}$ apart. In the last four experiments the heat was applied at eight 45-deg intervals. It is apparent that small azimuthal gradients can have serious effects. Furthermore, this effect becomes more pronounced as the transverse gradient is increased. 


\section{LIQUID THERMAL DIFFUSION}

Table 4.9-PARASITIC EFFECTS OF AZIMUTHAL GRADIENTS

\begin{tabular}{cccc}
\hline $\begin{array}{c}\text { Azimuthal } \\
\text { gradient, }{ }^{\circ} \mathrm{C} / \mathrm{cm}\end{array}$ & $\begin{array}{c}\text { Transverse } \\
\text { gradient, }{ }^{\circ} \mathrm{C} / \mathrm{cm}\end{array}$ & $\begin{array}{c}\text { Equilibrium } \\
\mathrm{c}_{\mathrm{B}} / \mathrm{c}_{\mathrm{T}}\end{array}$ & $\begin{array}{c}\text { Equilibrium } \mathrm{c}_{\mathrm{B}} / \mathrm{c}_{\mathrm{T}} \\
\text { (azimuthal gradient } \\
\text { approaches zero) }\end{array}$ \\
\hline 3.7 & 625 & 1.42 & 1.54 \\
4.1 & 700 & 1.44 & 1.75 \\
6.0 & 900 & 1.47 & 2.42 \\
1.0 & 625 & 1.53 & 1.54 \\
1.15 & 700 & 1.73 & 1.75 \\
1.45 & 900 & 2.23 & 2.30 \\
1.6 & 1000 & 1.93 & 2.96 \\
\hline
\end{tabular}

As a result of these experiments, efforts to use Calrod were abandoned, and steam was used as a source of heat. The use of steam greatly reduced parasitic effects.

\section{REFERENCE}

1. Korsching and Wirtz, Naturwissenschaften, 27: 110 and 367 (1939). 
Chapter 5

THE COLUMN

The key to the liquid thermal diffusion process is the individual column. In this chapter the principal factors involving the construction of this basic unit, its operation, and the analysis of samples from it are discussed.

\section{PROPERTIES OF PROCESS FLUID}

The design of equipment and most of the problems of developing the liquid thermal diffusion process hinged on the physical and the chemical properties of the process fluid, $U_{6}$. This substance is a crystalline solid at room temperature, with a density of about 4.60 . It melts at $64.1^{\circ} \mathrm{C}$ under a pressure of about $1 \frac{1 / 2}{2}$ atmospheres. The process of melting is accompanied by an increase in volume of nearly one-third. The liquid has a density of 3.7 at the melting point, which diminishes to 1.4 at the critical temperature $\left(232^{\circ} \mathrm{C}\right)$. In Appendix $\mathrm{A}$, curves are given showing the variation of density of the substance with temperature, as well as the dependence of the vapor pressure on temperature. Uranium hexafluoride has a thermal conductivity of about 0.00038 $\mathrm{cal} / \mathrm{cm} / \mathrm{sec}$, and it does not conduct electricity.

Uranium hexafluoride is very reactive chemically. It is instantly hydrolyzed by water, being converted into solid $\mathrm{UO}_{2} \mathrm{~F}_{2}$. Since $\mathrm{UO}_{2} \mathrm{~F}_{2}$ occupies more volume than $U_{6}$, the hydrolysis process can lead to difficulty when it occurs inside a limited space. Uranium hexafluoride reacts with most organic materials at a rate that is dependent on temperature, with the production of $U F_{4}, H F$, and $C$. It also reacts with most metals to form $U_{4}$, in addition to the metallic fluoride. With a few metals, such as nickel, an extremely thin coating of fluoride serves to protect the metal from further action. Very early in the development of the thermal diffusion process, a technique was evolved in which equipment was "conditioned" by exposing it to fluorine gas. At $300^{\circ} \mathrm{C}$ conditioned nickel reacts with $\mathrm{UF}_{6}$ at a rate of less than $2 \mathrm{mg} / \mathrm{sq} \mathrm{ft} /$ day. 
Of the substances tested, nickel is by far the most resistant to corrosion; hence, it was chosen for use wherever hot process fluid might be found. At temperatures below $100^{\circ} \mathrm{C}$, copper can be employed, although not so satisfactorily as nickel.

\section{COLUMN STRUCTURE}

"The basic requirements of the thermal diffusion process for $U F_{6}$ are a hot wall $\left(200\right.$ to $300^{\circ} \mathrm{C}$ ) and a cold wall (approximately $64^{\circ} \mathrm{C}$ ). The typical $48-\mathrm{ft}$ column consumes $200 \mathrm{Btu} / \mathrm{sec}$. The area through which this heat must be transmitted is close to $20 \mathrm{sq} f \mathrm{f}$. To maintain column stability in the process fluid, it is desirable that any gradient of density within the column be such that the fluid is less dense at the top. Consideration of the heat quantities and thermal coefficients involved dictates that the heat be supplied by condensing steam and that heat be removed from the cold wall by cooling water.

Therefore, the thermal diffusion column consisted of three concentric tubes. The central tube, made of nickel, was heated by condensing steam (introduced at the top) on its interior wall. The outside of the nickel tube and the inside of the second tube (copper) bounded an annular space about $0.025 \mathrm{~cm}$ wide that was filled with process fluid. The copper was cooled by the circulation of water flowing upward between it and the outer iron pipe.

The nickel tubing used was chiefly commercial grade, in 12-ft lengths, selected for accuracy. Nickel spacer buttons $1 / 16$ to $1 / 8$ in. in diameter were spot-welded to the surface of the tubing $90 \mathrm{deg}$ apart at 6 -in. intervals. They were finished to the proper height, with allowance made for expansion, to an accuracy of $\pm 0.001 \mathrm{~cm}$. Four lengths of tubing were acetylene-welded together to give the desired 48-ft length. The copper tubing used was commercial grade, processed in the mill with special care. The copper was slipped over the nickel and joined to it by a silver-soldering technique employing a collar also of copper. At the ends of the column a short length of nickel of the same diameter as the copper was spliced to the copper by silver soldering. This permitted junction of the hot and cold walls by means of a nickelnickel weld.

One of the factors to be considered in the design of a column is thermal expansion. If a copper tube and a nickel tube are $48 \mathrm{ft}$ long at room temperature, they will, if unconstrained, differ in length by over 1 in. under operating conditions. In early column design this expansion was taken up in Sylphon bellows, which had the disadvantage of excessive holdup. Because of the high pressures involved, it was necessary to use a four-ply bellows, which proved difficult to silver-solder so as 
to be leak-free. It was further learned that the nickel and copper tubings tended to become "hung up" on each other, thus minimizing the value of the expansion joint. Therefore, it was decided to fasten the hot and cold walls together rigidly at the ends of the column. To minimize stress, this welding was performed with a temperature difference one-half that of the operational conditions. Thus at room temperature the nickel was under a tension of $14,000 \mathrm{lb} / \mathrm{sq}$ in., whereas at operating temperature the nickel was under a compressive force of $14,000 \mathrm{lb} / \mathrm{sq}$ in. The copper was subjected to a force equal in magnitude, but opposite in direction, to that in the nickel. Both the metals were annealed during the welding and silver-soldering processes. Hence, it was necessary to work-harden them to prevent deformation when excessive stress was applied.

With respect to the outer jacket, expansion of the nickel-copper ensemble was provided for by means of a packed slip joint. Coincident with the longitudinal expansion was a change in relative diameters of the hot and cold walls. In a typical instance, the hot nickel expanded $0.010 \mathrm{~cm}$ in diameter with respect to the copper. This factor was taken into account when choosing pairs of tubing to form the hot and cold walls.

The crucial column variable is the spacing between the hot and cold walls. A typical spacing employed was $0.025 \mathrm{~cm}(0.010 \mathrm{in}$.). It was assumed, and later demonstrated, that the magnitude and accuracy of the spacing are extremely important.

In practice it proved difficult to maintain proper spacing in the column. The difficulty was due to the quality of tubing used, to faults in construction, and to various types of damage occurring during operation. These factors will be considered next.

\section{COLUMN IMPERFECTIONS}

Although typical commercial tubing is, for most purposes, surpris-

- ingly accurate, careful examination reveals deviations from perfection. One of the common faults is that the tubing is elliptical rather than circular. It is not uncommon to find a difference of $0.010 \mathrm{~cm}$ between the major and minor axes of 2-in. copper tubing, whereas nickel is more nearly circular. Another imperfection is a variation in diameter along the length of the tube. This discrepancy, which is more pronounced in nickel than in copper, can amount to as much as $0.08 \mathrm{~cm}$. A third imperfection is the eccentricity of the inside and outside circles. As a result, the wall of a tube may be nominally $0.150 \mathrm{in}$. thick but may be found to measure from 0.140 to $0.160 \mathrm{in}$. This effect was more pronounced in nickel than in copper. Of the three defects, oval- 
ness seemed to be the most serious and the most common. Studies showed that it could be removed by honing.

Very few serious divergences from perfect spacing arose as a result of constructing the column. Use of Precisionaire gauges and sufficient inspection assured accurate measurement of sizes and choice of the best lengths of tubing. Height gauges made it possible to obtain an accuracy of $0.0010 \mathrm{~cm}$ in spacer height.

The obvious imperfection introduced in construction came from joining the copper and nickel 12-ft lengths. Much of this error was eliminated by obtaining 24-ft lengths of nickel and, ultimately, 48-ft lengths of copper. Imperfection in both the nickel and the copper welds consisted mainly of an offset at the junction. In both cases, annealing occurred during the joining process. This was most serious in the case of copper. The metal became so thoroughly annealed that it was necessary to work-harden it in order to restore, at least partially, its elastic limit. The hardening process introduced imperfections in the spacing near the joints.

The most serious deviations in column spacing were those which were introduced during operation of the column. They were largely associated with the stresses set up when a column was brought from ambient temperature to operating temperature.

In some cases the copper tubing was not sufficiently hardened, and tension, which resulted from operating temperatures, caused the tubing to yield, increasing in length and decreasing in diameter. Often the $0.025-\mathrm{cm}$ spacing was reduced to practically zero. On other occasions, excessive fluid pressure in the column caused the copper tubing to bulge at the joints. Occasionally the annular space was increased by a factor of 10 .

Similarly, in the case of the inner nickel tubing, the compressive force was sometimes sufficient to exceed the elastic limit, resulting in a simultaneous local shortening and bulging of the nickel at the welds.

Imperfect conditioning of columns before the introduction of process fluid caused serious difficulty. In particular, incomplete removal of moisture resulted in the formation of $\mathrm{UO}_{2} \mathrm{~F}_{2}$ near the copper splices. In some instances, sufficient decomposition almost completely stopped the flow of fluid in the column.

Another source of imperfection in spacing arose as a result of the compressive force on the nickel tubing and tended to cause buckling. Resistance to this tendency was the function of the spacer buttons. Often the forces involved proved sufficient to press the spacer into the copper. This was particularly true when buttons $1 / 16$ in. in diameter were used. 


\section{COLUMN OPERATION}

The columns were hung vertically since they were supported on a

- steel framework. Steam was introduced at the top of the column, and condensate was removed at the bottom. A cooling water inlet was located at the bottom of the column, with the outlet at the top. To maintain the desired cooling temperature of about $64^{\circ} \mathrm{C}$, water was circulated through the column by means of a pump; some hot water was bled off at the top of the column, whereas sufficient fresh water was added at the bottom to the ingoing stream to keep the circulating stream at the desired temperature.

The handling of the process fluid required some special techniques. Suitable packing materials were not developea for $\mathrm{UF}_{\mathrm{g}}$ until late in the project. Efforts were therefore directed toward the development of packless devices. Valve action was obtained by freezing the process fluid. This was easy because most of the connecting lines carrying $\mathrm{UF}_{6}$ were of small bore and the melting point of the substance is $64.1^{\circ} \mathrm{C}$.

The transfer of fluid from one container to another was accomplished by taking advantage of the vapor pressure of $U F_{6}$. Liquid could be distilled out of the top of a container into a colder one or the pressure could be used to force liquid out of the bottom of a container into another container. Differential pressure in a closed fluid system was obtained by the use of the thermal syphon effect. By making the two arms of the syphon $48 \mathrm{ft}$ long, it was possible to obtain differentials of as much as 10 psi.

After a column was mounted in position and connected to steam and water lines, it was given a treatment designed to prepare it for the process fluid. It was degreased, washed with acid and water, and then thoroughly dried by passing air through the equipment and evacuating. The final preparatory step was to condition with fluorine gas at operating temperatures for $30 \mathrm{~min}$. With the conditioning procedure completed, the column was ready for process fluid. The average $48-\mathrm{ft}$ column had a holdup of $2000 \mathrm{~g}$ when operating with a hot-wall temperature of $188^{\circ} \mathrm{C}(160 \mathrm{psi}$ steam) and a holdup of $1600 \mathrm{~g}$ when operating with a hot-wall temperature of $286^{\circ} \mathrm{C}$ (1000 psi steam). To supply the fluid, an auxiliary chamber (termed a "reservoir"), containing from 3 to $170 \mathrm{~kg}$ of $\mathrm{UF}_{6}$, was connected to the column. With the cooling water for the columns heated to $64^{\circ} \mathrm{C}$ and the hot wall at a temperature midway between the cold-wall and operating temperatures, the reservoir was heated. As the temperature rose in the reservoir, the process material was first liquefied; then, as the temperature increased further, the vapor pressure in the chamber drove the process fluid into the column. In principle, almost any pressure can be developed simply by regulating the amount of fluid in the reservoir and by choosing a proper temperature. Reflection will show that it is necessary to sub- 
ject the column to a pressure greater than the vapor pressure of $\mathrm{UF}_{6}$ at the hot-wall temperature. If such a pressure is not applied, process fluid boils at the hot wall, and violent motions of fluid in the column occur which have a mixing effect far greater than the separating effect of the thermal diffusion process.

Another object in having a reservoir connected to the column was to take up changes in operating conditions. This was especially necessary when the hot-wall operating temperature was low $\left(188^{\circ} \mathrm{C}\right)$. Under these circumstances the process fluid was fairly incompressible, and a sudden temperature increase would cause it to expand. If there were no possibility of pressure relief, very large pressures could be developed. The converse is also true: If the operating temperatures dropped suddenly, the density of the process fluid would increase, its volume would decrease, and hence the fluid would no longer occupy the full volume of the column. As a result, boiling would occur at the hot wall, and the separative work that had previously been accomplished would be destroyed. The presence of a reservoir operating at a suitable pressure removed these difficulties.

It can be seen, however, that a certain interchange of fluid would occur between the reservoir and the end of the column to which it was attached. This interchange would be variable if it were not controlled. The obvious way of controlling it was to establish deliberately a continuous circulation between the reservoir and the column. To establish such a circulation, some pressure differential was required. The method chosen was that using a thermal syphon. Actually, with single columns, thermal syphons with members only a few feet long produced sufficient pressure differential, and hence velocity of circulation.

When the column was full, the temperature in the reservoir was regulated to obtain the desired pressure. The column temperatures were then brought to the desired operating condition. The action of the convective loop was checked by a calorimetric-type flowmeter to ascertain whether the fluid was actually flowing.

Most of the runs were uneventful. Occasionally, however, a sudden shutdown would occur. This introduced a problem. If the shutdown was caused by failure of power or of the steam supply, the column, as it cooled, increased in holdup for two reasons: (1) the actual spacing in the column increased by about 20 per cent and (2) the density of the process fluid increased by about 15 per cent. If the power supply failed for a long enough time so that the steam pressure fell to zero and the cooling water dropped below $64^{\circ} \mathrm{C}$, the column became filled with solid $\mathrm{UF}_{6}$, and the holdup of the column was increased about 70 per cent over normal. If the reservoir was located at the bottom of the column, this led to considerable difficulty. Since the steam was introduced at the top of the column, the fluid at that point would melt first. Since the 
process fluid on melting increased in volume by one-third, whereas at the same time the volume available for the fluid diminished as the temperature difference between the hot wall and cold wall increased, pressures of the order of 100,000 psi could be developed, causing stresses in the column greatly in excess of the elastic limits of the walls. As a result, either rupture or permanent deformation occurred. Two remedies were found. The first was to prevent flow of additional fluid into the column when a power failure occurred. This was accomplished by isolating the reservoir from the column. In this event, when the process fluid solidified in the column, it would solidify in the lower two-thirds of the unit, leaving the upper third empty and available as space for the expanding melting fluid when the column was again put into operation. The second remedy was to remove process fluid from the top of the column, obviously an inconvenient procedure.

In order to study the operation of the column, it was necessary to remove samples of process fluid from time to time. This was necessarily done while the column was in operation and under pressures of 500 to $1500 \mathrm{psi}$. By freezing a small section ( $5 \mathrm{~cm}$ in length) of the process fluid using dry ice, it was possible to establish a plug in a $1 / 8$-in. - I.D. tube that would not fail under the action of 1500 psi pressure. This tube could then be uncapped and a sampling tube attached. When the frozen portion was warmed to above the melting point of the process fluid, liquid flowed into the sampling tube. At first the samples taken were as large as $50 \mathrm{~g}$, later they were reduced to $10 \mathrm{~g}$, and finally, as a result of the intervention of the theoretical physicists, they were diminished to $1 \mathrm{~g}$.

\section{SAMPLE ANALYSIS}

One of the principal problems in any isotope research is the measurement of isotope separation. This is especially true when the separation factors are small, as was the case early in the research. The effects obtained with water solutions of potassium salts were measured by A. K. Brewer, using a mass spectrograph. Practically all the analytical work with uranium was performed on Nier mass spectrographs, the earliest analyses being made at the University of Minnesota by Nier himself. Later, about 750 samples were measured by E. P. Ney, F. C. Armistead, and J. H. McQueen, using a Nier-type instrument at the University of Virginia. Later still, a mass spectrograph was constructed by Ney and McQueen for use in the pilot plant at Philadelphia, and this instrument handled analytical problems for the Philadelphia installation. During the early phase of the research, some measurements were made by L. H. Curtiss at the National Bureau of Standards by means of an alpha-counting technique. 
Measurement of the isotope separation of uranium in the form of $\mathbf{U F}_{6}$ is complicated by an unlooked-for phenomenon that has been called "memory effect." When $\mathrm{UF}_{6}$ is introduced into the mass-spectrograph source, a stream of electrons ionizes it. Part of the ionized molecules pass through the slit system and arrive at the collecting electrode. A very large majority of the ionized molecules, however, do not follow this path but are deposited on the walls of the ion source. In chemical composition these molecules are largely $\mathrm{UF}_{4}$ or $\mathrm{UF}_{5}$. At room temperature, the vapor pressure of $U_{F}$ in the $U F_{5}$ is approximately 1 millimeter. Under high-vacuum conditions, therefore, $U F_{6}$ volatilizes out of the compound, leaving $U F_{4}$ behind. If new $U F_{8}$ is introduced into the instrument, some of it reacts with $\mathrm{UF}_{4}$ to form $U F_{5}$. When this $U F_{5}$ is reconverted into $\mathrm{UF}_{4}$ plus $\mathrm{UF}_{6}$, an exchange process occurs between the deposited $\mathrm{UF}_{4}$ and the new $\mathrm{UF}_{6}$, i.e., the $\mathrm{UF}_{6}$ coming off the wall does not have the same isotopic concentration as that which struck the wall. Hence, after an ion source acquires a thin layer of $\mathrm{UF}_{4}$, results obtained from the mass spectrograph are a function of the materials which have been analyzed previously in the instrument and which have been deposited on the walls of the ion source. For instance, if a large number of samples with an isotopic concentration about equal to that of normal uranium have been analyzed in the machine and then a sample with an enhanced quantity of $U^{235}$ is analyzed, the value obtained for the enhanced sample is less than that actually present. The error introduced by memory effect can result in a difference of 10 to 20 per cent in the observed isotope separation. All the errors that have so far been considered tend to lower the observed values obtainable in column studies rather than to increase them. One of the principal reasons memory effect was important in the study was that the sample to be measured was always compared with normal uranium. The memory effect always produced values tending toward those for normal uranium, whether the sample measured was enhanced or impoverished in $\mathrm{U}^{235}$.

One of the best solutions of the difficulty was to use substandards established immediately after a fresh ion source had been installed in the instrument and before appreciable quantities of $\mathrm{UF}_{4}$ could collect in the source. In making measurements, the sample was compared with a substandard having an isotope abundance about equal to that predicted for the sample. Even so, some memory effect was found to be present.

Experience in the analytical laboratory at S-50 pointed to another solution. At the S-50 plant, instruments were installed both for massspectrograph measurements and for measurements by the alphacounting technique. The alpha-counting technique proved eventually to be the more reliable. Obviously, this method was not complicated by the memory effect. 


\section{Chapter 6}

\section{EXPERIMENTAL COLUMN STUDIES}

In this chapter some of the experimental results obtained from studies of the thermal diffusion column are discussed. The principal questions to be considered are (1) determination of column constants, (2) approach to equilibrium, (3) product rate vs. concentration, and (4) column performance as a function of spacing, length, temperature, and fluid pressure. In addition, observations will be presented on columns supposedly identical in construction.

\section{COLUMN CONSTANTS}

The characteristics of a uniform column can be described by the quantities $X, Y, M$, and $H . M$ is the fluid holdup mass of the column, $X$ is the time constant, $Y$ is the logarithm of the separation factor at equilibrium, and $\mathrm{H}$ is the separative constant of the column. These constants will be discussed more fully in Part II. For the present it will suffice to point out that they satisfy the relation

$$
\mathrm{X}=\frac{\mathrm{M}}{\mathrm{HY}}
$$

- and that they play the following roles in the experimental work.

The equilibrium separation factor is given, of course, by $\mathrm{e}^{\mathrm{Y}}$. The constant $\mathrm{H}$ determines the product rate during steady operation; the

- greater $\mathrm{H}$ is, the greater is the product rate for a given value of $\mathrm{Y}$ at a given separation factor.

The relation among half-time, product withdrawal rate, figure of merit, and pyramid performance is extremely complicated. In contrast, it has been found that the quantity $X$, which has the dimensions of time, is simply related to the performance qualities of the column. Furthermore, it is easy to determine $X$ experimentally. Therefore, the time performance of the column is described in terms of $X$. The manner in which this quantity can be measured will be described later. For the 
case of an infinite reservoir, with the column closed at the top end, a few numerical values are given in Table 6.1 with a typical value of $\mathrm{X}$ to

Table 6.1-RE LATIONS AMONG COLUMN CONSTANTS

\begin{tabular}{cccccc}
\hline $\mathrm{Y}$ & $\mathrm{S}_{\mathrm{e}}$ & $\begin{array}{c}\mathrm{t} / \mathrm{X} \\
{\left[\mathrm{S}=\frac{1}{2}\left(\mathrm{~S}_{\mathrm{e}}+1\right)\right]}\end{array}$ & $\begin{array}{c}\text { Half-time } \\
(\mathrm{X}=40 \text { days })\end{array}$ & $\begin{array}{c}\mathrm{t} / \mathrm{X} \\
\left(\mathrm{S}=\mathrm{e}^{\mathrm{Y} / 2}\right)\end{array}$ & $\begin{array}{c}\text { Half-time } \\
(\mathrm{X}=40 \text { days })\end{array}$ \\
\hline 0.1 & 1.11 & 0.002 & 0.08 & 0.002 & 0.08 \\
0.2 & 1.22 & 0.009 & 0.36 & 0.009 & 0.36 \\
0.3 & 1.35 & 0.022 & 0.88 & 0.018 & 0.72 \\
0.4 & 1.49 & 0.040 & 1.60 & 0.033 & 1.32 \\
0.5 & 1.65 & 0.066 & 2.64 & 0.052 & 2.08 \\
0.6 & 1.82 & 0.102 & 4.08 & 0.075 & 3.00 \\
0.7 & 2.01 & 0.146 & 5.84 & 0.104 & 4.16 \\
0.8 & 2.23 & 0.202 & 8.08 & 0.138 & 5.44 \\
0.9 & 2.46 & 0.273 & 10.92 & 0.157 & 6.28 \\
1.0 & 2.72 & 0.356 & 14.24 & 0.220 & 8.80 \\
\hline
\end{tabular}

show the relation between the constants. Half-time can be defined conveniently in two ways: (1) the time required for $S$ to go halfway to its equilibrium value, $S=1 / 2\left(S_{e}+1\right)$, and (2) the time required for $\ln S$ to go halfway to its equilibrium value, $\ln S=1 / 2 Y$, or $S=e^{Y / 2}$.

It will be shown in Part II that the figure of merit of a column, a quantity to serve as a measure of the usefulness of the column, can be defined as

$$
\Phi \quad \mathrm{HY} \quad \frac{\mathrm{M}}{\mathrm{X}}
$$

In view of the relation among these quantities, it is necessary to know only $\mathrm{X}, \mathrm{Y}$, and $\mathrm{M}$ in order to predict the behavior of a column at any product rate or to predict the approach to equilibrium when the column is run either alone or as part of a pyramid. The problem of measuring the holdup is trivial and needs no elaboration. Measurement of $\mathrm{X}$ and $\mathrm{X}$ is therefore the principal problem in liquid thermal diffusion work. Theoretical work has shown how these quantities can be measured by studying the behavior of a column during its approach to equilibrium.

\section{APPROACH TO EQUILIBRIUM}

In Part II the equations governing the approach to equilibrium for a column closed at the top are derived and discussed. The solutions are of the form 


$$
\begin{aligned}
& S=1+\frac{2}{\sqrt{\pi}} \sqrt{\frac{t}{X}}+\frac{1}{2} \frac{t}{X}+\ldots\left(\frac{t}{X} \ll 1\right) \\
& S=e^{Y} \sum_{n-1}^{\infty} A_{n} e^{-k_{n} t / X} \quad \text { (t arbitrary) }
\end{aligned}
$$

It should be noted that the general form of these equations will be the same for various substances and that they are valid to the extent that the concentration of the rare isotopes is small compared with unity. The constants will, of course, vary from substance to substance.

The general characteristics of Eq. 4 are shown in Fig. 6.1. The solid line represents the theoretical curve. The points are experimental.

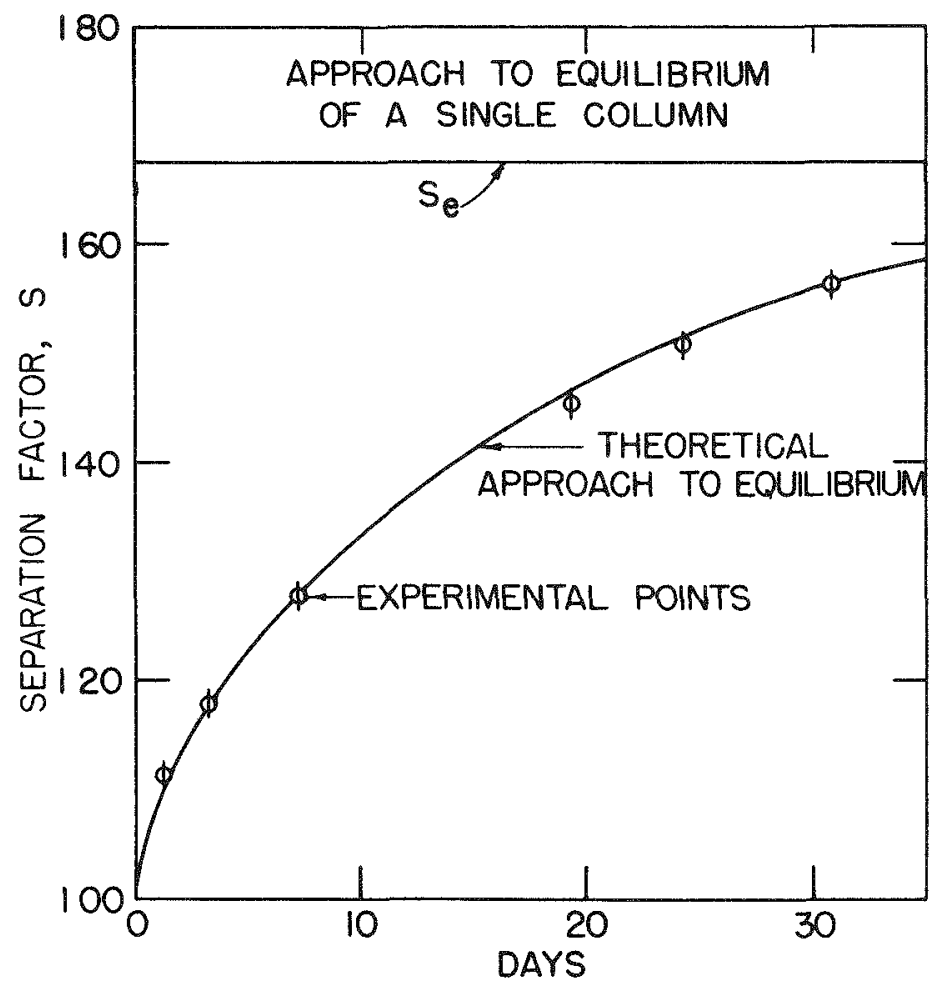

- Fig. 6.1-Approach to equilibrium of a single column with a large reservoir and no holdup at the top. Initial build-up of separation is $(t / X)^{1}$. At times greater than the half-time, the behavior follows the familiar exponential approach to equilibrium. 
Let us consider further the nature of Eqs. 3 and 4. The two variables appearing are $\mathrm{X}$ and $\mathrm{Y}$. At very short times the separation increases very rapidly, as $t^{1 / 2}$. At longer times the separation increases as $t$. At still longer times it follows an exponential approach toward a limiting value.

It will be seen that the time $t$ appears only in the combination $t / x$, as might be expected from the form of Eq. 3 and the boundary conditions. Hence, it is convenient to plot $S$ as a function of $t / X$, different curves being obtained for different values of $Y$. When such a family of curves has been derived, a comparison of the curve of $S$ vs. $t$ obtained experimentally for a given column with the calculated curves serves to determine the values of $\mathrm{X}$ and $\mathrm{Y}$ for which the best agreement is obtained.

The difficulty in such a comparison arises from the fact that different values of $X$ correspond to different time scales in the graph of $S$ vs. $t$, and it is not easy to determine simultaneously the appropriate time scale and the appropriate member of the calculated family of curves.

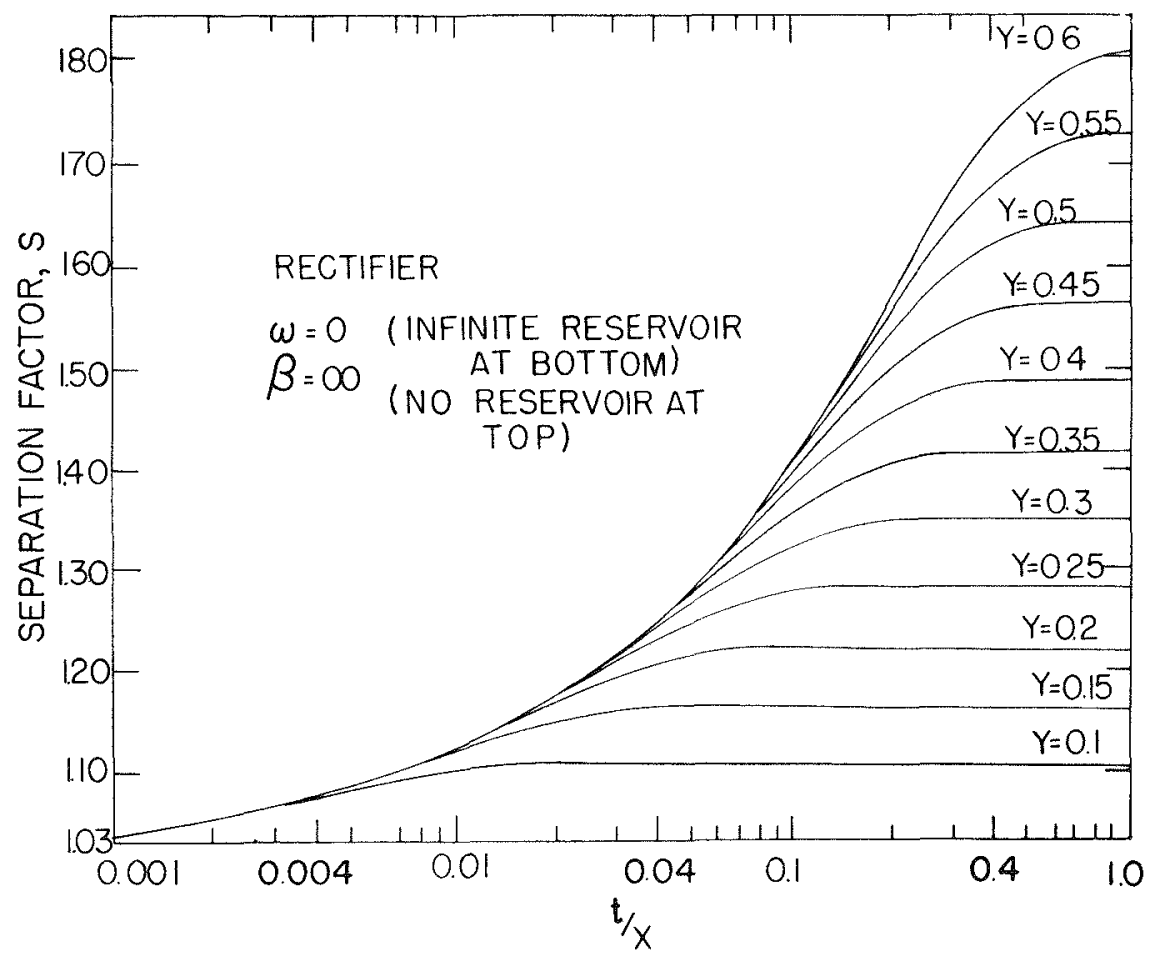

Fig. 6.2-Family of curves for rectifiers with various values of $Y$ showing approach to equilibrium. Plotted on a logarithmic scale, the curves permit easy determination of column constants. The curves apply where the concentration of the desired isotope is small. 
This difficulty has been largely overcome in Fig. 6.2, in which graphs of $S$ vs. $t / X$ are presented, with a logarithmic scale for $t / X$. In this case, a change of $X$ corresponds simply to a displacement of the curves horizontally without any change of shape. The procedure for using the curves of Fig. 6.2 is as follows:

The experimental values for $S$ are plotted on a thin sheet of graph paper with the same ruling as that in Fig. 6.2 , with the same scale of ordinates and with the time expressed in any convenient units. This sheet is superimposed on Fig. 6.2 so that corresponding ordinates coincide, then the sheet is placed horizontally in a manner that will ensure the best fit between the experimental points and one of the calculated curves. From this curve (or possibly by interpolation) $Y$ is obtained, and, from a corresponding pair of values of $t$ on the experimental graph and $t / X$ on the theoretical one, $X$ is obtained.

As pointed out previously, for small values of $t / X, S$ is independent of $\mathrm{Y}$; consequently, all the curves of Fig. 6.2 nearly coincide. This makes the curve fitting particularly simple: the fitting of experimental points for small values of $t$ to the (nearly unique) curve serves to determine $\mathrm{X}$; the experimental points for larger values of $t$ make it possible to determine $\mathrm{Y}$.

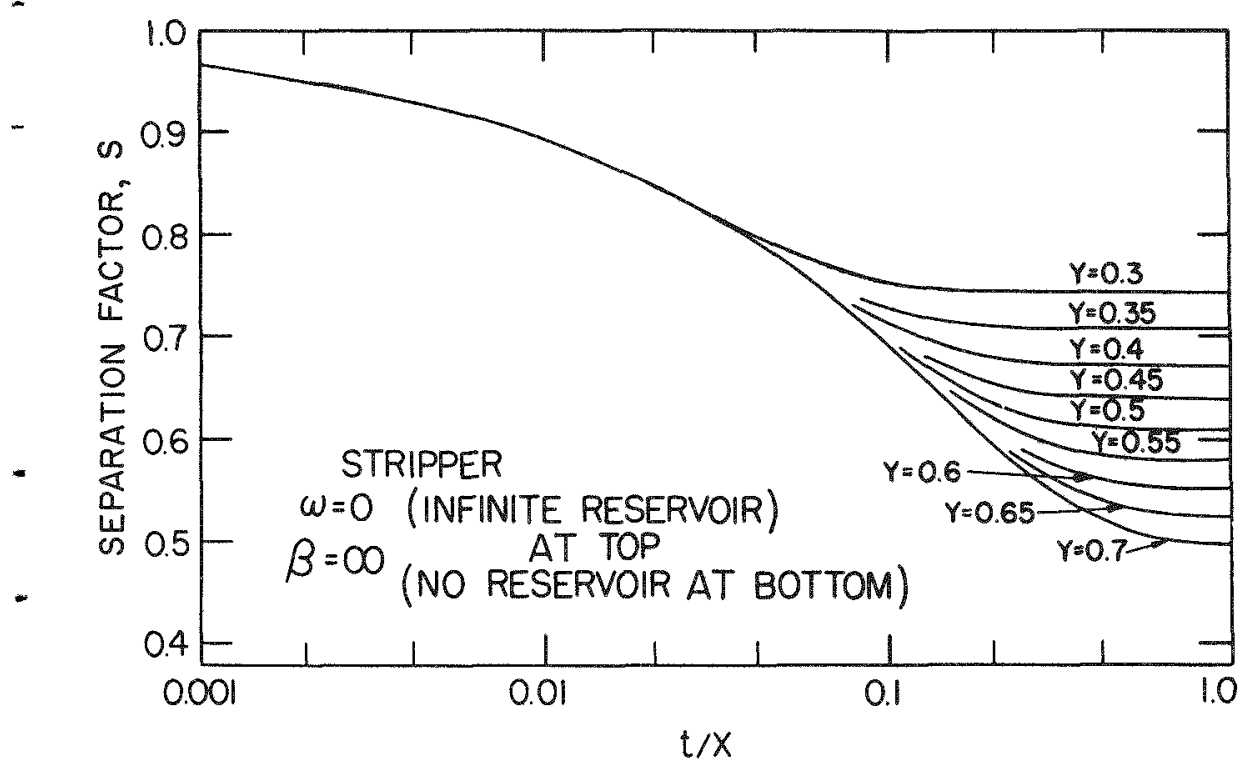

- Fig. 6.3-Family of curves for strippers with various values of $Y$ showing approach to equilibrium. Plotted on logarithmic scale, the curves permit easy determination of column constants. The curves apply where the concentration of the desired isotope is small. 
Figure 6.3 shows a family of curves for $S$ as a function of $t / X$, for various values of $Y$, for a stripper column. The curves are intended to be used to determine the constants of a stripper in the same way those of Fig. 6.2 are used for the rectifier. Columns have been run both as rectifiers and as strippers. If the column is uniform, the column constants should be the same in both cases. As might be expected, it was found that the value of $\mathrm{Y}$ was the same. In general, the value obtained for $X$ was somewhat larger (10 per cent) in the case of the stripper. This finding is attributed to the less satisfactory heat-transfer conditions at the bottom of the column, which result in a lower hot-wall temperature. In other cases it was found that $X$ for a column operated as a stripper was quite different from the value determined for a column operated as a rectifier. When the curve of approach to equilibrium was examined, it was noted that the value of $X$ at different points on the curve was not constant. The source of the discrepancy was traced to gross nonuniformities in the column, such as a constriction at one end.

\section{PRODUCT RATE VS. CONCENTRATION}

In Sec. 2 a convenient method of determining column constants was discussed. It was stated that knowledge of these quantities permitted the prediction of the behavior of a uniform column at any given withdrawal rate. Now the question of product removal from a single-stage rectifier will be discussed. For the case of an element where concentration of the sought species is small

$$
\mathrm{S}=\frac{1+\nu}{\nu+\mathrm{e}^{-(1+\nu) \mathrm{Y}}}
$$

$\nu=\mathrm{P} / \mathrm{H}$, where $\mathrm{P}$ is the product rate and $\mathrm{H}$ is a column constant. Both quantities are, of course, expressed in grams per unit time.

Table 6.2-ISOTOPE SEPARATION VS. PRODUCT RATE

\begin{tabular}{rccccccc}
\hline M, g & X, days & \multicolumn{1}{c}{ Y } & H, g/day & $\mathrm{P}_{\text {s }}$ g/day & $\nu$ & $\begin{array}{c}\text { Calcu- } \\
\text { lated S }\end{array}$ & $\begin{array}{c}\text { Ob- } \\
\text { served S }\end{array}$ \\
\hline 1980 & 153 & 0.48 & 27.0 & 87.4 & 3.24 & 1.26 & 1.27 \\
1980 & 1.52 & 0.43 & 30.4 & 47.2 & 1.55 & 1.35 & 1.35 \\
1980 & 181 & 0.4 & 27.4 & 22.8 & 0.83 & 1.40 & 1.39 \\
1500 & 34 & 0.65 & 68 & 226.0 & 3.32 & 1.28 & 1.27 \\
\hline
\end{tabular}

The relation has been verified in a number of experiments. In particular, results were obtained from several columns shown to be rea- 
sonably uniform by runs both as strippers and as rectifiers and by examination of the curve for the approach to equilibrium. The value taken for $\mathrm{X}$ was the average from the two types of runs. Results are given in Table 6.2, where it is seen that the agreement is very good.

\section{REPRODUCIBILITY OF RESULTS}

Observations on the reproducibility of results have been made. When a given column was studied it was found that results were reproducible even at intervals of several months. The situation was not so bright, however, when an attempt was made to build a number of columns all alike. Even with care and close inspection and with selected tubing, a variation in results was found. An experiment was conducted at the Naval Research Laboratory (NRL) on seven columns under particularly satisfactory conditions. The results obtained are shown in Table 6.3.

Table 6.3-COMPARATIVE PERF ORMANCE OF A GROUP OF COLUMNS

(Spacing, $0.026 \mathrm{~cm} ; \mathrm{T}_{1}, 185^{\circ} \mathrm{C} ; \mathrm{T}_{2}, 63^{\circ} \mathrm{C}$ )

\begin{tabular}{ccc}
\hline $\begin{array}{c}\text { Column } \\
\text { No. }\end{array}$ & $\mathrm{X}$ & $\mathrm{Y}$ \\
\hline 1 & 166 & 0.53 \\
2 & 153 & 0.48 \\
3 & 160 & 0.53 \\
4 & 153 & 0.43 \\
5 & 210 & 0.40 \\
6 & 181 & 0.40 \\
7 & 153 & 0.50 \\
\hline
\end{tabular}

An examination of the data in Table 6.3 makes it clear that there were relatively large variations in the most carefully built columns. Data for constants of a group of Philadelphia columns are shown in Table 6.4. It is clear from the data that rather large variations in performance are to be found in the run-of-the-mill column.

Although several explanations have been offered for the variation, no adequate proof has been produced. Variation in the performance of columns, supposedly of identical construction, is perhaps not surpris-

- $\quad$ ing in view of the small spacing normally used. An error of $0.001 \mathrm{in}$. in the spacing amounts to 10 per cent. Regardless of the source of the variation, its existence makes the study of liquid thermal diffusion extremely difficult. 
LIQUID THERMAL DIFFUSION

Table 6.4-PERFORMANCE OF PHILADELPHIA COLUMNS

\begin{tabular}{rrrr}
$\begin{array}{c}\text { Column } \\
\text { No. }\end{array}$ & $\mathrm{X}$ & $\mathrm{Y}$ & $\mathrm{H}$ \\
\hline 307 & 46 & 0.56 & 61 \\
308 & 51 & 0.67 & 46 \\
310 & 51 & 0.58 & 53 \\
231 & 81 & 0.39 & 49 \\
26 & 40 & 0.80 & 49 \\
230 & 110 & 0.42 & 35 \\
225 & 68 & 0.38 & 61 \\
311 & 82 & 0.55 & 35 \\
20 & 160 & 0.40 & 25 \\
312 & 53 & 0.66 & 45 \\
159 & 63 & 0.28 & 90 \\
315 & 70 & 0.68 & 33 \\
158 & 150 & 0.45 & 24 \\
316 & 31 & 0.52 & 98 \\
319 & 44 & 0.74 & 49 \\
\hline
\end{tabular}

\section{SPACING}

Spacing is the most crucial column variable. Both $\mathrm{X}$ and $\mathrm{Y}$ vary as spacing is changed. The general features are these: A maximum value of $\mathrm{Y}$ is observed in the vicinity of $0.020 \mathrm{~cm}$. At large spacings, $Y \mathrm{di}-$ minishes as $1 / \mathbf{a}^{4}$. At narrower spacings, depending on the accuracy of the column construction, $Y$ again diminishes. The quantity $X$ is also affected by column spacing, with a minimum occurring at about $0.025 \mathrm{~cm}$.

Before the effect of spacing is examined in more detail, two other column variables, temperature and fluid pressure, should be mentioned. Both affect the properties of the working substance, thus affecting both $\mathrm{X}$ and $\mathrm{Y}$. For instance, the effect of higher $\Delta \mathrm{T}$ is to change the optimum spacing toward smaller values. In addition, for a given column, spacing itself is a function of both pressure and temperature.

In an early series of experiments using 36-ft units, the effect of spacing was surveyed. For purposes of the test, independent facilities for a single column were constructed. Each column was tested under identical conditions. Steam temperature was held at $170^{\circ} \mathrm{C}$ and cooling water at $65^{\circ} \mathrm{C}$. The storage chamber was connected through one line to the bottom of the column. Thus each of the group of columns ran essentially as a combination of rectifier and stripper, with the point of unchanged concentration essentially at the middle of the column. Each column had a set of Sylphon expansion bellows at the top that had a 
process fluid holdup of about $200 \mathrm{~g}$. The quantity measured was the change in concentration at the top of the column. The results are shown in Fig. 6.4. The solid line represents a curve given by

$$
Y=\frac{a^{2}}{b+k a^{6}}
$$

which has been normalized at $0.02 \mathrm{~cm}$ and at $0.053 \mathrm{~cm}$.

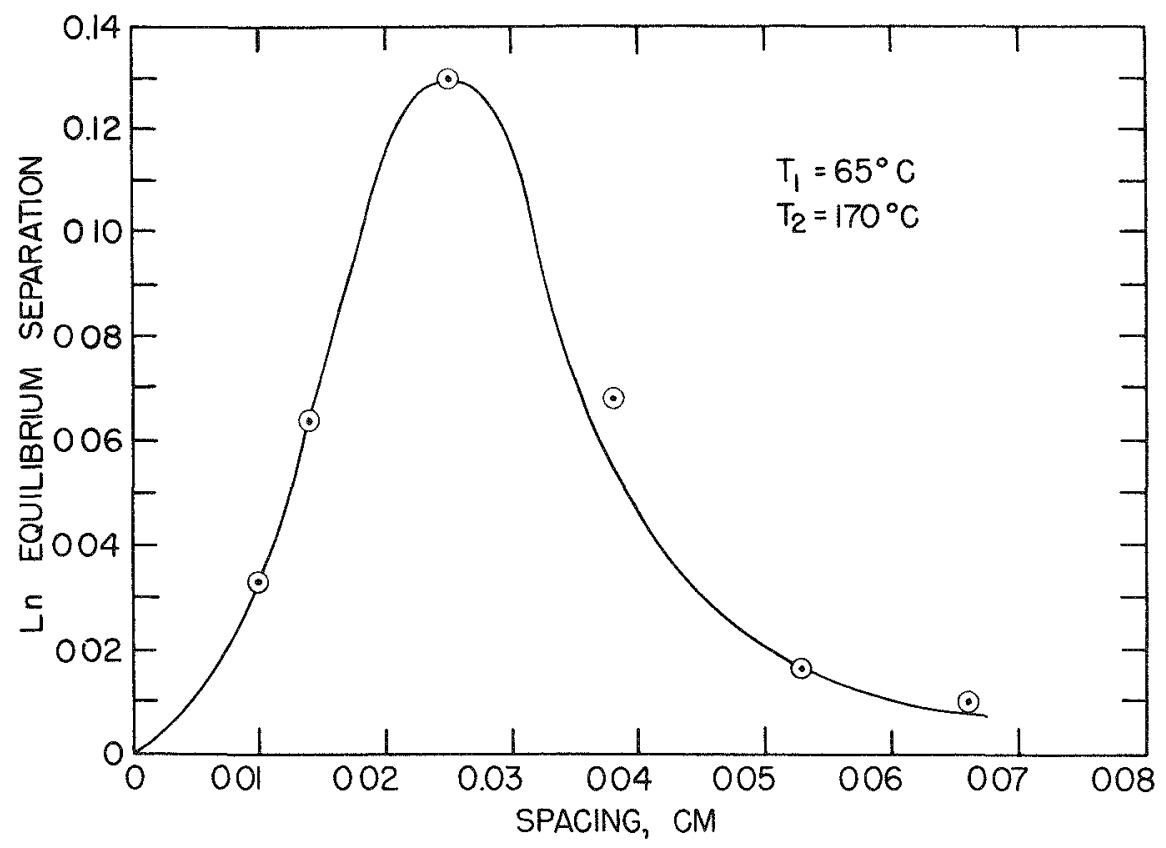

Fig. 6.4-Equilibrium separation factor as a function of spacing. Survey experiments to establish the region of optimum spacing. The separation shown was for an approximate $18 \mathrm{ft}$ of rectifier. The solid line represents a curve given by $\mathrm{Y}=\mathrm{a}^{2} /\left(\mathrm{b}+\mathrm{ka} \mathrm{a}^{6}\right)$.

At the same time, observations were made on the half-time (Table 6.5). The observations were rather rough since the separations observed were small, and probable errors in analysis are of a magnitude not much smaller than the effect itself.

It appears that an optimum spacing exists. The portion of the curve (Fig. 6.4) corresponding to the wider spacing shows a $1 / a^{4}$ relation that is in agreement with a theoretical deduction. Behavior in the region of narrow spacing is less clear. 
Table 6.5-APPROXIMATE HALF-TIME OF COLUMNS

\begin{tabular}{cc}
\hline Spacing, cm & Half-time, days \\
\hline 0.068 & $\sim 1$ \\
0.053 & $\sim 1$ \\
0.038 & $\sim 0.5$ \\
0.021 & $\sim 1.5$ \\
0.014 & $\sim 3.0$ \\
\hline
\end{tabular}

A theoretical prediction by Cohen places optimum spacing at a much smaller value. Two complicating factors enter: (1) imperfections in spacing become relatively more pronounced as the spacing becomes narrower and (2) the temperature drops in the walls and water films of the column. As smaller spacings are used, the temperature drop between the hot and cold walls diminishes for a given set of operating conditions. Therefore, it is believed that a "practical" optimum is obtained. If a column with more nearly perfect spacing were available, the optimum spacing would probably be smaller and the observed isotope separation would probably be larger.

It is not surprising that optimum spacing varies with temperature conditions since the spacing of a given column is a function of temperature. Therefore, it seems desirable to discuss the temperature dependence of column behavior.

\section{TEMPERATURE DEPENDENCE OF COLUMN BEHAVIOR}

Theoretical analysis has indicated that the relation between performance and temperatures in a column is very complicated. In fact, it is not possible to predict behavior when comparatively large temperature differences $(\Delta T)$ are employed, as was the case in these studies. A prediction might be made that an increase in temperature difference between the hot and cold walls would be beneficial. Studies involving water solutions and small temperature differences showed that $\mathrm{Y} \sim$ $\Delta \mathrm{T}^{2}$. This relation did not apply in the $\mathrm{UF}_{6}$ studies.

When making temperature studies on the columns, two factors should be considered. First, the temperatures at the hot and cold surfaces of the $\mathrm{UF}_{6}$ are different from those of the steam supply and the cooling water, respectively. Second, a variation in column spacing occurs when temperatures are changed.

When heat travels from the steam to the cooling water, it passes through the following layers: (1) a thin film of condensate at the inner surface of the nickel, (2) the nickel wall, (3) the process fluid, (4) the 
copper wall, and (5) a film of water on the surface of the copper. The principal uncertainty is in the thin film of condensate at the inner surface of the nickel. An examination of the standard works on heat transfer shows that this factor is variable and that condensate can occur on the surface in the form of a film or as drops. Measurements have been made on the temperature drop in this film under conditions of column operation. Temperature drops in the nickel, copper, and cooling-water film can be calculated. The results obtained for a typical temperature distribution in a column $(0.025-\mathrm{cm}$ spacing) are given in Table 6.6.

Table 6.6-OPERATING TEMPERATURES IN COLUMNS

\begin{tabular}{cccccc}
\hline $\begin{array}{c}\text { Steam } \\
\text { temperature, }{ }^{\circ} \mathrm{C}\end{array}$ & $\begin{array}{c}\text { Inner } \\
\text { nickel, }{ }^{\circ} \mathrm{C}\end{array}$ & $\begin{array}{c}\text { Hot } \\
\text { surface of } \\
\mathrm{UF}_{68}{ }^{\circ} \mathrm{C}\end{array}$ & $\begin{array}{c}\text { Cold } \\
\text { surface of } \\
\mathrm{UF}_{6},{ }^{\circ} \mathrm{C}\end{array}$ & $\begin{array}{c}\text { Outside of } \\
\text { copper, }{ }^{\circ} \mathrm{C}\end{array}$ & $\begin{array}{c}\text { Cooling-water } \\
\text { temperature, }{ }^{\circ} \mathrm{C}\end{array}$ \\
\hline 286 & 252 & 244 & 69 & 68 & 63 \\
188 & 169 & 164.6 & 66.6 & 66 & 63 \\
\hline
\end{tabular}

The second factor, the variation in spacing with temperature, is demonstrated in Table 6.7. The spacings are calculated at the actual temperatures that exist in the metals.

Table 6.7-EFFECT OF TEMPERATURE ON SPACING

\begin{tabular}{ccc}
\hline $\begin{array}{c}\text { Steam } \\
\text { temperature, }{ }^{\circ} \mathrm{C}\end{array}$ & $\begin{array}{c}\text { Water } \\
\text { temperature, }{ }^{\circ} \mathrm{C}\end{array}$ & Spacing, cm \\
\hline 20 & 20 & 0.030 \\
188 & 63 & 0.0273 \\
286 & 63 & 0.0249 \\
\hline
\end{tabular}

Hence it is not possible to determine the effect of temperature variations on a given column without simultaneously varying the spacing of the column.

In Table 6.8, results are given on studies of three carefully constructed columns which were run individually and which required special attention during their operation.

It appears that, at spacings of about $0.25 \mathrm{~cm}$, the main effect of increased $\Delta \mathrm{T}$ is to diminish $\mathrm{X}$, i.e., to speed up the processes in the column. It is interesting to observe how little the value of $Y$ is changed by an increase in $\Delta T$. In fact, a comparison of columns having a different $\Delta \mathrm{T}$ but the same spacing shows that, in this particular region of spacing, the separation is insensitive to $\Delta T$. 
Table 6.8-EFFECT OF TEMPERATURE ON COLUMN PERFORMANCE

\begin{tabular}{rccccccccr}
\hline $\begin{array}{c}\text { Steam, } \\
\text { psi }\end{array}$ & $\mathrm{T}_{1},{ }^{\circ} \mathrm{C}$ & $\mathrm{T}_{2},{ }^{\circ} \mathrm{C}$ & $\begin{array}{c}\text { Q, } \\
\mathrm{cal} / \mathrm{sec}\end{array}$ & $\begin{array}{c}\text { Spacing, } \\
\mathrm{cm}\end{array}$ & $\mathrm{M}, \mathrm{g}$ & $\mathrm{X}$ & $\mathrm{Y}$ & $\Phi$ & $\Phi / \mathrm{Q}$ \\
\hline 160 & 188 & 63 & 26,000 & 0.0273 & 2040 & 150 & 0.50 & 13.6 & 5.2 \\
600 & 254 & 63 & 41,200 & 0.0256 & 1720 & 63 & 0.53 & 27.3 & 6.6 \\
1000 & 286 & 63 & 48,000 & 0.0248 & 1600 & 32 & 0.6 & 50 & 10.4 \\
160 & 188 & 63 & 28,000 & 0.0253 & 1860 & 140 & 0.6 & 13.3 & 4.8 \\
800 & 271 & 63 & 51,000 & 0.023 & 1500 & 34 & 0.65 & 44.1 & 8.6 \\
160 & 188 & 63 & 31,400 & 0.225 & 1600 & 260 & $>0.7$ & 6.2 & 2.0 \\
750 & 267 & 63 & 51,500 & 0.200 & 1320 & 50 & 0.8 & 26.4 & 5.1 \\
\hline
\end{tabular}

The value of $\Phi / Q$ is of practical importance. It is a number that is proportional to the output per unit of heat consumed. At the S-50 plant it was particularly important to obtain maximum output from a limited steam supply. Hence it was desirable to have $\Phi / Q$ a maximum. Experience at NRL showed that $\Phi / Q$ diminished at spacings above 0.025 $\mathrm{cm}$ and below $0.020 \mathrm{~cm}$. This fact was confirmed later at Philadelphia. Hence it is believed that the spacing for optimum $\Phi / Q$ lies between 0.023 and $0.025 \mathrm{~cm}$.

\section{EFFECT OF PRESSURE ON PERFORMANCE}

The series of observations summarized in Table 6.9 throw some light on the role of pressure in column performance. The experiments were made with a $0.025-\mathrm{cm}-$ spaced column operating with 1000 psi steam.

Table 6.9-EFFECT OF UF $_{6}$ FLUID PRESSURE ON PERFORMANCE

\begin{tabular}{ccccccc}
\hline $\begin{array}{c}\text { Fluid } \\
\text { pressure, psi }\end{array}$ & Q, cal/sec & $\mathrm{X}$ & $\mathrm{Y}$ & $\mathrm{M}, \mathrm{g}$ & $\Phi$ & $\Phi / \mathrm{Q}$ \\
\hline 1000 & 48,500 & 36 & 9.60 & 1600 & 44.4 & 9.2 \\
1490 & 47,300 & 54 & 0.77 & 1700 & 31.5 & 6.6 \\
3000 & 45,000 & 58 & & 1810 & 31.2 & 6.9 \\
\hline
\end{tabular}

The effect of pressure is to increase the viscosity of the fluid and to diminish the difference in density between the hot and cold regions of the column. Both these effects tend to slow the action in the column, and performance suffers accordingly.

These results were obtained with a column that showed no instability. It is quite possible that the dependence of performance on pressure would be very different if an unstable column were used (see Sec. 8). 
No value of $Y$ is given for the 3000 psi run because the experiment was inter rupted. Of course, the value of $X$, which was obtained early in the run, was not affected. With a pressure of 3000 psi, calculations show that an appreciable increase in spacing occurs because of the elastic deformation of the copper.

\section{FLUCTUATIONS IN COLUMN PRESSURE}

It seems worthwhile to describe some observations on the behavior of columns when the pressure is varied.

A column was operated at a steam pressure of $480 \mathrm{psi}$ and a coldwater temperature of $65^{\circ} \mathrm{C}$. Allowing for the temperature drop in the condensate film and in the nickel wall, a value of $210^{\circ} \mathrm{C}$ is obtained for the temperature of the hot wall at the liquid $\mathrm{UF}_{6}$ surface. The reservoir was initially maintained at a temperature of $260^{\circ} \mathrm{C}$, and the pressure was $1250 \mathrm{psi}$. The reservoir was then cooled. When the temperature in the reservoir dropped below the critical point, the pressure in the reservoir became simply the vapor pressure of $\mathrm{UF}_{6}$. Power consumption in the column remained essentially constant, increasing a few per cent until the reservoir reached $210^{\circ} \mathrm{C}$. At this point the reservoir temperature and the wall temperature were approximately equal, and therefore the pressure at the hot wall was approximately equal to that in the reservoir. Hydrostatic head must be taken into account. The reservoir was at the top of the column. Hence, pressures at the top were equal, whereas at points lower in the column the total pressure exceeded that in the reservoir.

Suddenly, as the reservoir cooled a little further, there were loud sharp crackling noises in the column. Power consumption immediately rose by a factor of 2. Clearly a new mechanism of heat transfer had come into action. The term for the phenomenon is "pitching." It seemed appropriate to use a word other than "boiling" because it later appeared that the same effect also occurs at pressures greater than the critical. It was determined, through numerous observations, that pitching causes a profound mixing effect. If separation exists in a column when the phenomenon occurs, mixing takes place. If a column is started with fresh material, almost no separation occurs until pitching ceases.

Another experiment was conducted using a column heated with steam at 800 psi. The initial pressure in the reservoir was 1300 psi. When the reservoir temperature, and hence pressure, dropped, the pitching phenomenon occurred at a pressure of 720 psi. This corresponds to a temperature of $231^{\circ} \mathrm{C}$, which is not far from the estimates of the inner hot-wall temperature. 
A similar experiment was performed at a steam pressure of 1000 psi. The reservoir was held at a pressure of 1300 psi. As the fluid pressure was reduced, the power remained constant. At 950 psi a pressure gauge indicated a slight instability in the column. The indicating needle jumped from time to time with an amplitude of a few pounds per square inch. As the pressure was lowered further, the amplitude of the variations became greater and more rhythmic at about 5 cycles/sec; power consumption, however, remained unchanged. As the pressure was lowered further, the amplitude increased to $25 \mathrm{psi}$. At $770 \mathrm{psi}$ the pressure measured at the column suddenly dropped to about $100 \mathrm{psi}$, the power increased by a factor of 2 , and the sharp crackling noises were heard.

Later, studies on other columns were made when the steam pressure was 1000 psi. With less accurately constructed columns, instability set in at pressures as high as 2000 psi. At the plant in Philadelphia, data were collected on a group of columns. In Table 6.10 results for a group of 10 columns, all having a common steam and water supply, are shown.

Table 6.10-FLUCTUATIONS IN COLUMN PRESSURE

\begin{tabular}{cc|cc}
\hline Pressure, psi & $\Delta \mathrm{P}$, psi & Pressure, psi & $\Delta \mathrm{P}$, psi \\
\hline 1500 & 0 & 1200 & 5 \\
1510 & 40 & 1200 & 100 \\
1490 & 30 & 1210 & 60 \\
1500 & 10 & 1200 & 25 \\
1510 & 35 & 1190 & 60 \\
1510 & 0 & 1210 & 0 \\
1500 & 0 & 1200 & 2 \\
1490 & 50 & 1200 & 130 \\
1500 & 20 & 1210 & 40 \\
1500 & 10 & 1200 & 20 \\
\hline
\end{tabular}

The outstanding features in these data are the variations among the columns and the trend to greater instability at lower pressures. Attempts were made to relate the performance of the various columns to the magnitude of the instability. On the average, the less stable columns performed less satisfactorily than the stable units. It is perhaps not surprising that no exact correlation between $\Delta P$ and performance exists. If the source of the disturbance was some distance from the end of a column where measurements were made, the value observed would obviously be greatly diminished because of damping.

The observations further showed that the wide-spaced columns were the most unstable. At a pressure of 1200 psi, five columns at the spacings indicated gave the average variations shown in Table 6.11. 
Table 6.11-EFFECT OF SPACING ON FLUCTUATIONS OF COLUMN PRESSURE

\begin{tabular}{cc}
\hline Spacing, cm & $\Delta \mathrm{P}, \mathrm{psi}$ \\
\hline 0.028 & 80 \\
0.025 & 25 \\
0.023 & 6 \\
\hline
\end{tabular}

Coincident with the variation in stability was a variation in the pressure at which the various columns began to pitch. This ranged up to 1200 psi, which is far above the critical pressure of 740 psi. In a great deal of the production work, up to 26 columns were operated in parallel. It was found that pitching in one column tended to be communicated to neighboring units. Furthermore, disturbances, such as product removal, tended to initiate pitching. As a result, it was necessary to operate the 26-column circuits at 1500 to 1700 psi.

The earlier columns at NRL were constructed with individual attention and care. They showed much less instability than the columns in the pilot plant at Philadelphia or at the S-50 plant.

\section{EFFECT OF COLUMN LENGTH}

Experiments have been performed examining the role played by column length. The results are in only fair agreement with the theoretical predictions. According to theory, for a simple column, if the length $L$ is varied, keeping other factors constant, then $\mathrm{X}$, the logarithm of the equilibrium separation factor, will vary in proportion

$$
\mathbf{Y}=\alpha \mathbf{L}
$$

where $\alpha$ is a constant. On the other hand, the time constant $\mathrm{X}$ remains constant, independent of length.

Table 6.12 gives some experimental results to indicate the extent to which these theoretical predictions are borne out.

Table 6.12-EFFECT OF LENGTH ON COLUMN PERFORMANCE

\begin{tabular}{ccccccc}
\hline $\begin{array}{c}\text { Nominal } \\
\text { length, ft }\end{array}$ & $\begin{array}{c}\text { Working } \\
\text { length, ft }\end{array}$ & $\mathrm{Y}$ & $\mathrm{X}$, days & Spacing, cm & $\mathrm{T}_{1},{ }^{\circ} \mathrm{C}$ & $\mathrm{T}_{2},{ }^{\circ} \mathrm{C}$ \\
\hline 12 & 10.7 & 0.08 & 230 & 0.025 & 61 & 185 \\
48 & 46.7 & 0.50 & 170 & 0.025 & 61 & 185 \\
12 & 10.7 & 0.10 & 73 & 0.025 & 61 & 254 \\
48 & 46.7 & 0.53 & 63 & 0.025 & 61 & 254 \\
\hline
\end{tabular}


The "working length" refers to that portion of the column within the water jacket. On this basis, the ratio of the working lengths is 4.36 , whereas for the first two columns the $Y$ ratio is 6.25 and for the last two columns the ratio is 5.3. It appears that the separation is smaller in the short column than theory would predict. A reasonable explanation for this is that the cooling water enters the jacket through an opening at one side; therefore, in that region, there is an asymmetry in the cooling action of the water with reference to the column axis. This results in an asymmetrical temperature distribution at the cold wall of the process fluid, which leads to parasitic convection or mixing; hence, that portion of the column contributes very little to the separative action. A similar effect can be expected at the top near the cold-water outlet. If about $2 \mathrm{ft}$ is subtracted from the working length for each column to allow for the disturbance in the cooling water, agreement is obtained with the theoretical prediction for the behavior of $\mathrm{Y}$.

Relative to the behavior of $\mathrm{X}$, it is observed that here again the presence of dead spaces (regions that do not contribute to the separative action) can be thought of as contributing to the mass $M$ without contributing to the value of $Y$; therefore, the dead spaces would increase $X$ since $X=M / H Y$. This accounts for the fact that $X$ is larger for the smaller column in the case of each of the two pairs, instead of being the same for both. However, such considerations must be regarded as having only qualitative significance in view of the fact that the definition of $\mathrm{H}$ originally referred only to a uniform column without dead spaces. The largest variation in $X$ occurs where the discrepancy in $Y$ is the greatest. 


\title{
Chapter 7
}

\section{ENGINEERING AND OPERATION}

\author{
R. E. Ruskin, M. Drott, H. M. Moseley, and J. B. Bidwell
}

In this chapter some of the features of liquid thermal diffusion plant design and operation are discussed. An attempt is made to emphasize crucial and novel considerations. A minimum of space is given to the design involving conventional engineering practice. In order to give a clearer picture of the design, plant operation will be discussed briefly.

\section{PLANT OPERATION}

As mentioned in Chap. 1, the principal use of the liquid thermal diffusion process was as a source of feed for other plants. It was determined that best over-all results would be obtained by feeding in normal $\mathrm{UF}_{6}\left(0.715\right.$ per cent of $\left.\mathrm{U}^{235}\right)$, withdrawing product at 0.858 per cent, and rejecting waste at 0.679 per cent. This objective was accomplished in a rather simple manner. Columns were connected in parallel in groups of 25 or 26 . Feed from a reservoir (capacity $400 \mathrm{lb}$ ) was circulated through the bottoms of the columns, and product was removed from the tops of the columns.

Feed was delivered to the plant in cylinders holding $450 \mathrm{lb}$. The cylinder was placed in a steam jacket, and the contents were transferred to the reservoirs by distillation. The reservoirs were steam heated, with steam pressure adjusted to give the desired $U F_{6}$ pressure of $1550 \mathrm{psi}$. Circulation through the reservoir and the bottoms of the columns was maintained by a thermosyphon pump, described in Chap. 5 , at a flow rate of 6 to $10 \mathrm{lb} / \mathrm{hr}$.

The process of product removal was carried out as follows: At periodic intervals ( 2 to $4 \mathrm{hr}$ ) the columns were isolated from one another at the bottom by freezing the connecting links. A similar set of intercolumn connectors at the top of the columns was then unfrozen. Fluid from the columns was allowed to flow into a common metering device. Because of the compressibility of the process fluid, an appropriate quan- 
tity could be withdrawn without excessive lowering of pressure in the column. Once the product had been removed, the top intercolumn connectors were frozen, and circulation was reestablished through the bottoms of the columns. This is a type of procedure easily made automatic by the use of a cam timer and solenoid valves. Product removal at Philadelphia was carried on exclusively by these automatic means.

When the isotopic content of the reservoir became depleted so that the light-constituent concentration was down to 0.68 per cent, the reservoir was dumped and refilled with fresh feed. Depending on the number of columns connected to a given reservoir and their productivity, the waste was dumped from reservoirs every 8 to 16 days. While this process was being carried out, the columns were isolated. Because of the compressibility of the process fluid, this was a satisiactory procedure. Difficulties arose only when the steam supply failed.

The remaining operational problems in the liquid thermal diffusion plant were the maintenance of a reliable supply of heat in the form of steam and the maintenance of a steady supply of cooling water.

\section{S-50 PLANT}

The S-50 plant ${ }^{1}$ (Fig. 7.1) was built on the banks of the Clinch River adjacent to the K-25 steam power plant at the Clinton Engineer Works, Oak Ridge, Tenn. A building $525 \mathrm{ft}$ long, $82 \mathrm{ft}$ wide, and $75 \mathrm{ft}$ high housed 2142 columns assembled on 21 steel racks.

The principal steam source was the $\mathrm{K}-25$ powerhouse, which produced steam at about 1275 psi and $500^{\circ} \mathrm{C}$. Steam was desuperheated and reduced in pressure to $1000 \mathrm{psi}$. Part of the condensate from the columns was sent back to the powerhouse; the remainder was boosted in pressure and used for the desuperheating. The Clinch River served as a source of the $40,000 \mathrm{gal} / \mathrm{min}$ cooling-water make-up.

An oil-fired $450 \mathrm{psi}$ steam plant with a capacity of $400,000 \mathrm{lb} / \mathrm{hr}$ was completed about July 1, 1945. It served to supplement the $\mathrm{K}-25$ powerhouse supply, which at that time was being devoted increasingly to supplying power for the $\mathrm{K}-25$ plant.

The basic unit of the S-50 plant was the 102-column rack. This unit was almost exactly a copy of those in the Philadelphia installation. Hence, in discussing design features in more detail, the salient features of the pilot plant will be described.

\section{PROCESS AREA DESIGN (PHILADELPHIA)}

This section covers the principal mechanical engineering operations involved in building the Philadelphia pilot plant. The main design work, done between June and October 1943, was based on the 14-column pilot 


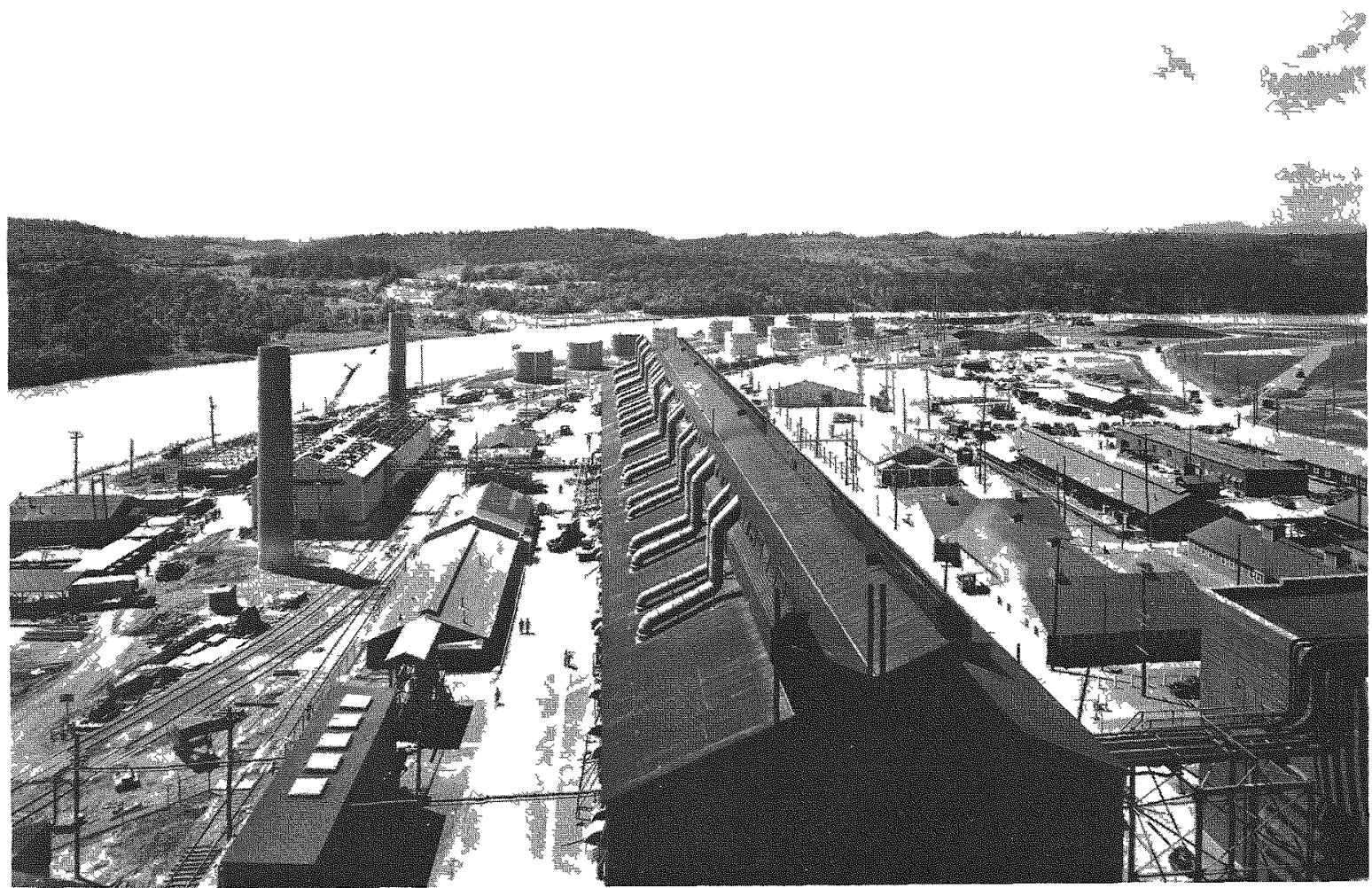

Fig. 7.1-View of S-50 plant at Oak Ridge, Tenn. 
plant at the Naval Research Laboratory (NRL), Washington, D. C. The principal objective was the erection of a unit which, by simple multiplication, could be expanded to a production plant of any desired size. In addition, provision had to be made for the continuation of development work begun in Washington.

The column (Fig. 7.2) was essentially a central tube of nickel ( $\mathrm{C}$ to D) through which steam was passed, surrounded by a small annular space $(G)$ in which the process material was confined by a larger tube of copper ( $E$ to $F$ ). Around the copper was a larger annular space for circulating hot water, enclosed by a casing of 4-in. ips pipe. Suitable adapters were provided at the ends of each unit to admit steam, process material, and water simultaneously, each under considerable pressure, and at the same time to permit differential expansions due to temperature changes.

The basic objective was simply to maintain the inside nickel tubing of a heat exchanger at as high a temperature as practicable and at the same time to keep the temperature of the outer copper tubing just above the melting point of the material being processed. In order to accomplish this, water was recirculated through the water jacket, enough make-up being added to keep the temperature constant, while steam entered the inner nickel tube at the top and was condensed over a $48-\mathrm{ft}$ length and the condensate was removed at the bottom.

The optimum size and physical dimensions of individual columns were determined during the operation of the pilot plant at NRL, where 25,000 $\mathrm{lb} / \mathrm{hr}$ of saturated steam at $165 \mathrm{psi}$ and $1000 \mathrm{lb} / \mathrm{hr}$ of saturated steam at 1000 psi were available. Experimentation showed that the columns giving the best performance were those with a spacing $(G)$ of 0.010 in. Consequently, the design of the plant was based on the requirements of such a column, $1088 \mathrm{lb} / \mathrm{hr}$ of $1000 \mathrm{psi}$ saturated steam.

The design of the rack, pipe sizes, and weights were determined on the basis of standard engineering practice. Pipe sizes were based on economy as calculated on the basis of power consumption cost for a two-year operation.

3.1 Site. After a study of possible locations, the Naval Boiler and Turbine Laboratory was chosen as the operation site (Fig. 7.3). Half of a building, originally designed for turbine testing, was made available to house three racks and also the necessary steam generating equipment. The approximate dimensions of the plant were $164 \mathrm{ft}$ by 81 $\mathrm{ft}$, with one-half this area at a level $10 \mathrm{ft}$ below grade; therefore, although the clear height of the upper level was only $46 \mathrm{ft}$, the distance from the pit floor to the bottom of the roof truss was $56 \mathrm{ft}$, the minimum height necessary to accommodate the columns. All the boilers and auxiliaries, except the condenser, were installed in the remaining space at ground level. About $7200 \mathrm{sq} \mathrm{ft}$ of additional space was occupied by auxiliary buildings. 


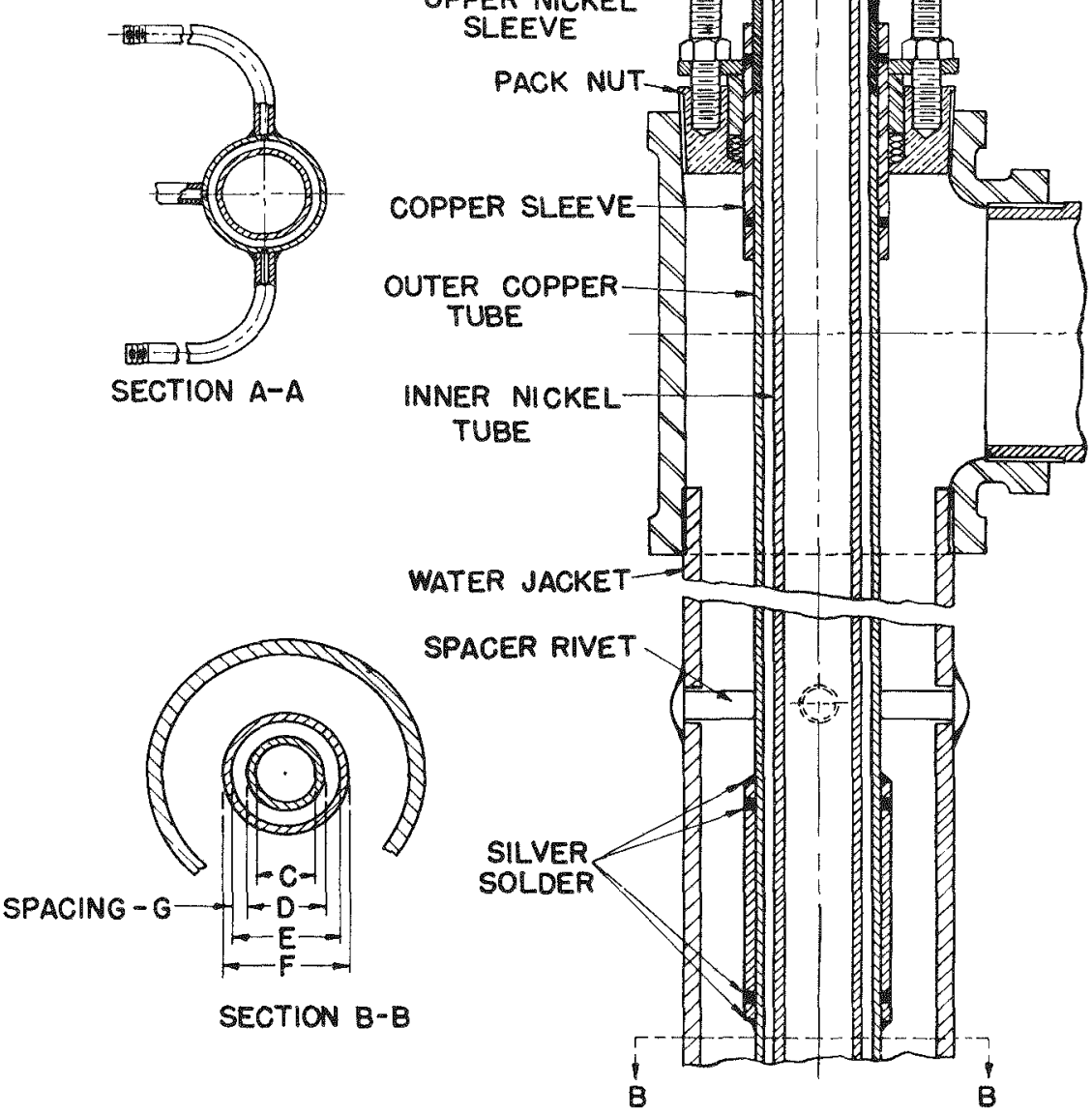

Fig. 7.2-The liquid thermal diffusion column.

3.2 Rack. Considerations taken into account in arriving at the number of columns per unit were: (1) the cost of erection and the avallability of piping capable of feeding the necessary amounts of steam and water to and from various numbers of columns, (2) the cost of operating for a two-year period, (3) the length of transfer lines for process material, and (4) the layout of the steel frame. The resultant design was a 102-column unit $50 \mathrm{ft}$ long, $7 \mathrm{ft}$ wide, and $54 \mathrm{ft}$ high, with two sides of three divisions each with each division containing 17 columns. 


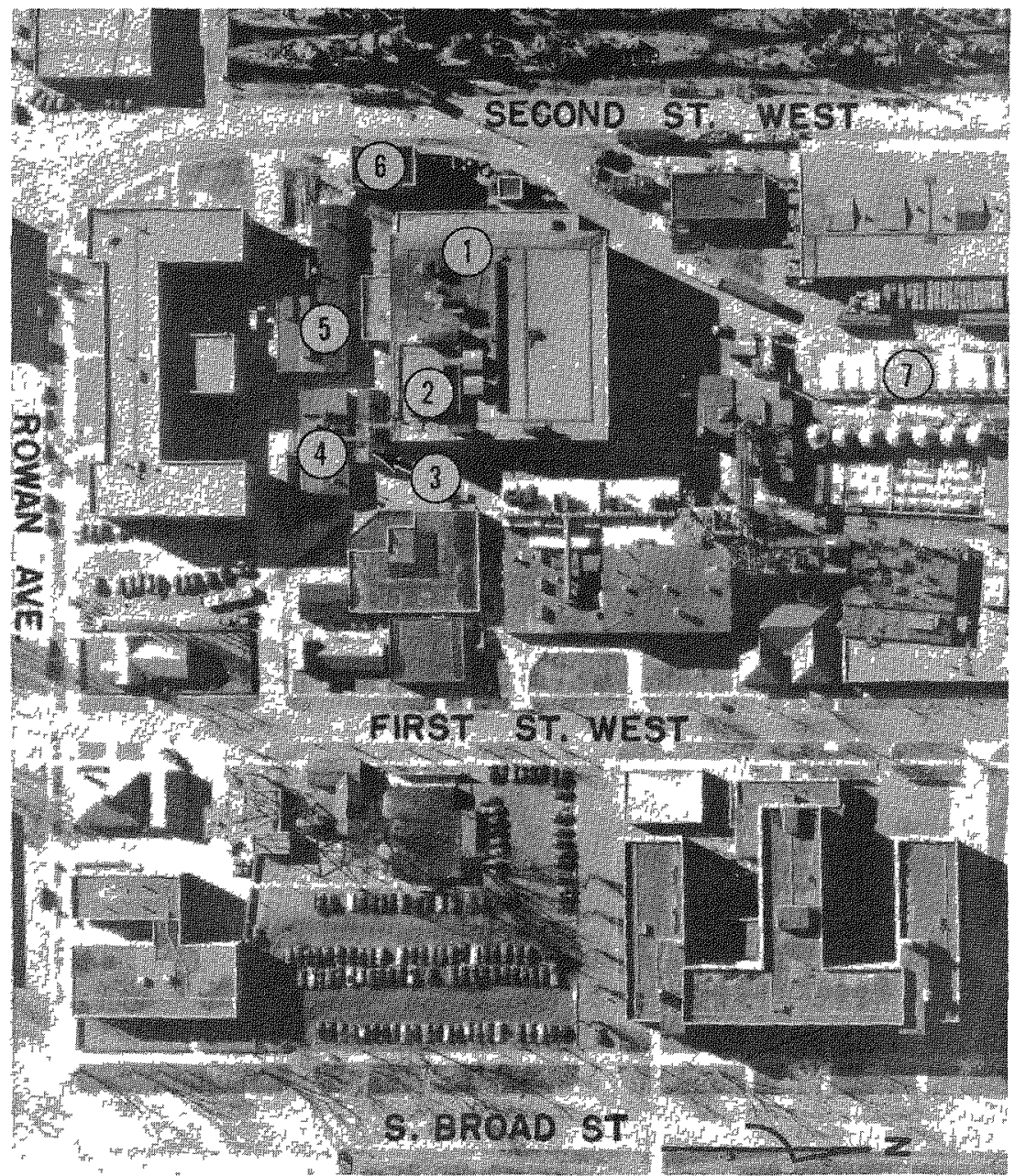

Fig. 7.3-Aerial view of Philadelphia pilot plant at Philadelphia naval base, showing (1) boiler room, (2) main pilot plant, (3) transfer room, (4) laboratory building, (5) office and column construction building, (6) pump building, and (7) oil-tank farm.

Standard structural sections made up the rack, which was constructed in two parts to allow the use of a crane located in the building for erecting the heavier structural members of the base and for assembling the condenser and larger pieces of machinery in the pit. The base (Fig. 7.4), which was $41 \mathrm{ft}$ high, supported the weight of the columns, the two 24 -in. recirculating water heaters, and the condensate piping. The 13-ft-high superstructure carried the upper operational deck, the steam piping, and the 1-ton capacity monorail hoist used for hanging columns in place. 


\section{ENGINEERING AND OPERATION}

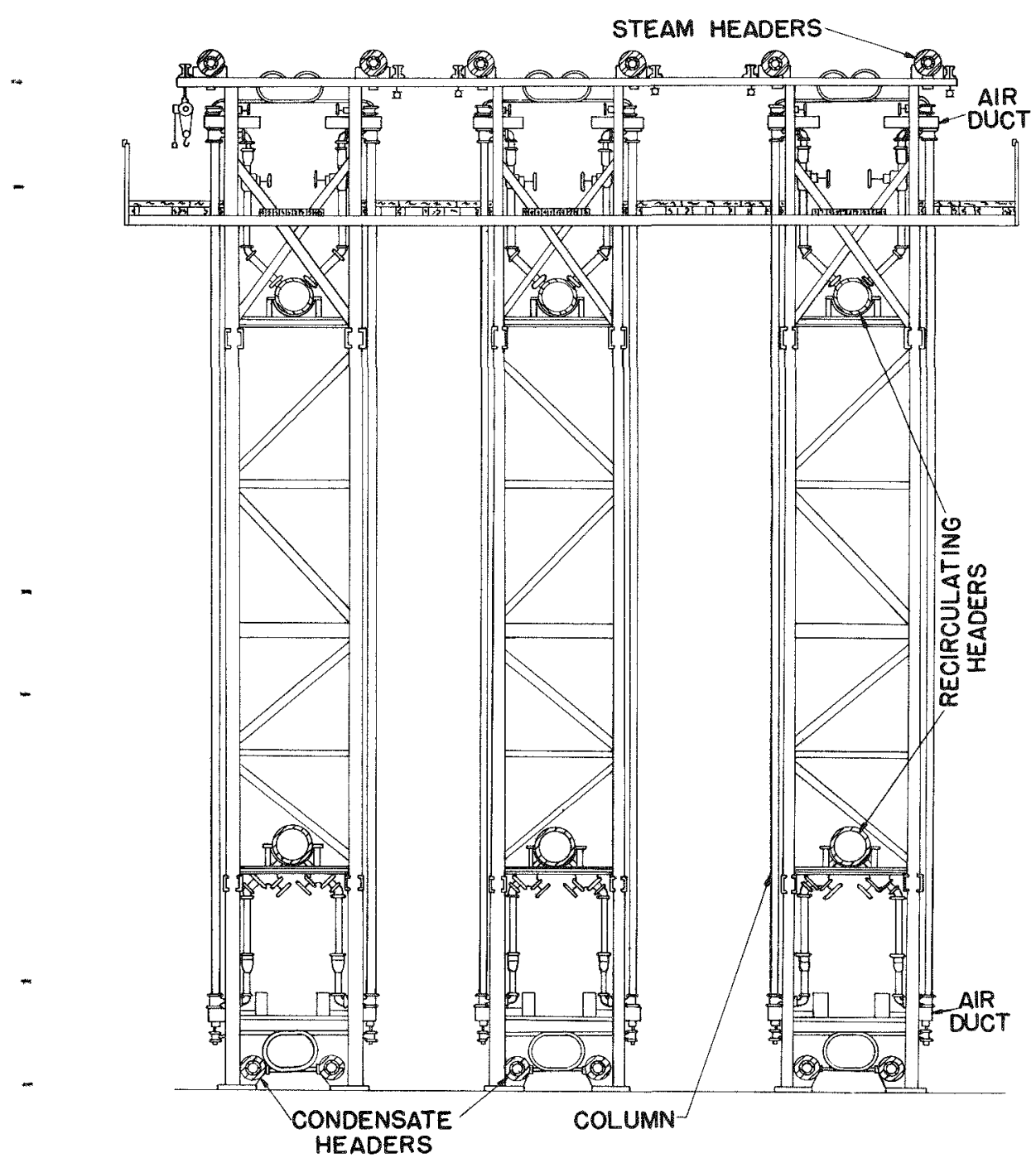

Fig. 7.4-End view of the three racks at Philadelphia plant. Each rack carried 102 columns spaced 11 in. apart. 
The upper operational deck was built with 2- by 8-ft trap doors around the columns (Fig. 7.5) to facilitate their installation in the rack. The lower deck was sloped toward floor drains to carry away the considerable amounts of water used at times.

Experience had shown that it was desirable to have approximately $200 \mathrm{gal} / \mathrm{min}$ of water recirculated through each column. In order to hold the temperature of the inner copper wall of a refluxer above $69^{\circ} \mathrm{C}$ (the melting point of the material at the operating pressure), the recirculating water entered the unit at $65^{\circ} \mathrm{C}$, allowing for film and conductance losses of $4^{\circ} \mathrm{C}$ for clean copper. In passing the length of the column, the water was heated $4^{\circ} \mathrm{C}$ to an outlet temperature of $69^{\circ} \mathrm{C}$. On this basis, a maximum per rack of $2200 \mathrm{gal} / \mathrm{min}$ of river water at a summer temperature of $30^{\circ} \mathrm{C}$ was needed for make-up. Severe fouling of the metal surface by river impurities caused a greater temperature drop from copper to water in operation; consequently, the final temperature of the overboard water had to be lowered below $69^{\circ} \mathrm{C}$, and more make-up had to be added.

The path of the recirculating water through the system can be traced on the flow diagram (Fig. 7.6). Water was pumped from the river through a $72-$ in. main by one of two $50,000 \mathrm{gal} / \mathrm{min}$ circulators that were part of the permanent test equipment of the Naval Boiler and Turbine Laboratory. This line primarily fed the condensers, a maximum of $6000 \mathrm{gal} / \mathrm{min}$ going to the reflux racks through the booster pumps, which added enough head to force the water out of the overboard line and to maintain a water level above the column tops. A steady temperature was maintained on all three racks by the automatic valve on pump 2 with the control bulb located in the inlet header to rack 1 .

The recirculators pumped the water from the pump suction header into the lower 24-in. inlet manifolds by way of the pump discharge header. Gate valves on inlet and outlet headers permitted one rack to be shut down while others continued to operate. The water traveled down the connecting piping into the bottom of the column, up the unit, down the 4-in. upper connecting piping, and into the top 24-in. outlet header. Overboard water, equal in amount to make-up, was removed at one end through a line whose highest point passed above that of the columns so that the units remained full of water. The reas on for this was, if the copper of the columns were exposed to air, the steam would heat it above $200^{\circ} \mathrm{C}$ (the annealing temperature of the metal) and destroy all the units so affected. The bulk of the water circulated out the other end of the manifold, down the outlet piping (Fig. 7.7), and back into the pump suction header.

Each of the two booster pumps had a capacity of $5000 \mathrm{gal} / \mathrm{min}$, and an auxiliary line from the yard fire main (Fig. 7.6) could put 1400 $\mathrm{gal} / \mathrm{min}$ into the booster pump header; therefore, in the event of failure 


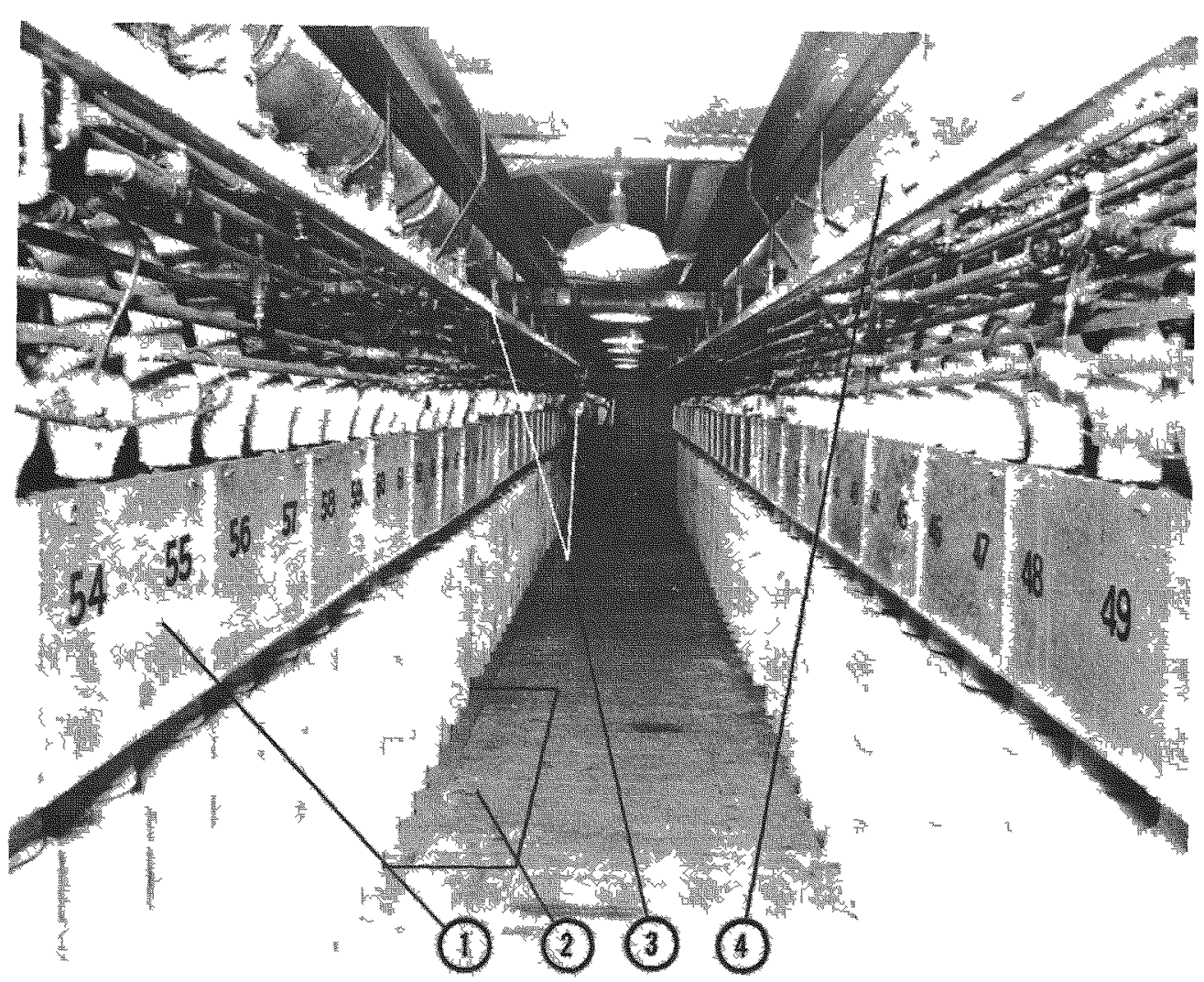

团

Fig. 7.5-View between two racks (top), showing (1) heating duct, (2) trap door, (3) hoist and monorail, and (4) 6-1n. steam headers. 


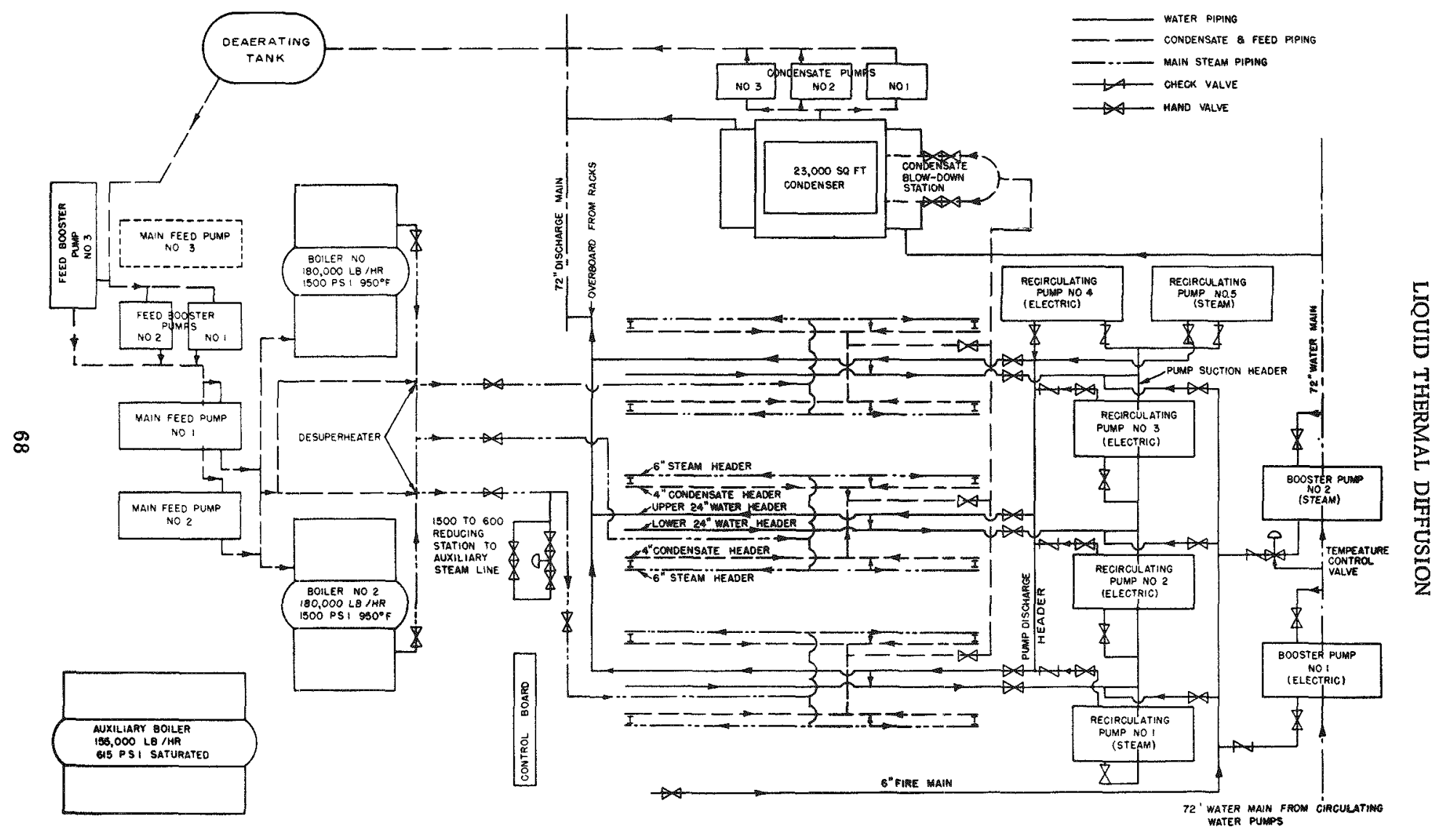

Fig. 7.6 - Schematic layout of main steam and water piping for Philadelphia plant. 


\section{ENGINEERING AND OPERATION}

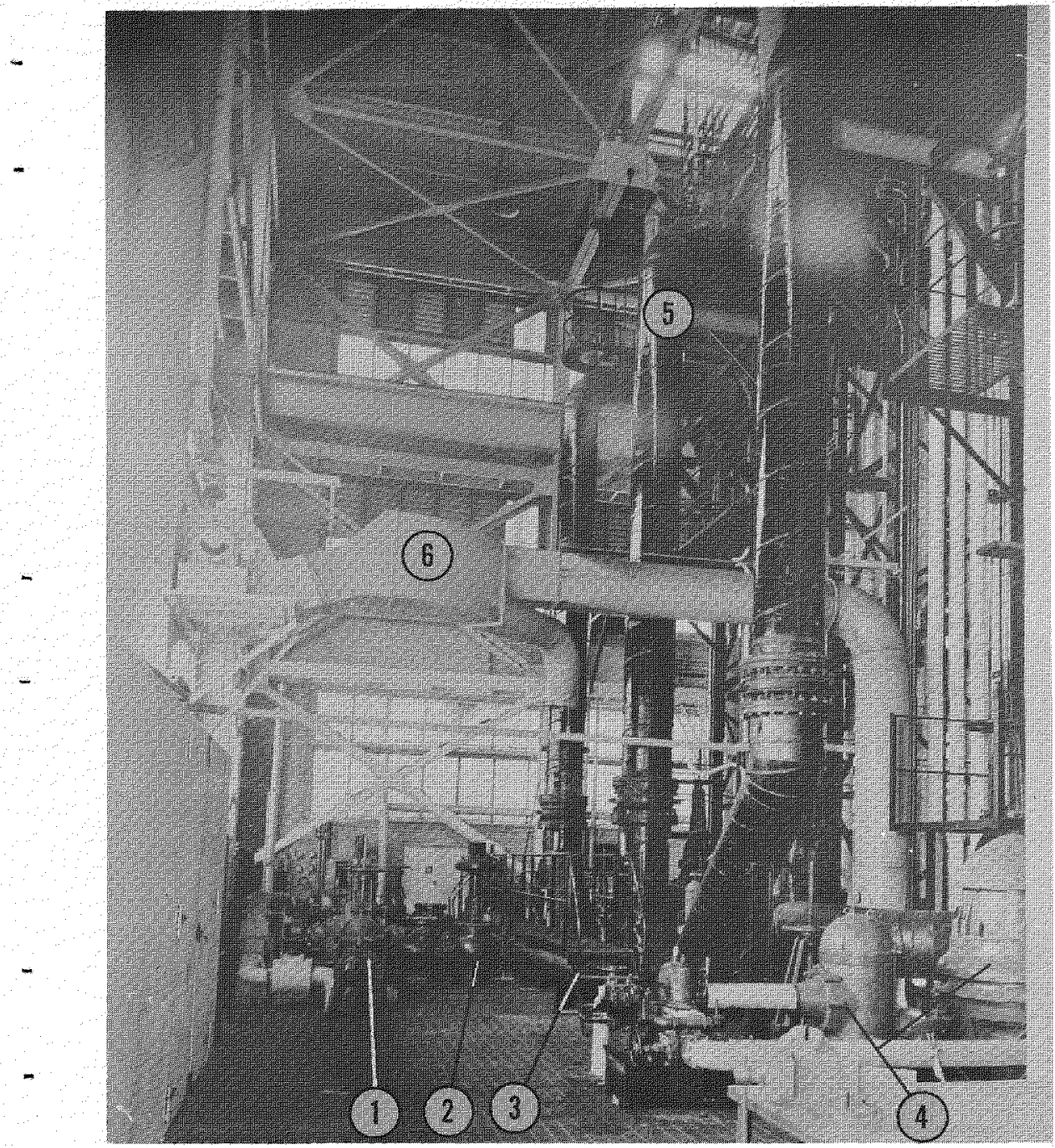

Fig. 7.7-View across ends of racks, showing (1) booster pumps, (2) automatic temperature-control valves, (3) booster-pump header, (4) recirculating water pumps, (5) recirculating water-discharge piping from 24-in. top header, and (6) ventilating air ducts. 
of either booster unit, the other unit and the fire-main supply could keep the plant operating at full load. If the circulating pumps should stop, this auxiliary source of water would keep the temperature below $100^{\circ} \mathrm{C}$ for $5 \mathrm{~min}$ and thereafter supply enough water to make up that boiled off. If both sources of supply failed during normal operation, the quantity in the system was such that $3 \frac{1}{2}$ min would elapse before boiling occurred.

Two recirculators were used so that, if one were shut down for repairs or broken down, the other allowed operations to continue. It will be seen that the pumps supplied only enough head to overcome pipe and velocity head losses in the water circuit; they provided no static lift.

Part of the pump capacity was motor driven and part was turbine driven; therefore, in the event of either an electric or an auxiliary steam power failure, some water would be pushed through the racks, giving $3 \frac{1}{2}$ min to close the steam supply valve before the water began to boil rather than $1 \mathrm{~min}$, which would be the time required to heat the water in a column to boiling if none were being recirculated.

Air-vent headers and piping prevented air from accumulating at the top of the column and then going over into the upper 24-in. manifold in slugs and served as an inlet for low-pressure steam into the water jacket for the conditioning of units.

Inlet and outlet stops on each column were necessary for experimental uses to allow individual regulation of recirculating water, and also to shut down single units for inspection while the others in the rack continued in operation. These valves were also useful in column conditioning operations.

3.3 Steam. The essential path of steam flow is shown in Fig. 7.6. Superheated steam, $450^{\circ} \mathrm{C}$ at $1000 \mathrm{psi}$, was generated in the two main boilers, passed through the superheater headers, and later desuperheated to $286^{\circ} \mathrm{C}$ before going into one of the three rack feeders. The branch from line 1, going to the 1000 to 600 psi reducing station, was an emergency device to feed steam auxiliaries if the boiler provided for that purpose should fail. Steam entered at the center of the 6-in. steam manifolds and passed through them to the upper expansion loops, beyond the 1-in. steam stop and into the columns, where it was condensed.

The condensate followed a path out of the bottom of the column, past the $3 / 4$-in. stops, through the bottom expansion loops, and into the condensate manifold to the condensate blow-down station, where one-third of the hot $\left(276^{\circ} \mathrm{C}\right)$ water was flashed to steam at atmospheric pressure, condensed, and subcooled along with the unflashed portion to $180^{\circ} \mathrm{F}$, the temperature at which the condensate pumps could handle the liquid.

The level of the condensed steam was kept somewhat below the lowest point of the process fluid in the columns on the first rack by manual 
adjustment of the condensate blow-down valves, the height being indicated by a water-level indicator connected across the steam and condensate headers. The level in the other two racks was maintained by slowly closing down the valves on the connecting piping from the lower 4-in. manifolds until the temperature of the condensate in them began to drop off, indicating that live steam was no longer present.

From the condenser back to the boilers, the piping followed conventional lines, the condensate going first through the deaerating tank to remove most of the air and to heat the water to $240^{\circ} \mathrm{F}$ with exhaust steam from boiler auxiliaries. The hot wall of the tank discharged into the suction of the feed boosters that supplied suction head to the main feed pumps. In addition to feeding the boilers, these units also supplied water to the desuperheaters.

3.4 Equipment. Two Foster-Wheeler oil-burning marine-type steam generators were assigned to supply heat to the column units, and a 600 psi 156,000 lb/hr Alaska-type marine boiler from the Naval Boiler and Turbine Laboratory was set up for boiler and plant auxiliaries. Each of the main boilers was rated at $180,000 \mathrm{lb} / \mathrm{hr}$ of steam at $1500 \mathrm{psi}$ and $450^{\circ} \mathrm{C}$. With desuperheating, the capacity of each was $225,000 \mathrm{lb} / \mathrm{hr}$ of saturated steam at $1500 \mathrm{psi}$. Since 306 columns consumed 336,000 $\mathrm{lb} / \mathrm{hr}$, the total steam capacity of $450,000 \mathrm{lb} / \mathrm{hr}$ was high enough to handle plant overloading caused by a column disturbance (pitching) which at times increased the consumption by 25 per cent. Although it appears at first glance that using the boiler superheaters increases the output by 25 per cent, they actually raised it 40 per cent because the hot gases from the superheater bank passed through the saturated side of the boiler and some steam was generated by these hot gases. The original boiler contracts had called for automatic controls; however, because the controls were untested, the Naval Boiler and Turbine Laboratory deemed it advisable to dispense with them for the sake of continuous reliable operation, although this meant the use of more man power. The boilers were served by enough auxiliary equipment to ensure plant operation in spite of the failure of any single unit.

In the original experiments at NRL with $1000 \mathrm{lb}$ steam, a gravity return system was used for a single column so that the hot condensate was fed directly back to the boiler. Thus the boiler was required to supply only the heat of vaporization, in addition to a few British thermal units that were lost in subcooling the liquid 10 to $20^{\circ} \mathrm{F}$. When the expanded program was laid out, the plan was to follow the same system, using a high-pressure high-temperature pump to return the feed water to the boilers. An alternative scheme was to use part of the hot condensate for desuperheating and to cool down the rest in a condenser. Both these proposals were discarded when investigation showed that, although such pumps were being developed, none had been thoroughly 
proved capable of handling hot water at 1000 psi pressure and producing a differential head of 250 psi or greater. Consequently, in the interest of moving the plant completion date as far ahead as possible and also of having a dependable source of steam, the system of cooling down all the condensate in a condenser was used.

It will be seen that a tremendous amount of heat was being wasted in this arrangement. The total heat of 1000 psi saturated steam was 1191 $\mathrm{Btu} / \mathrm{lb}$ as it went into the columns. At the bottom, after condensation and a slight subcooling, the heat of the liquid was $530 \mathrm{Btu} / \mathrm{lb}$. If this hot condensate had been returned directly to the boiler, only $661 \mathrm{Btu} / \mathrm{lb}$ would have had to be added; however, if the liquid was subcooled to $80^{\circ} \mathrm{C}, 1011 \mathrm{Btu} / \mathrm{lb}$ had to be supplied. For one rack the actual steam consumption was $39,400,000 \mathrm{Btu} / \mathrm{hr}$, or 50 per cent more fuel than would be required if hot condensate were returned. Obviously the acquisition and use of suitable pumps and of boilers designed to operate with hot feed water are essential to the economical operation of a liquid thermal diffusion plant.

3.5 Process-fluid Piping. In a thermal diffusion plant the re are many miles of process-fluid piping. In the interest of safety, the size of the nickel tubing used for the purpose was held as small as possible. In general, $3 / 16^{-}, 1 / 8^{-}, 3 / 32^{-}$, and $1 / 16^{-i n}$. I.D. sizes were employed. Since the melting point of the process material was $70^{\circ} \mathrm{C}$ at $1550 \mathrm{psi}$, it was necessary to keep fluid lines above this temperature to prevent solidification. For long pipes this was accomplished by jacketing and heating with 5 psi steam. As many as 32 nickel lines were included in one jacket.

An alternative method of maintaining fluidity was to keep the tubing at a sufficiently high temperature in a heated enclosed space.

Thermosyphon pumps were located at frequent intervals along the rack. One leg of the pump was jacketed with 5 psi steam and the other with 150 psi steam.

3.6 Duct System. The ducts around the tops and bottoms of the heat exchangers provided a heated space for link lines carrying process fluid from one unit to another and carried away fumes caused by any breaks in the material system.

The front heating ducts, as originally laid out, were divided into units of two columns each, with one connecting duct to the collection duct behind each column (Fig. 7.8). The purpose of the division plates was to prevent cooling of the links between more than two columns when an operator had a door open. After operation showed that the columns could be run in larger groups than was at first thought feasible, these dividers were removed; consequently, the number of connecting ducts could be reduced to three or four per group of 17 columns so long as their size was increased appropriately. 


\section{ENGINEERING AND OPERATION}

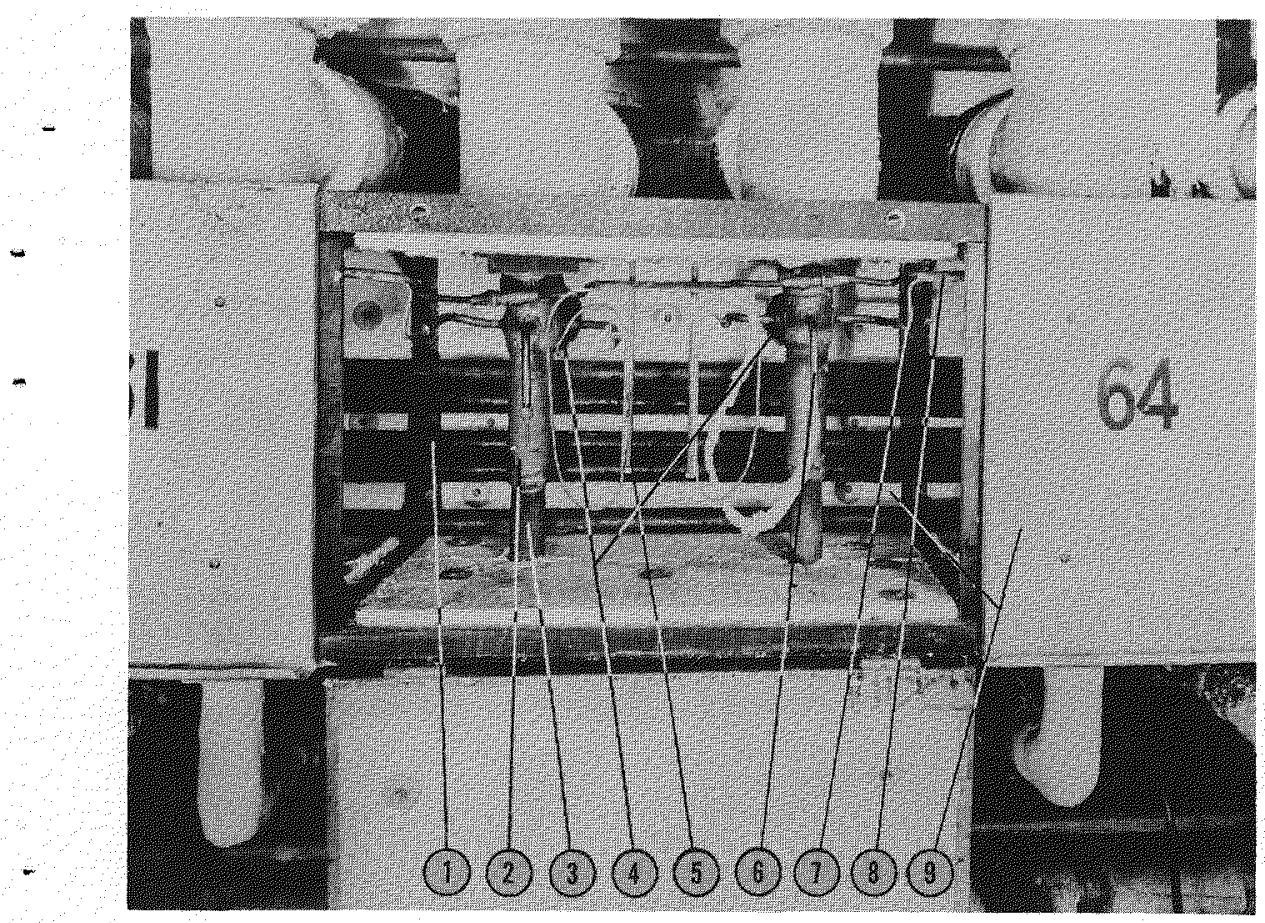

Fig. 7.8-View at bottom of columns, showing (1) duct steam-heating lines, (2) bottom of columns, (3) piping to column condensate expansion loop, (4) connecting openings to collection duct, (5) flowmeter for process fluid, (6) processfluid adapter, (7) intercolumn connectors, (8) freezer, and (9) hot-air duct.

The front half of the top of the lower duct and the bottom of the upper duct were made removable to aid in installing columns. Onehundred-pound steam lines (Fig. 7.8) were laid in the ducts to enable a temperature of about $100^{\circ} \mathrm{C}$ to be maintained therein. Back-collection ducts were connected through a stack to blowers on the roof of the plant. Gravity dampers had to be installed in these stacks between the lower and upper heating ducts and ahead of the exhaust fan to prevent the chimney effect from forcing cold air into the system.

By careful plant operation, the number and size of process-material leaks can be held so low that the collection system can be dispensed with, provided the building is properly designed with natural convection currents and the process material is of low $\mathrm{U}^{235}$ concentration.

Although all steam piping and the columns themselves were insulated, the amount of heat passed to the air was large enough to make operations on the rack very uncomfortable. Louvers were installed in the lower part of the building, and vents were cut in the roof. 


\section{PLANT INSTRUMENTATION}

For the most part, the instrumentation served one of two purposes: (1) to minimize man-power requirements by providing automatic control of operation or (2) to minimize loss of time and equipment by providing an automatic alarm system actuated by controls at points where trouble might occur. To illustrate the use of the control system, a typical one-stage circuit is described in detail.

4.1 Product Circuit. Figure 7.9 shows a typical product circuit.

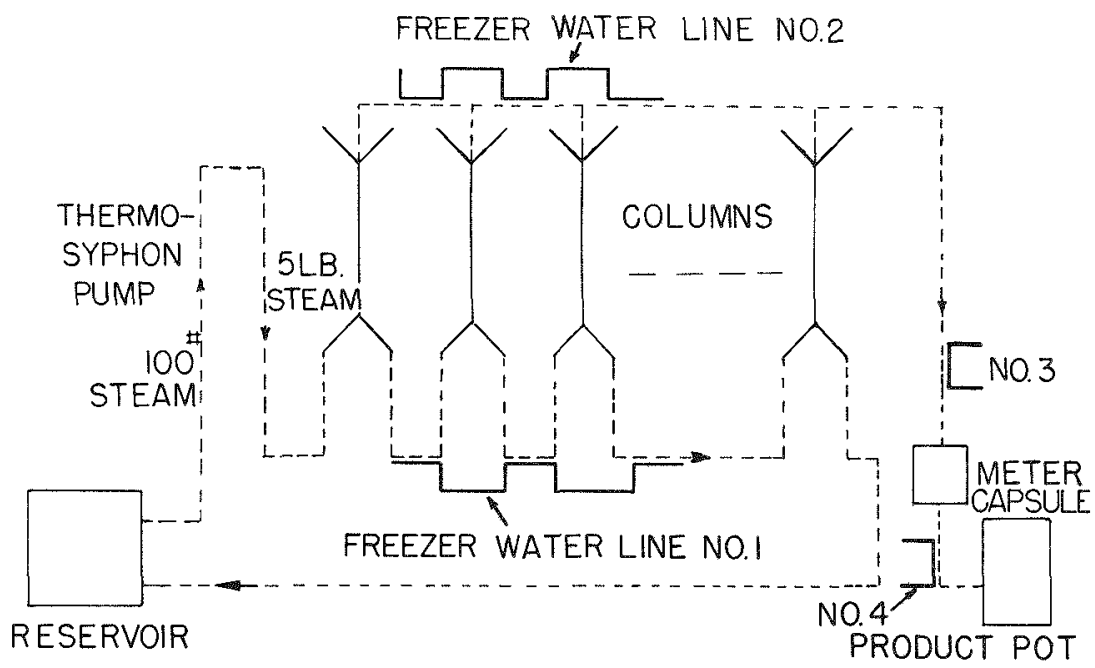

Fig. 7.9-Schematic diagram of typical one-stage product circuit. Valve action on flow of $\mathrm{UF}_{6}$ was obtained by freezing the substance. Automatic operation was attained by controlling freezer water flow with solenoid valves and a cam timer.

Any two adjacent columns in the circuit were connected both at the top and at the bottom. Connections at the bottom were made by $1 / 8$-in. nickel tubing attached to the end column adapters, and connections at the top were made through a manifold. Copper tubing was silver-soldered to these intercolumn connecters at the points indicated and was connected to a source of water and compressed air. During normal operation, water flowed through the copper line at the tops of the columns (line 2) and through the premeter freezer (line 3). The cold water froze the material in the attached nickel lines. The water was then turned off water lines 1 and 4, allowing the material in the nickel tubes attached to these lines to melt since the bottoms and tops of the columns and the intercolumn connectors were all contained in a steam-heated duct maintained at 100 to $130^{\circ} \mathrm{C}$. Thus raw material circulated from the 
reservoir, through the convector pump, through the bottoms of the columns, and back to the reservoir. Also, if there was any material in the meter chamber (which was maintained at a higher temperature than the product pot), this material distilled into the product pot. This process continued until it became desirable to draw off product, at which time water was turned into lines 1 and 4 . The water was next turned off line 2, and compressed air was blown through this line for a period of time sufficient to purge it of water. The material in the manifold then melted; whereupon water was turned off line 3 , allowing the $\mathrm{UF}_{6}$ to melt at this point, so that the meter chamber filled from the tops of the columns. It was necessary to allow the material in the manifold to melt before the premeter freezer (line 3 ) was thawed; otherwise, it would be possible for the meter to be filled by $\mathrm{UF}_{6}$ from only one column or a few columns. Water was then turned back on lines 2 and 3 and blown out of lines 1 and 4 , and fluid circulation through the bottom resumed.

4.2 Timer, Solenoid Valves, and Related Apparatus. In order to provide continuous automatic operation of the cycle described, a system of solenoid valves was used to control the flow of water and air through the copper lines. The periodic opening and closing of the solenoid valves was controlled by an electrical timer that made, and broke, the electrical circuits to the valves at preset intervals of time.

A schematic diagram of the timer circuit is shown in Fig. 7.10. It is seen that power was supplied to the solenoid valves through the timer and through a contactor. In series with the coil of the contactor were several stop buttons and a normally closed contact of relay $\mathrm{CR}_{2}$. The coil of relay $C_{2}$ was connected in series with a pressure switch communicating with the main steam supply and set so that the pressure switch made contact at about 900 psi (with process steam at 1000 psi), opening the contact in the contactor coil circuit and thus breaking the circuit that supplied power to operate the solenoid valves. The purpose of this device was as follows: If, for some reason, the main steam pressure were to fail and the columns were left to communicate with the reservoir as they cooled down, about two additional pounds of $\mathrm{UF}_{6}$ would flow into each column from the storage chamber. If the steam were then turned back into the columns containing this excess mate rial, it would be possible for the rapid expansion of the extra material to generate pressures sufficiently high to rupture the columns. The inclusion of the relay $\mathrm{CR}_{2}$ prevented this possibility since interruption of the power supply to the timer opened all water valves and closed all air valves, isolating the columns from the reservoir. A short-circuiting switch was placed around this contact for use during start-up.

Stop buttons were located at various strategic points in the plant, making it possible for an operator to isolate immediately all units from one another (by freezing) and from the reservoir. 


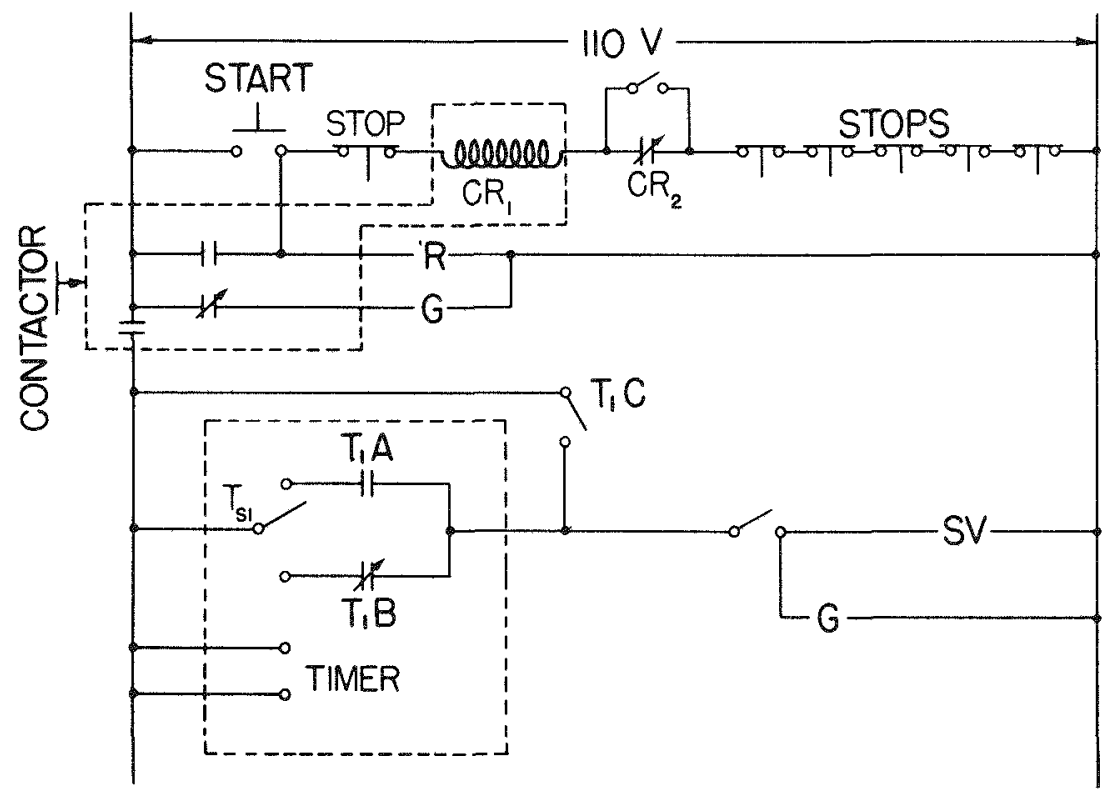

Fig. 7.10-Schematic diagram of cam timer and associated controls. In the event of an accident leading to the loss of process fluid, all columns could be isolated from one another by pressing stop buttons located at strategic spots around the plant.

The toggle switch $T_{\mathrm{S} 1}$ was a selector switch located inside the timer. $\mathrm{T}_{1} \mathrm{~A}$ and $\mathrm{T}_{1} \mathrm{~B}$ represented one cam of the timer; the selector switch $\mathrm{T}_{\mathrm{S} 1}$ was thrown to $T_{1} A$ if contact was desired for 0 to 50 per cent of a cycle. If no such contact was desired, the switch was thrown to $T_{1} B$. SV was the solenoid valve controlled by this cam, and $G$ represents a green light mounted on the panel, showing at a glance whether the corresponding valve was actuated or not. $\mathrm{T}_{1} \mathrm{C}$, when closed, formed a short circuit around the cam, permitting the valves to operate independently of the timer if this should be desirable. The inclusion of $\mathrm{T}_{1} \mathrm{C}$ was, of course, optional; it was found to be time-saving during start-up and experimental runs but of no use once steady production had been obtained. Other cams in the timer were connected paralleling the one shown.

4.3 Signal System. The main signal system consisted of an annunciator and the necessary normally open switches at the various control points. The drops of the annunciator were actuated by such factors as (1) failure of the 440-volt power, (2) failure of the 110-volt power, (3) low main steam pressure, (4) high circulating-water temperature, (5) low freeze-off water pressure, and (6) low circulating-water pressure. An independent power supply was used for the annunciator (a bank of 
d-c storage batteries). In series with the individual drops of the annunciator was either a 6 -volt bell or a relay whose output contacts were in series with a 110-volt bell, or both.

One control, in particular, requires a detailed description with regard to purpose. It was found that the best solenoid valves commercially available were not 100 per cent reliable, i.e., they had a limited life and they occasionally stuck in either an open or a closed position. Reference to Fig. 7.9 shows that all columns were connected at both the top and the bottom; however, as stated above, at all times either the tops or the bottoms were frozen so that at no time could the individual columns communicate with one anothe $r$ both at the top and at the bottom. However, if a water solenoid valve should burn out or stick closed, then during part of the cycle the columns would communicate with one another at both the top and the bottom. This condition was found to be very detrimental to the process, although it might exist for as small a time as 5 to 10 per cent of the total cycle period. The reason for such behavior lies in the inherent variations in the structure of the columns that will be found in any plant. Although these variations from column to column are small, they result in different average densities of the process material in two adjacent columns; therefore, if the columns communicate with each other both at the top and at the bottom, a circulating flow of material will take place, resulting in a general mixing of material. This mixing was found to be very effective in cutting down the separation factor; hence, it was desirable to have an alarm that would annunciate whenever both the upper and the lower freeze-off lines were simultaneously without cooling water.

It should be emphasized that a freeze-off water alarm system is a near must in any pyramid arrangement. A multistage pyramid will require, in general, over a month to come up to product concentration. Intercolumn circulation for $30 \mathrm{~min}$ could nullify over half the separative work achieved during the build-up period.

4.4 Process-fluid Flow Indicators. For proper operation of a circuit, the process fluid must flow through the circulation loop for as large a fraction of the total cycle time as possible. Since it is quite easy for a "plug" of some sort to form in this line, some type of flow indicator was required. Thermocouples were attached to two adapters of a column, and their readings were recorded by use of a recording potentiometer calibrated to read temperature when the thermocouples were in use. When flow was in process, the fluid flowing out of one adapter of the column was about $100^{\circ} \mathrm{C}$ hotter than that flowing into the column. If there was no flow, the two temperatures were about the same. Thus simultaneous reading of the temperatures of the ingoing: and outgoing adapters served to indicate whether $\mathrm{UF}_{6}$ flow was taking place. 


\section{LIQUID THERMAL DIFFUSION}

It was also possible merely to attach two the rmometers to a line through which $\mathrm{UF}_{6}$ was flowing, one of them being near an adapter through which fluid flowed as it left the column and the other being a foot or so down the line.

\section{TRANSFER ROOM}

Uranium hexafluoride is a poison of the same general level of toxicity as chlorine. One of the features of a liquid thermal diffusion plant is the high process-fluid pressures that must be employed (1550 ps1). Large quantities of process flund must be maintained in reservoirs at these pressures. Transfers of flund must be made routinely from shipping cylinders to reservoirs.

It is clear that rather serious operational hazards existed. To minimize these, it seemed desirable to perform all tasks relating to the bulk handling of $\mathrm{UF}_{6}$ in a separate building especially designed to minimize potential risks. This bulding was termed the "transfer room" (Fig. 7.11). It functioned as the pount for (1) transfer of $\mathrm{UF}_{6}$ from ship-

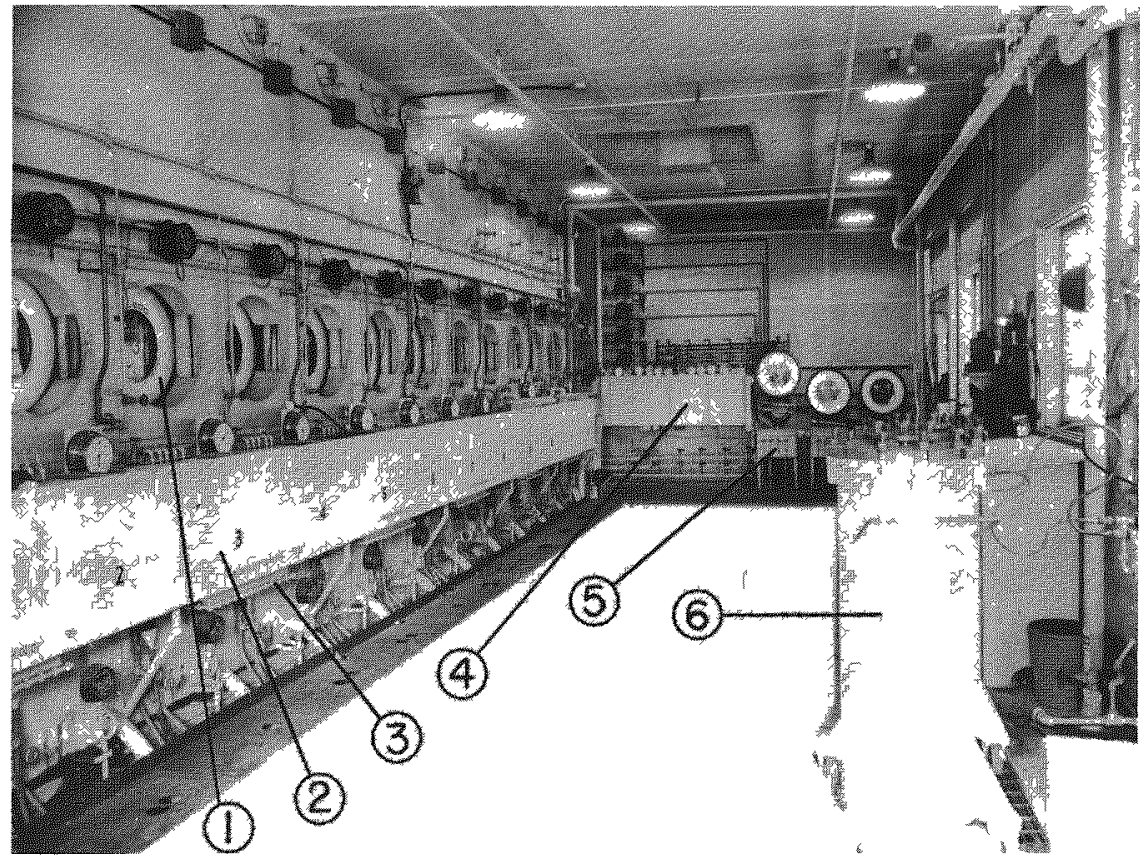

Fig. 7.11-View of transfer room, showing (1) scales for the 12 reservorrs; (2) hot-air duct to maintain fluidity of $\mathrm{UF}_{6}$; (3) terminal box, terminus for $1 / 8-1 \mathrm{n}$. O.D. nickel piping connecting transfer room and main process area; (4) product meter duct; (5) product weighıng scales; and (6) steam jacket for rapid distillation of $\mathrm{UF}_{6}$ from shipping containers. 
ping cylinders to reservoirs, (2) control for keeping all process equipment at proper fluid pressure, (3) product metering, (4) product removal, (5) product dumping, (6) waste dumping, and (7) routine transfer of process fluid.

5.1 General Considerations. The arrangement of instruments allowed convenient and constant observation of all gauges and meters. A sprinkler system was provided to protect against bursting of $\mathrm{UF}_{6}$ containers in case of extreme heat during a fire.

A great deal of piping for gas, water, and steam was needed to handle these services. In order to avoid crowding of the lines around the room, the majority of the lines were placed in trenches running under the reservoir and product ducts along with condensate returns and water drain lines.

5.2 Reservoirs. The 12 reservoirs were the most important items of equipment in the transfer room, as well as the most dangerous because of the large amount (approximately $450 \mathrm{lb}$ ) of material at 1550 psi. Each tank was a cylinder made of $1 / 2$-in. nickel plate, $81 / 2 \mathrm{ft}$ long and $8 \mathrm{in}$. in inside diameter. The ends were elliptical in form and were somewhat thicker than the walls. The cylinder was made in two halves and welded along the axis with pure nickel rod. The ends were attached with a circumferential weld. A coiled nickel heating pipe was constructed along the axis on the inside of the reservoir for heating the $\mathbf{U F}_{6}$. A steel heating jacket surrounded the full length of the cylinder and served both for low-temperature heating when starting up and for rapid cooling of the contents of the reservoir in an emergency. Near the bottom of the tank, five nickel adapters projected outward for use in filling and connecting the reservoirs into the process-fluid circuits. At the same level a thermometer well was welded into the tank. Additional adapters projected from the top and bottom for cleaning. Blow-off diaphragm flanges were welded into the chamber at the top.

Each tank was mounted vertically upon a framework on a scale platform. The scale dial, which had a 1000-1b range, was turned so that it faced into the transfer room (Fig. 7.12). The tare weight of tanks and associated equipment was balanced out so that the scale read the weight of $\mathrm{UF}_{6}$ in the reservoir. The scale beam and dial were actually in the wall of the transfer room and were separated from the tanks by a steel plate. The suspension of the tank and scales, of course, necessitated generous loops or coils in all steam and water pipe attached thereto in order to eliminate extraneous support. This was well accomplished, as tests with weights indicated.

The inner coiled nickel heating tube was attached to a steam loop above the top of the reservoir. The loop received steam from a line in the transfer-room wall which at first was supplied through a reducing valve from a 600 psi steam line in the trench; however, because of 


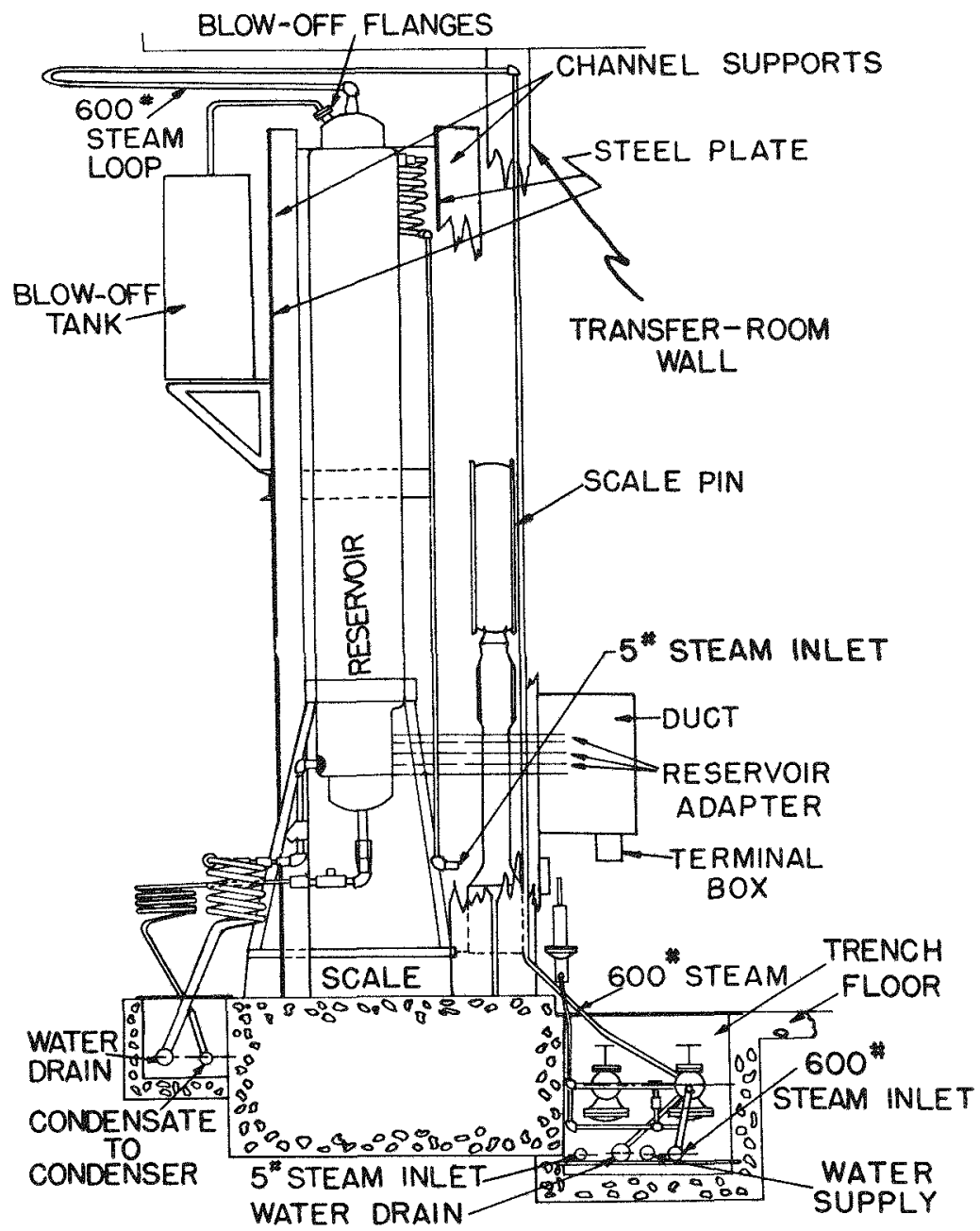

Fig. $7.12-$ Detail of reservoir mounting and piping.

faulty operation, the reducing valves were removed and replaced with $1 / 2$-in. globe valves. Regulation of the steam pressure provided temperature control at the temperature of condensing steam. The bottom of the coil fed into a steam trap and then into a condensate return line in a trench behind the chambers.

The outer jacket was connected to 5 psi steam and water lines in the trench along the front of the chambers. The lines were arranged with suitable valves low on the transfer-room walls so that either lowpressure steam or water could be routed into the jacket. 
Because the reservoirs were outside the transfer room, the nickel adapters on them were very long and had to be heated to prevent freezing. Therefore, a small jacket surrounded them from the point where they left the tanks to the point where they entered the ducts in the transfer-room wall. The jackets could be heated with steam, or cold water could be run through them to freeze off the adapters in case of a break. These jackets were connected to an automatic freezer valve. In addition, each adapter had a copper freeze-off line silver-soldered to it inside the duct. Cold water could be run through any one of these lines to freeze it off by opening a cock just above the duct.

A remote-indicating dial thermometer was placed just above the scale dial, and the element was placed in a nickel wall in the reservoir. Steam-pressure gauges were attached beneath the duct and measured the pressure in the steam heating coil. The $\mathrm{UF}_{6}$ pressure gauges were connected through an adapter to the interiors of the tanks. The gauges were located just above the duct and were individually steam heated. They were of standard 3000 psi Bourdon tube design with berylliumcopper tubes and silver-soldered joints.

To prevent the possibility of reservoirs bursting and the attendant damage, several precautions were taken. The tanks were placed outside the room and were completely surrounded by steel plate. Channel sections were used to isolate one tank from another. The plates were supported on channels set into the concrete scale footing. The tanks were then tested hydrostatically to 4000 psi before installation. Finally, each chamber was fitted with a blow-off diaphragm mounted between the flanges which would rupture at about $2200 \mathrm{psi}$. The effective size of the disk was kept to $1 / 2$-in. in diameter so that the jet effect of the blow would not be sufficient to cause damage to the scale mechanism but would be large enough to be reliable and to prevent plugging. In order to prevent the loss of $\mathrm{UF}_{6}$ after a blow, the diaphragm communicated with a blow-off tank mounted on the back of the steel shield. The tanks were made large enough so that, under the worst possible conditions of weight of material and temperature in the reservoir, the pressure would be dropped to a safe level after blow-off. A well was provided in the blow-off tanks, into which was inserted the sensitive element of a thermal relay that operated an alarm bell when hot material entered the tank. When blow-off occurred, the scale indicator increased momentarily but rapidly dropped off as material went over to the blow-off tank; the process-fluid pressure dropped off immediately.

All the connections between the reservoirs and the process piping leading to the racks were made in a duct that was mounted on the wall in front of the reservoirs below the scale dials. The duct contained the transfer manifolds and terminal boxes for all the lines leading to the columns on racks, in addition to the adapters of the reservoirs. The 
duct was heated by means of steam lines and was well insulated. A blower system was arranged to clear the duct in the event of a break inside it. The air was drawn out of the ducts through circular conduits to a header mounted on the plate behind the storage chambers. The header fed to a blower, mounted on the wall of an adjacent building, which forced the air through a washer to remove all the $\mathrm{UF}_{6}$. In addition, blowers were placed in ventilators in the roof of the transfer room to clear out smoke and discharge it at some height above the roof.

5.3 Filling of Reservoirs. Provisions were made for the simultaneous operation of two transfer pots at the end of the line of reservoirs. The pots were simply steam jackets used to heat the UF ${ }_{6}$ sufficiently to distill it into the reservoirs. The transfer pots were mounted on wheels and had a removable top to allow insertion of the shipping containers. Although the pots were heavy, they were easily handled on their wheels. The pots were designed with sufficient volume and wall thickness so that, in the event of failure of the shipping containers, the pots would hold the material liberated. The head was placed on the shipping tanks and sealed with a neoprene ring, and then the assembly was lowered into the jacket with an electric hoist. The pots could then be wheeled onto the scales used to measure the amount transferred. The steam and drain lines were attached to the pots, and the heated material flowed through a heated line to the reservoir. Steam-pressure regulating valves on the adjacent wall, along with pressure gauges, provided temperature control. Water valves operating through checks ensured rapid cooling of the pots in an emergency. The steam-heated processfluid line was connected to a manifold inside the duct in front of the reservoirs to allow filling or draining any reservoir from either pot.

5.4 Product Metering and Removal. The product withdrawal operations were carried on in a duct on the wall that separated the two rooms of the transfer building and in the smaller of the two rooms. A large duct, with access doors on both sides of the wall, extended the full width of the transfer room. All metering operations were carried out in this room.

Each circuit had its individual metering chamber, which was essentially a capsule with a freezer valve at each end. The capsule was enclosed in a steam jacket and communicated with a pressure gauge, which indicated whether the capsule was metering properly. Originally the gauge was steam heated, but later it was found easier to install all but the face in the duct. In operation, an automatic timer first froze the capsule outlet and unfroze the inlet that communicated with the columns. This permitted $\mathrm{UF}_{6}$ to enter the capsule at full system pressure, which was indicated on the gauge. The inlet was then frozen and the outlet opened, allowing the contents of the capsule to pass out into the product pots. All these operations were automatic and were carried out by a 
cam timer that operated solenoid valves mounted on the wall above the product duct.

After metering, each of the product lines continued through a steamjacket conduit to its individual product pot. These containers were arranged in units of four on a scale with an air-jack arrangement, which made individual weighing of the containers possible and yet conserved space. In the pyramid circuit, which utilized similar equipment, this product-removal system was duplicated by a waste-material withdrawal system.

\section{REFERENCE}

1. M. C. Fox, Chem. \& Met. Eng., 52: 102 (1945). 
Chapter 8

THE PYRAMID

F. J. Gradishar

In principle, any desired degree of isotope separation could be obtained from a column by sufficiently increasing its length. In practice, such a procedure is impractical for at least two reasons: The first is the obvious one of the awkwardness of such equipment. The second is more subtle and is best illustrated by the results of the following experiment.

Three columns were connected in series as shown in Fig. 8.1. Samples were removed from time to time, and the results listed in Table 8.1 were observed.

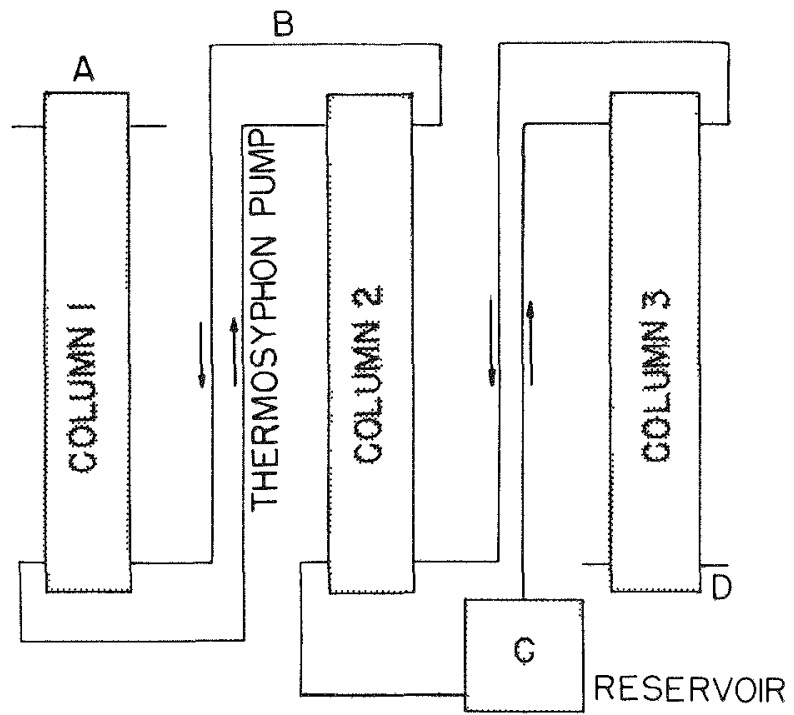

Fig. 8.1-Three columns connected in series. Samples were removed from points $A, B, C$, and $D$. 
The numbers given in Table 8.1 show that only columns 1 and 3 are performing separative work. The remaining column could have been out of operation so far as affecting the result during the initial days of operation is concerned.

Table 8.1 - OPERATION OF COLUMNS CONNECTED IN SERIES

\begin{tabular}{ccccc}
\hline $\begin{array}{c}\text { Duration } \\
\text { of run, } \\
\text { days }\end{array}$ & \multicolumn{4}{c}{ Enrichment at sampling point, \% } \\
\hline 2.67 & 1.131 & 0.998 & 0.998 & 0.864 \\
6.75 & 1.239 & 0.994 & 0.993 & 0.799 \\
10.67 & 1.273 & 0.984 & 0.995 & \\
\hline
\end{tabular}

To enhance enrichment of $U^{235}$ beyond that produced by a single stage of optimum-length columns requires a system of cascading. A batchwise process, in which the product from one bank or stage is collected in a reservoir and used as feed material for another, involves excessive handling. It is evident that this disadvantage is eliminated by a process in which the product from one stage is fed up to the next stage and the waste is fed downward. Such a system is approximated in the National Research Laboratory (NRL) pyramid, which deviates from the ideal because the transportation of material is effected at frequent intervals rather than continuously.

The purpose of the investigation reported in this chapter was to devise pyramids consisting of several stages and to demonstrate the practicability of operating them.

\section{PHYSICAL MAKE-UP}

To test the feasibility of pyramiding in a practical setup, two totally

- rectifying units were assembled: one was a two-stage unit (designated as "pyramid 5") and the other was a four-stage unit (designated as "pyramid 7"). A set of 24 columns previously used as parallel recti-

- fiers in production circuit 5 was incorporated into pyramid 5 , and 47 columns comprising production circuits 7 and 8 were combined into pyramid 7. The columns in circuit 5 had been tested when they were used as producers, and two obviously "bad" columns were replaced by new ones.

Data taken on circuit 5 during production over a one-month period gave the results shown in Table 8.2 . The isotope concentration given is relative to that of ordinary uranium. 
The columns comprising circuit 5 were somewhat variable in their characteristics. Values of $Y$ ranged from 0.35 to 0.45 . If, for simplicity, an effective value of $Y$ is taken as 0.4 , it later becomes possible to make a comparison of the experimental results with theory. On the basis of $\mathrm{Y}=0.4$ and $\mathrm{M}=1600 \mathrm{~g} / \mathrm{column}$, the withdrawal data given in Table 8.2 are fitted by the value $H=34.8 \mathrm{~g} /$ day. This leads to an average value of $\mathrm{X}=115$ days. The columns comprising pyramid 7 were never tested individually; consequently, they must be considered a combination of a random choice of columns.

Table 8.2-CHARACTERISTICS OF COLUMNS USED IN PYRAMID 5

\begin{tabular}{cccc}
\hline $\begin{array}{c}\text { Average feed } \\
\text { concentration }\end{array}$ & Grams/column/day & $\begin{array}{c}\text { Product } \\
\text { concentration }\end{array}$ & $\begin{array}{c}\text { Sepa- } \\
\text { ration }\end{array}$ \\
\hline 0.975 & 132.3 & 1.184 & 1.214 \\
0.975 & 156.9 & 1.163 & 1.193 \\
\hline
\end{tabular}

During production, circuit 7 (23 columns at the bottom of pyramid 7) averaged $2040 \mathrm{~g} /$ day of product at 1.199 . Circuit 8 (24 columns at the top of pyramid 7) produced $2508 \mathrm{~g} /$ day at 1.226 . The data are summarized in Table 8.3 .

Table 8.3-CHARACTERISTICS OF COLUMNS USED IN PYRAMID 7

\begin{tabular}{ccccc}
\hline $\begin{array}{c}\text { Circuit } \\
\text { No. }\end{array}$ & $\begin{array}{c}\text { Average feed } \\
\text { concentration }\end{array}$ & Grams/column/day & $\begin{array}{c}\text { Product } \\
\text { concentration }\end{array}$ & $\begin{array}{c}\text { Sepa- } \\
\text { ration }\end{array}$ \\
\hline 7 & 0.975 & 88.7 & 1.199 & 1.230 \\
8 & 0.975 & 104.5 & 1.226 & 1.257 \\
\hline
\end{tabular}

The distribution of the columns into the respective stages followed a plan developed from theoretical considerations. This plan proposed the following ratios: two-stage pyramid, 2.5:1; three-stage pyramid, 4.5:2.5:1; four-stage pyramid, $7: 4.5: 2.5: 1$; and a five-stage pyramid, $10: 7: 4.5: 2.5: 1$. In accordance with these ratios, pyramid 5 consisted of 17 columns in the first stage and 7 columns in the second stage, whereas the 47 columns in the four-stage pyramid 7 were proportioned $22: 14: 8: 3$, respectively.

The physical arrangement of pyramids 5 and 7 is represented schematically in Figs. 8.2 and 8.3, respectively. In the arrangement shown, circulation loops powered by convector pumps connect the top of one stage to the bottom of the next stage for the purpose of interchanging material. Obviously the most efficient system would be one in which 


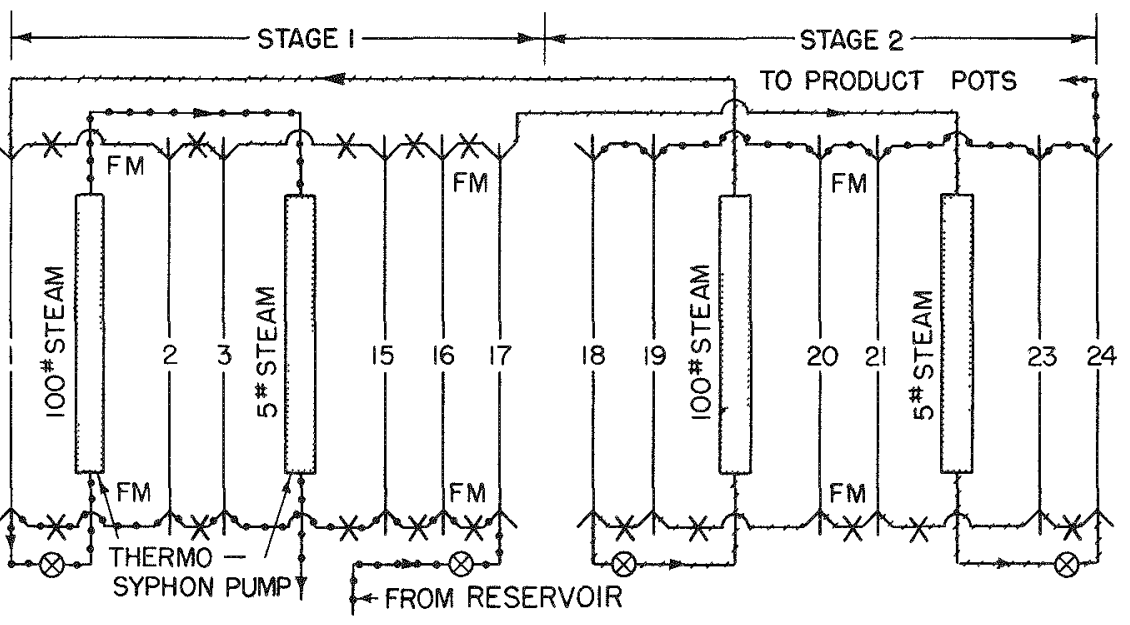

TO RESERVOIR

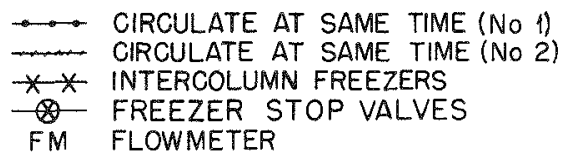

Fig. 8.2-Schematic process-fluid flow diagram of a two-stage pyramid.

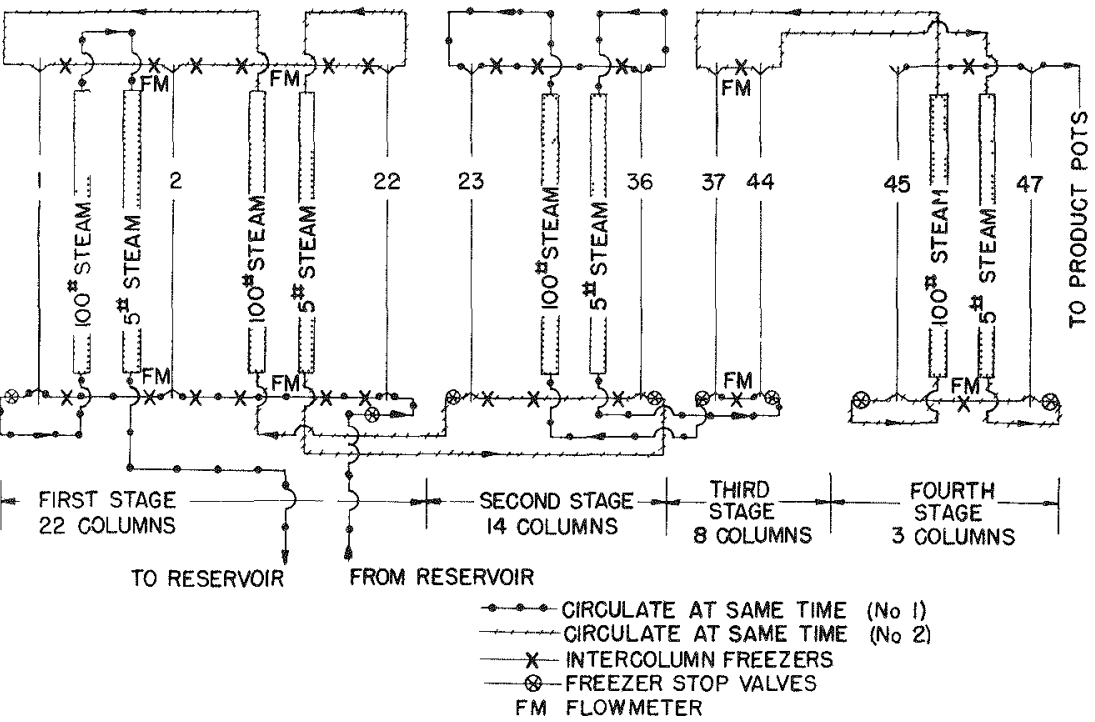

Fig. 8.3--Schematic process-fluid flow diagram of a four-stage pyramid. 
continuous motion of material between adjacent stages occurred. This arrangement, however, would result in thermosyphon effects between adjacent columns and adjacent stages, thereby nullifying the separation process. Consequently, the expedient of stopping alternate loops at alternate hours was adopted, i.e., the number 1 circuits were "frozen" when the number 2 loops were circulated, and vice versa. A cam timer controlled the process by alternately actuating the appropriate solenoid valves every hour, Auxiliary valves, which permitted freeze water to be introduced manually at will into any link, were installed in parallel with the automatic valves. Nickel lines $1 / 16$ in, in inside diameter interconnected various other units of the pyramid. Freezer stop valves were installed to permit the isolation of any part of the circuits.

\section{OPERATIONAL PROCEDURE}

Since most of the columns had been in operation for some time previous to their assembly in pyramids, it was necessary only to drain out the process fluid to prepare them for pyramid assembly. In the case of new columns, the accepted procedure for conditioning the material space was followed: a carbon tetrachloride degreasing wash, a water wash, blowing with heated nitrogen until the columns were dry, and a final flushing with gaseous fluorine. The system was ready for the introduction of the process material $\left(\mathrm{UF}_{6}\right)$ after assembling the component links and testing for pressure tightness. When the system was completely filled and all obstructions (plugs) to normal operation were removed, the system was placed under the control of the automatic cam timer, which permitted fluid to flow in alternate hours in the number 1 and the number 2 circuits.

As in any exploratory experiment, numerous operational difficulties were encountered. Plugs or restrictions to flow of material in the relatively small interlink lines were the principal nuisance; detection and elimination were hindered by the increased complexity of the system. For example, a plug in the fourth-stage loop could be detected best by following the pressure changes from the storage chamber to the loop concerned. This involved leading the pressure-induced flow through selected channels of the first three stages to the stage in question and observing the point at which the flow terminated, as indicated by the flowmeters. Care was exercised to reverse the flow in an identical manner in order not to produce any ultimate disturbance in the relative position of the process fluid.

Excessive leaks in the steam system caused several shutdowns during the term of operation. Shutting down the system and resuming operation at a later date had a disturbing effect since it caused pitching, a boiling action that stirred up the material within the col- 
umns. At such times the various stages were completely isolated from one another. Although there was some mixing within a stage, only a small amount of separative work was lost.

The method of removing product from the top stage of the pyramid was similar to that used with the single-stage circuits. At 2-hr intervals the line connecting the top of the last stages to the product receiver was cleared. A metering cylinder of appropriate size was allowed to fill. The contents of the metering cylinder were later released automatically into a product receiver. Compared with the system, the capacity of the reservoir was so great that it showed appreciable impoverishment of the light material only after a considerable length of time. When the assay reached 0.67 per cent of $U^{235}$, the contents of the reservoir were replaced with fresh material. A group of columns set up as "strippers" could be utilized further to impoverish the waste if this was considered desirable.

\section{RESULTS FROM PYRAMID 5}

The most successful studies were those pursued on pyramid 5 . One run was made to follow the approach to equilibrium. Samples were taken from each stage at a representative point at regular intervals.

Two mishaps occurred to mar the continuity of the experiment. On the eighth day of the run, $3 \mathrm{lb}$ of $\mathrm{UF}_{6}$ was lost by accident from the top of the first stage. Shortly thereafter the circuit was shut down owing to a lack of adequate steam supply. When operation was resumed, seven days passed before a parasitic circulation loop in the top stage was discovered and removed. Thereafter, operation was smooth and uninterrupted until the end of the run.

Figure 8.4 shows the approach to equilibrium. The solid curves represent the theoretical values for a pyramid having columns all alike, $Y=0.4, X=115$, and $H=34.8 \mathrm{~g} /$ day. The dotted curves show the actual values observed. The dip in the upper curve is the result of the parasitic circulation.

The inter ruption caused by the parasitic convective loop mainly affected the seven columns composing the top stage. The bottom stage continued performing separative work during the seven-day interval. The principal result of the interruptions, therefore, was the loss of the separative work of seven columns for seven days. In addition, the efficiency of the bottom 17 columns suffered slightly during this period because the concentration at the top of the first stage was higher than it should have been; consequently, there was more back diffusion. The net effect of the interruption was, therefore, the loss of two to three days of separative work for the pyramid taken as a whole. 
One other complication in the interpretation of the experiment is the fact that the reservoir concentration diminished during the course of the run. The theoretical curve given is calculated on the basis of a constant reservoir concentration held at that for normal uranium. After taking all these factors into consideration, it appears that pyramid 5 performed in fairly good agreement with the theoretically expected behavior.

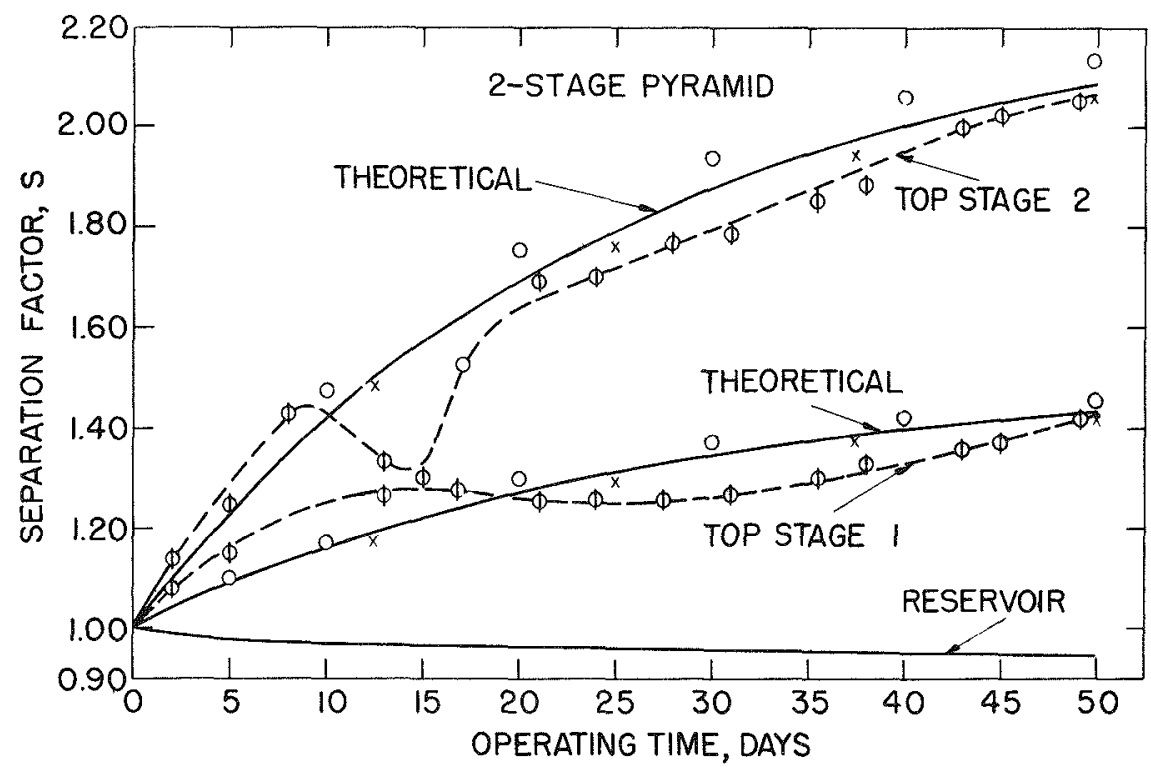

Fig. 8.4-Approach to equilibrium of a two-stage rectifying pyramid. The dip beginning on the eighth day was due to a parasitic convective loop.

A run was made to determine the separation during product withdrawal, and the results of this run are given in Table 8.4.

These results were observed during a steady withdrawal over a period of $\mathbf{2 5}$ days, and they are the average of five samples taken after

Table 8.4-PERFORMANCE OF TWO-STAGE PYRAMID

\begin{tabular}{cccccc}
\hline & $\begin{array}{c}\text { Average } \\
\text { concentration, } \\
\text { bottom } \\
\text { rate, } \\
\text { g/day }\end{array}$ & Stage 1 & Concentration, top & \multicolumn{2}{c}{ Separation factor } \\
\hline 760 & 0.975 & 1.19 & 1.56 & 1.220 & 1.31 \\
\hline
\end{tabular}


steady-state conditions had been established. The over-all separation factor of the final product is 1.60 instead of an expected value of 1.54,

- calculated on the hypothesis that all columns are alike and have $M=$ $1600, \mathrm{Y}=0.4, \mathrm{X}=115$, and $\mathrm{H}=34.8 \mathrm{~g} /$ day.

\section{RESULTS FROM PYRAMID 7}

The performance curve of pyramid 7, a four-stage 47-column unit, is given in Fig. 8.5. Operation was sluggish for the first few weeks, with numerous constrictions and plugs in the $1 / 8$-in. link lines. For 32 days the system was allowed to build up toward equilibrium before the product-withdrawal mechanism was set into operation. A run of 40 days, during which product was withdrawn, established steady-state

4-STAGE PYRAMID

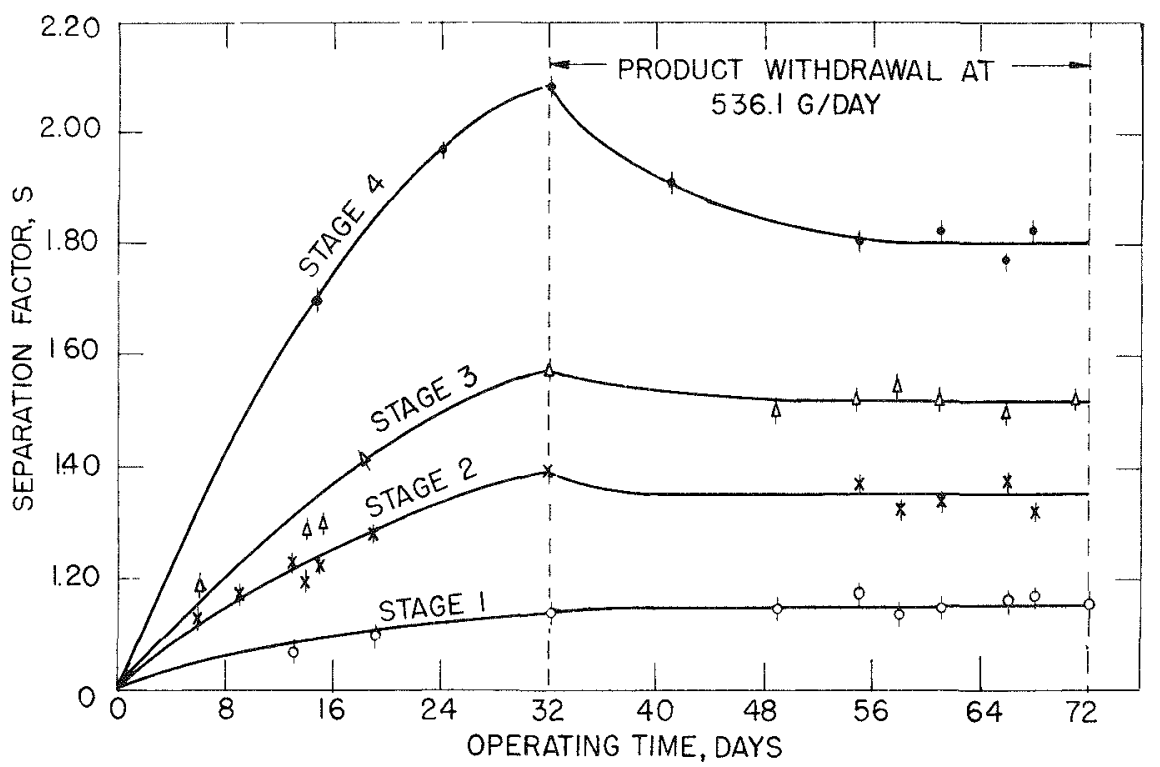

Fig. 8.5-Performance curve for a four-stage pyramid. No product was removed during the first 32 days. Product was removed at the rate of $536.1 \mathrm{~g} /$ day during the remainder of the run.

concentrations in the various stages. These values are listed in Table 8.5. Table 8.6 shows the separations for each stage.

It is clear that stage 3 performed very poorly. This fact was probably due to one or more very poor columns in the stage. The remaining stages show a behavior not much different from the theoretical. By 
Table 8.5-PRODUCT WITHDRAWAL FROM PYRAMID 7

\begin{tabular}{|c|c|c|c|c|c|}
\hline \multicolumn{5}{|c|}{ Termina ${ }^{\top}$ concentrations } & \multirow[b]{2}{*}{$\begin{array}{l}\text { Withdrawal } \\
\text { rate, g/day }\end{array}$} \\
\hline $\begin{array}{l}\text { Stage } 1 \\
\text { (bottom) }\end{array}$ & $\begin{array}{l}\text { Stage } 2 \\
\text { (bottom) }\end{array}$ & $\begin{array}{l}\text { Stage } 3 \\
\text { (bottom) }\end{array}$ & $\begin{array}{l}\text { Stage 4 } \\
\text { (bottom) }\end{array}$ & $\begin{array}{c}\text { Stage } 4 \\
\text { (top) }\end{array}$ & \\
\hline 0.975 & 1.155 & 1.354 & 1.523 & 1.80 & 536.1 \\
\hline
\end{tabular}

taking an effective $\mathrm{Y}=0.4$, the results from the single-stage operation of circuit 8 gave $H=36.0 \mathrm{~g} /$ day and $X=111$ days. From these values a separation factor of 1.18 is predicted for the top stage of the pyramid.

Table 8.6-ISOTOPE SEPARATION IN PYRAMID 7

\begin{tabular}{cccc}
\hline \multicolumn{5}{c}{ Stage No. } \\
1 & 2 & 3 & 4 \\
\hline 1.182 & 1.172 & 1.117 & 1.182 \\
\hline
\end{tabular}

The NRL studies of pyramid behavior led to the following observations:

1. The pyramid was easy to operate automatically once the proper fluid flow was obtained.

2. The principal difficulty was plugging, which could be eliminated.

3. It was found especially important that the "freezer" mechanism for alternate circulation be completely dependable.

4. A program of elimination of poorly performing columns was found to be essential.

5. With uniform columns it was possible to approach the theoretically predicted performance. 
Part II

THEORETICAL ASPECTS 


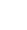




\section{Chapter 9}

\section{THE COLUMN}

\section{PROCESSES IN THE COLUMN}

As pointed out in Chap. 1, the functioning of a liquid thermal diffusion column involves three basic processes: convection, thermal diffusion, and ordinary diffusion. The liquid near the hot wall is carried upward by convection, whereas that near the cold wall is carried downward. At the same time the process of thermal diffusion takes place, generally involving a transfer of molecules of the light isotope from the cold to the hot wall. The combination of these two processes results in the accumulation of the lighter isotope near the top of the column, while the heavier molecules collect near the bottom. However, ordinary diffusion also sets in as soon as any appreciable concentration gradient develops and acts to reduce such a gradient. The first theoretical treatment of the liquid thermal diffusion column was given by Debye. ${ }^{1}$ However, his calculation applies only to the case of small temperature differences. The method used here will be essentially that of Furry, Jones, and Onsager, ${ }^{2}$ which they developed for gases but which, with some modifications, can be applied to liquids.

The behavior of each of the basic processes can be described by writing the expression for the corresponding mass current density of the light isotope. Let $\mathrm{c}$ denote the concentration of the light constituent, i.e., its molecular fraction. Since the two isotopes under consideration are so nearly equal in atomic weight, this can also be taken as the mass fraction. Let $\rho$ be the density and $\vec{v}$ the velocity of the liquid due to convection. It will be assumed that, as is usually the case in practice, the flow of the liquid is lamellar, so that the velocity is a smoothly varying function of position. If $i_{\mathrm{H}}$ denotes the hydrodynamical mass current density, i.e., the rate of flow per unit cross section of the light component associated with the convection, then

$$
\dot{\mathrm{i}}_{\mathrm{H}}=\rho \mathrm{cv}
$$


In the case of ordinary diffusion, the corresponding current density associated with the transfer of light molecules by diffusion is given by

$$
\mathrm{i}_{\mathrm{D}}=-\rho \mathrm{D} \nabla \mathbf{c}
$$

where the ordinary diffusion coefficient, $D$, will be a function of the temperature but will be very nearly independent of the concentration, $c$, because of the great similarity in the properties of the two isotopes.

The current density associated with thermal diffusion, $\mathrm{i}_{\mathrm{T}}$, can be written

$$
\mathbf{i}_{\mathrm{T}}=\mathbf{F} \nabla \mathrm{T}
$$

where $T$ is the temperature and $F$ is a coefficient that is dependent, in general, both on the temperature and on the concentration. Since there is no thermal diffusion if either species of molecule is present alone, $F$ can be assumed to contain a factor $c(1-c)$. Therefore

$$
\mathbf{i}_{\mathrm{T}}=\mathrm{Dq} \mathrm{c}(1-\mathrm{c}) \nabla \mathrm{T}
$$

where $D$ is the ordinary diffusion coefficient previously defined and $q$ is what will be referred to as the "thermal diffusion coefficient."

It can be expected that $\mathrm{q}$ will depend on $\mathrm{T}$ and that it will be, in general, a slowly varying function of the concentrations. In fact, since the problem deals with isotopes, i.e., with molecules of very similar physical properties, it is reasonable to believe that $q$ will be very nearly independent of the concentration $c$. This assumption is borne out by the fact that such is the case for thermal diffusion in gases. ${ }^{3}$ Therefore, it may be assumed that $q$ in Eq. 4 is a function of the temperature only. The nature of this function is not known at present. In the case of gases it has been found to be of the form $\alpha / T$, where $T$ is the absolute temperature and $\alpha$ is nearly a constant; this is the function used by Furry, Jones, and Onsager. ${ }^{2}$ For liquids, very rough theoretical arguments ${ }^{4}$ have led to either $\alpha / \mathrm{T}$ or $\alpha / \mathrm{T}^{2}$, depending on the model assumed.

If all three processes take place simultaneously, then the resultant light-constituent current density is given by

$$
\mathbf{i}=\mathbf{i}_{H}+\mathbf{i}_{T}+\mathbf{i}_{D}
$$

The equation of continuity, representing the condition for the conservation of the light constituent, is then

$$
\frac{\partial}{\partial t}(\rho \mathbf{c})=-\nabla \cdot \vec{i}
$$




\section{DIFFERENTIAL EQUATION OF THE COLUMN}

- A column will be considered as consisting of two vertical coaxial tubes, spaced a distance, a, apart, each of length $L$, between which the working liquid is contained in the annular space of mean circumference b. The inner surface of the outer tube, the "cold wall," is maintained at a low temperature, $T_{1}$, by means of some cooling agent (water). The outer surface of the inner tube, the "hot wall," is maintained at a high temperature, $T_{2}$, by some heating agent in this tube (steam).

Since in practice the spacing, $a$, is very small compared with the mean circumference, $b$, the curvature of the walls can be neglected, and they can be treated as plane surfaces. Furthermore, because the spacing, a, is extremely small compared with the length, $L$, "end effects" can be neglected at the ends of the column where the temperature distributions vary from those prevailing elsewhere and where the convection streams curve back to reverse their directions.

In order to obtain the differential equation for the column, the process of convection will be investigated first since this will not be affected appreciably by the other two processes because of the similarity of the two species of molecules. Assume that the liquid is between two parallel vertical walls a distance a apart, of breadth $b$ and height $L$. Then take a Cartesian coordinate system with the $\mathrm{X}$ axis at right angles to the walls and the $\mathrm{Z}$ axis vertical so that in the working space $0 \leq \mathrm{x} \leq \mathrm{a}$, $0 \leq \mathrm{z} \leq \mathrm{L}$. For the present the ideal case, in which none of the quantities to be discussed varies in the direction of the third (y) coordinate, will be considered. Take the cold wall at $\mathrm{x}=0$ as having the temperature $T_{1}$ and the hot wall at $\mathrm{x}=\mathrm{a}$ as having the temperature $\mathrm{T}_{2}$, so that $\Delta \mathrm{T}=\mathrm{T}_{2}-\mathrm{T}_{1}>0$.

Let $\mathrm{p}$ be the pressure and $\mathrm{g}$ the acceleration of gravity. Furthermore, $\rho$ and $\mu$ denote the density and viscosity, respectively, of the liquid; these will, in general, be functions of the temperature, $T$, but will be practically independent of the concentration, $c$, because of the

- similarity of the molecules being separated. For the present it will be assumed that the temperature and hence these quantities are independent of the coordinate $z$.

Following Furry, Jones, and Onsager, ${ }^{2}$ the convection velocity may be calculated by solving the hydrodynamical equation for the steady flow of a viscous fluid in the form

$$
\nabla \cdot(\mu \nabla \overrightarrow{\mathrm{v}})=\nabla \mathrm{p}-\rho \overrightarrow{\mathrm{g}}
$$

where $\vec{v}$, the velocity vector, is taken to have a component only in the $\mathrm{z}$ direction but is independent of $\mathrm{z}$ and $\overrightarrow{\mathrm{g}}$ is the gravitational acceleration vector with the magnitude $\mathrm{g}$ and direction $-\mathrm{z}$. For the $\mathrm{x}$ component

- it is found, from Eq. 7, that 


$$
\frac{\partial p}{\partial x}=0
$$

so that $\mathrm{p}=\mathrm{p}(\mathrm{z})$, and for the $\mathrm{z}$ component

$$
\frac{d}{d x}\left(\mu \frac{d v}{d x}\right)=\frac{d p}{d z}+\rho g
$$

Since in Eq. 9 all terms except $d p / d z$ depend only on $x$, it can be seen that

$$
\frac{\mathrm{dp}}{\mathrm{dz}}=\mathbf{B}
$$

where $B$ is a constant, and the equation can be written

$$
\frac{d}{d x}\left(\mu \frac{d v}{d x}\right)=B+\rho g
$$

This equation is to be solved subject to the boundary conditions

$$
v(0)=v(a)=0
$$

the layers of fluid in contact with the walls being taken to be at rest. The constant $B$, the pressure gradient along the column, is to be determined from the condition

$$
\mathrm{b} \int_{0}^{\mathrm{a}} \rho \mathrm{v} \mathrm{dx}=\mathbf{P}
$$

where $\mathbf{P}$ is the product rate, i.e., the mass of material removed from the top of the column per unit time. Ordinarily, in experiments on approach to equilibrium, $\mathrm{p}=0$.

Integration of $\mathrm{Eq} .11$ gives

$$
\mathrm{v}=\mathrm{g} \int_{0}^{\mathrm{x}} \frac{1}{\mu} \mathrm{dx} \int_{0}^{\mathrm{x}} \rho \mathrm{dx}+\mathrm{B} \int_{0}^{\mathrm{x}} \frac{\mathrm{x}}{\mu} \mathrm{dx}+\mathrm{C} \int_{0}^{\mathrm{x}} \frac{1}{\mu} \mathrm{dx}
$$

with $\mu$ and $\rho$ functions of $x$, and $C$ a constant of integration. The constants $B$ and $C$ can be determined from the two relations

$$
\mathrm{v}(\mathrm{a})=\mathrm{g} \int_{0}^{\mathrm{a}} \frac{\mathrm{dx}}{\mu} \int_{0}^{\mathrm{x}} \rho \mathrm{dx}+\mathrm{B} \int_{0}^{\mathrm{a}} \frac{\mathrm{x}}{\mu} \mathrm{dx}+\mathrm{C} \int_{0}^{\mathrm{a}} \frac{\mathrm{dx}}{\mu}=0
$$


and

$\mathrm{g} \int_{0}^{\mathrm{a}} \rho \mathrm{dx} \int_{0}^{\mathrm{x}} \frac{\mathrm{dx}}{\mu} \int_{0}^{\mathrm{x}} \rho \mathrm{dx}+\mathrm{B} \int_{0}^{\mathrm{a}} \rho \mathrm{dx} \int_{0}^{\mathrm{x}} \frac{\mathrm{x} \mathrm{dx}}{\mu}$

$$
+\mathrm{C} \int_{0}^{\mathrm{a}} \rho \mathrm{dx} \int_{0}^{\mathrm{x}} \frac{\mathrm{dx}}{\mu}=\frac{\mathrm{P}}{\mathrm{b}}
$$

In order to carry out the integrations, it is necessary to have the relation between $\mathrm{x}$ and the temperature $\mathrm{T}$, since $\mu$ and $\rho$ are actually known as functions of $T$ rather than of $x$. In the case of steady heat flow (except near the edges of the walls), it can be written

$$
\mathrm{Q}=\lambda \frac{\mathrm{dT}}{\mathrm{dx}}
$$

where $\lambda$ is the thermal conductivity of the material (in general, a function of $T$ ) and $Q$ is the rate of heat flow per unit area of wall. Integration of this gives

$$
\mathrm{x}=\frac{1}{\mathrm{Q}} \int_{\mathrm{T}_{1}}^{\mathrm{T}} \lambda \mathrm{dT}
$$

and

$$
Q=\frac{1}{a} \int_{T_{1}}^{T_{2}} \lambda d T
$$

With $Q$ known, $d x$ can be expressed in terms of $d T$ in the preceding integrals by means of Eq. 17.

After the convection velocity, $v$, is obtained, the other processes in the column can be considered. The equation of continuity in the present case takes the form

$$
\frac{\partial}{\partial t}(\rho c)=-\frac{\partial}{\partial x}\left[-\rho D \frac{\partial c}{\partial x}+\rho D q c(1-c) \frac{d T}{d x}\right]-\left(\rho v \frac{\partial c}{\partial z}-\rho D \frac{\partial^{2} c}{\partial z^{2}}\right)
$$

Integration with respect to $x$, and making use of the fact that at $x=0$ the expression in the brackets vanishes, gives

$$
\frac{\partial}{\partial t} \int_{0}^{x} \rho c d x=\rho D \frac{\partial c}{\partial x}-\rho D q c(1-c) \frac{d T}{d x}-\int_{0}^{x}\left(\rho v \frac{\partial c}{\partial z}-\rho D \frac{\partial^{2} c}{\partial x^{2}}\right) d x
$$


from which it may be seen that

$\frac{\partial c}{\partial x}=\frac{1}{\rho D} \frac{\partial}{\partial t} \int_{0}^{x} \rho c d x+q c(1-c) \frac{d T}{d x}+\frac{1}{\rho D} \int_{0}^{x}\left(\rho v \frac{\partial c}{\partial z}-\rho D \frac{\partial^{2} c}{\partial z^{2}}\right) d x$

Now let $\tau$ denote the net rate of transport of the light constituent up the column. Then

$$
\tau=\mathrm{b} \int_{0}^{\mathrm{a}} \rho \mathrm{cv} \mathrm{dx}-\mathrm{b} \int_{0}^{\mathrm{a}} \rho \mathrm{D} \frac{\partial \mathrm{c}}{\partial \mathrm{z}} \mathrm{dx}
$$

Define a function

$$
\mathrm{G}(\mathrm{x})=\mathrm{b} \int_{0}^{\mathrm{x}} \rho \mathrm{v} \mathrm{dx}
$$

so that

$$
\mathrm{G}(0)=0 \quad \mathrm{G}(\mathrm{a})=\mathrm{P}
$$

It follows then that the first term in the expression for $\tau$ is given by

$$
\begin{aligned}
\text { b } \int_{0}^{a} \rho c v d x=\int_{0}^{a} c \frac{d G}{d x} d x=[c G]_{0}^{a}-\int_{0}^{a} G \frac{\partial c}{\partial x} d x & \\
& =P c-\int_{0}^{a} G \frac{\partial c}{\partial x} d x
\end{aligned}
$$

where, in the first term, c represents the value of $c$ for $x=a$; however, since $c$ varies only slightly across the section $(0 \leq x \leq a)$, it is not important what value is given to $x$. If Eq. 22 is now substituted into Eq. 26 and then the latter is used in Eq. 23, the resulting equation is

$$
\begin{aligned}
\tau= & \mathrm{Pc}-\int_{0}^{\mathrm{d}} \frac{\mathrm{G}}{\rho \mathrm{D}} \mathrm{dx} \int_{0}^{\mathrm{x}} \frac{\partial \mathrm{c}}{\partial \mathrm{t}} \mathrm{dx} \\
& -\int_{0}^{\alpha} \mathrm{Gq} \mathrm{c}(1-\mathrm{c}) \frac{\mathrm{dT}}{\mathrm{dx}} \mathrm{dx}-\int_{0}^{\mathrm{a}} \frac{\mathrm{G}}{\rho \mathrm{D}} \mathrm{dx} \int_{0}^{\mathrm{x}} \rho \mathrm{v} \frac{\partial \mathrm{c}}{\partial \mathrm{z}} \mathrm{dx} \\
& +\int_{0}^{\mathrm{d}} \frac{\mathrm{G}}{\rho \mathrm{D}} \mathrm{dx} \int_{0}^{\mathrm{x}} \rho \mathrm{D} \frac{\partial^{2} \mathrm{c}}{\partial \mathrm{z}^{2}} \mathrm{dx}-\mathrm{b} \int_{0}^{\mathrm{a}} \rho \mathrm{D} \frac{\partial \mathrm{c}}{\partial \mathrm{z}} \mathrm{dx}
\end{aligned}
$$


Since c varies only slightly with $x$ and none of the integrals in Eq. 27 is critically dependent on the variation of $c$ with $x$, this equation can be written

$$
\tau=\mathrm{Pc}+\mathrm{W} \frac{\partial \mathrm{c}}{\partial t}+\mathrm{H} \mathrm{c}(1-\mathrm{c})-\mathrm{K} \frac{\partial \mathrm{c}}{\partial \mathrm{z}}-\mathrm{N} \frac{\partial^{2} \mathrm{c}}{\partial \mathrm{z}^{2}}
$$

where $c$ is now regarded as a function of $z$ and $t$ only, and the coefficients are given by

$$
\begin{aligned}
& H=-\int_{0}^{d} G q \frac{d T}{d x} d x \\
& K=K_{M}+K_{D} \\
& K_{M}=\int_{0}^{a} \frac{G}{\rho D} d x \int_{0}^{x} \rho v d x=\frac{1}{b} \int_{0}^{a} \frac{G^{2}}{\rho D} d x \\
& K_{D}=b \int_{0}^{d} \rho D d x \\
& N=\int_{0}^{d} \frac{G}{\rho D} d x \int_{0}^{x} \rho D d x \\
& W=\int_{0}^{d} \frac{G}{\rho D} d x \int_{0}^{x} \rho d x
\end{aligned}
$$

If $\mathrm{x}=\mathrm{a}$ is introduced into Eq. 21 , noting that the same boundary condition holds as for $x=0$, multiplication by $b$ gives

$$
\frac{M}{\mathrm{~L}} \frac{\partial \mathrm{c}}{\partial \mathrm{t}}=-\frac{\partial \tau}{\partial \mathrm{z}}
$$

where $M / L$ has replaced $b \int_{0}^{a} \rho d x, M$ being the mass of all the material in the column. Equation 30, with $\tau$ given by Eq. 28, describes the behavior of the column as an isotope separator.

In order to get some idea of the magnitudes of the various integrals encountered thus far, an approximate calculation can be carried out by assuming that the temperature difference $\Delta \mathrm{T}$ between the hot and cold walls is small, so that all the quantities, except the density, associated with the liquid can be treated as constant. It is necessary to take account of the variation in density in order to get convection. (Another way of expressing this is to say that all these quantities, which are 
functions of the temperature, will be replaced by suitable mean values.) In this way the convection velocity is given by

$$
v=\left[\frac{g \Delta \rho}{6 \mu} a^{2}\left(\frac{x}{a}-\frac{1}{2}\right)+\frac{6 P}{a b \rho}\right] \frac{x}{a}\left(1-\frac{x}{a}\right)
$$

where $\Delta \rho$ is the difference between the density of the fluid at the cold wall and that at the hot wall. From this function it is found that

$$
G=\left(\frac{x}{a}\right)^{2}\left[-\frac{g \rho \Delta \rho b^{3}}{24 \mu}\left(1-\frac{x}{a}\right)^{2}+p\left(3-2 \frac{x}{a}\right)\right]
$$

The integrals are given in this case by the following expressions:

$$
\begin{aligned}
& \mathrm{H}=\left(\frac{\mathrm{g} \rho \Delta \rho \mathrm{ba}^{3}}{720 \mu}-\frac{1}{2} \mathrm{p}\right) \mathrm{q} \Delta \mathrm{T} \\
& \mathrm{K}_{\mathrm{M}}=\frac{\mathrm{g}^{2} \rho(\Delta \rho)^{2} \mathrm{ba}^{7}}{362880 \mu^{2} \mathrm{D}}-\frac{\mathrm{g} \Delta \rho \mathrm{a}^{4} \mathrm{p}}{720 \mu \mathrm{D}}+\frac{13}{35} \frac{\mathrm{p}^{2} \mathrm{a}}{\rho \mathrm{Db}} \\
& \mathrm{K}_{\mathrm{D}}=\rho \mathrm{Dab} \\
& \mathrm{N}=\frac{\mathrm{g} \rho \Delta \rho \mathrm{ba}^{5}}{1440 \mu}-\frac{7}{20} \mathrm{~Pa}^{2} \\
& \mathrm{~W}=\frac{\mathrm{N}}{\mathrm{D}}
\end{aligned}
$$

First the importance of the terms involving the product rate, $P$, should be investigated. As an example, consider the expression for $\mathrm{H}$. It may be written

$$
\mathrm{H}=\mathrm{H}_{0}(1-\xi)
$$

where

$$
\mathrm{H}_{0}=\frac{\mathrm{g} \rho \Delta \rho \mathrm{ba}^{3} \mathrm{q} \Delta \mathrm{T}}{720 \mu}
$$

is the value of $H$ for $P=0$, and $\xi$ is a dimensionless quantity

$$
\xi=\mathrm{P} /\left(\frac{\mathrm{g} \rho \Delta \rho \mathrm{ba}^{3}}{360 \mu}\right)
$$

To get orders of magnitude in the present and the following cases, let: $\rho=2 \mathrm{~g} / \mathrm{cm}^{3}, \Delta \rho=1 \mathrm{~g} / \mathrm{cm}^{3}, \mu=6 \times 10^{-3}$ poise, $\mathrm{D}=2 \times 10^{-5} \mathrm{~cm}^{2} / \mathrm{sec}, \mathrm{a}=$ 
$0.025 \mathrm{~cm}, \mathrm{~b}=13 \mathrm{~cm}$, and $\mathrm{L}=1500 \mathrm{~cm}$. It follows that $\mathrm{g} \rho \Delta \rho \mathrm{ba}^{3} / 360 \mu$ is of the order of $0.2 \mathrm{~g} / \mathrm{sec}$. On the other hand, $\mathrm{P}$ is of the order of $100 \mathrm{~g} /$ day in practice, or of the order of $10^{-3} \mathrm{~g} / \mathrm{sec}$. Hence, $\xi$ is of the order of 0.005 , so that it can be neglected under ordinary circumstances.

This means that $\mathrm{H}$ can be replaced by $\mathrm{H}_{0}$, a constant with respect to the variation of the product rate. In the same way it is found that the other integrals likewise depend on $\xi$; therefore, if $\xi$ is small compared with unity, the terms involving $\mathbf{P}$ can be neglected. It follows then that all the integrals for zero product rate can be calculated and used for product rates occurring in practice. Hereafter the integrals of Eq. 29 will be treated as independent of $P$.

Next, note the orders of magnitude of the expressions in Eq. 33 (with $\mathrm{P}=0$ ). For the case being considered it is found that, in cgs units,

$$
\begin{aligned}
& \mathrm{H} \sim \frac{1}{10} \mathrm{q} \Delta \mathrm{T} \\
& \mathrm{K}_{\mathrm{M}} \sim 0.6 \\
& \mathrm{~K}_{\mathrm{D}} \sim 10^{-5} \\
& \mathrm{~N} \sim 3 \times 10^{-5} \\
& \mathrm{~W} \sim 1
\end{aligned}
$$

Actually, experimental values of $\mathrm{H}$ are of the order of $60 \mathrm{~g} / \mathrm{day}$, or $10^{-3}$ $\mathrm{g} / \mathrm{sec}$.

Since it is found that it takes several days to build up an appreciable increase in concentration, the term W( $\partial \mathrm{c} / \partial \mathrm{t})$ in $\mathrm{Eq} .28 \mathrm{is}$, in general, of the order of $10^{-5} \mathrm{c}$. The term $\mathrm{K}(\partial \mathrm{c} / \partial \mathrm{z})$ is of the order of $10^{-3} \mathrm{c}$ if it is assumed that the variation of $c$ over the length of the column is of the order of $c$ itself. The term $N\left(\partial^{2} c / \partial z^{2}\right)$ is of the order of $10^{-11}$ on the basis of this assumption. The term $\mathrm{H} \mathrm{c}(1-\mathrm{c})$, with $\mathrm{c} \ll 1$, is of the order of $10^{-3} \mathrm{c}$. On the basis of such rough estimates, it appears plausible to neglect ${ }^{5}$ the terms $W(\partial c / \partial t)$ and $N\left(\partial^{2} c / \partial z^{2}\right)$ in Eq. 28. This will be done hereafter.

Accordingly,

$$
\tau=\mathbf{P c}+\mathrm{H} \mathbf{c}(1-\mathrm{c})-\mathrm{K} \frac{\partial \mathrm{c}}{\partial \mathrm{z}}
$$

for the net transport rate of the light constituent up the column.

For a steady state of operation, $\tau$ is constant and equal to $\mathrm{PC}_{\mathrm{T}}$, where $\mathrm{c}_{\mathrm{T}}$ is the concentration at the top of the column at the point where the - product is removed. Equation 37 then becomes 


\section{LIQUID THERMAL DIFFUSION}

$$
K \frac{\partial c}{\partial z}=H c(1-c)-P\left(c_{T}-c\right)
$$

For a process of approach to equilibrium, Eq. 37 must be substituted into Eq. 30 to get the equation for the column. Usually in a process of this sort $P=0$. If, furthermore, $c \ll 1$, as is the case of principal interest, then

$$
\tau=\mathrm{Hc}-\mathrm{K} \frac{\mathrm{\partial c}}{\mathrm{\partial z}}
$$

and, if this is substituted into Eq. 30 , the result is

$$
\mathrm{X} \alpha^{2} \frac{\partial \mathrm{c}}{\partial \mathrm{t}}=\frac{\partial^{2} \mathrm{c}}{\partial \mathrm{z}^{2}}-\alpha \frac{\mathrm{c}}{\mathrm{z}}
$$

where

$$
\alpha=\frac{\mathrm{H}}{\mathrm{K}}
$$

and

$$
\mathrm{X}=\frac{\mathrm{MK}}{\mathrm{H}^{2} \mathrm{~L}}=\frac{\mathrm{M}}{\mathrm{HY}}
$$

if

$$
\mathbf{Y}=\alpha \mathbf{L}
$$

\section{COLUMN IN STEADY STATE}

The simplest case to deal with is the one in which the column has reached equilibrium and no product is being removed. In this case $\tau=$ 0 , and the equation determining the concentration is of the form

$$
H c(1-c)-K \frac{d c}{d z}=0
$$

If $c_{B}$ denotes the concentration at the bottom of the column, the solution of this equation can be written

$$
\frac{c}{1-c}=\frac{c_{B}}{1-c_{B}} e^{\alpha z}
$$


where, as before, $\alpha=\mathrm{H} / \mathrm{K}$. If $\mathrm{c}_{\mathrm{T}}$ denotes the concentration at the top of the column and the separation factor $S$ is defined by the relation

$$
S=\frac{c_{T} /\left(1-c_{T}\right)}{c_{B} /\left(1-c_{B}\right)}
$$

it follows that, at equilibrium, $\mathrm{S}$ has the value

$$
\mathrm{S}_{\mathrm{e}}=\mathrm{e}^{\mathrm{Y}}
$$

where, as before, $\mathrm{Y}=\alpha \mathrm{L}$.

If the column is operated with continuous product removal so that it remains in a steady state, then the transport rate up the column is constant and is equal to the rate at which the light constituent is withdrawn in the product, $\mathbf{P c}_{\mathrm{T}}$. The equation for this case, Eq. 38, can be written

$$
\frac{\mathrm{dc}}{\mathrm{dz}}=\alpha \mathrm{c}(1-\mathrm{c})-\alpha \nu\left(\mathrm{c}_{\mathrm{T}}-\mathrm{c}\right)
$$

where

$$
\nu=\frac{\mathrm{P}}{\mathrm{H}}
$$

This equation can be integrated. ${ }^{2}$ If

$$
\omega=\sqrt{(1+\nu)^{2}-4 \nu c_{T}}
$$

then the solution can be written

$$
\ln \frac{2 c-1-\nu+\omega}{2 c-1-\nu-\omega}=\omega \alpha z+\text { constant }
$$

It follows from this that the separation factor for the column is given by

$$
\mathrm{S}=\frac{(\omega+\nu+1) \mathrm{e}^{\omega \mathrm{Y}}+\omega-\nu-1}{(\omega+\nu-1) \mathrm{e}^{\omega \mathrm{Y}}+\omega-\nu+1}
$$

The concentration, $c$, along the column can be obtained from the relation

$$
\frac{\mathrm{c}}{\mathrm{c}_{\mathrm{T}}}=\frac{(\omega+\nu-1) \exp [\omega \alpha(\mathrm{L}-\mathrm{z})]+\omega-\nu+1}{\left(\omega+\nu+1-2 \mathrm{c}_{\mathrm{T}}\right) \exp [\omega \alpha(\mathrm{L}-\mathrm{z})]+\omega-\nu-1+2 \mathrm{c}_{\mathrm{T}}}
$$


which is convenient if $c_{T}$ is known. Frequently it happens that $c_{B}$ is known rather than $c_{T}$. In that case, $c_{T}$ can be calculated either numerically or graphically by means of Eqs. 46 and 52, and then Eq. 53 can be used.

The calculations can be simplified considerably if $c \ll 1$, which is usually the case. Then Eq. 48 can be approximated by

$$
\frac{\mathrm{dc}}{\mathrm{dz}}=\alpha(1+\nu) \mathrm{c}-\nu \mathrm{c}_{\mathrm{T}}
$$

and the solution of this equation is given by

$$
\frac{\mathrm{c}}{\mathrm{c}_{\mathrm{T}}}=\frac{\nu+\exp [\alpha(1+\nu)(\mathrm{z}-\mathrm{L})]}{\nu+1}
$$

If $c \ll 1$, then the separation factor, $S$, is given by

$$
\mathrm{S}=\frac{\mathrm{c}_{\mathrm{T}}}{\mathrm{c}_{\mathrm{B}}}
$$

and from Eq. 55 the result is

$$
S=\frac{\nu+1}{\nu+\exp [-\mathrm{Y}(1+\nu)]}
$$

From Eqs. 55 and 57 the following equation can also be written

$$
\frac{\mathrm{c}}{\mathrm{c}_{\mathrm{B}}}=\frac{\nu+\exp [\alpha(1+\nu)(\mathrm{z}-\mathrm{L})]}{\nu+\exp [-\mathrm{Y}(1+\nu)]}
$$

\section{IRREGULARITIES}

The equations derived earlier in this chapter referred to an ideal column in which the hot and cold walls were assumed to be perfectly plane and parallel and the temperature of each perfectly uniform, with the fluid in a state of lamellar flow. In the case of any actual column, these assumptions are fulfilled only approximately at best, and it is to be expected, therefore, that there will be deviations from the behavior predicted on the basis of the preceding equations. The discrepancies arising in practice are associated with factors that can be classified roughly under three headings: (1) geometrical irregularities, (2) temperature irregularities, and (3) vibrations and turbulence.

By geometrical irregularities are meant such things as variations in the spacing between the walls, producing variations in the convection 
current, or the presence of spacers in the working space, forming obstacles around which the current must flow. Obviously, in the presence of such irregularities, the flow of the process material will not be so simple as was assumed.

Temperature irregularities produce parasitic convection, i.e., local convection, the effect of which is to bring about mixing of the fluid, thus reducing the separative action of the column. It is clear that geometrical irregularities will always be accompanied by temperature irregularities. It is possible, however, to have temperature irregularities in the working space without having geometrical irregularities. This can occur if there are variations in the thickness of the walls or if there are spatial or temporal changes in the steam or cooling water.

Turbulence may set in, so that the particles of the fluid will no longer move along smooth streamlines but will move erratically, so that mixing will take place, resulting in a reduction or cessation of separative action. Such turbulence will arise if the convection velocity exceeds some critical value. In this connection, it is well known that the critical velocity in a body of fluid having two streams flowing side by side in opposite directions is very much lower than that in a single stream. Furthermore, the presence of mechanical vibrations, and in plant operation such vibrations are inevitable, lowers the critical velocity. Turbulence or oscillations may also set in under certain conditions of temperature and pressure as a result of boiling or density fluctuations in the fluid near the hot wall.

It appears that the operating conditions can be adjusted in order to make the effect of turbulence relatively unimportant. With columns constructed by the usual methods from commercial tubing, however, it is impossible to eliminate parasitic convection.

It is possible to calculate the parasitic convection for some simple temperature distributions and to determine the effect of this convection on the performance of the column. ${ }^{2}$ For the irregularities of temperature that are present in actual cases, however, the calculations would be very difficult to carry out. A study of the equations shows that the general effect of such convection is essentially equivalent to an increase in the column constant $K$. That is, in the differential equation for column behavior and in the expression for $\tau, \mathrm{K}$ should be replaced by

$$
\mathrm{K}^{\prime}=\mathrm{K}+\mathrm{K}_{\mathrm{p}}
$$

where $\mathrm{K}_{\mathrm{p}}$ is the contribution due to parasitic convection. The extra term, $K_{p}$, may be appreciably larger than $K$. In particular, as the spacing, a, is made smaller and smaller, the geometrical irregularities 
become relatively more and more important and $K_{p} / K$ becomes very large. As pointed out by Cohen, ${ }^{6}$ the effect of parasitic convection will cause the curve of $\ln S_{e}$ vs. a to have its maximum lowered and displaced to a larger value of a than would otherwise be the case.

A point to note in this connection is that, if the parasitic convection is distributed nearly uniformly down the column (as will be the case if the irregularities are randomly distributed or if, for example, the two tubes surrounding the working space are parallel but not coaxial), then the $K^{\prime}$ introduced above will be constant. The behavior of the column will be qualitatively similar to that of the ideal column. However, if the distribution of the irregularities varies along the length of the column so that $\mathrm{K}^{\prime}$ is a function of $\mathrm{z}$, then marked differences will be found between the observed behavior and that predicted by the simple theory.

\section{VARIATION OF CONDITIONS}

The next question to consider is how the behavior of a column will vary if its dimensions or the conditions under which it is operated are varied.

If the validity of the results obtained in Sec. 2 is assumed for the present, it follows that, if the temperatures at the two walls and the pressure are kept fixed, the constants $H, K_{M}$, and $K_{D}($ for $P=0)$ can be written

$$
\begin{aligned}
& H=C_{1} b a^{3} \\
& K_{M}=C_{2} b a^{7} \\
& K_{D}=C_{3} b a
\end{aligned}
$$

where the C's are constants. It follows that

$$
Y=\ln S_{e}=\frac{C_{1} a^{2} L}{C_{2} a^{6}+C_{3}}
$$

This means that, for a fixed spacing $a, \ln S_{e}$ should be proportional to the length, $\mathrm{L}$, of the column, and that, for a fixed value of $\mathrm{L}$, it should vary as $1 / a^{4}$ for large values of a and as $a^{2}$ for small values of $a$, with a maximum value for some point between.

The position of the maximum can be obtained by setting the derivative of the right-hand member of Eq. 63, with respect to a, equal to zero. The corresponding value of $a$, denoted by $a_{s}$, is

$$
a_{s}=\sqrt[6]{\frac{C_{3}}{2 C_{2}}}
$$




\section{THE COLUMN}

and for this value of a

$$
Y_{\max }=\frac{2 C_{1} L}{3\left(2^{1 / 3} C_{2}^{1 / 3} C_{3}^{2 / 3}\right)}
$$

For the conditions assumed above, the following equation can also be written

$$
\mathrm{M}=\mathrm{C}_{4} \mathrm{abL}
$$

and, by Eq. 42 ,

$$
X=\frac{C_{4}\left(C_{2} a^{6}+C_{3}\right)}{C_{1}^{2} a^{4}}
$$

The value of a for which $\mathrm{X}$ is a minimum, denoted by $a_{\mathrm{X}}$, is found to be given by

$$
a_{x}=\sqrt[6]{\frac{2 C_{3}}{C_{2}}}=1.26 a_{s}
$$

and the corresponding value of $\mathrm{X}$

$$
X_{\min }=\frac{3 C_{2}^{2 / 3} C_{3}^{1 / 3} C_{4}}{2^{2 / 3} C_{1}^{2}}
$$

It will be convenient later to introduce a function, the figure of merit, $\Phi$, defined by the relation

$$
\Phi=\mathrm{HY}
$$

With the present assumptions it can be written

$$
\Phi=\frac{C_{1}^{2} a^{5} b L}{C_{2} a^{6}+C_{3}}
$$

It follows that the value of a which this function has a maximum is

- given by

$$
a_{\Phi}=\sqrt[6]{\frac{5 C_{3}}{C_{2}}}=1.47 a_{\mathrm{S}}
$$

and the corresponding value of $\Phi$ by

$$
\Phi_{\max }=\frac{5^{5 / 6} C_{1}^{2} b L}{6 C_{2}^{5 / 6} C_{3}^{1 / 6}}
$$


The preceding results, obtained for an ideal case, will differ from those for an actual case for several reasons. Thus, it has been assumed that the temperature has been kept fixed while the spacing has been varied. Actually, with given steam and cooling-water temperatures, if the spacing is varied, the temperatures of the hot and cold walls will also vary because of the variation of the heat flow.

A more important cause of discrepancy between the theoretical and experimental results is the presence of parasitic convection, discussed in Sec. 5. As Cohen ${ }^{6}$ pointed out, this will become increasingly important at smaller spacings and will cause $Y_{\max }$ to decrease and $\mathrm{a}_{\mathrm{s}}$ to increase. It does not mean very much to try to calculate $Y$ as a function of $a$ in this case since the parasitic convection, being associated with irregularities, will vary from column to column in an unpredictable manner, giving rise to statistical variations. For large values of a, the above calculations should still be applicable, and $Y$ should vary as $1 / \mathbf{a}^{4}$.

It is difficult to make any accurate predictions concerning the effect of varying the temperature and pressure because of the lack of knowledge of the dependence of some of the properties of the process fluid on these variables. In particular, the thermal diffusion coefficient is at present known only with regard to the order of magnitude, and there is no reliable information on its variation with temperature. Some calculations were carried out by Cohen ${ }^{6}$ on these questions; however, because of the lack of data, he had to make a number of speculative assumptions, and it is not clear how valid the results are.

\section{QUASI-CONTINUOUS PRODUCT REMOVAL}

In practice it is difficult to arrange to have continuous product removal. Usually the nearest approach to it is the withdrawal of small fixed quantities at regular, short intervals, a procedure that will be referred to as "quasi-continuous withdrawal." The question arises: How is this process related to the continuous one considered in Sec. 2, and how is it used to derive the differential equations for the behavior of the column?

In the case of continuous product removal $(P \neq 0)$, the differential equation governing the process at small concentrations, corresponding to $E q .40$ for $P=0$, is given by

$$
\mathrm{X} \alpha^{2} \frac{\partial \mathrm{c}}{\partial \mathrm{t}}=\frac{\partial^{2} \mathrm{c}}{\partial \mathrm{z}^{2}}-\alpha(1+\nu) \frac{\partial \mathrm{c}}{\partial \mathrm{z}}
$$

where $c$ is the concentration, $t$ is the time, $z$ is the distance up the column, $\mathrm{X}$ is the time constant, $\alpha=\mathrm{H} / \mathrm{K}$, and $\nu=\mathrm{P} / \mathrm{H}$, with $\mathrm{H}$ and $\mathrm{K}$ are 
the column constants, and $\mathrm{P}$ is the rate of product withdrawal. To simplify the calculations without affecting the essentials of the problem, it is assumed that the column is connected at the bottom to an infinite reservoir. Then, one boundary condition is

$$
\mathrm{z}=0 \quad \mathrm{c}=\mathrm{c}_{0}
$$

where $c_{0}$ is a constant. On the other hand, at the top of the column the boundary condition expresses the fact that the transport of light constituent, aside from that due to flow, vanishes at that point. If $L$ is the length of the column, then

$$
\mathbf{z}=\mathbf{L} \quad \frac{\partial \mathrm{c}}{\partial \mathbf{z}}-\alpha \mathrm{c}=\mathbf{0}
$$

In the case of a steady process, $\partial \mathrm{c} / \partial \mathrm{t}=0$, and Eq. 74 becomes

$$
\frac{d^{2} c}{d z^{2}}-\alpha(1+\nu) \frac{d c}{d z}=0
$$

The solution of this equation, satisfying the boundary conditions, is found to be

$$
c=\frac{c_{0} \nu \exp [(1+\nu) Y]}{1+\nu \exp [(1+\nu) Y]}+\frac{c_{0} \exp [(1+\nu) \alpha z]}{1+\nu \exp [(1+\nu) \mathrm{Y}]}
$$

where $\mathrm{Y}=\alpha \mathrm{L}$. If $\mathrm{z}=\mathrm{L}$ and $\mathrm{S}=\mathrm{c} / \mathrm{c}_{0}$, the result is

$$
\mathrm{S}=\frac{(1+\nu) \exp [(1+\nu) \mathrm{Y}]}{1+\nu \exp [(1+\nu) \mathrm{Y}]}
$$

In the case of quasi-continuous product removal, the appropriate differential equation during the time between withdrawals is the one obtained by putting $\nu=0$ in Eq. 74:

$$
\mathrm{X} \alpha^{2} \frac{\partial \mathrm{c}}{\partial \mathrm{t}}=\frac{\partial^{2} \mathrm{c}}{\partial \mathrm{x}^{2}}-\alpha \frac{\partial \mathrm{c}}{\partial \mathrm{z}}
$$

with the same boundary conditions as above. However, at regular intervals, say at $\mathrm{t}=\mathrm{nT}(\mathrm{n}=1,2,3, \ldots)$, where $\mathrm{T}$ is the period, product is removed and the conditions are altered. The time of product withdrawal is short in practice and can be neglected. During one cycle, a mass, $m$, of product is removed so that the average product rate $\bar{\sigma}=$ $\mathrm{m} / \mathrm{T}$. Let $\bar{\nu}=\bar{\sigma} / \mathrm{H}$. The mass, $\mathrm{m}$, is equal to the mass of a portion of the column of length $L^{\prime}=m L / M$, where $M$ is the column holdup. 
Let $\epsilon$ denote the time during which product is removed, and assume that it is so short that during this time no appreciable change in the concentration occurs because of separation. The only change occurs because of the flow in the column accompanying product removal. One can expect to get a reasonable approximation to what actually takes place by assuming that, during the product removal process, there is an upward displacement of all the material in the column through the distance $L^{\prime}$. After the product withdrawal has been carried out a number of times, the concentration, $c$, will become a periodic function of $t$ with a period $T$. This periodic behavior can be represented in the following way:

For $t$ in the range $0 \leq t \leq T-\epsilon$, c satisfies Eq. 80. For $t$ in the range $\mathrm{T}-\epsilon<\mathrm{t}<\mathrm{T}$, the product removal takes place, so that

$$
c(T, z)=c\left(T-\epsilon, z-L^{\prime}\right)
$$

where, for $\mathrm{z} \leq \mathrm{L}^{\prime}$, let $\mathrm{c}=\mathrm{c}_{0}$. At the end, the initial distribution has been regained:

$$
c(T, z)=c(0, z)
$$

It is possible to solve rigorously the problem formulated in this way. Since the calculations involved are somewhat tedious, however, this will not be done here; instead, some of the properties of the solution will be investigated. The present case can be regarded as one which can be treated by Eq. 74, provided $\nu$ is considered not as a constant but as a function of $t$ which differs from zero only in the range $T-\epsilon<$ $\mathrm{t}<\mathrm{T}$ (during the first cycle). By integrating both sides of Eq. 74 over a complete period of the time, the left-hand side of the equation becomes zero because of the periodicity of the function $c$, as expressed by Eq. 82 . Hence

$$
\int_{0}^{T} \frac{\partial^{2} c}{\partial z^{2}} d t-\alpha \int_{0}^{T} \frac{\partial c}{\partial z} d t-\alpha \int_{0}^{T} \nu \frac{\partial c}{\partial z} d t=0
$$

or

$$
\frac{d^{2}}{d z^{2}} \int_{0}^{T} c(t, z) d t-\alpha \frac{d}{d z} \int_{0}^{T} c(t, z) d t-\alpha \int_{T-\epsilon}^{T} \nu \frac{\partial c}{\partial z} d t=0
$$

Now investigate the last integral more closely. If it is assumed that the material is being carried up the column during product removal without any mixing, then, if the distance through which it has moved is denoted by $\xi$, the following equation can be written 


$$
\nu=\frac{\sigma}{\mathrm{H}}=\frac{\mathrm{M}}{\mathrm{L}} \frac{\mathrm{v}}{\mathrm{H}}=\frac{\mathrm{M}}{\mathrm{HL}} \frac{\mathrm{d} \xi}{\mathrm{dt}}
$$

where $\mathrm{v}$ is the velocity of the material in the column resulting from product removal. Hence

$$
\begin{aligned}
& \int_{T-\epsilon}^{\mathrm{T}} \nu \frac{\partial c(t, z)}{\partial \mathrm{z}} \mathrm{dt}=\int_{\mathrm{T}-\epsilon}^{\mathrm{T}} \frac{\mathrm{M}}{\mathrm{HL}} \frac{\mathrm{d} \xi}{\mathrm{dt}} \frac{\partial c(\mathrm{t}, \mathrm{z})}{\partial \mathrm{z}} \mathrm{dt}=\frac{\mathrm{M}}{\mathrm{HL}} \int_{0}^{\mathrm{L}^{\prime}} \frac{\partial c(T-\epsilon, \mathrm{z}-\xi)}{\partial \mathrm{z}} \mathrm{d} \xi \\
& =-\frac{M}{H L} \int_{0}^{L^{\prime}} \frac{\partial c(T-\epsilon, z-\xi)}{\partial \xi} d \xi \\
& =\frac{\mathrm{M}}{\mathrm{HL}}\left[\mathrm{c}(\mathrm{T}-\epsilon, \mathrm{z})-\mathrm{c}\left(\mathrm{T}-\epsilon, \mathrm{z}-\mathrm{L}^{\prime}\right)\right] \\
& =\bar{\nu} \mathbf{T} \frac{1}{\mathrm{~L}^{\prime}}\left[\mathrm{c}(\mathrm{T}-\epsilon, \mathrm{Z})-\mathrm{c}\left(\mathrm{T}-\epsilon, \mathrm{z}-\mathrm{L}^{\prime}\right)\right]
\end{aligned}
$$

Now define

$$
\tilde{c}(z)=\frac{1}{L^{\prime}} \int_{z-L^{\prime}}^{z} c(T-\epsilon, x) d x
$$

Then

$$
\int_{T-\epsilon}^{T} \nu \frac{\partial}{\partial z} c(t, z) d t=\bar{\nu} T \frac{d \tilde{c}}{d z}
$$

If this is substituted into Eq. 84, divided by $T$, and the following is introduced

$$
\bar{c}(z)=\frac{1}{T} \int_{0}^{T} c(t, z) d t
$$

Eq. 84 becomes

$$
\frac{\mathrm{d}^{2} \overline{\mathrm{c}}}{\mathrm{dz}^{2}}-\alpha \frac{\mathrm{d} \overline{\mathrm{c}}}{\mathrm{dz}}-\alpha \bar{\nu} \frac{\mathrm{d} \tilde{\mathrm{c}}}{\mathrm{dz}}=0
$$

Now if

$$
\tilde{\mathbf{c}}(z)=\bar{c}(z)
$$

then Eq. 90 becomes

$$
\frac{\mathrm{d}^{2} \overline{\mathrm{c}}}{\mathrm{d \textrm {z } ^ { 2 }}}-\alpha(1+\bar{\nu}) \frac{\mathrm{d} \overline{\mathrm{c}}}{\mathrm{dz}}=0
$$


which is of the same form as Eq. 77, but with $\bar{\nu}$ instead of $\nu$. Since the boundary conditions, Eqs. 75 and 76 , hold at all times for $c$, they must also hold for $\bar{c}$. Hence it is clear that, to the extent that Eq. 91 is valid, the quasi-continuous process is equivalent to a continuous process having the same average product rate. This will be the case if $T / X$ and $\mathrm{L}^{\prime} / \mathrm{L}$ are sufficiently small, for then the variations of the concentrations over the time 0 to $T-\epsilon$ and the distance $L^{\prime}$ will be nearly linear, and

$$
\begin{aligned}
\bar{c}(z) & \doteq \frac{1}{2}[c(0, z)+c(T-\epsilon, z)] \\
& =\frac{1}{2}\left[c(T-\epsilon, z)+c\left(T-\epsilon, z-L^{\prime}\right)\right] \doteq \widetilde{c}(z)
\end{aligned}
$$

to a good approximation.

To get a rough estimate of the errors involved in this approximation, assume that at a certain time $(t=0)$ the column is in a state described in $\mathrm{Eq} .78$, so that the separation factor is given by Eq. 79. Identify the $\nu$ in Eqs. 78 and 79 with $\bar{\nu}$, and denote the corresponding value of $\mathrm{S}$ by $S_{0}$. Equation 80 can be solved with the boundary conditions in Eqs. 75 and 76 for this case to get the subsequent behavior of the column. A calculation, based on the Laplace transformation, leads to the result that, for $\mathrm{t} \ll \mathrm{X}$, the separation factor is given by

$$
\mathrm{S}=\mathrm{S}_{0}\left[1+\nu\left(\frac{\mathrm{t}}{\mathrm{X}}\right)-\frac{4 \nu^{2}}{3 \sqrt{\pi}}\left(\frac{\mathrm{t}}{\mathrm{X}}\right)^{3 / 2}+\ldots\right]
$$

Thus the fractional deviation from linearity during a time of the order $\mathrm{T}$ is of the order of $\left(4 \nu^{2} / 3 \sqrt{\pi}\right)(\mathrm{T} / \mathrm{X})^{3 / 2}$. For example, with $\mathrm{T} / \mathrm{X} \sim 0.002$ and $\nu \sim 2$, this is about $3 \times 10^{-4}$.

On the other hand, to get some idea of the variation with height near the top of the column, it can be noted that, if $\xi$ represents the distance down from the top of the column, then from Eqs. 78 and 79 it is found that

$$
\mathrm{S}=\mathrm{S}_{0}\left[1-\alpha \xi+\frac{1}{2}(1+\nu) \alpha^{2} \xi^{2}-\ldots\right]
$$

If $\xi=L^{\prime}$, the fractional deviation from linearity is of the order of $1 / 2(1+\nu) \mathrm{Y}^{2}\left(\mathrm{~L}^{\prime 2} / \mathrm{L}\right)$. For example, if $\mathrm{L}^{\prime} / \mathrm{L}=0.01, \mathrm{Y}=0.5$, and $\nu=2$, this is of the order of $10^{-4}$.

Since the actual function will not be very different from the one used in the preceding calculations, the order of magnitude of the deviations 


\section{THE COLUMN}

from linearity can be expected to be about the same as that given above. Hence Eq. 93, and therefore Eq. 92, should be valid in the usual cases.

The question might be raised of the effect of the short region near the bottom of the column, where the behavior is somewhat exceptional because of the arrival of material of concentration $\mathrm{C}_{0}$ during the product removal. The variation in concentration during a cycle is small in this region, however, and its reaction on the behavior of the other end of the column during a short time $\mathrm{T}$ can be expected to be unimportant.

Finally, on the basis of the preceding calculations, the variation in product concentration during the course of its removal can be estimated. By any of several lines of reasoning, it is found quite readily that the maximum variation in the separation factor is of the order of

$$
\Delta \mathbf{S}=\left(\alpha \mathrm{L}^{\prime}\right) \mathbf{S}_{0}=\mathbf{Y}\left(\frac{\mathcal{L}^{\prime}}{\mathrm{L}}\right) \mathbf{S}_{0}=\frac{\bar{\nu} \mathbf{T}}{\mathbf{X}} \mathbf{S}_{\mathbf{0}}
$$

where $S_{0}$ is the mean separation factor or that for continuous operation, as given by Eq. 79 .

\section{REFERENCES}

1. P. Debye, Ann. Physik, 36: 284 (1939).

2. W. H. Furry, R. C. Jones, and L. Onsager, Phys. Rev., 55: 1083 (1939).

3. Chapman and Cowling, "The Mathematical Theory of Nonuniform Gases," Cambridge University Press, 1939.

4. K. Wirtz, Ann. Physik, 36: 295 (1939).

5. J. Bardeen, Phys. Rev., 58: 95 (1940).

6. K. Cohen, Report A-531, Feb. 5, 1943. 
Chapter 10

\section{APPROACH TO EQUILIBRIUM BY A SINGLE COLUMN}

\section{GENERAL CONSIDERATIONS}

The question of the approach to equilibrium by a column is of interest for at least two reasons. Sometimes the time required for a column to reach a concentration at which continuous operation can begin is appreciable and is important to know. More frequently, however, the question is of interest because, by studying the behavior of a column as it approaches equilibrium, information can be obtained to predict its performance in continuous operation. This chapter will be concerned mainly with the latter standpoint.

From Chap. 9 it can be seen that, for a column approaching equilibrium without any products being removed, the differential equation ${ }^{1}$ is given by

$$
\mathrm{X} \alpha^{2} \frac{\partial \mathrm{c}}{\partial \mathrm{t}}=\frac{\partial^{2} \mathrm{c}}{\partial \mathrm{z}^{2}}-\alpha \frac{\partial \mathrm{c}}{\partial \mathrm{z}}
$$

where

$$
\alpha=\frac{\mathrm{H}}{\mathbf{K}} \quad \mathbf{X}=\frac{\mathrm{M}}{\mathrm{HY}} \quad \mathrm{Y}=\alpha \mathrm{L}
$$

for a column of length $\mathrm{L}$, holdup mass $\mathrm{M}$, and characteristic constants $\mathrm{H}$ and $\mathrm{K}$, provided the concentration, $\mathrm{c}$, is much smaller than 1 .

Equation 1, with appropriate initial and boundary conditions, determines the concentration of the light constituent $c(z, t)$ as a function of the distance up the column, $z$, and the time, $t$, during the approach to equilibrium. If a concentration $c_{0}$, that of normal material, is used at the beginning, the separation factors can be defined as

$$
S_{T}=\frac{c(L, t)}{c_{0}} \quad S_{B}=\frac{c(0, t)}{c_{0}} \quad S=\frac{S_{T}}{S_{B}}
$$


from linearity can be expected to be about the same as that given above. Hence Eq. 93, and therefore Eq. 92, should be valid in the usual cases.

The question might be raised of the effect of the short region near the bottom of the column, where the behavior is somewhat exceptional because of the arrival of material of concentration $\mathrm{C}_{0}$ during the product removal. The variation in concentration during a cycle is small in this region, however, and its reaction on the behavior of the other end of the column during a short time $\mathrm{T}$ can be expected to be unimportant.

Finally, on the basis of the preceding calculations, the variation in product concentration during the course of its removal can be estimated. By any of several lines of reasoning, it is found quite readily that the maximum variation in the separation factor is of the order of

$$
\Delta S=\left(\alpha L^{\prime}\right) S_{0}=\mathbf{Y}\left(\frac{L^{\prime}}{\mathbf{L}}\right) S_{0}=\frac{\bar{\nu} T}{X} S_{0}
$$

where $S_{0}$ is the mean separation factor or that for continuous operation, as given by Eq. 79 .

\section{REFERENCES}

1. P. Debye, Ann. Physik, 36: 284 (1939).

2. W. H. Furry, R. C. Jones, and L. Onsager, Phys. Rev., 55: 1083 (1939).

3. Chapman and Cowling, "The Mathematical Theory of Nonuniform Gases," Cambridge University Press, 1939.

4. K. Wirtz, Ann. Physik, 36: 295 (1939).

5. J. Bardeen, Phys. Rev., 58: 95 (1940).

6. K. Cohen, Report A-531, Feb. 5, 1943.

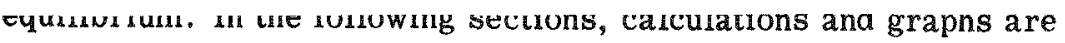
given for this purpose for several typical cases.

\section{COLUMN WITH INFINITE RESERVOIR}

In practice, the most common procedure for testing a column is to let it approach equilibrium while it is attached at one end to a large reser- 


\section{LIQUW THERMAL DIFFUSION}

voir and the other end is closed. Depending on whether the lower end or the upper end is the one connected to the reservoir, the column is a rectifier or a stripper. Frequently there is occasion to deal with the case in which $M_{R}$, the holdup of the reservoir, is large compared with $M$, the holdup of the column, so that $\omega=M / M_{R}$ is small. In that case a good approximation can be obtained by considering the reservoir to be infinite, i.e., $\omega=0$. Since this case is somewhat simpler to treat than the more general one, it will be taken up first.

In the case of a rectifier with an infinite reservoir, the boundary and initial conditions are

$$
\begin{aligned}
& c=c_{0}(z=0, t \geq 0) \\
& \tau=0(z=L, t \geq 0) \\
& c=c_{0}(0 \geq z \geq L, t=0)
\end{aligned}
$$

If it is assumed that the reservoir and the column, initially, are filled with material of concentration $c_{0}$.

The solution can be obtained readily by the use of operational calculus. Multiply the differential (Eq. 1) by $\mathrm{e}^{-\mathrm{pt}}$ and integrate over $\mathrm{t}$ from 0 to $\infty$. Let the Laplace transformation be given by

$$
f=\int_{0}^{\infty} c e^{-p t} d t
$$

Then the equation becomes, after an integration by parts,

$$
\mathrm{X} \alpha^{2}\left(\mathrm{pf}-\mathrm{c}_{0}\right)=\frac{\mathrm{d}^{2} \mathrm{f}}{\mathrm{dz} \mathrm{z}^{2}}-\alpha \frac{\mathrm{df}}{\mathrm{dz}}
$$

In terms of $\mathrm{f}$, the boundary conditions are

$$
\begin{aligned}
& \mathrm{f}=\frac{\mathrm{c}_{0}}{\mathrm{p}} \quad(\mathrm{z}=0) \\
& \frac{\mathrm{df}}{\mathrm{dz}}-\alpha \mathrm{f}=0 \quad(\mathrm{z}=\mathrm{L})
\end{aligned}
$$

The solution of Eq. 10 satisfying the boundary conditions in Eq. 11 is

$$
f=\frac{c_{0}}{p}+\frac{2 c_{0}}{p} \frac{\exp [1 / 2(1+\lambda) \alpha z]-\exp [1 / 2(1-\lambda) \alpha z]}{(\lambda-1) \exp [1 / 2(1+\lambda) Y]+(\lambda+1) \exp [1 / 2(1-\lambda) Y]}
$$

where

$$
\lambda=\sqrt{1+4 \mathrm{Xp}}
$$


or, in terms of hyperbolic functions,

$$
f=\frac{c_{0}}{p}+\frac{2 c_{0}}{p} \exp [1 / 2(\alpha z-Y)] \frac{\sinh \frac{\lambda \alpha z}{2}}{\lambda \cosh \frac{\lambda Y}{2}-\sinh \frac{\lambda Y}{2}}
$$

After $f$ is obtained, the inverse Laplace transformation must be applied to get $c$. This can be accomplished by means of a line integral in the complex plane:

$$
c=\frac{1}{2 \pi i} \int_{\beta-1 \infty}^{\beta+1 \infty} e^{p t} f d p
$$

where $\beta$ is an arbitrary real number, sufficiently large so that all the poles of the integrand are on the left of the path of integration. The integral can be evaluated by summing over the residues at the poles of the integrand. At $p=0$, the residue is $c_{0} \mathrm{e}^{\alpha \mathrm{z}}$. The other poles are at the values of $p$ for which

$$
\lambda \cosh \frac{\lambda Y}{2}-\sinh \frac{\lambda Y}{2}=0
$$

At each of these poles, the residue is

$$
\begin{aligned}
\frac{2 c_{0} \exp [1 / 2(\alpha z-Y)] \sinh \frac{\lambda \alpha Z}{2} e^{p t}}{p\left(\cosh \frac{\lambda Y}{2}+\frac{\lambda Y}{2} \sinh \frac{\lambda Y}{2}-\frac{Y}{2} \cosh \frac{\lambda Y}{2}\right) \frac{d \lambda}{d p}} \\
=\frac{4 c_{0} \lambda \exp [1 / 2(\alpha z-Y)] \sinh \frac{\lambda \alpha z}{2} e^{p t}}{\left(\lambda^{2}-1\right)\left[\left(1-\frac{Y}{2}\right) \cosh \frac{\lambda Y}{2}+\frac{\lambda Y}{2} \sinh \frac{\lambda Y}{2}\right]}
\end{aligned}
$$

If $\mathrm{Y}<2$, it can be shown that the roots of Eq. 16 are all purely imaginary. Hence it is convenient to set $\lambda=i(2 \theta / Y)$. Equation 16 then becomes

$$
\tan \theta=\frac{2 \theta}{\mathbf{Y}}
$$

and, if the residue is expressed in terms of $\theta$, the solution is 
$c=c_{0} e^{\alpha z}-4 c_{0} \exp \mid[-(\alpha / 2)(L-z)]$

$$
\times \sum_{n=1}^{\infty} \frac{\sin \theta_{n} \sin 2 \theta_{n}}{2 \theta_{n}-\sin 2 \theta_{n}} \sin \frac{\theta_{n} z}{L} e^{-k_{n} t / x}
$$

where $\theta_{\mathrm{n}}$ is the $\mathrm{n}$ th positive root of Eq. 18 , omitting $\theta=0$, and $\mathrm{k}_{\mathrm{n}}$ is given by

$$
\mathrm{k}_{\mathrm{n}}=\frac{\theta_{\mathrm{n}}^{2}}{\mathrm{Y}^{2}}+\frac{1}{4}=\frac{1}{4 \cos ^{2} \theta_{\mathrm{n}}}
$$

For $\mathrm{z}=\mathrm{L}$, it is found that $\mathrm{S}=\mathrm{S}_{\mathbf{T}}$

$$
\mathrm{S}=\mathrm{e}^{\mathrm{Y}}-4 \sum_{\mathrm{n}=1}^{\infty} \frac{\sin ^{2} \theta_{\mathrm{n}} \sin 2 \theta_{\mathrm{n}}}{2 \theta_{\mathrm{n}}-\sin 2 \theta_{\mathrm{n}}} \mathrm{e}^{-\mathrm{k}_{\mathrm{n}} \mathrm{t} / \mathrm{X}}
$$

From Eq. 19 the mean value of $\mathrm{c}, \overline{\mathrm{c}}$, is obtained by integration:

$$
\overline{\mathrm{c}}=\frac{1}{\mathrm{~L}} \int_{0}^{\mathrm{L}} \mathrm{c} \mathrm{dz}
$$

It is found that

$$
\overline{\mathrm{S}}=\frac{\overline{\mathrm{c}}}{\mathrm{c}_{\mathrm{o}}}=\frac{1}{\mathrm{Y}}\left(\mathrm{e}^{\mathrm{Y}}-1-4 \mathrm{e}^{-\mathrm{Y} / 2} \sum_{\mathrm{n}=1}^{\infty} \frac{\sin \theta_{\mathrm{n}} \sin ^{2} 2 \theta_{\mathrm{n}}}{2 \theta_{\mathrm{n}}-\sin 2 \theta_{\mathrm{n}}} \mathrm{e}^{-\mathrm{k}_{\mathrm{n}} \mathrm{t} / \mathrm{X}}\right)
$$

with the increase in the light-constituent mass, m, given by

$$
\mathbf{m}=\mathbf{M}\left(\overline{\mathbf{c}}-\mathrm{c}_{0}\right)=\mathrm{Mc}_{0}(\overline{\mathrm{S}}-1)
$$

From Eq. 19 the light-constituent transport is also obtained:

$$
\begin{aligned}
\tau=\frac{4 c_{0} K}{L} \exp [-(\alpha / 2)(L-z)] & \sum_{n=1}^{\infty} \frac{\sin \theta_{n} \sin 2 \theta_{n}}{2 \theta_{n}-\sin 2 \theta_{n}} \\
& \times\left(\theta_{n} \cos \frac{\theta_{n} z}{L}-\frac{Y}{2} \sin \frac{\theta_{n} z}{L}\right) \mathrm{e}^{-k_{n} t / x}
\end{aligned}
$$

which, for $\mathrm{z}=0$, gives the transport from the reservoir to the column

$$
\tau_{0}=4 \mathrm{Hc}_{0} \mathrm{e}^{-\mathrm{Y} / 2} \sum_{\mathrm{n}=1}^{\infty} \frac{\sin ^{3} \theta_{\mathrm{n}}}{2 \theta_{\mathrm{n}}-\sin 2 \theta_{\mathrm{n}}} \mathrm{e}^{-\mathrm{k}_{\mathrm{n}} \mathrm{t} / \mathrm{X}}
$$


It follows from the preceding equations that

$$
\tau_{0}=\frac{\mathrm{dm}}{\mathrm{dt}}
$$

as was to be expected.

From these equations a number of results have been obtained as series expansions. For sufficiently large values of $t / X$, these series converge very rapidly, so that only the first one or two terms are needed. For small values of $t / x$, however, a large number of terms may be required, and, in that case, the above expansions become inconvenient. Therefore, it is desirable to have some other form of solution which is more appropriate for this case.

With reference to the solution in the form of Eq. 12, for sufficiently large (positive, real) values of $\lambda, f$ can be expanded as follows:

$$
\begin{aligned}
f= & \frac{c_{0}}{p}+\frac{2 c_{0}}{p(\lambda-1)} \exp [1 / 2 \alpha(z-L)]\{\exp [1 / 2 \lambda \alpha(z-L)] \\
& -\exp [-1 / 2 \lambda \alpha(z+L)]\}\left[1-\frac{\lambda+1}{\lambda-1} e^{-\lambda Y}+\left(\frac{\lambda+1}{\lambda-1}\right)^{2} e^{-2 \lambda Y}+\ldots\right]
\end{aligned}
$$

If $z$ is not very much smaller than $L$, the second term in the braces can be neglected. In fact, all but the first term in the series can be neglected. If $\lambda$ is also expanded,

$$
\lambda=\sqrt{1+4 \mathrm{Xp}}=2 \sqrt{\mathrm{Xp}}\left(1+\frac{1}{8 \mathrm{Xp}}+\cdots\right)
$$

then $f$ can be written approximately

$$
f=\frac{c_{0}}{p}+c_{0} \exp [\alpha(z-L)(1 / 2+\sqrt{X p})]\left(\frac{1}{X^{1 / 2} p^{3 / 2}}+\frac{1}{2 X p^{2}}+\cdots\right)
$$

On carrying out the inverse Laplace transformation, the result is

$$
\begin{aligned}
c= & c_{0}+c_{0} \exp [1 / 2 \alpha(z-L)]\left\{2 \sqrt{\frac{t}{\pi X}} \exp \left[\frac{-\alpha^{2}(L-z)^{2} \mathrm{X}}{4 t}\right]\right. \\
& -\alpha(L-z) \operatorname{erfc}\left[\frac{\alpha(L-z) \sqrt{X}}{2 \sqrt{t}}\right] \\
& \left.+\frac{1}{2 X} \int_{0}^{t} \operatorname{erfc}\left[\frac{\alpha(L-z) \sqrt{X}}{2 \sqrt{t}}\right] d \tau+\ldots\right\}
\end{aligned}
$$


where

$$
\operatorname{erfc}(x)=\frac{2}{\sqrt{\pi}} \int_{x}^{\infty} e^{-u^{2}} d u
$$

If $\mathrm{z}=\mathrm{L}$, the following equation is obtained through such a procedure:

$$
S=1+\frac{2}{\sqrt{\pi}} \sqrt{\frac{t}{X}}+\frac{1}{2} \frac{t}{X}+\frac{1}{6 \sqrt{\pi}}\left(\frac{t}{X}\right)^{3 / 2}+\ldots
$$

which is an expansion appropriate for small values of $t / X$. It should be noted that, to the approximation to which Eq. 32 is valid, $s$ depends only on $t / X$ and does not depend on $Y$.

By a similar procedure it is found that, for small values of $t$, the light-constituent holdup, $\mathrm{m}$, is given by

$$
\mathrm{m}=\mathrm{Hc}_{0} \mathrm{t}
$$

If Eq. 30 is examined, it is found that, for very small values of $t, c$ differs appreciably from $c_{0}$ only for $z$ nearly equal to $L$. This means that the $\mathrm{m}$ given by Eq. 33 is accumulated only in a thin layer close to the top of the column early in the process.

To give some idea of the general behavior of a column approaching equilibrium under the conditions being considered, Fig. 10.2 shows, by means of the solid curve, the dependence of $S$ on $t / X$ for the case of $Y=$ 0.6 , according to Eq. 21. The dotted curve describes the dependence obtained from Eq. 21 by neglecting all but the first term in the series. In this case it will be seen that the two curves practically coincide for $\mathrm{t} / \mathrm{X} \geq 0.05$.

The relation between the time constant, $X$, and the half-time of approach to equilibrium, $\mathrm{T}_{1 / 2}$, can be investigated. The half-time can be defined in either of two ways: (1) the time for $S$ to go halfway to equilibrium, i.e.,

$$
\mathrm{S}=\frac{1}{2}\left(1+\mathrm{S}_{\mathrm{e}}\right)=\frac{1}{2}\left(1+\mathrm{e}^{\mathrm{Y}}\right)
$$

or (2) the time for $\ln \mathrm{S}$ to go halfway to equilibrium, i.e.,

$$
\ln \mathrm{S}=\frac{\mathrm{Y}}{2}
$$

Figure 10.3 shows curves for $T_{1 / 2} / X$ as a function of $Y$, with the halftime, $T_{1 / 2}$, defined in each of the preceding ways. 


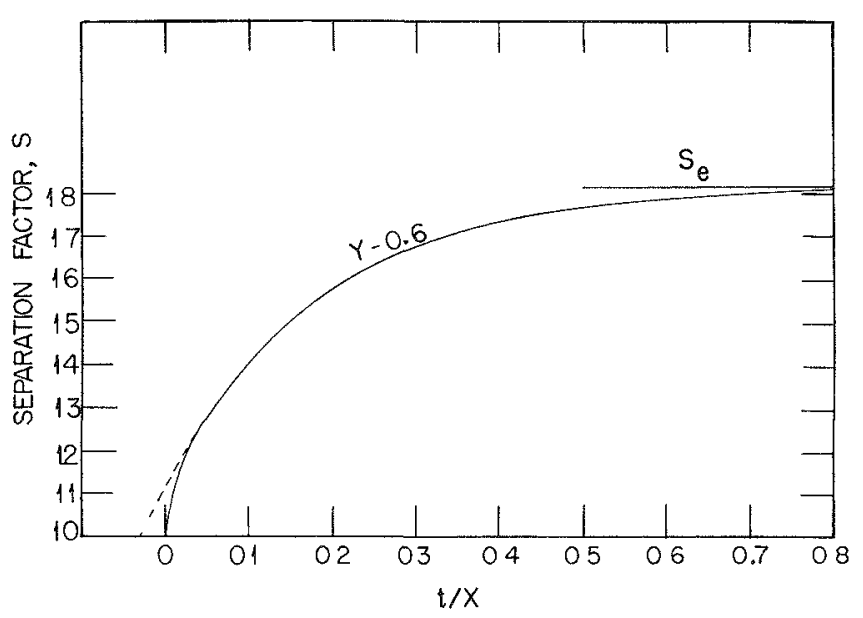

Fig. 10.2-The solid curve shows the dependence of the separation factor on time for the case of $Y=0.6$ calculated on the basis of $\mathbf{E q} .21$. The dotted curve shows the approximate dependence obtained from Eq. 21 by neglecting all but the first term in the series.

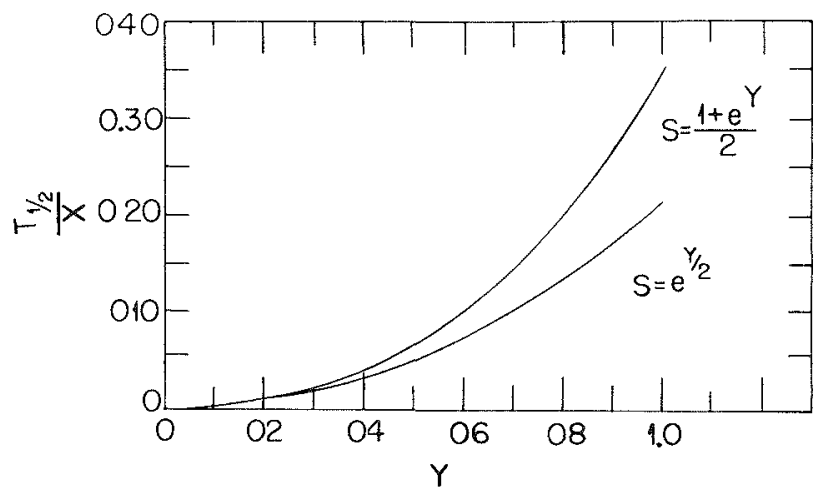

Fig. 10.3- On the basis of two different definitions of half-time, this figure shows how the ratio of the half-tıme to the time constant $\mathrm{X}$ depends on $\mathrm{Y}$.

Figure 10.4 shows the distribution of concentration along the column at various times. It should be noted that, for small values of $t$, the concentration is very small everywhere except at the top, near which it increases rather abruptly. As time progresses, the concentration increases lower down, and the gradient becomes more nearly uniform - throughout the column. 


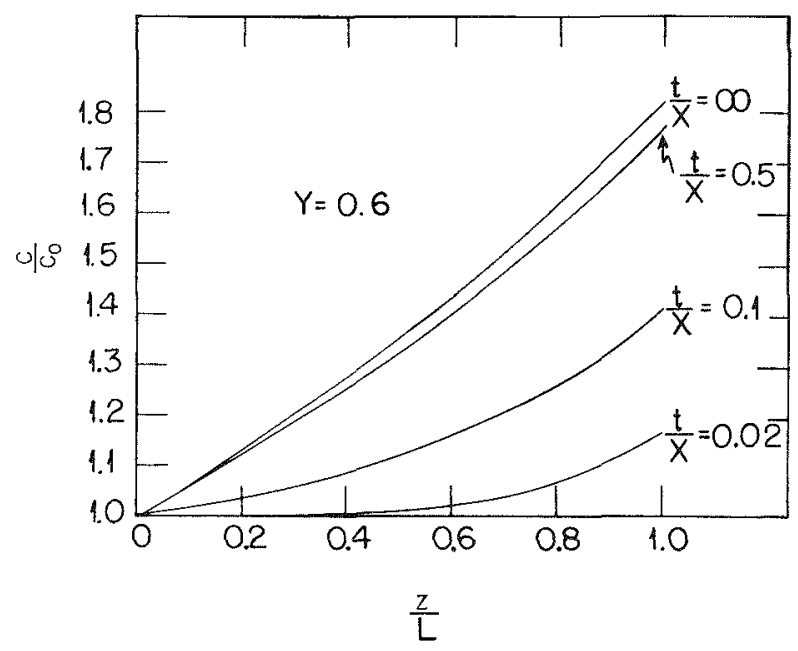

Fig. 10.4-Distribution of concentration along the column at various times.

The results obtained in this section can be used to study the properties of a given column. It will be seen that the time, $t$, appears only in the combination $t / x$, as might have been anticipated from the form of Eq. 1 and the boundary conditions. Hence it is convenient to plot $S$ as a function of $t / X$, different curves being obtained for different values of $Y$. With such a family of curves, a comparison of the curve of $S$ vs. $t$, obtained experimentally for the given column, with the calculated curves serves to determine the values of $\mathrm{X}$ and $\mathrm{Y}$ for which best agreement is obtained.

A difficulty in such a comparison arises from the fact that different values of $X$ correspond to different time scales in the graph of $S$ vs. $t$, and it is necessary to determine simultaneously the appropriate time scale and the appropriate member of the calculated family of curves. This difficulty has been largely overcome in Fig. 10.5, in which graphs of $S$ vs. $t / X$ are presented, with a logarithmic scale for $t / X$. Since in this case a change of $X$ corresponds simply to a displacement of the curves horizontally without any change of shape, it becomes easy to fit the experimental data to the theoretical curves.

It has been pointed out previously that, for small values of $t / X, S$ is independent of $\mathrm{Y}$; consequently, all the curves of Fig. 10.5 nearly coincide. This makes the curve fitting particularly simple: Fitting the experimental points for small values of $t$ to the (nearly unique) curve serves to determine $X$; the experimental points for larger values of $t$ permit the determination of $\mathrm{Y}$. 


\section{APPROACH TO EQUILIBRIUM BY A STNGLE COLUMN}

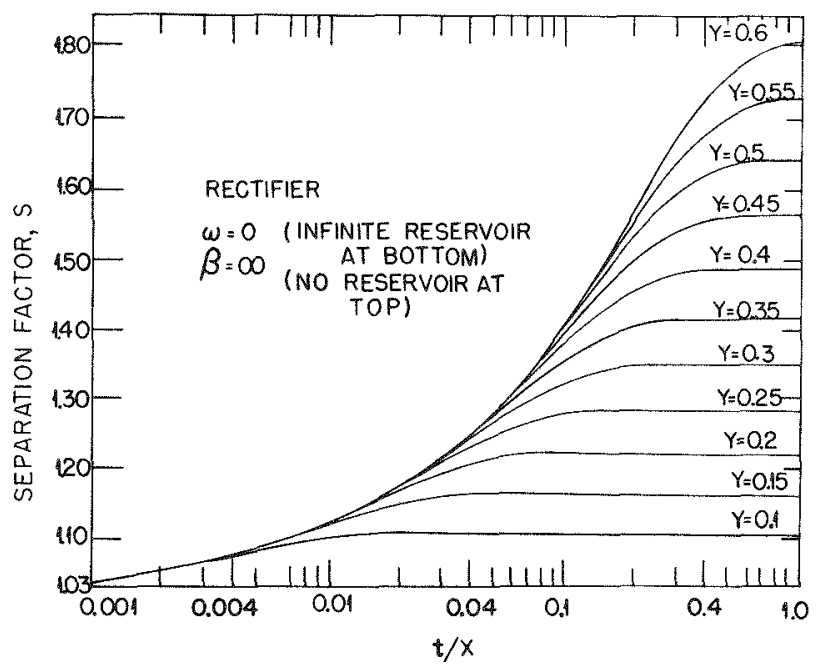

Fig, 10.5-A family of curves for the separation factor as a function of $t / X$ for various values of $Y$. This is for the case of a rectifier operating from an infinite reservoir and with no storage chamber.

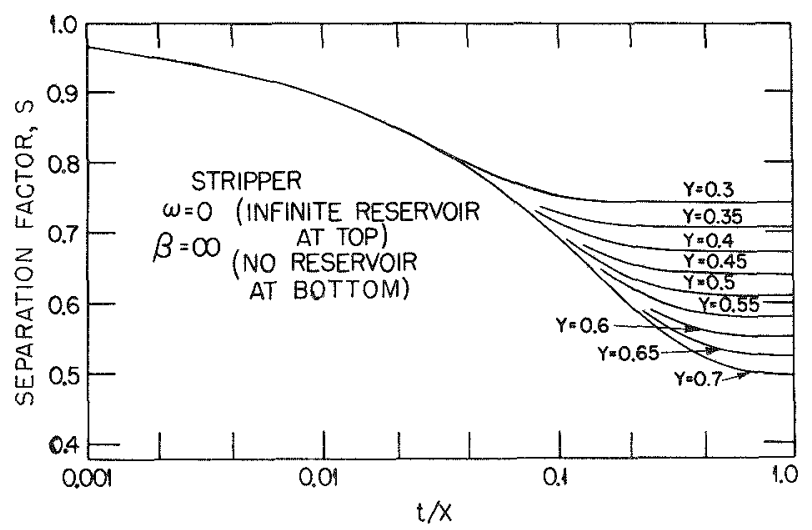

Fig. 10.6- A family of curves for the separation factor as a function of $t / X$. This is for the case of an infinite reservoir at the top of the column and no storage chamber. 
Thus far the column to be operated has been considered as a rectifier. At times it is desirable to experiment with the column operated as a stripper. First, the column approaches equilibrium more rapidly when it is run as a stripper. Second, it is sometimes of interest to compare the column constants as obtained for the same column in the two different kinds of operation since an appreciable discrepancy might indicate the presence of some source of disturbance in the system.

For a column run as a stripper, some modifications in the formulas given above are required. If now $\mathrm{z}=0$ at the top of the column where the reservoir is connected, then $z=-L$ at the bottom of the column; therefore, $Y$ has to be replaced by $-Y$ in the formulas. It is convenient in this case to replace $z$ by $-z$, so that $z$ now represents the distance measured down from the top of the column and $z=L$ at the bottom of the column. Certain other changes must also be made, e.g., $\mathrm{H}$ must be replaced by $-\mathrm{H}$ and, hence, $\alpha$ by $-\alpha$. In place of Eq. 18 now

$$
\tan \theta=-\frac{2 \theta}{Y}
$$

the roots of which, $\theta_{\mathrm{n}}$, are to be put into the equation

$c=c_{0} e^{-\alpha z}-4 c_{0} \exp [(\alpha / 2)(L-z)]$

$$
\times \sum_{n=1}^{\infty} \frac{\sin \theta_{n} \sin 2 \theta_{n}}{2 \theta_{n}-\sin 2 \theta_{n}} \sin \frac{\theta_{n} z}{L} e^{-k_{n} t / x}
$$

$k_{n}$ being given by the same formula as before but with the new roots $S_{n}$. For $\mathrm{z}=\mathrm{L}, \mathrm{S}=\mathrm{c}_{\mathrm{B}} / \mathrm{c}_{0}$ from the equation

$$
S=e^{-Y}-4 \sum \frac{\sin ^{2} \theta_{n} \sin 2 \theta_{n}}{2 \theta_{n}-\sin 2 \theta_{n}} e^{-k_{n} t / X}
$$

If the calculation is repeated for small values of the results obtained for the rectifier can be carried over to the stripper, provided that the signs of some of the constants are changed as described above and that, in addition, $\sqrt{\mathrm{X}}$ is replaced by $-\sqrt{\mathrm{X}}$. In particular, for $t / \mathrm{X} \ll 1$

$$
S=1-\frac{2}{\sqrt{\pi}} \sqrt{\frac{t}{x}}+\frac{1}{2} \frac{t}{x}-\frac{1}{6 \sqrt{\pi}}\left(\frac{t}{x}\right)^{3 / 2}+\cdots
$$

Figure 10.6 presents a family of curves for $S$ as a function of $t / X$, for various values of $Y$. These curves are intended to be used to determine the constants of a stripper in the same way as those of Fig. 10.5 for the rectifier. 


\section{COLUMN WITH FINITE RESERVOIR}

- If the column approaching equilibrium is connected to a reservoir having a holdup that is not very large compared with that of the column, the concentration in the reservoir will change during the process, and some of the results of Sec. 2 will no longer be applicable. This situation is described in the literature as a special case of a more general one worked out by Bardeen. ${ }^{2}$

Let us begin with the rectifier. If we have a finite reservoir of holdup $M_{R}$, the boundary conditions are now

$$
\begin{aligned}
& \tau=\mathbb{M}_{\mathrm{R}} \frac{\partial \mathrm{c}}{\partial \mathrm{t}} \quad(\mathrm{z}=0, \mathrm{t} \geq 0) \\
& \tau=0 \quad(\mathrm{z}=\mathrm{L}, \mathrm{t} \geq 0)
\end{aligned}
$$

with the initial condition

$$
\mathrm{c}=\mathrm{c}_{0} \quad(0 \leq \mathrm{z} \leq \mathrm{L}, \mathrm{t}=0)
$$

if it is assumed that the system is filled initially with normal material.

Using the method of operational calculus, or the Laplace transformation, it is found that, for the range of values of constants encountered in practice, the solution is given by

$$
c=\frac{c_{0}(1+\omega) e^{\alpha z}}{1+\frac{\omega}{Y}\left(e^{Y}-1\right)}-\frac{8 \omega}{Y} e^{\alpha z / 2} \sum_{n=1}^{\infty} \frac{A_{n}-B_{n}}{D_{n}} e^{-k_{n} t / X}
$$

where

$$
\begin{aligned}
& \mathbf{A}_{\mathrm{n}}=\mu_{\mathrm{n}} \sin \frac{\theta_{\mathrm{n}}(\mathrm{z}-\mathrm{L})}{\mathrm{L}}+\mu_{\mathrm{n}}^{2} \cos \frac{\theta_{\mathrm{n}}(\mathrm{z}-\mathrm{L})}{\mathrm{L}} \\
& \mathbf{B}_{\mathrm{n}}=\mu_{\mathrm{n}} \mathrm{e}^{-\mathbf{Y} / 2}\left\{\left[1-\frac{\mathbf{Y}}{2 \omega}\left(1+\mu_{\mathrm{n}}^{2}\right)\right] \sin \frac{\theta_{\mathrm{n}} \mathbf{z}}{\mathrm{L}}+\mu_{\mathrm{n}} \cos \frac{\theta_{\mathrm{n}} \mathrm{Z}}{\mathrm{L}}\right\}
\end{aligned}
$$

and

$$
D_{n}=\left(1+\mu_{n}^{2}\right)^{2}\left(\frac{\theta_{n}}{\sin \theta_{n}}-\cos \theta_{n}\right)
$$

where $\theta_{\mathrm{n}}$ is the $\mathrm{n} t h$ positive root of the equation

$$
\tan \theta=\frac{\theta}{\frac{Y}{2}-\omega}
$$


and

$$
\omega=\frac{M}{M_{R}} \quad \mu_{n}=\frac{2 \theta_{n}}{Y} \quad k_{n}=\frac{1}{4}\left(\mu_{n}^{2}+1\right)
$$

From Eq. 41, putting $z=L$, the result is

$$
\begin{aligned}
& \mathrm{S}_{\mathrm{T}}=\frac{(1+\omega) \mathrm{e}^{\mathrm{X}}}{1+\frac{\omega}{\mathrm{Y}}\left(\mathrm{e}^{\mathrm{Y}}-1\right)}-\frac{8 \omega}{\mathrm{Y}} \\
& \times \sum_{\mathrm{n}=1}^{\infty} \frac{\mu_{\mathrm{n}}^{2}\left[\mathrm{e}^{\mathrm{Y} / 2}+\mu_{\mathrm{n}} \sin \theta_{\mathrm{n}}+\frac{1}{2 \omega}\left(1+\mu_{\mathrm{n}}^{2}\right)(\mathrm{X}-1) \cos \theta_{\mathrm{n}}\right] \mathrm{e}^{-\mathrm{K}_{\mathrm{n}} \mathrm{t} / \mathrm{X}}}{\left(1+\mu_{\mathrm{n}}^{2}\right)^{2}\left(\frac{\theta_{\mathrm{n}}}{\sin \theta_{\mathrm{n}}}-\cos \theta_{\mathrm{n}}\right)}
\end{aligned}
$$

and, for $\mathrm{z}=0$,

$$
\begin{aligned}
& S_{B}=\frac{1+\omega}{1+\frac{\omega}{Y}\left(e^{Y}-1\right)}+\frac{8 \omega}{Y} \\
& \quad \times \sum_{n=1}^{\infty} \frac{\left(\mu_{n}^{2} e^{-Y / 2}+\mu_{n} \sin \theta_{n}-\mu_{n}^{2} \cos \theta_{n}\right) e^{-k_{n} t / x}}{\left(1+\mu_{n}^{2}\right)^{2}\left(\frac{\theta_{n}}{\sin \theta_{n}}-\cos \theta_{n}\right)}
\end{aligned}
$$

In addition to the above results, expressions useful for small values of $t$ are also needed. By the method used in Sec. 2 it is found that, for $\mathrm{t} / \mathrm{X} \ll 1$

$$
\begin{aligned}
& S_{T}=1+\frac{2}{\sqrt{\pi}}\left(\frac{t}{X}\right)^{1 / 2}+\frac{1}{2}\left(\frac{t}{X}\right)+\frac{1}{6 \sqrt{\pi}}\left(\frac{t}{X}\right)^{3 / 2}+\cdots \\
& S_{B}=1-\frac{\omega}{Y}\left(\frac{t}{X}\right)+\frac{4}{3 \sqrt{\pi}} \frac{\omega^{2}}{Y^{2}}\left(\frac{t}{X}\right)^{3 / 2}+\cdots
\end{aligned}
$$

As an illustration, Fig. 10.7 shows a family of curves for $S_{T}$ and $S_{B}$ as functions of $t / X$ for $\omega=M / M_{R}=1.0$. It will be noted that the general character of $S_{T}$ is the same as that of $S$ for $\omega=0$, and the curves can be used in the same way as those of Fig. 10.5 to determine the constants of the column.

The formulas for the stripper can be obtained from those for the rectifier by introducing the same changes as were made in Sec. 2. Now 


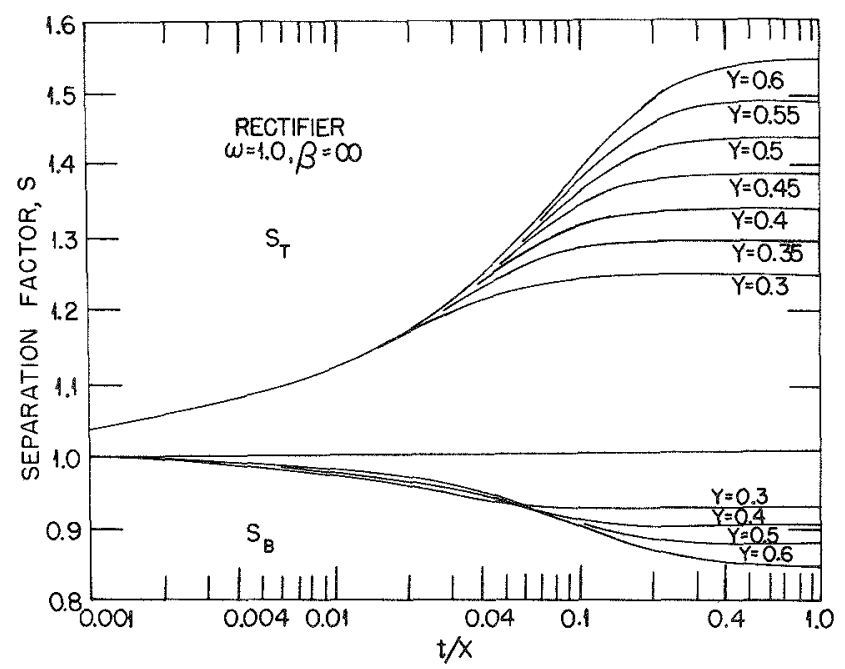

Fig. 10.7-A family of curves for the separation factor as a function of $t / \mathrm{X}$ for various values of $Y$. This is for the case of a reservoir at the bottom of the column having a holdup equal to that of the column, with no storage chamber.

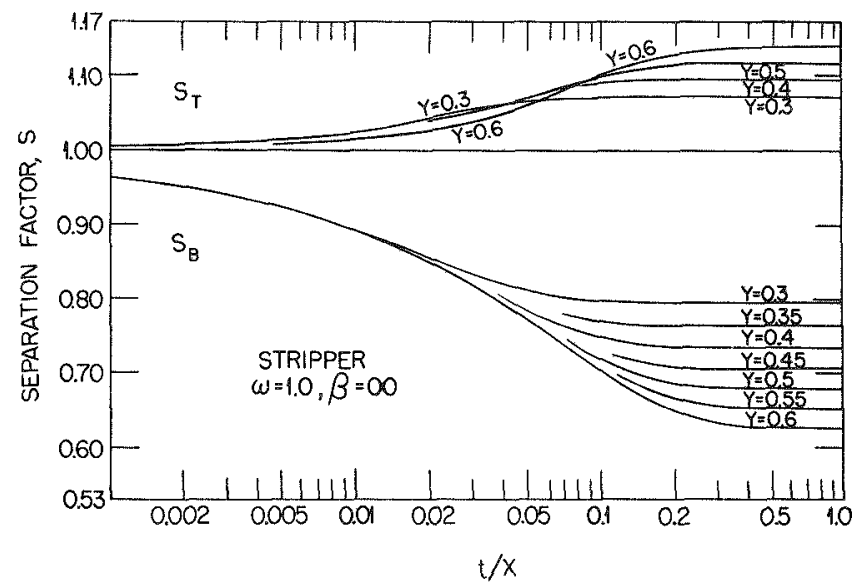

Fig. 10.8-A family of curves for the separation factor as a function of $t / X$ for various values of $Y$. This is for the case of a stripper having a reservoir with a capacity equal to the holdup of the column and no storage chamber.

letting $\mathrm{z}$ denote the distance from the top, the sign of $\mathrm{H}, \alpha, \mathrm{Y}$, and $\sqrt{\mathrm{X}}$ must be changed. Figure 10.8 shows graphs of $S_{T}$ and $S_{B}$ for a stripper with $\omega=1.0$ and various values of $Y$. 


\section{ISOLATED COLUMN}

The simplest case to treat mathematically is that of a column closed at both ends. From the experimental standpoint this case has several advantages. The column approaches equilibrium much more rapidly than under any other conditions, so that much less time is required for the experiment. Furthermore, the column is less likely to experience disturbances when isolated than when connected to a reservoir or storage chamber to which other columns are also connected. On the other hand, this arrangement has the disadvantage that, if samples of appreciable size are removed for analysis, the material pressure gradually drops in the course of the experiment, thereby altering conditions and, if the pressure change is sufficiently great, producing instability. It is possible to use a method of sample withdrawal in which the material removed is almost completely replaced, but the procedure is then more complicated.

The isolated column is described by Eq. 1 with the boundary conditions

$$
\tau=0 \quad(z=0, L)
$$

If the column is filled with material of normal concentration at the beginning of the experiment, then for the initial condition

$$
c=c_{0} \quad(t=0)
$$

The solution of Eq. 1 with the above conditions has been given by Bardeen $^{2}$ in the form of an infinite series expansion in characteristic functions. In the present notation, it can be written

$$
\begin{aligned}
\frac{c}{c_{0}}=\frac{Y e^{\alpha z}}{e^{Y}-1} & +16 \pi Y e^{\alpha z / 2} \\
& \times \sum_{n=1}^{\infty} \frac{\left[1-(-1)^{n} e^{-Y / 2}\right]\left(n Y \sin \frac{n \pi z}{L}+2 n^{2} \pi \cos \frac{n \pi z}{L}\right) e^{A}}{\left(Y^{2}+4 n^{2} \pi^{2}\right)^{2}}
\end{aligned}
$$

where $A=-\left(\frac{n^{2} \pi^{2}}{Y^{2}}+\frac{1}{4}\right) \frac{t}{X}$

From this the following equation can be obtained for $z=L$ :

$$
S_{T}=\frac{Y e^{Y}}{e^{Y}-1}+8 Y \sum_{n=1}^{\infty} \frac{4 n^{2} \pi^{2}}{\left(Y^{2}+4 n^{2} n^{2}\right)^{2}}\left[(-1)^{n} e^{Y / 2}-1\right] e^{A}
$$


and, for $\mathrm{z}=0$,

$$
S_{B}=\frac{Y}{e^{Y}-1}+8 Y \sum_{n=1}^{\infty} \frac{4 n^{2} \pi^{2}}{\left(Y^{2}+4 n^{2} \pi^{2}\right)^{2}}\left[1-(-1)^{n} e^{-Y / 2}\right] e^{A}
$$

In place of the expansion method for obtaining the solution, the operational calculus or the Laplace transformation method can be used. This gives a solution in the same form as above (this solution being the limiting form of that obtained in Sec. 3 for $\omega=\infty)$. As indicated, however, it can also be used to obtain a solution in the form of a power series in $t / x$, which converges rapidly for small values of this variable. In this way it can be found that, for $t / X$ sufficiently small,

$$
\begin{aligned}
& S_{T}=1+\frac{2}{\sqrt{\pi}}\left(\frac{t}{X}\right)^{1 / 2}+\frac{1}{2}\left(\frac{t}{X}\right)+\frac{1}{6 \sqrt{\pi}}\left(\frac{t}{X}\right)^{3 / 2}+\ldots \\
& S_{B}=1-\frac{2}{\sqrt{\pi}}\left(\frac{t}{X}\right)^{1 / 2}+\frac{1}{2}\left(\frac{t}{X}\right)-\frac{1}{6 \sqrt{\pi}}\left(\frac{t}{X}\right)^{3 / 2}+\ldots
\end{aligned}
$$

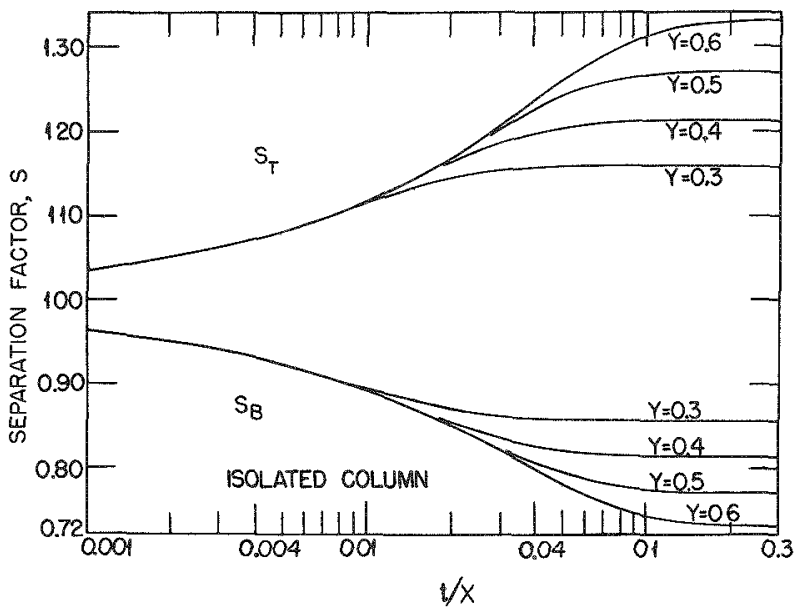

Fig. 10.9-A family of curves for the separation factor as a function of $t / X$ for various values of $Y$. This is for the case of an isolated column closed at both ends.

Figure 10.9 presents a ramily of curves for $S_{T}$ and $S_{B}$ as functions of $\mathrm{t} / \mathrm{X}$ for various values of $Y$. Consistent with the curves given in Secs. 2 and 3 , it uses a logarithmic time scale to facilitate the determination of $\mathrm{X}$ for a given column. 


\section{COLUMN WITH INFINITE RESERVOIR AND FINITE STORAGE CHAMBER}

Thus far consideration has been given only to the behavior of columns that were closed at one end, the other end being either also closed or else connected to a reservoir. Now consider the case of a column that has one end connected to a reservoir while the other end is connected to a small storage chamber. The presence of the storage chamber lengthens the time of approach to equilibrium. However, it is sometimes used because, among other things, it reduces the disturbance due to sample removal.

First, simplify the problem by assuming the reservoir to be infinitely large. This case has been discussed by Cohen. ${ }^{3}$ Let $M_{S}$ be the holdup of the storage chamber. The boundary and initial conditions (if the system is filled throughout with normal material) are given by

$$
\begin{array}{lll}
z=0 & t \geqslant 0 & c=c_{0} \\
z=L & t \geqslant 0 & M_{s} \frac{\partial c}{\partial t}=\tau \\
t=0 & 0 \leqslant z \leqslant L & c=c_{0}
\end{array}
$$

By the use of operational calculus, as before, the solution is

$$
\begin{aligned}
\frac{c}{c_{0}}=e^{\alpha z}-4 \exp [(\alpha / 2)(z-L)] & \frac{\mu_{n} \sin \frac{\theta_{n} z}{L} e^{-k_{n} t / x}}{\sum_{n=1}^{\infty} \frac{\left(1+\mu_{n}^{2}\right)\left(\frac{2 \theta_{n}}{\beta} \sin \theta_{n}+\frac{\theta_{n}}{\sin \theta_{n}}-\cos \theta_{n}\right)}{(1)}}
\end{aligned}
$$

where

$$
\beta=\frac{M}{M_{S}} \quad \mu_{n}=\frac{2 \theta_{n}}{Y} \quad k_{n}=\frac{1}{4}\left(\mu_{n}^{2}+1\right)
$$

and $\theta_{\mathrm{n}}$ is the $\mathrm{n} t h$ positive root of the equation

$$
\tan \theta=\frac{\theta}{\frac{\mathrm{Y}}{2}+\frac{1}{\beta}\left(\theta^{2}+\frac{\mathrm{Y}^{2}}{4}\right)}
$$

Setting $z=L$, then, for $S=S_{T}$,

$$
\mathrm{S}=\mathrm{e}^{\mathrm{Y}}-4 \sum_{\mathrm{n}=1}^{\infty} \frac{\mu_{\mathrm{n}} \sin \theta_{\mathrm{n}} \mathrm{e}^{-\mathrm{k}_{\mathrm{n}} \mathrm{t} / \mathrm{X}}}{\left(1+\mu_{\mathrm{n}}^{2}\right)\left(\frac{2 \theta_{\mathrm{n}}}{\beta} \sin \theta_{\mathrm{n}}+\frac{\theta_{\mathrm{n}}}{\sin \theta_{\mathrm{n}}}-\cos \theta_{\mathrm{n}}\right)}
$$


Certain other functions are of interest. From Eq. 62 the light-constituent holdup in the storage chamber, $\mathrm{m}_{\mathrm{s}}$, can be obtained by means of the relation

$$
\mathrm{m}_{\mathrm{s}}=\frac{\mathrm{MSc}_{0}}{\beta}
$$

and the total light-constituent holdup in the column and storage chamber is found, after some calculation, to be

$$
\begin{aligned}
\mathrm{m}+\mathrm{m}_{\mathrm{s}} & =M c_{0}\left[\frac{\left(\mathrm{e}^{\mathrm{Y}}-1\right)\left(1+\frac{Y}{\beta}\right)-\mathrm{Y}}{\mathrm{Y}}\right. \\
& \left.-\frac{8 \mathrm{e}^{-Y / 2}}{\mathrm{Y}} \sum_{n=1}^{\infty} \frac{\mu_{n}^{2} \mathrm{e}^{-k_{\mathrm{n}} t / \mathrm{X}}}{\left(1+\mu_{\mathrm{n}}^{2}\right)^{2}\left(\frac{2 \theta_{\mathrm{n}} \sin \theta_{n}}{\beta}+\frac{\theta_{n}}{\sin \theta_{n}}-\cos \theta_{n}\right)}\right]
\end{aligned}
$$

For small values of $t / X$, by the method used in Sec. 2 , it is found that

$$
S=1+\frac{\beta t}{Y X}-\frac{4}{3 \sqrt{\pi}} \frac{\beta^{2}}{X^{2}}\left(\frac{t}{X}\right)^{3 / 2}+\ldots
$$

If the column is being operated as a stripper rather than as a recti-

- fier, i.e., if the small storage chamber is at the bottom and the large reservoir is at the top, the same changes have to be made in the results obtained above as were given in the preceding sections.

If $S$ is plotted as a function of $t / X$ for a given value of $\beta$, the family of curves obtained for various values of $\mathrm{Y}$ is unsatisfactory because the different members of the family cross each other, which makes curve fitting difficult. Hence it is better to take, in place of $t / x$, the variable $\beta t / X Y$ since, for small values of this variable, all the curves come together (as can be seen from Eq. 65), whereas for larger values the curves of a particular family spread apart without intersecting.

Figure 10.10 shows graphs of $S$ vs. $\beta t / X Y$ for various values of $Y$ for the case of a rectifier with $\beta=1$. As before, a logarithmic scale of abscissas is used to facilitate fitting the calculated curves to experimental points. Figure 10.11 shows the corresponding curves for the case of the column run as a stripper.

\section{GENERAL CASE}

Finally, consider the general case of a column of holdup $M$ connected at the bottom to a reservoir of holdup $\mathrm{M}_{R}$ and connected at the top to a 


\section{LIQUD THERMAL DIFFUSION}

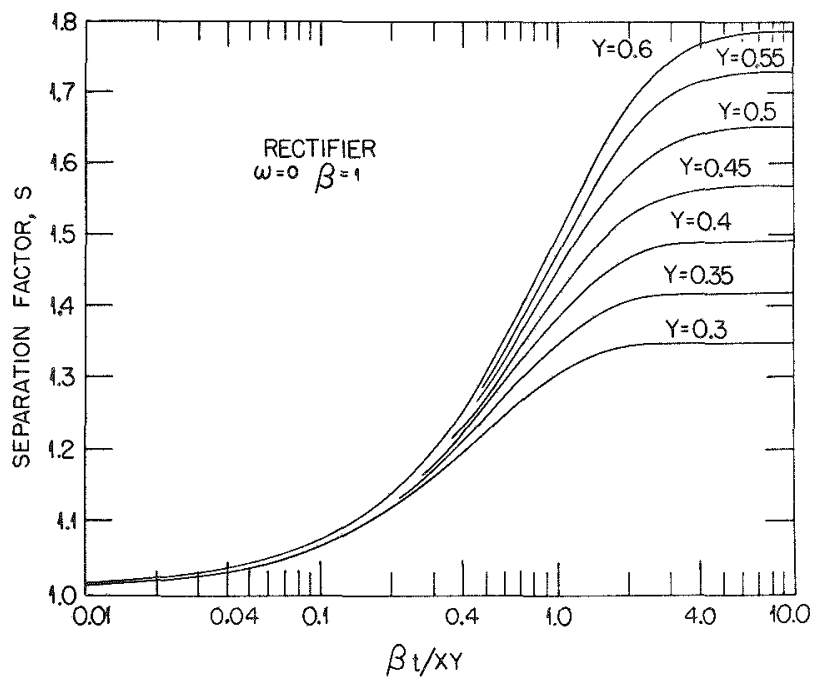

Fig. 10.10-A family of curves for the separation factor as a function of $\beta \mathrm{t} / \mathrm{XY}$ for various values of $Y$. This is for the case of a rectifier having an infinite reservoir and a storage chamber at the top with a holdup equal to that of the column.

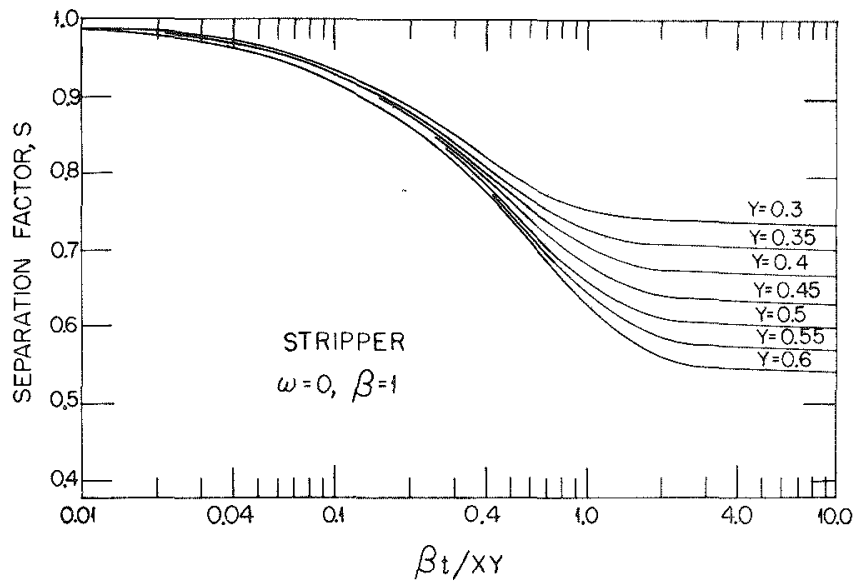

Fig. 10.11-A family of curves for the separation factor as a function of $\beta t / X Y$ for various values of $Y$. This is for the case of a stripper having an infinite reservoir and a storage chamber at the bottom with a holdup equal to that of the column. 
storage chamber of holdup $\mathrm{M}_{\mathrm{S}}$. The differential equation is the same as before. The boundary and initial conditions are now given by

$$
\begin{array}{lll}
\mathbb{Z}=0 & \mathrm{t} \geqslant 0 & \mathbb{M}_{\mathbb{R}} \frac{\partial c}{\partial t}=\tau \\
\mathbb{Z}=L & \mathrm{~L} \geqslant 0 & \mathbb{M}_{\mathrm{S}} \frac{\partial c}{\partial t}=\tau \\
\mathrm{t}=0 & 0 \leqslant \mathrm{z} \leqslant \mathbb{L} & \mathrm{c}=\mathrm{c}_{0}
\end{array}
$$

The solution for this case, obtained by the use of operational calculus, is found to be

$$
c=c_{0} \frac{Y(\beta \omega+\beta+\omega) e^{\alpha Z}}{\beta(Y-\omega)+\omega(Y+\beta) e^{Y}}+\frac{c_{0} \beta \omega e^{\alpha z / 2}}{2 Y} \sum_{n} \frac{A B}{C}
$$

where $\mathbf{A}=\left(1+\frac{2 Y k_{n}}{\beta}\right) \sin \theta_{n}+\mu_{n}\left(e^{-Y / 2}-\cos \theta_{n}\right)$

$$
\begin{aligned}
& \mathbb{B}=\left[\mu_{n} \cos \frac{\theta_{n} z}{L}+\left(1-\frac{2 Y k_{n}}{\omega}\right) \sin \theta_{n} \frac{z}{L}\right] e^{-k_{n} t / X} \\
& C=k_{n}^{2}\left[2 \theta_{n} \sin \theta_{n}+(\beta+\omega)\left(\frac{\theta_{n}}{\sin \theta_{n}}-\cos \theta_{n}\right)\right]
\end{aligned}
$$

and where $\beta=\mathrm{M} / \mathrm{M}_{\mathrm{S}}$

$$
\begin{aligned}
\omega & =\mathrm{M} / \mathbf{M}_{\mathrm{R}} \\
\alpha & =\mathrm{H} / \mathrm{K} \\
\mathbf{Y} & =\alpha \mathrm{L} \\
\mathrm{X} & =\mathrm{M} / \mathrm{HY} \\
\mu_{\mathrm{n}} & =2 \theta_{\mathrm{n}} / \mathrm{Y} \\
\mathrm{k}_{\mathrm{n}} & =1 / 4\left(1+\mu_{\mathrm{n}}^{2}\right)
\end{aligned}
$$

and $\theta_{\mathrm{n}}$ is the $\mathrm{n}$ th positive root of the equation

$$
\left[\left(\beta+\frac{Y}{2}\right)\left(\omega-\frac{Y}{2}\right)-\theta^{2}\right] \sin \theta+\theta(\beta+\omega) \cos \theta=0
$$

It follows that, for $z=L$,

$$
\begin{aligned}
S_{T}= & \frac{Y(\beta \omega+\beta+\omega)}{\omega(Y+\beta)+\beta(Y-\omega) e^{-Y}} \\
& -\frac{\beta \omega}{2 \Psi} \sum_{n} \frac{\left[\mu_{n}^{2}\left(e^{Y / 2}-\cos \theta_{n}\right)+\mu_{n}\left(\frac{2 Y k_{n}}{\omega}-1\right) \sin \theta_{n}\right] e^{-k_{n} t / x}}{k_{n}^{2}\left[2 \theta_{n} \sin \theta_{n}+(\beta+\omega)\left(\frac{\theta_{n}}{\sin \theta_{n}}-\cos \theta_{n}\right)\right]}
\end{aligned}
$$


whereas, for $\mathrm{z}=0$,

$$
\begin{aligned}
\mathrm{S}_{\mathrm{B}}= & \frac{\mathrm{Y}(\beta \omega+\beta+\omega)}{\beta(\mathrm{Y}-\omega)+\omega(\mathrm{Y}+\beta) \mathrm{e}^{\mathrm{Y}}} \\
& +\frac{\beta \omega}{2 \mathrm{Y}} \sum_{\mathrm{n}} \frac{\left[\mu_{\mathrm{n}}^{2}\left(\mathrm{e}^{-\mathrm{Y} / 2}-\cos \theta_{\mathrm{n}}\right)+\mu_{\mathrm{n}}\left(\frac{2 \mathrm{Y} \mathbf{k}_{\mathrm{n}}}{\beta}+1\right) \sin \theta_{\mathrm{n}}\right] \mathrm{e}^{-\mathrm{k}_{\mathrm{n}} \mathrm{t} / \mathrm{X}}}{\mathrm{k}_{\mathrm{n}}^{2}\left[2 \theta_{\mathrm{n}} \sin \theta_{\mathrm{n}}+(\beta+\omega)\left(\frac{\theta_{\mathrm{n}}}{\sin \theta_{\mathrm{n}}}-\cos \theta_{\mathrm{n}}\right)\right]}
\end{aligned}
$$

For small values of $t$, the power series expansions are of the form

$$
\begin{aligned}
& \mathrm{S}_{\mathrm{T}}=1+\frac{\beta}{\mathrm{Y}}\left(\frac{\mathrm{t}}{\mathrm{X}}\right)-\frac{4}{3 \sqrt{\pi}} \frac{\beta^{2}}{\mathrm{Y}^{2}}\left(\frac{\mathrm{t}}{\mathrm{X}}\right)^{3 / 2}+\frac{1}{2}\left(\frac{\beta^{3}}{\mathrm{Y}^{3}}+\frac{\beta^{2}}{2 \mathrm{Y}^{2}}\right)\left(\frac{\mathrm{t}}{\mathrm{X}}\right)^{2} \\
&-\frac{8}{15 \sqrt{\pi}}\left(\frac{\beta^{4}}{\mathrm{Y}^{4}}+\frac{\beta^{3}}{\mathrm{Y}^{3}}+\frac{\beta^{2}}{8 \mathrm{Y}^{2}}\right)\left(\frac{\mathrm{t}}{\mathrm{X}}\right)^{5 / 2}+\ldots \\
& \mathrm{S}_{\mathrm{B}}=1-\frac{\omega}{\mathrm{Y}}\left(\frac{\mathrm{t}}{\mathrm{X}}\right)+\frac{4}{3 \sqrt{\pi}} \frac{\omega^{2}}{\mathrm{Y}^{2}}\left(\frac{\mathrm{t}}{\mathrm{X}}\right)^{3 / 2}+\frac{1}{2}\left(-\frac{\omega^{3}}{\mathrm{Y}^{3}}+\frac{\omega^{2}}{2 \mathrm{Y}^{2}}\right)\left(\frac{\mathrm{t}}{\mathrm{X}}\right)^{2} \\
&+\frac{8}{15 \sqrt{\pi}}\left(\frac{\omega^{4}}{\mathrm{Y}^{4}}-\frac{\omega^{3}}{\mathrm{Y}^{3}}+\frac{\omega^{2}}{8 \mathrm{Y}^{2}}\right)\left(\frac{\mathrm{t}}{\mathrm{X}}\right)^{5 / 2}+\ldots
\end{aligned}
$$

Because of the large number of parameters involved, no systematic numerical calculations have been carried out for the general case discussed in this section. For given values of the constants, however, it is rot difficult to obtain numerical results by the use of Eqs. 68 to 72 .

\section{REFERENCES}

1. W. H. Furry, R. C. Jones, and L. Onsager, Phys. Rev., 55: 1083 (1939).

2. J. Bardeen, Phys. Rev., 57: 35 (1940); 58: 95 (1940).

3. K. Cohen, Report A-530, Feb. 4, 1943. 
Chapter 11

\section{EFFECT OF CIRCULATION}

\section{BOUNDARY CONDITIONS}

In previous calculations on the approach to equilibrium by a single column, it was assumed that the column was connected to a reservoir or storage chamber so that the concentration at the bottom of the column was the same as that in the reservoir, whereas the concentration at the top was the same as that in the storage chamber. In practice, however, the reservoir, or the storage chamber, is connected to the column by means of two tubes through which a continuous circulation of material is maintained by the presence in the circuit of a "convection loop" consisting of two lengths of vertical tubing maintained at different temperatures and connected in series. There may be an appreciable difference in concentration between the bottom of the column and the reservoir. This chapter deals with the effect of this circulation on the behavior of the column during the approach to equilibrium.

The first case to be considered will be that of the reservoir attached to the bottom of the column, as indicated schematically in Fig. 11.1.

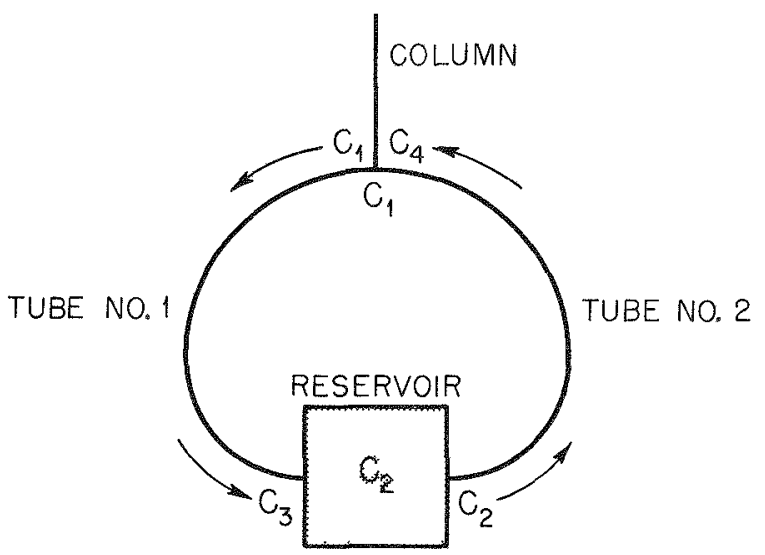

Fig. 11.1-Schematic diagram showing the column, reservoir, and circulating system. 
The reservoir has a holdup, $\mathbf{M}_{\mathbf{r}}$, and is connected by two tubes to the column. Tube 1 carries material from the column to the reservoir, and tube 2 carries material in the reverse direction. Using subscripts 1 and 2 to denote the two tubes, let $\mathrm{L}$ be the length, $\mathrm{A}$ the cross-sectional area, $v$ the velocity of the material, and $\rho$ the density (determined by the temperature). For simplicity, assume $\mathrm{A}, \mathrm{v}$, and $\rho$ to be constant over the entire length of each tube, although possibly different for the two tubes. The generalization to the case where these quantities vary along each tube will be apparent later. If a steady state of circulatory flow is considered, then

$$
\mathrm{A}_{1} \rho_{1} \mathrm{v}_{1}=\mathbf{A}_{2} \rho_{2} \mathrm{v}_{2}=\mathbf{U}
$$

where $U$ is the mass of material circulated per unit time.

Let $c_{1}$ be the light-constituent concentration at the bottom of the column at a given time $t$, and assume that the material, in passing through the bottom of the column, acquires this concentration so that $c_{1}$ is the concentration at the column end of tube 1 at this instant. Let $c_{2}$ be the concentration in the reservoir at time $t$, and again assume that this is the concentration at the reservoir end of tube 2 . In general, the concentrations will vary along the tubes. Let $c_{3}$ be the concentration at the reservoir end of tube 1 and $c_{4}$ that at the column end of tube 2 at time $t$. At the bottom of the column, there will be an upward rate of transport of light constituent, $\tau$, given by

$$
\tau=H c_{1}-K \frac{\partial c_{1}}{\partial z}
$$

where $H$ and $\mathrm{K}$ are the column constants. This rate of transport must be equal to the net rate at which the light constituent is brought into the column by circulation, or

$$
\tau=U\left(c_{4}-c_{1}\right)
$$

Correspondingly, for the reservoir, the relation can be written

$$
\mathbf{M}_{\mathrm{r}} \frac{\mathrm{dc} \mathrm{c}_{2}}{\mathrm{dt}}=\mathrm{U}\left(\mathrm{c}_{3}-\mathrm{c}_{2}\right)
$$

If $\mathrm{v}$ denotes the fluid velocity in either of the tubes, then, at a given point in the tube, the concentration, $c$, will ordinarily satisfy the equation

$$
\frac{\partial c}{\partial t}+v \frac{\partial c}{\partial x}=0
$$


where $\mathrm{x}$ is the distance along the tube in the direction of flow. The equation expresses the fact that the concentration in a given column element carried along with the fluid remains constant in time. The solution of Eq. 5 is, of course,

$$
c=f\left(t-\frac{x}{v}\right)
$$

where $f$ is an arbitrary function.

Let us set

$$
c_{1}=f(t) \quad c_{2}=g(t)
$$

where $f$ and $g$ are functions to be determined. Then, from the preceding considerations, it follows that

$$
c_{3}=f\left(t-\frac{L_{1}}{v_{1}}\right) \quad c_{4}=g\left(t-\frac{L_{2}}{v_{2}}\right)
$$

Equations 3 and 4 can be written, respectively,

$$
\begin{aligned}
& g\left(t-\frac{L_{2}}{v_{2}}\right)=f(t)+\frac{1}{U} \tau(t) \\
& f\left(t-\frac{L_{1}}{v_{1}}\right)=g(t)+\frac{M_{r}}{U} g^{\prime}(t)
\end{aligned}
$$

where the prime denotes the derivative with respect to $t$.

From Eq. 10 the following can be written:

$$
f\left(t-\frac{L_{1}}{v_{1}}-\frac{L_{2}}{v_{2}}\right)=g\left(t-\frac{L_{2}}{v_{2}}\right)+\frac{M_{r}}{U} g^{\prime}\left(t-\frac{L_{2}}{v_{2}}\right)
$$

and, if the values obtained from Eq. 9 are substituted for the terms on the right-hand side, the result is

$$
f\left(t-\frac{L_{1}}{v_{1}}-\frac{L_{2}}{v_{2}}\right)=f(t)+\frac{1}{U} \tau(t)+\frac{M_{r}}{U}\left[f^{\prime}(t)+\frac{1}{U} \tau^{\prime}(t)\right]
$$

If

$$
\mathrm{T}_{\mathrm{c}}=\frac{\mathrm{L}_{1}}{\mathrm{v}_{1}}+\frac{\mathrm{L}_{2}}{\mathrm{v}_{2}}, \quad \mathrm{~T}_{\mathrm{r}}=\frac{\mathrm{M}_{\mathrm{r}}}{\mathrm{U}}
$$




\section{LIQUID THERMAL DIF FUSION}

so that $T_{c}$, the circulation time, is essentially the time required for a particle of the fluid to go around the circulation loop, and $T_{r}$, the replacement time, is the time that would be required to fill the reservoir if material were brought to it at the rate $\mathrm{U}$, then $\mathrm{Eq} .12$ can be put into the form

$$
M_{r^{\prime}} f^{\prime}(t)+U\left[f(t)-f\left(t-T_{c}\right)\right]=-\tau(t)-T_{r} \tau^{\prime}(t)
$$

If $\mathrm{f}(\mathrm{t})$ is replaced by $\mathrm{c}(\mathrm{t})$, which is to represent the concentration at the bottom of the column, previously denoted by $c_{1}$, the boundary condition that is to hold at the bottom of the column during approach to equilibrium is obtained

$$
M_{r} \frac{d c(t)}{d t}+U\left[c(t)-c\left(t-T_{c}\right)\right]=-\tau(t)-T_{r} \frac{d \tau(t)}{d t}
$$

where $\tau$ is given by

$$
\tau=H c-K \frac{\partial c}{\partial z}
$$

It is readily seen that Eq. 15 will remain valid in the case where $A$, $v$, and $\rho$ are different at different points along the tubes, provided the meanings assigned above for $T_{c}$ and $T_{r}$ are retained.

In the cases encountered in practice, the circulating time, $\mathrm{T}_{\mathrm{c}}$, is generally negligibly small compared with the time during which the concentration at the bottom of the column changes by an appreciable amount. Usually, the replacement time, $\mathrm{T}_{\mathrm{r}}$, is too large to be neglected. Under these conditions, Eq. 15 can be replaced by

$$
M_{r} \frac{d c}{d t}=-\tau-T_{r} \frac{d \tau}{d t}
$$

where all the quantities refer to the same moment of time. As a boundary condition, Eq. 16 leads to much simpler calculations than those connected with Eq. 15 and will be used in the subsequent work. Hereafter $\mathrm{T}_{\mathrm{r}}$ will be denoted simply by $\mathrm{T}$.

The discussion given above can be carried over to the case of a storage chamber connected to the top of a column if $M_{r}$ is replaced by $M_{S}$, the holdup of the storage chamber, and if the signs of the terms involving $\tau$ and $\mathrm{d} \tau / \mathrm{dt}$ in Eqs. 15 and 16 are changed. 


\section{EFFECT OF CIRCULATION}

\section{CIRCULATION TO RESERVOIR}

Assume that there is a column (closed at the top) of holdup $\mathrm{M}$, length $L$, and constants $H$ and $K$, attached at the bottom to a reservoir of holdup $\mathrm{M}_{\mathbf{r}}$ by a circuit with replacement time $\mathrm{T}$ and negligible holdup. The concentration, $\mathrm{c}$, in the column, if small compared with unity, satisfies the equation

$$
\mathrm{X} \alpha^{2} \frac{\partial \mathrm{c}}{\partial \mathrm{t}}=\frac{\partial^{2} \mathrm{c}}{\partial \mathrm{z}^{2}}-\alpha \frac{\partial \mathrm{c}}{\partial \mathrm{z}}
$$

where

$$
\alpha=\mathrm{H} / \mathrm{K} \quad \mathrm{X}=\mathrm{M} / \mathrm{HY} \quad \mathrm{Y}=\alpha \mathrm{L}
$$

and $\mathrm{z}$ is the distance up the column measured from the bottom. The boundary conditions are

$$
\begin{aligned}
& \mathrm{z}=0 \quad \mathrm{M}_{\mathrm{r}} \frac{\partial \mathrm{c}}{\partial \mathrm{t}}=-\left(\mathrm{Hc}-\mathrm{K} \frac{\partial \mathrm{c}}{\partial \mathrm{z}}\right)-\mathrm{T} \frac{\partial}{\partial \mathrm{t}}\left(\mathrm{Hc}-\mathrm{K} \frac{\partial \mathrm{c}}{\partial \mathrm{z}}\right) \\
& \mathrm{z}=\mathrm{L} \quad \mathrm{Hc}-\mathrm{K} \frac{\partial \mathrm{c}}{\partial \mathrm{z}}=0
\end{aligned}
$$

and the initial condition is

$$
\mathrm{t}=\mathrm{0} \quad \mathrm{c}=\mathrm{c}_{0}
$$

where $c_{0}$ is the normal concentration.

This problem can be solved by means of a Laplace transformation. Take

$$
\mathrm{h}=\int_{0}^{\infty} c \mathrm{e}^{-\mathrm{pt}} \mathrm{dt}
$$

Going over to this variable by carrying out a similar integration of the preceding equations, we get, corresponding to Eq. 17, if a prime denotes differentiation with respect to $\mathrm{z}$,

$$
\mathbf{h}^{\prime \prime}-\alpha \mathbf{h}^{\prime}-\mathrm{X} \alpha^{2} \mathrm{ph}=-\mathrm{X} \alpha^{2} \mathrm{c}_{0}
$$

Similarly, Eq. 19 gives

$$
\mathrm{z}=0 \quad \mathrm{M}_{\mathrm{r}}\left(\mathrm{ph}-\mathrm{c}_{0}\right)=-\left(\mathrm{Hh}-\mathrm{Kh} \mathbf{h}^{\prime}\right)-\mathrm{pT}\left(\mathrm{Hh}-\mathrm{Kh}^{\prime}\right)+\tau_{0}
$$

where $\tau_{0}$ is the initial value of $\tau$, which is taken to be zero in the present case. Equation 20 becomes 


\section{LIQUID THERMAL DIFFUSION}

$$
\mathbf{z}=\mathbf{L} \quad \mathrm{Hh}-\mathrm{Kh}^{\prime}=0
$$

These equations can be solved for $h$ by letting $\lambda=\sqrt{1+4 X p}$ and setting

$$
h=\frac{c_{0}}{p}+A e^{\alpha z / 2} \sinh \frac{\alpha \lambda}{2}(L-z)+B e^{\alpha z / 2} \cosh \frac{\alpha \lambda}{2}(L-z)
$$

which satisfies Eq. 23 for arbitrary values of $\mathrm{A}$ and $\mathrm{B}$, and then by determining these constants in order to satisfy the boundary conditions, Eqs. 24 and 25. After an expression for $h$ is obtained, the transformation (Eq. 22) can then be inverted to obtain $c$. The final result is found to be

$$
\begin{aligned}
\frac{c}{c_{0}} & =\frac{(1+\omega) e^{\alpha z}}{1+\frac{\omega}{Y}\left(e^{Y}-1\right)} \\
& -e^{\alpha z / 2} \sum_{n=1}^{\infty} \frac{P_{n}}{Q_{n} k_{n}^{2}}\left[\mu_{n} \cos \theta_{n}\left(1-\frac{z}{L}\right)-\sin \theta_{n}\left(1-\frac{z}{L}\right)\right] e^{-k_{n} t / x}
\end{aligned}
$$

where

$$
\omega=\frac{\mathrm{M}}{\mathrm{M}_{\mathrm{r}}} \quad \mu_{\mathrm{n}}=\frac{\mathbf{Y}}{2} \theta_{\mathrm{n}} \quad \mathbf{k}_{\mathrm{n}}=\frac{1}{4}\left(1+\mu_{\mathrm{n}}^{2}\right)
$$

with $\theta_{\mathrm{n}}$ the $\mathrm{n}$ th positive root of the equation

$$
\tan \theta=\frac{\theta}{\frac{Y}{2}-\omega\left[1-\frac{T}{X}\left(\frac{\theta^{2}}{Y^{2}}+\frac{1}{4}\right)\right]}
$$

and where $P_{n}$ and $Q_{n}$ are given by

$$
\begin{aligned}
P_{n}=\frac{1}{2} & \omega \mu_{n}\left(1-\frac{T k_{n}}{X}\right) \\
& \times\left[1+e^{-Y / 2}\left(\mu_{n} \sin \theta_{n}-\cos \theta_{n}\right)+Y \mu_{n} k_{n} e^{-Y / 2} \cos \theta_{n}\right] \\
Q_{n} & =Y\left(\frac{\theta_{n}}{\sin \theta_{n}}-\cos \theta_{n}\right)+\frac{\omega T}{X} \mu_{n} \sin \theta_{n}
\end{aligned}
$$

If $c_{B}$ denotes the concentration at the bottom of the column $(z=0)$ and $c_{T}$ that at the top of the column $(z=L)$, then from Eq. 27 it follows that 
$S_{B} \equiv \frac{c_{B}}{c_{0}}=\frac{1+\omega}{1+\frac{\omega}{Y}\left(e^{Y}-1\right)}$

$$
\begin{array}{r}
-\sum_{n=1}^{\infty} \frac{P_{n}}{Q_{n} k_{n}^{2}}\left(\mu_{n}^{\prime} \cos \theta_{n}-\sin \theta_{n}\right) e^{-k_{n} t / X} \\
S_{T} \equiv \frac{c_{T}}{c_{0}}=\frac{(1+\omega) e^{Y}}{1+\frac{\omega}{Y}\left(e^{Y}-1\right)}-e^{Y / 2} \sum_{n=1}^{\infty} \frac{P_{n} \mu_{n}}{Q_{n} k_{n}^{2}} e^{-k_{n} t / X}
\end{array}
$$

From Eq. 27 it is also found that, for $z=0$,

$$
\tau=2 H c_{0} \sum_{n=1}^{\infty} \frac{P_{n}}{Q_{n} k_{n}} \sin \theta_{n} e^{-k_{n} t / x}
$$

Now, if $c_{R}$ denotes the concentration in the reservoir and $U$ is the rate of circulation in the connecting tubes, then (if the circulation time is neglected) from Eq. 3 the result is

$$
c_{R}=c_{B}+\frac{\tau}{U}
$$

Using Eqs. 32 and 34

$$
\frac{c_{R}-c_{B}}{c_{0}}=\frac{2 \omega T}{X Y} \sum_{n=1}^{\infty} \frac{P_{n}}{k_{n} Q_{n}} \sin \theta_{n} e^{-k_{n} t / X}
$$

By way of illustration, Fig. 11.2 shows graphs of $\mathrm{S}_{\mathrm{T}}, \mathrm{s}_{\mathrm{B}}$, and $\mathrm{S}_{\mathrm{R}}=$ $c_{R} / c_{0}$ as functions of $t / X$ for the case $Y=0.35$ and $\omega=0.6$, with $T / X=0$ and 0.2 . It can be seen that, for a sufficiently large value of $T / X$, the behavior of the concentration can differ markedly from that where $T / X$ is negligible.

\section{CIRCULATION TO STORAGE CHAMBER}

In this section the case considered is that of a column attached at the bottom to a very large reservoir, causing the concentration at that point to remain constant. At the top the column is attached to a storage chamber by means of a circulating system, as previously described. Let $\mathbf{M}_{\mathbf{S}}$ be the holdup mass of the storage chamber, and let $\mathrm{T}$ be the replacement time. The differential equation satisfied by the concentration, $c$, is the same as in Sec. 2, i.e., Eq. 17; however, the boundary conditions are different. Now 


\section{LIQUID THERMAL DIFFUSION}

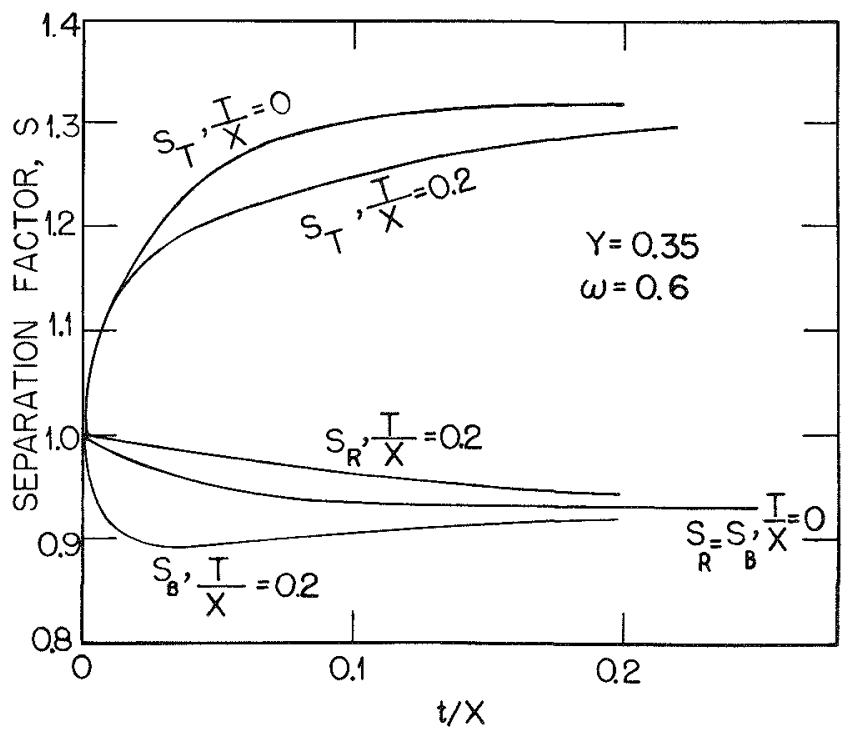

Fig. 11.2-Comparison of the effect of fast circulation $(\mathrm{T} / \mathrm{X}=0)$ with that of slow circulation $(T / X=0.2)$. The result of poor circulation is to slow down the approach to equilibrium. This is for the case of a rectifier with an infinite reservoir at the bottom and closed at the top.

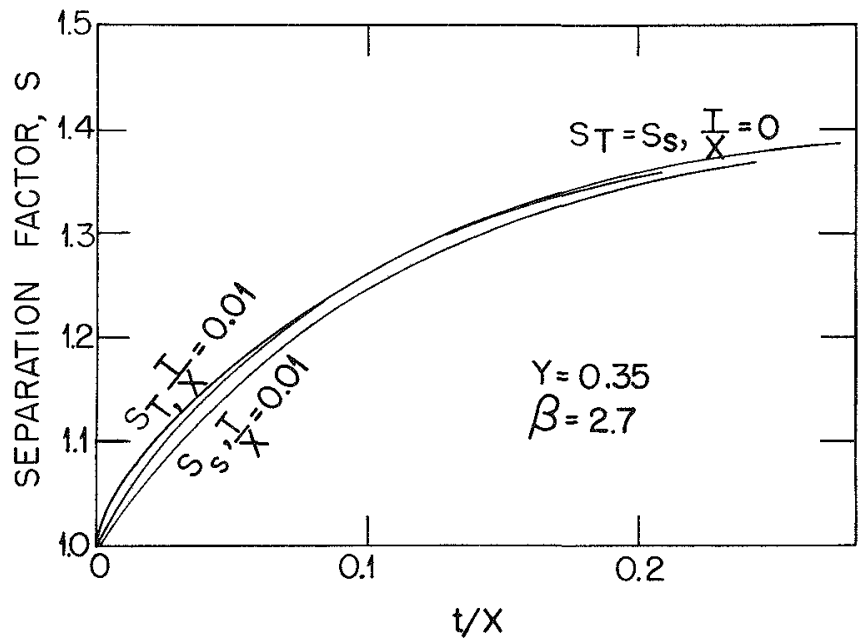

Fig. 11.3-Comparison of the effect of fast circulation $(\mathrm{T} / \mathrm{X}=0$ ) with that of slow circulation ( $T / X=0.01$ ) on approach to equilibrium. This is for the case of a rectifier with an infinite reservoir and a finite storage chamber at the top, connected by a recirculating system, $T$ being the replacement time. 


$$
\begin{aligned}
& z=0 \quad c=c_{0} \\
& z=L \quad M_{S} \frac{\partial c}{\partial t}=H c-K \frac{\partial c}{\partial z}+T \frac{\partial}{\partial t}\left(H c-K \frac{\partial c}{\partial z}\right)
\end{aligned}
$$

The initial conditions are given by

$$
\begin{aligned}
& \mathrm{t}=0 \quad \mathrm{c}=\mathrm{c}_{0} \quad(0 \leq \mathrm{z} \leq \mathrm{L}) \\
& \tau=0 \quad(\mathbf{z}=\mathbf{L})
\end{aligned}
$$

The solution in this case can be obtained again by the use of the Laplace transformation and is found to be

$\frac{c}{c_{0}}=e^{\alpha z}-\exp \left[\frac{\alpha}{2}(z-L)\right] \sum_{n=1}^{\infty} \frac{\mu_{n}\left[1-\left(T k_{n} / X\right)\right] \sin \frac{\theta_{n} z}{L} e^{-k_{n} t / X}}{R_{n} k_{n}}$

where

$$
\begin{aligned}
R_{\mathrm{n}}=\left(\frac{\mathrm{Y}}{\beta}-\frac{\mathrm{T}}{2 \mathrm{X}}\right) \mu_{\mathrm{n}} \sin \theta_{\mathrm{n}}+\left(1-\frac{\mathrm{T} k_{\mathrm{n}}}{\mathrm{X}}\right) \frac{\theta_{\mathrm{n}}}{\sin \theta_{\mathrm{n}}} \\
-\left[1-\frac{\mathrm{T}}{\mathrm{X}}\left(\mathrm{k}_{\mathrm{n}}+\frac{1}{2} \mu_{\mathrm{n}}^{2}\right)\right] \cos \theta_{\mathrm{n}}
\end{aligned}
$$

with

$$
\beta=\frac{\mathrm{M}}{\mathrm{M}_{\mathrm{s}}}
$$

and $\theta_{\mathrm{n}}$ the $\mathrm{n}$ th root of the equation

$$
\tan \theta=\frac{\theta}{\frac{Y}{2}+\frac{Y^{2}}{\beta} \frac{k}{1-(T k / X)}}
$$

where

$$
\mathrm{k}=\frac{1}{4}\left(1+\mu^{2}\right)=\frac{\theta^{2}}{\mathrm{Y}^{2}}+\frac{1}{4}
$$

From Eq. 40 one gets

$$
\mathrm{S}_{\mathrm{T}}=\frac{\mathbf{c}_{\mathrm{T}}}{\mathbf{c}_{0}}=\mathrm{e}^{\mathrm{Y}}-\sum_{\mathrm{n}=1}^{\infty} \frac{\mu_{\mathrm{n}}}{\mathbf{k}_{\mathrm{n}} \mathrm{R}_{\mathrm{n}}}\left(1-\frac{T \mathrm{k}_{\mathrm{n}}}{\mathrm{X}}\right) \sin \theta_{\mathrm{n}} \mathrm{e}^{-\mathrm{k}_{\mathrm{n}} \mathrm{t} / \mathrm{X}}
$$


where $c_{T}$ is the concentration at the top of the column $(z=L)$.

If $\mathfrak{c}_{\mathbf{S}}$ denotes the concentration in the storage chamber, then

$$
\mathrm{c}_{\mathrm{S}}=\mathrm{c}_{\mathrm{T}}-\frac{\beta \mathrm{T}}{\mathrm{M}} \tau_{(\mathrm{z}=\mathrm{L})}
$$

It follows that

$\frac{c_{T}-c_{s}}{c_{0}}=\frac{\beta T}{2 X Y} \sum_{n=1}^{\infty} \frac{\mu_{n}}{k_{n} R_{n}}\left(1-\frac{T k_{n}}{X}\right)\left(\mu_{n} \cos \theta_{n}-\sin \theta_{n}\right) e^{-k_{n} t / X}$

As an example, Fig. 11.3 gives $\mathrm{S}_{\mathrm{T}}$ and $\mathrm{S}_{\mathrm{S}} \equiv \mathrm{c}_{\mathrm{S}} / \mathrm{c}_{0}$ for the case $\mathrm{Y}=$ $0.35, \beta=2.7$, and $\mathrm{T} / \mathrm{X}=0.01$; also, for comparison, $\mathrm{S}_{\mathrm{T}}=\mathrm{S}_{\mathrm{S}}$ for $\mathrm{T} / \mathrm{X}=0$. 


\section{Chapter 12}

\section{THE CONTINUOUS PYRAMID}

\section{EQUATIONS}

When a pyramid containing a large number of stages is considered, it is often possible to obtain a good approximation by assuming that the actual pyramid is replaced by a single column having a continuously varying cross section, the latter at any height being nearly proportional to the number of parallel columns in the pyramid at the corresponding stage. Such a continuous pyramid, or a pyramid with infinitesimal steps, has been discussed by Jones and Furry ${ }^{1}$ and by Cohen. ${ }^{2}$

First consider the case of steady flow. The process in a single column is described approximately by the equation

$$
\tau=\mathbf{P} c+H c(1-c)-K \frac{d c}{d z}
$$

where $\tau$ is the net upward rate of transport of the light constituent; $P$ is the rate of upward flow of the fluid, or rate of withdrawal; $c$ is the concentration of the light constituent; $z$ is the distance up the column measured from the bottom; and $\mathrm{H}$ and $\mathrm{K}$ are the "column constants." The column constants, $\mathrm{H}$ and $\mathrm{K}$, are proportional to the cross-sectional area of the column. Hence, if there are $n$ columns in parallel instead of a single column, the following can be written then for the equivalent column

$$
\mathrm{H}=\mathrm{nH}_{1} \quad \mathrm{~K}=\mathrm{nK}_{1}
$$

where $H_{1}$ and $K_{1}$ are the corresponding constants for a single column. It should be pointed out that Eq. 1 was originally derived for the case in which $\mathrm{H}$ and $\mathrm{K}$ are constant, whereas they will be considered here as functions of $\mathrm{z}$. If, however, $\mathrm{n}$ in Eq. 2 is a function of $\mathrm{z}$ that varies slowly enough, it is expected that the equation can still be used. 


\section{LIQUID THERMAL DIFFUSION}

In the case of steady flow, $\tau$ is constant and is given by

$$
\tau=\mathrm{PC}^{*}
$$

where $c^{*}$ is the value of $c$ at the top of the pyramid where the liquid is withdrawn. Now define

$$
\alpha=\frac{\mathrm{H}}{\mathrm{K}}=\frac{\mathrm{H}_{1}}{\mathrm{~K}_{1}}
$$

and

$$
\nu=\frac{\mathbf{P}}{\mathrm{H}}=\frac{\mathrm{p}}{\mathrm{nH}_{1}}
$$

Then Eq. 1 can be written

$$
\frac{\mathrm{dc}}{\mathrm{dz}}=\alpha \mathrm{c}(1-\mathrm{c})-\alpha \nu\left(\mathrm{c}^{*}-\mathrm{c}\right)
$$

\section{OPTIMUM PERFORMANCE}

The problem of the optimum design of a continuous pyramid can be formulated in various ways. One possibility is to require $\mathrm{n}$ as a function of $\mathrm{z}$ so that the pyramid will yield a fixed product rate, $\mathrm{P}$, of material of fixed concentration, $c^{*}$, when the input concentration is $c_{0}$, with the smallest possible number of columns.

If $\mathrm{L}_{1}$ is the length of a single column, then the number of columns in an element of length $d z$ will be $n d z / L_{1}$, and the total number of columns, $N$, in the pyramid, by Eqs. 4 to 6 , will be

$$
N=\frac{K_{1}}{L_{1}} \int_{c_{0}}^{c^{*}} \frac{n^{2} d c}{H_{1} n c(1-c)-p\left(c^{*}-c\right)}
$$

Now introduce a small arbitrary variation in $n, \delta n$. The corresponding variation $\delta \mathrm{N}$ of $\mathrm{N}$ is then

$$
\delta \mathrm{N}=\frac{K_{1}}{L_{1}} \int_{c_{0}}^{c^{*}} \frac{H_{1} n^{2} c(1-c)-2 n P\left(c^{*}-c\right)}{\left[H_{1} n c(1-c)-P\left(c^{*}-c\right)\right]^{2}} \delta n d c
$$

The necessary condition that $\mathrm{N}$ be a minimum is that $\delta \mathrm{N}$ vanish for arbitrary $\delta \mathrm{n}$. The latter will be the case if

$$
\mathrm{n}=\frac{2 \mathrm{P}\left(\mathrm{c}^{*}-\mathrm{c}\right)}{\mathrm{H}_{1} \mathrm{c}(1-\mathrm{c})}=\frac{2 \mathrm{P}}{\mathrm{H}_{1}}\left(\frac{\mathrm{c}^{*}}{\mathrm{c}}-\frac{1-\mathrm{c}^{*}}{1-\mathrm{c}}\right)
$$


or

$$
\nu=\frac{c(1-c)}{2\left(c^{*}-c\right)}
$$

It follows from Eq. 6 that in this case

$$
\frac{d c}{d z}=\frac{\alpha}{2} c(1-c)
$$

This integrates to give

$$
\mathrm{S}=\mathrm{e}^{\alpha z / 2}
$$

where

$$
S=\frac{c\left(1-c_{0}\right)}{c_{0}(1-c)}
$$

For the whole pyramid $c$ equals $c^{*}$, and

$$
\mathrm{S}^{*}=\mathrm{e}^{\alpha \mathrm{L} / 2}
$$

If Eqs. 12 and 13 are solved for $c$ and substituted into Eq. 9, $\mathrm{n}$ is obtained as a function of $\mathrm{z}$. This case will be considered below in greater detail.

It will be noticed that in the equilibrium case, in which $\sigma=0$, integration of Eq. 6 gives, corresponding to Eq. 12,

$$
\mathrm{S}_{\mathrm{e}}=\mathrm{e}^{\alpha \mathbf{z}}
$$

so that

$$
S=\sqrt{S_{e}}
$$

- for optimum performance. This relation holds for any part of the pyramid, as well as for the pyramid as a whole.

An alternative formulation of the optimum-design problem is to require $n$ as a function of $z$ so that the pyramid will contain a fixed number of columns, $\mathrm{N}$; will give a fixed product rate, $\mathrm{P}$; and, for a given input concentration, $c_{0}$, will have a maximum withdrawal concentration, $c^{*}$.

In this case the number of columns, $N$, as given by Eq. 7 is fixed, so that $\delta \mathrm{N}$ vanishes. If a small variation $\delta \mathrm{n}$ is carried out, a possible variation, $\delta c^{*}$ of $c^{*}$, must be taken into account since the latter is not 
fixed. Letting $n^{*}$ be the value of $n$ for $c=c^{*}$, the result is

$$
\begin{aligned}
\left\{\frac{n^{*}}{H_{1} c^{*}\left(1-c^{*}\right)}+\right. & \left.P \int_{c_{0}}^{c^{*}} \frac{n^{2} d c}{\left[H_{1} n c(1-c)-P\left(c^{*}-c\right)\right]^{2}}\right\} \delta c^{*} \\
& +\int_{c_{0}}^{c^{*}}\left\{\frac{2 n}{\frac{H_{1} n c(1-c)-P\left(c^{*}-c\right)}{\left[H_{1} n c(1-c)-P\left(c^{*}-c\right)\right]^{2}}}\right\} \delta n d c=0
\end{aligned}
$$

If, however, $c^{*}$ has its maximum value, then $\delta c^{*}$ vanishes for arbitrary $\delta \mathrm{n}$. This will occur only if the coefficient of $\delta \mathrm{n}$ vanishes, in which case Eq. 9 is obtained again.

The continuous pyramid for which Eq. 9 holds will be referred to as the "ideal pyramid."

\section{STRUCTURE OF THE PYRAMID}

From the equations in the preceding sections, the number of columns in parallel at any height $\mathrm{z}$ in the ideal pyramid can be found. If the complementary separation factor $\mathrm{S}^{\mathrm{c}}$ is defined by the equation

$$
\mathrm{S}^{\mathrm{c}}=\mathrm{S}^{*} / \mathrm{S}=\exp [(\alpha / 2)(\mathrm{L}-\mathrm{z})]
$$

then

$$
c=\frac{c^{*}}{c^{*}+S^{c}\left(1-c^{*}\right)}
$$

and, putting this into Eq. 9, the result is

$$
\begin{aligned}
& \mathrm{n}= \frac{2 \mathrm{P}}{\mathrm{H}_{1}}\left[\left(1-\mathrm{c}^{*}\right)\left(\mathrm{S}^{\mathrm{c}}-1\right)+\mathrm{c}^{*}\left(1-\frac{1}{\mathrm{~S}^{\mathrm{C}}}\right)\right] \\
&=\frac{2 \mathrm{P}}{\mathrm{H}_{1}}\left\{\left(1-\mathrm{c}^{*}\right) \exp [(\alpha / 2)(\mathrm{L}-\mathrm{z})]-\mathrm{c}^{*} \exp [-(\alpha / 2)(\mathrm{L}-\mathrm{z})]\right. \\
&\left.+2 \mathrm{c}^{*}-1\right\}
\end{aligned}
$$

Let $\mathrm{N}\left(\mathrm{z}_{1}, \mathrm{z}_{2}\right)$ be the number of columns in the pyramid in the height range between $z_{1}$ and $z_{2}\left(z_{2}>z_{1}\right)$. It is given by

$$
\mathrm{N}\left(\mathrm{z}_{1}, \mathrm{z}_{2}\right)=\frac{1}{\mathrm{~L}_{1}} \int_{\mathrm{z}_{1}}^{\mathrm{z}_{2}} \mathrm{ndz}
$$


and, using Eqs. 9 and 11

$$
\begin{aligned}
& N\left(z_{1}, z_{2}\right)=\frac{4 P}{\alpha L_{1} H_{1}} \int_{c_{2}}^{c_{2}} \frac{c^{*}-c}{c^{2}(1-c)^{2}} d c=\frac{4 P}{\alpha L_{1} H_{1}}\left[\left(2 c^{*}-1\right) \ln \frac{S_{2}}{S_{1}}\right. \\
& \left.+\left(1-c^{*}\right) S^{*}\left(\frac{1}{S_{1}}-\frac{1}{S_{2}}\right)-\frac{c^{*}}{S^{*}}\left(S_{2}-S_{1}\right)\right]
\end{aligned}
$$

where $c_{1}=c_{z_{1}}, c_{2}=c_{z_{2}}, s_{1}=s_{z_{1}}, s_{2}=S_{z_{2}}$. From $E q .23$, or by direct integration of $\mathrm{Eq}$. 21, the result is

$$
\begin{aligned}
& \mathrm{N}\left(\mathrm{z}_{1}, \mathrm{z}_{2}\right)=\frac{4 \mathrm{P}}{\alpha \mathrm{L}_{1} \mathrm{H}_{1}}\left[\left(\mathrm{c}^{*}-\frac{1}{2}\right) \alpha\left(\mathrm{z}_{2}-\mathrm{z}_{1}\right)\right. \\
& \left.\quad+\left(1-\mathrm{c}^{*}\right) \mathrm{e}^{\alpha \mathrm{L} / 2}\left(\mathrm{e}^{-\alpha z_{1} / 2}-\mathrm{e}^{-\alpha \mathrm{z}_{2} / 2}\right)-\mathrm{c}^{*} \mathrm{e}^{-\alpha \mathrm{L} / 2}\left(\mathrm{e}^{\alpha \mathrm{z}_{2} / 2}-\mathrm{e}^{\alpha \mathrm{z}_{1} / 2}\right)\right]
\end{aligned}
$$

By means of the relation between $S^{*}$ and $c^{*}$, corresponding to Eq. 13, $\mathrm{Eq} .23$ can be converted into

$$
\begin{aligned}
N\left(z_{1}, z_{2}\right)=\frac{4 P}{\alpha L_{1} H_{1}} & \left\{c^{*}\left[\frac{1-c_{1}}{c_{1}}+\ln \frac{1-c_{1}}{c_{1}}-\left(\frac{1-c_{2}}{c_{2}}+\ln \frac{1-c_{2}}{c_{2}}\right)\right]\right. \\
& \left.+\left(1-c^{*}\right)\left[\frac{c_{1}}{1-c_{1}}+\ln \frac{c_{1}}{1-c_{1}}-\left(\frac{c_{2}}{1-c_{2}}+\ln \frac{c_{2}}{1-c_{2}}\right)\right]\right\}
\end{aligned}
$$

Now assume that the actual pyramid consists of $m$ stages, so that its height $\mathrm{L}$ is given by

$$
\mathbb{L}=\mathrm{mL}_{1}
$$

Let $c_{k}$ and $S_{k}$ be the values of $c$ and $S$, respectively, at the top of the $k$ th stage, where $\mathrm{k}=1$ for the bottom stage and $\mathrm{k}=\mathrm{m}$ for the top stage of the pyramid. Then, from Eqs. 12 and 13, it is found that

$$
\begin{aligned}
& S_{k}=e^{\alpha k L_{1} / 2} \\
& c_{k}=\frac{c_{0} S_{k}}{1+c_{0}\left(S_{k}-1\right)} \\
& c^{*}=c_{m}=\frac{c_{0} e^{\alpha L / 2}}{1+c_{0}\left(e^{\alpha L / 2}-1\right)}
\end{aligned}
$$

To get the total number of columns in the pyramid, $N=N(0, L)$, some of the formulas given above are used. It is found that 


$$
\begin{aligned}
N & =\frac{4 P}{\alpha L_{1} H_{1}}\left[c^{*}\left(\frac{1}{S^{*}}+\ln S^{*}-1\right)+\left(1-c^{*}\right)\left(S^{*}-\ln S^{*}-1\right)\right] \\
& =\frac{4 P}{\alpha L_{1} H_{1}}\left[\left(2 c^{*}-1\right) \ln S^{*}+\frac{\left(c^{*}-c_{0}\right)\left(1-2 c_{0}\right)}{c_{0}\left(1-c_{0}\right)}\right] \\
& =\frac{2 m P}{H_{1}} \frac{c_{0}\left(S^{*}+1\right)+\left(1-2 c_{0}\right)\left(S^{*}-1\right) / \ln S^{*}}{1+c_{0}\left(S^{*}-1\right)}
\end{aligned}
$$

There are several different ways to get the number of columns, $\mathrm{N}_{\mathrm{k}}$, in the $\mathrm{k}$ th stage. One possibility is to use the value of $\mathrm{n}$, as given by $\mathrm{Eq}$. 9 , for some suitable value of $z$, e.g., $z=(k-1 / 2) L_{1}$, corresponding to a point halfway up the $\mathrm{k}$ th stage. Another possibility is to get $\mathrm{n}$ from Eq. 9 with $c=c_{k}$ and $c=c_{k-1}$ and then to take the mean of the two values of $n$. The best procedure, however, is to take $N_{k}=N\left[(k-1) L_{1}, k L_{1}\right]$, which is found to be given by

$$
\begin{aligned}
N_{k}=\frac{2 P}{H_{1}}\left\{c^{*}\right. & {\left[1+\frac{2\left(1-c_{k}\right)}{c_{k} \alpha L_{1}}\left(e^{\alpha L_{1} / 2}-1\right)\right] } \\
& \left.-\left(1-c^{*}\right)\left[1+\frac{2 c_{k}}{\left(1-c_{k}\right) \alpha L_{1}}\left(1-e^{-\alpha L_{1} / 2}\right)\right]\right\} \\
N_{k}=\frac{2 P}{H_{1}}\left[c^{*}\right. & \left\{1-\frac{2}{\alpha L_{1}}\left(1-e^{-\alpha L_{1} / 2}\right) \exp \left[-1 / 2 \alpha L_{1}(m-k)\right]\right\} \\
& \left.+\left(1-c^{*}\right)\left\{\frac{2}{\alpha L_{1}}\left(e^{\alpha L_{1} / 2}-1\right) \exp \left[1 / 2 \alpha L_{1}(m-k)\right]-1\right\}\right]
\end{aligned}
$$

With $\mathrm{N}_{\mathrm{k}}$ given by Eq. 33 or Eq. 34 , it is obvious that

$$
\mathrm{N}=\sum_{\mathrm{k}=1}^{\mathrm{m}} \mathrm{N}_{\mathrm{k}}
$$

From Eq. 34 it follows that, in the top stage of the pyramid, the number of columns is given by

$$
\begin{aligned}
\mathrm{N}_{\mathrm{m}}=\frac{2 \mathrm{P}}{\mathrm{H}_{1}}\left\{\mathrm{c}^{*}\left[1-\frac{2}{\alpha \mathrm{L}_{1}}\left(1-\mathrm{e}^{-\alpha \mathrm{L}_{1} / 2}\right)\right]\right. \\
\left.\quad+\left(1-\mathrm{c}^{*}\right) \frac{2}{\alpha \mathrm{L}_{1}}\left[\left(\mathrm{e}^{\alpha \mathrm{L}_{1}}-1\right)-1\right]\right\}
\end{aligned}
$$

For values of $\alpha \mathrm{L}_{1}$ small compared with unity, this becomes 


$$
\mathrm{N}_{\mathrm{m}}=\frac{\mathrm{P}}{2 \mathrm{H}_{1}}\left[\alpha \mathrm{L}_{1}+\frac{1}{6} \alpha^{2} \mathrm{~L}_{1}^{2}\left(1-2 \mathrm{c}^{*}\right)\right]
$$

\section{TIME REQUIRED TO PUT PYRAMID INTO OPERATION}

To determine the time required to put the pyramid into operation, adopt the method used by Jones and Furry ${ }^{1}$ and by Cohen. ${ }^{2}$ Let $U$ be the holdup of the light constituent in the pyramid in the steady state of flow, and let $U_{I}$ be the initial holdup. Then the time required is taken as

$$
T=\frac{U-U_{I}}{P\left(c^{*}-c_{0}\right)}
$$

that is, the time for the column to reproduce the increase of its holdup from its initial value. To evaluate this quantity, note that, if $M_{1}$ is the mass of material (total holdup) in one column, then, provided that interstage holdup can be neglected,

$$
\begin{aligned}
\mathrm{U} & =\frac{\mathrm{M}_{1}}{\mathrm{~L}_{1}} \int_{0}^{\mathrm{L}} \mathrm{nc} d \mathrm{z} \\
& =\frac{4 \mathrm{PM}_{1}}{\alpha \mathrm{L}_{1} \mathrm{H}_{1}} \int_{\mathrm{c}_{0}}^{\mathrm{c} *} \frac{\mathrm{c}^{*}-\mathrm{c}}{\mathrm{c}(1-\mathrm{c})^{2}} \mathrm{dc}
\end{aligned}
$$

Carrying out the integration

$$
\mathrm{U}=\frac{4 \mathrm{PM}_{1}}{\alpha \mathrm{L}_{1} \mathrm{H}_{1}}\left(\mathrm{c}^{*} \ln \mathrm{S}^{*}-\frac{\mathrm{c}^{*}-\mathrm{c}_{0}}{1-\mathrm{c}_{\mathrm{o}}}\right)
$$

On the other hand

$$
\mathrm{U}_{\mathrm{I}}=\mathrm{NM}_{1} \mathrm{c}_{0}
$$

whence, by Eq. 31 , it is found that

$$
U-U_{I}=\frac{4 P M_{1}}{\alpha L_{1} H_{1}}\left[\left(c^{*}-2 c_{0} c^{*}+c_{0}\right) \ln S^{*}-2\left(c^{*}-c_{0}\right)\right]
$$

If this is substituted into Eq. 38

$$
T=\frac{4 M_{1}}{\alpha L_{1} H_{1}}\left(\frac{c^{*}-2 c_{0} c^{*}+c_{0}}{c^{*}-c_{0}} \ln S^{*}-2\right)
$$




\section{LIQUID THERMAL DIFFUSION}

If the time constant for a single column, $\mathrm{X}$, is defined by

$$
\mathrm{X}=\frac{\mathrm{M}_{1}}{\alpha \mathrm{L}_{1} \mathrm{H}_{1}}=\frac{\mathrm{M}_{1} \mathrm{~K}_{1}}{\mathrm{H}_{1}^{2} \mathrm{~L}_{1}}
$$

then the final result ${ }^{1}$ is

$$
T=4 X\left(\frac{c^{*}-2 c_{0} c^{*}+c_{0}}{c^{*}-c_{0}} \ln S^{*}-2\right)
$$

\section{REFERENCES}

1. R. C. Jones and W. H. Furry, unpublished work.

2. K. Cohen, Report A-530, Feb. 4, 1943. 
Chapter 13

\section{PERFORMANCE CRITERIA}

\section{COLUMN CONSTANTS}

It is desirable to have some convention for assigning numbers to columns in order to provide a means for comparing two different columns, as well as the performance of the same column under different conditions.

It will be recalled that, from the theoretical standpoint, the quantities first encountered in connection with a single column are the constants $\mathrm{H}$ and $\mathrm{K}$ which enter into the differential equation for equilibrium separation. $H$ is a measure of the rate of the separating process, and $K$ is that of the remixing process. Setting

$$
\alpha=\frac{\mathrm{H}}{\mathrm{K}} \quad \mathrm{Y}=\alpha \mathrm{L}
$$

where $L$ is the length of the column, the equilibrium separation factor is

$$
\mathrm{S}_{\mathrm{e}}=\mathrm{e}^{\mathrm{Y}}
$$

In the differential equation describing the approach to equilibrium, there occurs the quantity $X$, the "time constant" of the column, given by

$$
\mathrm{X}=\frac{\mathrm{ab} \rho \mathrm{K}}{\mathrm{H}^{2}}
$$

where $a$ is the spacing, $b$ is the mean wall circumference, and $\rho$ is the mean fluid density. Since, for a column having negligible dead space, the total material holdup, $M$, is given by

$$
\mathbf{M}=\rho \mathrm{abL}
$$

it is possible to write 


$$
\mathrm{X}=\frac{\mathrm{MK}}{\mathrm{H}^{2} \mathrm{~L}}=\frac{\mathrm{M}}{\mathrm{HY}}
$$

From the experimentally determined values of $S_{e}$ and $X$, for a column of given $\mathrm{L}$ and $\mathrm{M}, \mathrm{H}$ and $\mathrm{K}$ can be calculated from the preceding equations

$$
H=\frac{M}{X \ln S_{e}} \quad K=\frac{M L}{X\left(\ln S_{e}\right)^{2}}
$$

\section{PERFORMANCE CRITERION (Q)}

Chapter 12 shows that, for a large pyramid which can be treated as consisting of infinitesimal steps (continuous pyramid) and which is designed for optimum performance (ideal pyramid), the number of columns required is given by

$$
N=\frac{4 P}{H Y}\left[\left(1-c^{*}\right)\left(S^{*}-1-\ln S^{*}\right)+c^{*}\left(\frac{1}{S^{*}}-1+\ln S^{*}\right)\right]
$$

where $H$ and $Y$ refer to a single column, all the columns in the pyramid being supposed identical. $P$ is the product rate of the pyramid, $c^{*}$ is the output concentration of the light constituent, and $S^{*}$ is the separation factor developed by the pyramid.

On the basis of Eq. 7 it appears reasonable to take as the "figure of merit" of a column

$$
\Phi=H Y=\frac{H^{2} L}{K}
$$

since the number of columns required in a pyramid operating at a given product rate between given concentrations is inversely proportional to $\Phi$. The figure of merit permits a quantitative comparison of two given columns. It will be noted that, by Eq. 5

$$
\Phi=\frac{M}{\mathrm{X}}
$$

Suppose it is desired to maintain a column in operation at a given separation factor. First, define the productivity of the column, p, by

$$
\mathrm{p}=\frac{\mathrm{P}}{\Phi}=\frac{\mathrm{P}}{\mathrm{HY}}=\frac{\nu}{\mathrm{Y}}
$$


where $\mathbf{P}$ is the product rate of the column and

$$
\nu=\frac{\mathrm{P}}{\mathrm{H}}
$$

For columns with the same cross section, operating under the same conditions, the cost of fuel per unit time is nearly proportional to $\mathrm{L}$. Hence, $p$ varies almost inversely as the operational cost per unit mass of enriched material. If, now, for fixed concentrations at the top and bottom, $\mathrm{P}$ (or $\nu$ ) is varied and at the same time $\mathrm{L}$ (or $\mathrm{Y}$ ) is varied (to keep the concentrations fixed), there will be a certain value of $P$ for which $\mathrm{p}$ will be a maximum. This has been taken by some authors (Jones and Furry; ${ }^{1}$ Cohen $^{2}$ ) as the condition for optimum performance, namely, that $\mathrm{p}$ be a maximum.

It is possible to go farther in this direction. Again suppose that $\nu$ is varied and at the same time $Y$ is varied to keep the concentration at the top of the column fixed, with a given concentration at the bottom. Let $\mathrm{p}_{\mathrm{m}}$ denote the maximum value of $\mathrm{p}$, and let $\nu_{0}$ denote the value of $\nu$ for which it occurs. For any other value of $\nu$ the productivity quotient is

$$
\mathrm{Q}=\frac{\mathrm{p}}{\mathrm{p}_{\mathrm{m}}}
$$

This is a measure of how well the column has been chosen (as regards $\mathrm{Y}$ or $\mathrm{S}_{\mathrm{e}}$ ) for the particular task involved. Optimum performance, as defined above, means operating at a $Q$ of 100 per cent.

Suppose a single column (or one at the top of a pyramid) is being considered. If the relation among $\nu, \mathrm{Y}, \mathrm{S}$, and $\mathrm{c}_{\mathrm{T}}$, the concentration at the top of the column $\left(=\mathrm{c}^{*}\right)$ is written and the preceding condition for optimum performance is imposed, it is found that, for a fixed value of $\mathrm{c}_{\mathrm{T}}$, the quantities $\nu\left(=\nu_{0}\right)$ and $\mathrm{S}\left(=\mathrm{S}_{0}\right)$ are determined for each value of $\mathrm{Y}$. Thus $\mathrm{p}_{m}$ can be obtained as a function of any one of the variables $\nu, \mathbf{S}$, and $Y$. For example, Fig. 13.1 gives $p_{m}$ as a function of $S$, if $c_{T}$ is much smaller than 1.

Now suppose that there is a particular column with a given value of $Y$ and that it is operated at various values of $\nu$. For each value of $\nu$ the corresponding value of $\mathrm{S}$ can be determined. For example, under the conditions being considered, and with $c_{T} \ll 1$

$$
S=\frac{\nu+1}{\nu+\exp [-\mathrm{Y}(\nu+1)]}
$$

To get $Q$ as a function of $\nu$ for this case, $p$ is found by means of Eq. 10, $\mathrm{p}_{\mathrm{m}}$ is obtained from Fig. 13.1, using the value of $\mathrm{S}$ given by $\mathrm{Eq} .13$, and 


\section{LIQUID THERMAL DIFFUSION}

substitution is made into Eq. 12. In this way the actual productivity is compared with the maximum productivity that might occur by a suitable choice of $\nu$ and $\mathrm{y}$ but with the same $\mathrm{S}$.

As an example, Fig. 13.2 gives $Q$ as a function of $\nu_{0} / \nu$ for the case $\mathrm{Y}=0.6, \mathrm{c}_{\mathrm{T}}=\mathrm{c}^{*} \ll 1, \nu_{0}=1.77$. This independent variable has been

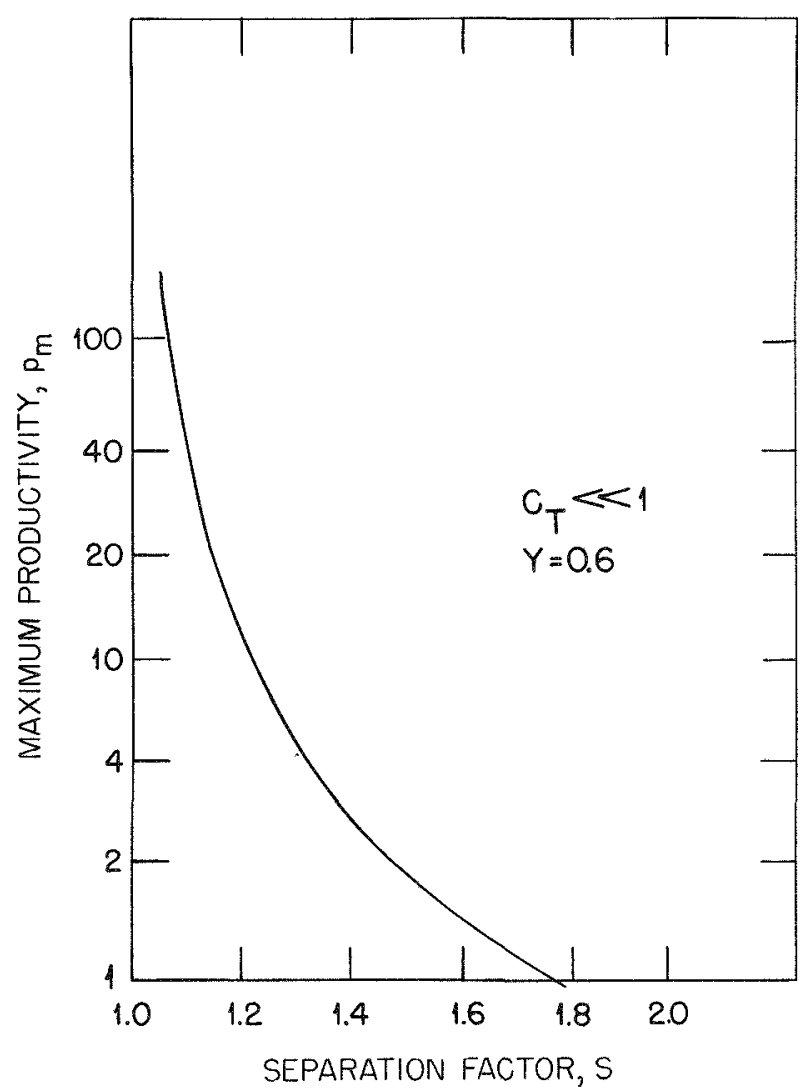

Fig. 13.1-Maximum productivity of a column as a function of the separation factor for the case of low concentration of the desired isotope.

chosen because, for the case in which a certain product rate is to be maintained and the re are $n$ columns in parallel,

$$
\frac{\mathrm{n}}{\mathrm{n}_{\mathrm{o}}}=\frac{\nu_{\mathrm{o}}}{\nu}
$$

where $\mathrm{n}$ is the number of columns and each has the value $\nu$, whereas $n_{0}$ is the number corresponding to $\nu_{0}$. The graph shows that the curve is 


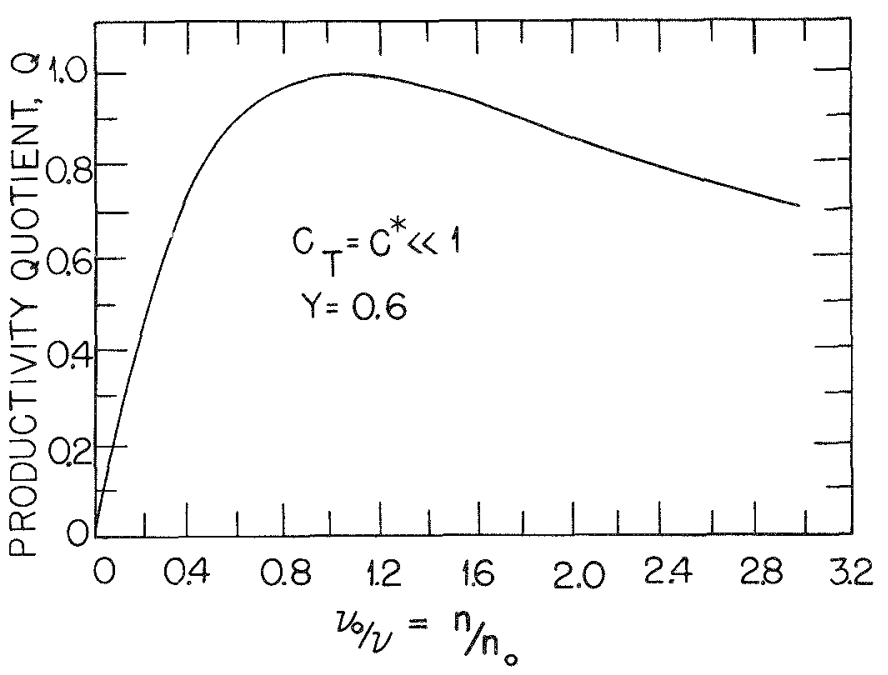

Fig. 13.2-Productivity quotient as a function of the product rate for the case of a single column operating at low concentration of the desired isotope.

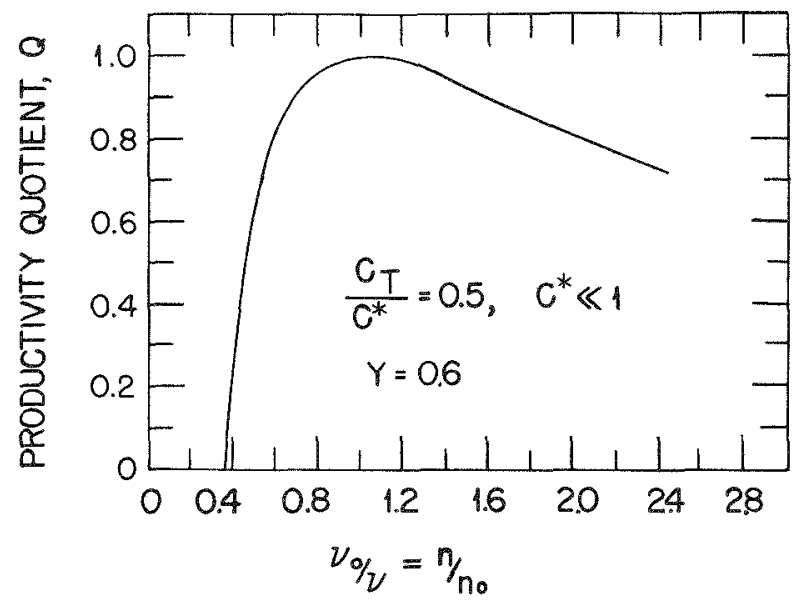

Fig. 13.3-Productivity quotient as a function of product rate for the case of a column in a pyramid at the point where $c_{T}$ (concentration at the top of this column) equals $0.5 c^{*}$ (concentration at the top of the pyramid) for the case of low concentration of the desired isotope.

flat near the maximum, so that the number of columns can be decreased by 40 per cent or increased by 80 per cent as compared with the optimum value without bringing down the productivity quotient below 90 per 
cent. Doubling the optimum number results in a $Q$ of over 87 per cent, whereas halving the number gives nearly 84 per cent. It is obvious then that the re is considerable latitude in the number that can be chosen without sacrificing $Q$ excessively.

By the same general procedure $Q$ can be determined for other cases. Figure 13.3 refers to the case of a column that is in a pyramid, far enough below the top so that $c_{T}=0.5 c^{*}$, and for which all the concentrations are small compared with unity. In the last case it will be noted that, if $\nu$ is increased to a certain critical value, separation ceases and $Q$ drops to zero, an effect which could have been predicted from the equation for a single column.

The preceding and other examples lead to the conclusion that the choice of the number of columns in each stage of a pyramid is not very critical. Moreover, it appears that it is generally safer to have an excess of a given number of columns rather than a deficit of the same number.

\section{PERFORMANCE CRITERION (E)}

Although the productivity quotient $Q$, introduced in the previous section, has considerable usefulness, it suffers from the drawback that its calculations may be somewhat lengthy, particularly as regards the determination of $\mathrm{p}_{\mathrm{m}}$. Moreover, it fails to provide any means of compar ing directly the performance of a column at two different separation factors.

To be sure, any evaluation of performance involving a comparison at two different separation factors is arbitrary to some extent and depends on the purpose for which the product is intended. There is one standpoint from which this question can be treated, however, which recommends itself because of its plausibility, self-consistency, and mathematical simplicity, and that is the one based on a comparison with the ideal pyramid. If Eq. 7 is referred to for the ideal pyramid, it is seen that the quantity

$$
\Psi=4 \mathrm{P}\left[\left(1-\mathrm{c}^{*}\right)\left(\mathrm{S}^{*}-1-\ln \mathrm{S}^{*}\right)+\mathrm{c}^{*}\left(\frac{1}{\mathrm{~S}^{*}}-1+\ln \mathrm{S}^{*}\right)\right]
$$

is proportional to the number of columns, $\mathrm{N}$, being used and is thus a measure of what is being accomplished by the pyramid. $\Psi$ is defined as the enrichment rate. It is also natural to use this quantity as a measure of what is being accomplished by a single column or group of columns. Other factors being equal, it is desirable to operate the column or group of columns so that the enrichment rate is as high as possible. It turns out in practice that the condition for maximum $Q$, as discussed previously, is nearly the same as that for maximum $\Psi$. 
The figure of merit of a single column has already been defined by Eq. 8. Now extend the definition to $\mathrm{N}$ columns by the relation

$$
\Phi=\mathrm{NHY}
$$

The fact that the $\Phi$ 's of individual columns combine additively, independently of the method of connecting them, as implied by Eq. 16, can be made plausible from a consideration of two identical columns. If they are connected in series, $H$ is unchanged and $Y$ is doubled; if in parallel, $Y$ is unchanged while $H$ is doubled, so that in either case $\Phi$ is doubled.

Now define the separative efficiency of a column or system of columns by

$$
\mathbf{E}=\frac{\Psi}{\Phi}
$$

where $\Psi$ is calculated by Eq. 15, with $\mathrm{c}^{*}$ and $\mathrm{S}^{*}$ referring to the top of the column or group, and $\Phi$ is calculated by Eq. 16, using for $\mathrm{N}$ the number of columns under consideration. From Eq. 7 it is seen that $\mathbf{E}=1$ for the ideal pyramid. For any single column or finite pyramid, $E<1$, and the value of $E$ gives a comparison of the performance with that of the ideal pyramid. It is reasonable to use Eq. 17 as a measure of how effectively a column, or pyramid, is being used.

Up to this point only a single column or a whole group, or a pyramid has been considered. From the theory of the ideal pyramid, a generalization of Eq. 15 is obtained which can be applied to columns forming a part of a pyramid. One gets as a more general definition of the enrichment rate, in place of Eq. 15,

$\Psi=4 P\left\{\left(1-c^{*}\right)\left[S^{*}\left(\frac{1}{S_{1}}-\frac{1}{S_{2}}\right)+\ln \frac{S_{1}}{S_{2}}\right]+c^{*}\left[\frac{1}{S^{*}}\left(S_{1}-S_{2}\right)+\ln \frac{S_{2}}{S_{1}}\right]\right\}$

where $S_{1}$ and $S_{2}$ are the separation factors between the bottom of the pyramid and the bottom and top of the group of columns, respectively.

In the case of low concentrations $\left(c^{*} \ll 1\right)$, letting $S=S_{2} / S_{1}, E q .18$ becomes

$$
\Psi=4 P\left[\frac{c^{*}}{c_{T}}(S-1)-\ln S\right]
$$

whereas, for a single column or the top column of a pyramid $\left(c_{T}=c^{*}\right)$, Eq. 15 gives

$$
\Psi=4 P(S-1-\ln S)
$$


For $\mathrm{S}$ near unity, Eq. 20 can be approximated by

$$
\Psi=2 P(\ln S)^{2}
$$

In the case of low concentrations, it can be shown that, as $Y$ tends toward zero, the separative efficiency of a column approaches 0.814 if the column is operating singly or at the top of a pyramid, whereas it approaches unity if it is far down in the pyramid.

It is sometimes convenient to split up the enrichment rate into two factors

$$
\Psi=\mathrm{PR}
$$

where $P$ is the product rate and $R$ is the enrichment factor (to be distinguished from the separation factor $\mathrm{S}$ ):

$R=4\left\{\left(1-c^{*}\right)\left[S^{*}\left(\frac{1}{S_{1}}-\frac{1}{S_{2}}\right)-\ln S\right]+c^{*}\left[\frac{1}{S^{*}}\left(S_{1}-S_{2}\right)+\ln S\right]\right\}$

It follows that Eq. 17 can be written

$$
\mathrm{E}=\frac{\nu_{\mathrm{a}} \mathrm{R}}{\mathrm{Y}}
$$

where $\nu_{\mathrm{a}}$ is defined by

$$
\nu_{\mathrm{a}}=\frac{\mathrm{P}}{\mathrm{NH}}
$$

It might be well to remark that it is often convenient to define, along with the separative efficiency defined above, the power efficiency $E$ by the relation

$$
\mathbf{E}=\frac{\Psi}{\pi}
$$

where $\pi$ is the power supplied to the column or pyramid that is producing the enrichment rate $\Psi$.

\section{RELATION BETWEEN CRITERIA}

In Sec. 2 what might be referred to as the "Q criterion" was discussed; and, in Sec. 3, the E criterion was discussed. It is of interest to investigate the relation between them. If there is a column forming part of a 
pyramid with a fixed output concentration, then by Eqs. 11 and 23 to 25 it follows that

$$
\mathrm{E}=\frac{\nu}{\mathrm{Y}} \mathrm{R}(\mathrm{S})
$$

Now $\mathrm{S}, \nu$, and $\mathrm{Y}$ are connected by a relation that can be written in the general form

$$
\mathbf{F}(\mathbf{S}, \nu, \mathbf{Y})=\mathbf{0}
$$

and by means of which any one of these can be expressed in terms of the other two.

The $Q$ criterion for optimum performance is given by

$$
\left(\frac{\partial \mathrm{p}}{\partial \nu}\right)_{\mathrm{S}}=0
$$

However, by Eq. 10, this is equivalent to

$$
\left(\frac{\partial E}{\partial \nu}\right)_{S}=0
$$

On the other hand, the E criterion for optimum performance of a given column (with a given value of $\mathrm{Y}$ ) is obviously

$$
\left(\frac{\partial \mathrm{E}}{\partial \nu}\right)_{\mathrm{Y}}=0
$$

Taking account of the relation shown in Eq. 28, it is seen that, in general, the conditions in Eqs. 30 and 31 are not the same. It turns out, however, that the consequences of these conditions are practically equivalent in the cases of interest. For example, in Fig. 13.4 there is

- a comparison of the curves of $Q$ and $E$ as functions of $\nu$ for the case $\mathrm{Y}=0.6, \mathrm{c}_{\mathrm{T}}=\mathrm{c}^{*} \ll 1$. The ordinates of the two curves are nearly proportional, and the maximums are nearly coincident.

In practice, it is found that for a given set of conditions it is generally simpler to calculate $E$ rather than $Q$. On the other hand, in determining the conditions for optimum performance, the $Q$ criterion usually leads to simpler calculations than the $\mathbf{E}$ criterion.

\section{ENRICHMENT RATE AND RELATED FUNCTIONS}

Equation 18, after some manipulation, can be rewritten in the form 


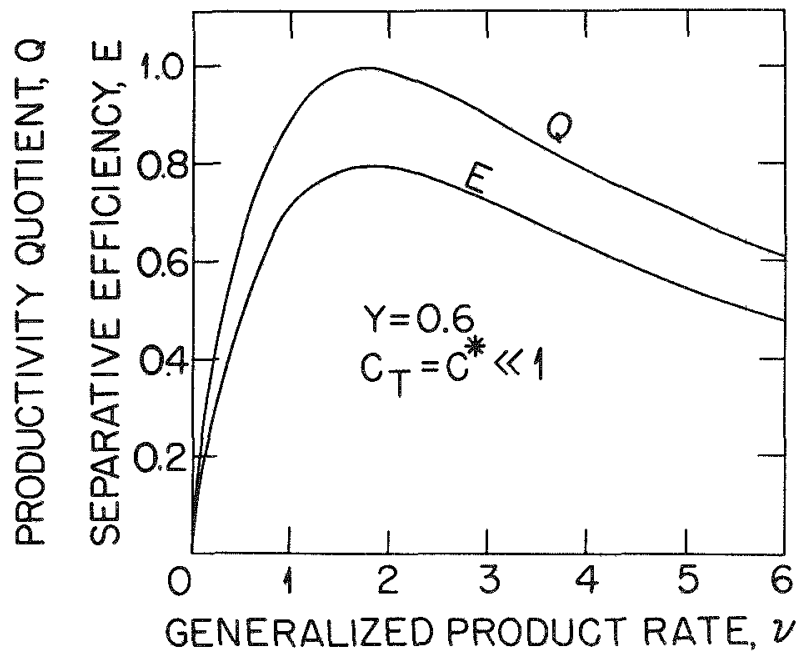

Fig. 13.4-A comparison of the dependence of the productivity quotient and the separative efficiency on the product rate.

$$
\begin{aligned}
\Psi=4 P\left[c^{*}\left(\frac{1-c_{\mathrm{B}}}{c_{\mathrm{B}}}+\ln \frac{1-c_{\mathrm{B}}}{c_{\mathrm{B}}}-\frac{1-c_{\mathrm{T}}}{c_{\mathrm{T}}}-\ln \frac{1-\mathrm{c}_{\mathrm{T}}}{\mathrm{c}_{\mathrm{T}}}\right)\right. \\
\left.\quad+\left(1-c^{*}\right)\left(\frac{c_{\mathrm{B}}}{1-c_{\mathrm{B}}}+\ln \frac{\mathrm{c}_{\mathrm{B}}}{1-c_{\mathrm{B}}}-\frac{\mathrm{c}_{\mathrm{T}}}{1-\mathrm{c}_{\mathrm{T}}}-\ln \frac{\mathrm{c}_{\mathrm{T}}}{1-\mathrm{c}_{\mathrm{T}}}\right)\right]
\end{aligned}
$$

where $c_{B}$ and $c_{T}$ are the bottom and top concentrations of the column or group under consideration. Now the rate of transport of the lighter component in the steady state is constant throughout the system and is given by

$$
\tau=\mathrm{PC}^{*}
$$

whereas that of the heavier component is given by

$$
\tau^{\prime}=\mathrm{P}\left(1-\mathrm{c}^{*}\right)
$$

If quantities referring to the heavier component are denoted by primes $\left(c^{\prime}=1-c\right)$, then the equation can be written

$$
\Psi=-\tau \Delta \theta-\tau^{\prime} \Delta \theta^{\prime}
$$


where

$$
\begin{aligned}
& \theta=4\left(\frac{1-c}{c}+\ln \frac{1-c}{c}\right) \\
& \theta^{\prime}=4\left(\frac{c}{1-c}+\ln \frac{c}{1-c}\right)
\end{aligned}
$$

and $\Delta$ is the change in going from the bottom of the column or group of columns up to the point in question. From Eq. 35 and the properties of $\tau$ and $\tau^{\prime}$, it can be seen that $\Psi$ is additive: The value for the whole is the sum of the values for the parts of a system. The function $\theta$ varies from $+\infty$ to $-\infty$ as $c$ varies from 0 to 1 .

If $\mathrm{z}$ is the distance up along a column or pyramid, then from Eq. 35 the enrichment rate per unit length is

$$
\frac{\mathrm{d} \Psi}{\mathrm{d} z}=-\tau \frac{\mathrm{d} \theta}{\mathrm{dz}}-\tau^{\prime} \frac{\mathrm{d} \Theta^{\prime}}{\mathrm{dz}}
$$

Now, from the theory of a column

$$
\begin{aligned}
& \tau=\mathrm{Pc}+\mathrm{H} \mathrm{c}(1-\mathrm{c})-\mathrm{K} \frac{\mathrm{dc}}{\mathrm{dz}} \\
& \tau^{\prime}=\mathrm{P}(1-\mathrm{c})-\mathrm{H} \mathrm{c}(1-\mathrm{c})+\mathrm{K} \frac{\mathrm{dc}}{\mathrm{dz}}
\end{aligned}
$$

and from Eqs. 36 and 37

$$
\frac{d \theta}{d z}=-\frac{4}{c^{2}(1-c)} \frac{d c}{d z} \quad \frac{d \theta^{\prime}}{d z}=\frac{4}{c(1-c)^{2}} \frac{d c}{d z}
$$

It follows that

$$
\frac{d \Psi}{d z}=4\left[H \frac{d \ln S}{d z}-K\left(\frac{d \ln S}{d z}\right)^{2}\right]
$$

where, as usual,

$$
S=\frac{c\left(1-c_{0}\right)}{c_{0}(1-c)}
$$

From Eq. 42 it can be seen that, for $\mathrm{d} \Psi / \mathrm{dz}$ to be a maximum, one must have 


$$
\frac{\mathrm{d} \ln \mathrm{S}}{\mathrm{dz}}=\frac{\mathrm{H}}{2 \mathrm{~K}}=\frac{1}{2} \frac{\mathrm{d} \ln \mathrm{S}_{\mathrm{e}}}{\mathrm{dz}}
$$

where $S_{e}$ is the equilibrium value of $\mathbf{S}$ for the case of zero product rate. If Eq. 44 holds, then

$$
\frac{\mathrm{d} \Psi}{\mathrm{d} z}=\frac{\mathrm{H}^{2}}{\mathrm{~K}}
$$

Equation 44 is exactly the condition holding for the ideal continuous pyramid.

\section{REFERENCES}

1. R. C. Jones and W. H. Furry, unpublished work.

2. K. Cohen, Report A-530, Feb. 4, 1943. 


\section{Chapter 14}

\section{COLUMNS IN A PYRAMID}

\section{EQUATIONS}

The differential equation for the light-constituent concentration, $c$, in a column under steady operation has the form

$$
\frac{d c}{d z}=\alpha c(1-c)-\alpha \nu\left(c^{*}-c\right)
$$

where

$$
\alpha=\frac{\mathrm{H}}{\mathrm{K}} \quad \nu=\frac{\mathrm{P}}{\mathrm{H}}
$$

$\mathrm{H}$ and $\mathrm{K}$ being the column constants, $\mathrm{P}$ the product rate, $\mathrm{z}$ the distance up the column (measured from the bottom), and $c^{*}$ the concentration at the top of the pyramid where product is removed.

Equation 1 can be integrated. Let $c_{B}$ and $c_{T}$ be the concentrations at the bottom and top of the column, respectively. The solution of Eq. 1 can be written

$$
\text { In } \frac{(2 c-1-\nu+q)\left(2 c_{B}-1-\nu-q\right)}{(2 c-1-\nu-q)\left(2 c_{B}-1-\nu+q\right)}=q \alpha z
$$

where

$$
q=\sqrt{(1+\nu)^{2}-4 \nu c^{*}}
$$

Solving Eq. 3 for c

$$
c=\frac{\left[2 \nu c^{*}-(1+\nu+q) c_{B}\right] e^{q \alpha z}+(1+\nu-q) c_{B}-2 \nu c^{*}}{\left(1+\nu-q-2 c_{B}\right) e^{q \alpha z}+2 c_{B}-(1+\nu+q)}
$$


If $\mathrm{z}=\mathrm{L}$, the length of the column, and $\mathrm{c}=\mathrm{c}_{\mathrm{T}}, \mathrm{Eq} .3$ becomes

$$
\ln \frac{\left(2 c_{T}-1-\nu+q\right)\left(2 c_{B}-1-\nu-q\right)}{\left(2 c_{T}-1-\nu-q\right)\left(2 c_{B}-1-\nu+q\right)}=q Y
$$

where $\mathrm{Y}=\alpha \mathrm{L}$. If a single column or one in the top stage of a pyramid is being dealt with, then $c_{T}=c^{*}$.

Now consider the case in which $c \ll 1$. Then Eq. 1 can be written to a sufficient accuracy

$$
\frac{\mathrm{dc}}{\mathrm{dz}}=\alpha(1+\nu) \mathrm{c}-\alpha \nu \mathrm{c}_{\mathrm{m}}
$$

The solution of this equation is given by

$$
\ln \frac{(1+\nu) \mathrm{c}-\nu \mathrm{c}^{*}}{(1+\nu) \mathrm{c}_{\mathrm{B}}-\nu \mathrm{c}^{*}}=\alpha(1+\nu) \mathrm{z}
$$

so that

$$
\ln \frac{(1+\nu) \mathrm{c}_{\mathrm{T}}-\nu \mathrm{c}^{*}}{(1+\nu) \mathrm{c}_{\mathrm{B}}-\nu \mathrm{c}^{*}}=(1+\nu) \mathrm{Y}
$$

Solving Eq. 8 for c

$$
c=\frac{\nu \mathrm{c}^{*}}{1+\nu}+\left(\mathrm{c}_{\mathrm{B}}-\frac{\nu \mathrm{c}^{*}}{1+\nu}\right) \exp [\alpha(1+\nu) \mathrm{z}]
$$

On the other hand, if $\mathrm{c} \sim 1$, so that $1-\mathrm{c} \ll 1$, it is written

$$
c=1-c^{\prime} \quad c^{*}=1-c^{*}
$$

and for $\mathrm{c}^{\prime}$ the equation is

$$
\frac{d c^{\prime}}{d z}=\alpha c^{\prime}+\alpha \nu\left(c^{*}-c^{\prime}\right)
$$

which takes on the same form as Eq. 7 if $\alpha$ and $\nu$ are replaced by $\alpha^{\prime}$ and $\nu^{\prime}$

$$
\alpha=\alpha^{\prime} \quad \nu=\nu^{\prime}
$$


The separation factor for the column, $\mathrm{S}$, is defined as

$$
S=\frac{c_{T}\left(1-c_{B}\right)}{c_{B}\left(1-c_{T}\right)}
$$

If $\mathrm{c} \ll 1$,

$$
S=\frac{\mathrm{c}_{\mathrm{T}}}{\mathrm{c}_{\mathrm{B}}}
$$

and, if $1-\mathrm{c} \ll<$,

$$
S=\frac{1-c_{B}}{1-c_{T}}=\frac{c_{B}^{\prime}}{c_{T}^{\prime}}
$$

where

$$
c_{B}^{\prime}=1-c_{B} \quad c_{T}^{\prime}=1-c_{T}
$$

\section{COLUMN IN TOP STAGE OR SINGLE COLUMN}

Suppose that a column operated singly or in the top stage of a pyramid is being considered, so that $\mathbf{c}_{\mathrm{T}}=\mathrm{c}^{*}$, and that the question under consideration is: What is the best rate of flow, $P$, in this column, or, by Eq. 2, what is the best value of $\nu$ ? Chapter 13 showed that a reasonable criterion (the $Q$ criterion) was that based on maximizing $\mathrm{p}=\nu / \mathrm{Y}$, or, what is the same thing, minimizing $1 / \mathrm{p}=\mathrm{Y} / \nu$. Then the condition for the optimum rate of flow is

$$
\frac{\partial}{\partial \nu}\left(\frac{Y}{\nu}\right)=0
$$

where $\mathrm{Y}$ is to be expressed by means of Eq. 6 and where $c_{\mathrm{B}}$ and $\mathrm{c}_{\mathrm{T}}$ are to be kept constant in the differentiation.

Let

$$
\psi=\frac{(\omega+q)(\lambda-q)}{(\omega-q)(\lambda+q)}
$$

where

$$
\omega=1+\nu-2 \mathrm{c}_{B}
$$




$$
\lambda=1+\nu-2 \mathrm{c}_{\mathrm{T}}
$$

Then Eq. 17 becomes

$$
\left(\frac{q}{\nu}+\frac{\lambda}{q}\right) \ln \psi=\frac{\lambda+q}{\omega+q}+\frac{\lambda-q}{\omega-q}-2
$$

This is to be solved simultaneously with Eq.6, which can be written

$$
q=\frac{\ln \psi}{Y}
$$

From Eq. 18

$$
\omega=q \frac{\lambda(\psi+1)+q(\psi-1)}{\lambda(\psi-1)+q(\psi+1)}
$$

and from Eq. 4, with $c^{*}=c_{T}$, it is found that

$$
\lambda=\frac{\mathrm{q}^{2}+\nu^{2}-1}{2 \nu}
$$

Using Eqs. 22 to 24 to eliminate $\ln \psi, \omega$, and $\lambda$ in Eq. 21, an equation for $\nu$ of the following form is obtained:

$$
\mathrm{A} \nu^{2}-\mathrm{B} \nu+\mathrm{C}=0
$$

where

$$
\begin{aligned}
& \mathrm{A}=2 \mathrm{Yq} \psi+1-\psi^{2} \\
& \mathrm{~B}=2(\psi-1)^{2} \mathrm{q} \\
& \mathbf{C}=6 \mathrm{Y} \psi \mathrm{q}^{3}-2 \mathrm{Y} \psi \mathrm{q}-\left(\psi^{2}-1\right)\left(\mathrm{q}^{2}-1\right)
\end{aligned}
$$

Now there is a procedure for solving the equations numerically. For a given value of $\mathrm{Y}$, the steps are as follows:

(a) Assume some value for $\psi$ (or $\ln \psi$ ).

(b) Get q from Eq. 22.

(c) Set up Eq. 25 and solve for $\nu$.

(d) Get $\lambda$ from Eq. 24 and $c_{T}$ from Eq. 20.

(e) Get $\omega$ from Eq. 23 and $c_{B}$ from Eq. 19.

In this way, for a given value of $\mathrm{Y}$, values of $\nu, c_{\mathrm{B}}$, and $\mathrm{c}_{\mathrm{T}}$ are obtained. If $\psi$ has been chosen so that $\nu>0,0<c_{B}<c_{T}<1$, these values are usable. By taking a number of values of $\psi$, graphs can be plotted to 
give $\nu$ as a function of $c_{T}$ and to give $S$ as a function of $c_{T}$, where $S$ is given by Eq. 11. Such graphs are shown in Figs. 14.1 and 14.2 for $Y=$ $0.5,0.6,0.7$, and 0.8 .

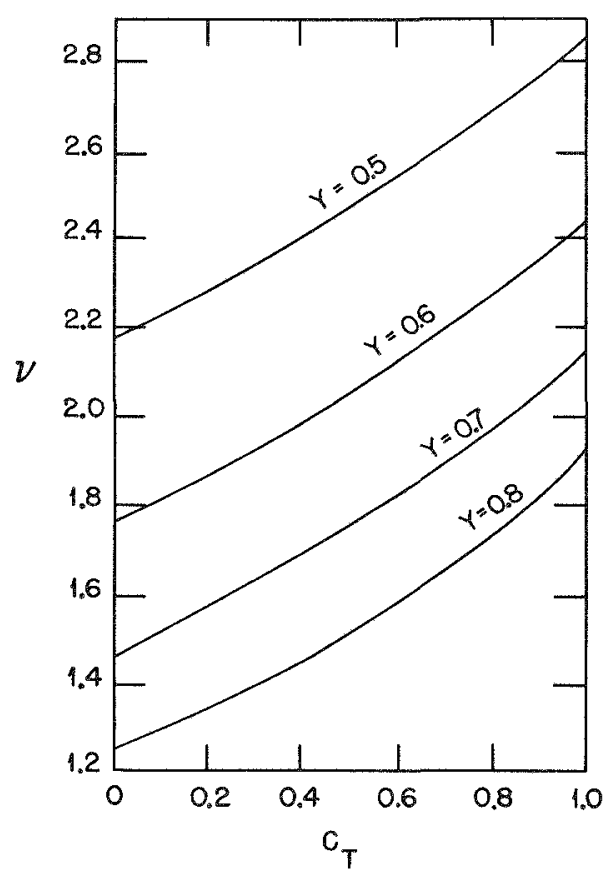

Fig. 14.1-Graphs of generalized product rate, $\nu$, as a function of the concentration at the top of the column, $c_{T}$, for optimum performance. This applies to a column being operated singly or as the top stage of a pyramid.

It is convenient to have analytical expressions for these functions. It is found that, at least in the range $-1 \leq Y \leq 1, \ln S$ is nearly a linear function of $c_{T}$. Hence it is possible to write

$$
\ln S=A^{\prime} c_{T}+B^{\prime}\left(1-c_{T}\right)+C^{\prime} c_{T}\left(1-c_{T}\right)
$$

where the last term has been added to allow for a small deviation from linearity. The coefficients $\mathrm{A}^{\prime}$ and $\mathrm{B}^{\prime}$ can be determined from the behavior of $\ln S$ for $\mathrm{c}_{\mathrm{T}} \rightarrow 1$ and $\mathrm{c}_{\mathrm{T}} \rightarrow 0$, respectively. The latter case was investigated by a method to be described in Sec. 3 . The coefficient $\mathrm{C}^{\prime}$ was determined by the deviation from linearity in the cases previously calculated numerically. The result obtained in this way was given by 


$$
\begin{aligned}
\frac{\ln S}{Y}=0.5693+0.0124 Y\left(1-2 c_{T}\right) & \\
& +Y^{2}\left[0.0013+0.0082 c_{T}\left(1-c_{T}\right)\right]
\end{aligned}
$$

A similar procedure gave

$$
\nu \mathrm{Y}=1.256-0.339 \mathrm{Y}\left(1-2 \mathrm{c}_{\mathrm{T}}\right)+\mathrm{Y}^{2}\left[0.019-0.315 \mathrm{c}_{\mathrm{T}}\left(1-\mathrm{c}_{\mathrm{T}}\right)\right]
$$

a result less accurate than Eq. 28.

In terms of $c_{B}$ the corresponding relations are

$$
\begin{aligned}
& \frac{\ln S}{\mathrm{Y}}=0.5693+0.0124 \mathrm{Y}\left(1-2 \mathrm{c}_{\mathrm{B}}\right) \\
& +\mathrm{Y}^{2}\left[0.0013-0.0059 \mathrm{c}_{\mathrm{B}}\left(1-\mathrm{c}_{\mathrm{B}}\right)\right] \\
& \nu \mathrm{Y}=1.256-0.339 \mathrm{Y}\left(1-2 \mathrm{c}_{\mathrm{B}}\right)+\mathrm{Y}^{2}\left[0.019+0.070 \mathrm{c}_{\mathrm{B}}\left(1-\mathrm{c}_{\mathrm{B}}\right)\right]
\end{aligned}
$$

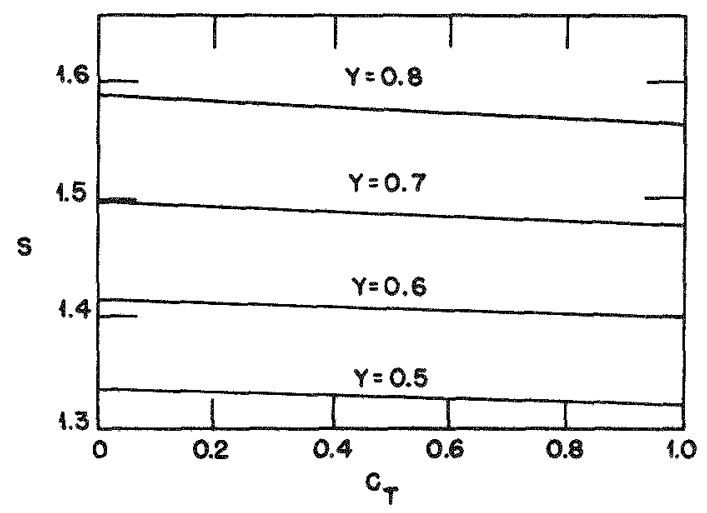

Fig. 14.2-Separation factor at optimum withdrawal rate for a column operated singly or as the top stage of a pyramid. $c_{T}$ is the concentration of the desired isotope at the top of the column.

\section{COLUMN ANYWHERE IN PYRAMID}

The case of a column operated singly or in the top stage of a pyramid was considered in Sec. 2. Now consider the general case of a column anywhere in a pyramid. This general case is characterized by the fact that $c_{T} \neq \mathfrak{c}^{*}$, in which event the calculations required to determine 
the optimum rate of flow become rather tedious. For this reason the discussion is limited to two cases: (1) $c<1$ and (2) $1-c<1$.

First consider the case $c \ll 1$. Then Eq. 7 is valid, and hence Eq. 9 follows. To determine the optimum value of $\nu$, we again set $\partial / \partial \nu(\mathrm{Y} / \nu)=$ 0 , expressing $\mathrm{Y}$ as a function of $\nu$ by means of $\mathrm{Eq} .9$, and keep $\mathrm{c}^{*}, \mathrm{c}_{\mathrm{B}}$, and $c_{T}$ constant. In this way the following equation is obtained:

$\ln \frac{(1+\nu) \mathrm{c}_{\mathrm{T}}-\nu \mathrm{c}^{*}}{(1+\nu) \mathrm{c}_{\mathrm{B}}-\nu \mathrm{c}^{*}}=\frac{\nu(1+\nu)}{1+2 \nu}\left[\frac{\mathrm{c}^{*}-\mathrm{c}_{\mathrm{B}}}{(1+\nu) \mathrm{c}_{\mathrm{B}}-\nu \mathrm{c}^{*}}-\frac{\mathrm{c}^{*}-\mathrm{c}_{\mathrm{T}}}{(1+\nu) \mathrm{c}_{\mathrm{T}}-\nu \mathrm{c}^{*}}\right]$

which must be satisfied together with Eq. 9 .

For a given value of $\mathrm{Y}$ these two equations can be solved parametrically by taking as a variable

$$
\psi=\ln \frac{(1+\nu) c_{T}-\nu c^{*}}{(1+\nu) c_{B}-\nu c^{*}}
$$

Then from Eq. 9

$$
\nu=\frac{\psi}{\mathrm{Y}}-1
$$

and from Eqs. 32 and 33 it is found that

$$
\begin{aligned}
& \frac{c_{\mathrm{T}}}{c^{*}}=\frac{\nu}{1+\nu} \frac{1+\xi}{\xi} \\
& \frac{c_{\mathrm{B}}}{c^{*}}=\frac{\nu}{1+\nu} \frac{1+\zeta}{\zeta} \\
& \frac{c_{T}}{c_{B}}=\frac{1+\xi}{\xi} \frac{\zeta}{1+\zeta}
\end{aligned}
$$

where

$$
\xi=\frac{\psi\left(\frac{2 \psi}{\mathrm{Y}}-1\right)}{\mathrm{e}^{\psi}-1} \quad \xi=\xi \mathrm{e}^{\psi}
$$

By assigning various values to $\psi$, it is possible to find sets of related values of $\mathrm{c}_{\mathrm{T}} / \mathrm{c}^{*}, \mathrm{~S}=\mathrm{c}_{\mathrm{T}} / \mathrm{c}_{\mathrm{B}}$, and $\nu$ for a fixed value of $\mathrm{Y}$.

On the basis of such calculations, Fig. 14.3 shows curves of $S$ as a function of $\mathrm{c}_{\mathrm{T}} / \mathrm{c}^{*}$ for a number of values of $\mathrm{Y}$, and Fig. 14.4 gives curves of $\nu$ as a function of the same variable. 


\section{LIQUTD THERMAL DIF FUSION}

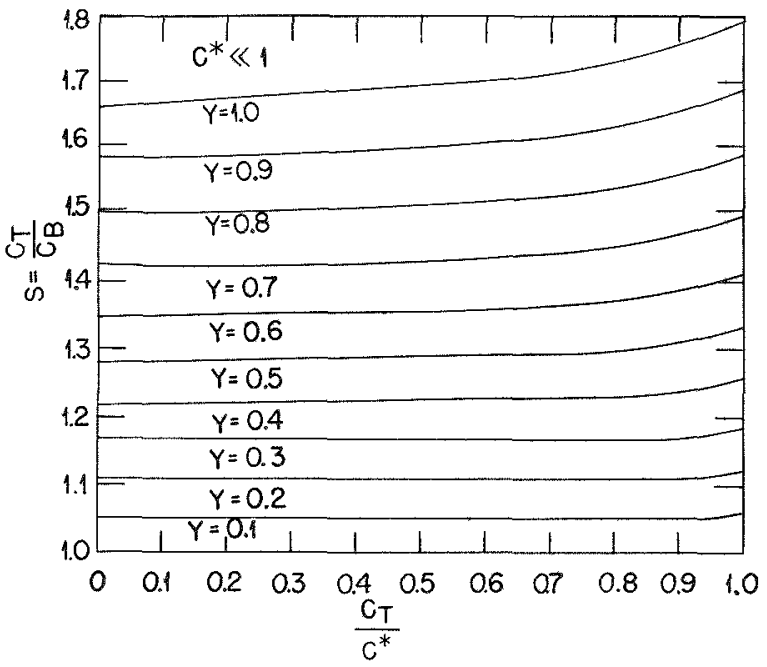

Fig. 14.3-These curves refer to the optimum performance in a column operating as part of a pyramid at low concentrations of the desired isotope. Here $c_{T}, c_{B}$, and $c^{*}$ are the concentrations at the top of the column, the bottom of the column, and the top of the pyramid, respectively.

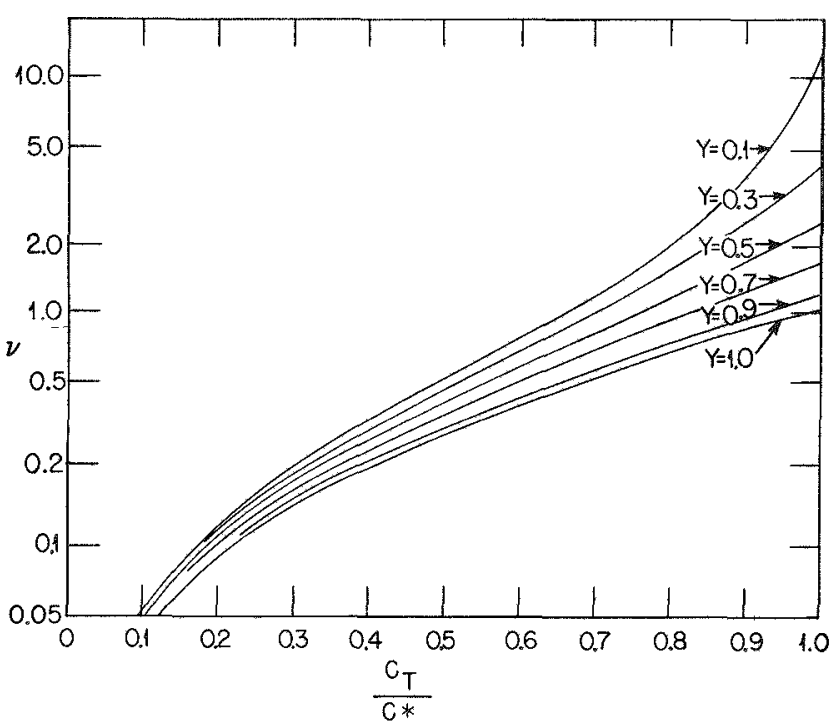

Fig. 14.4-These curves refer to the optimum performance in a column operating as part of a pyramid at low concentrations of the desired isotope. Here $\nu$ is the generalized product rate and $c_{\mathrm{T}}$ and $\mathrm{c}^{*}$ are the concentrations at the top of the column and at the top of the pyramid, respectively. 
Certain limiting values are of interest. For the case $c_{T}=c^{*}$ the results can be represented in the range $0 \leq Y \leq 1$ by

$$
\frac{\ln S}{Y}=0.5693+0.0124 Y+0.0013 Y^{2}
$$

and

$$
\nu \mathrm{Y}=1.2564-0.3392 \mathrm{Y}+0.0189 \mathrm{Y}^{2}+0.0015 \mathrm{Y}^{3}
$$

In particular, it is found that

$$
\lim _{Y \rightarrow 0}\left(\frac{\ln S}{Y}\right)=\frac{2}{\gamma} \quad \lim _{Y \rightarrow 0}(\nu Y)=\ln \gamma
$$

where

$$
2 \ln \gamma=\gamma-1
$$

which has a solution $\gamma=3.5129$, In $\gamma=1.2564$, so that $2 / \gamma=0.5693$. Equations 37 and 38 are plotted in the right-hand half of Fig. 14.5.

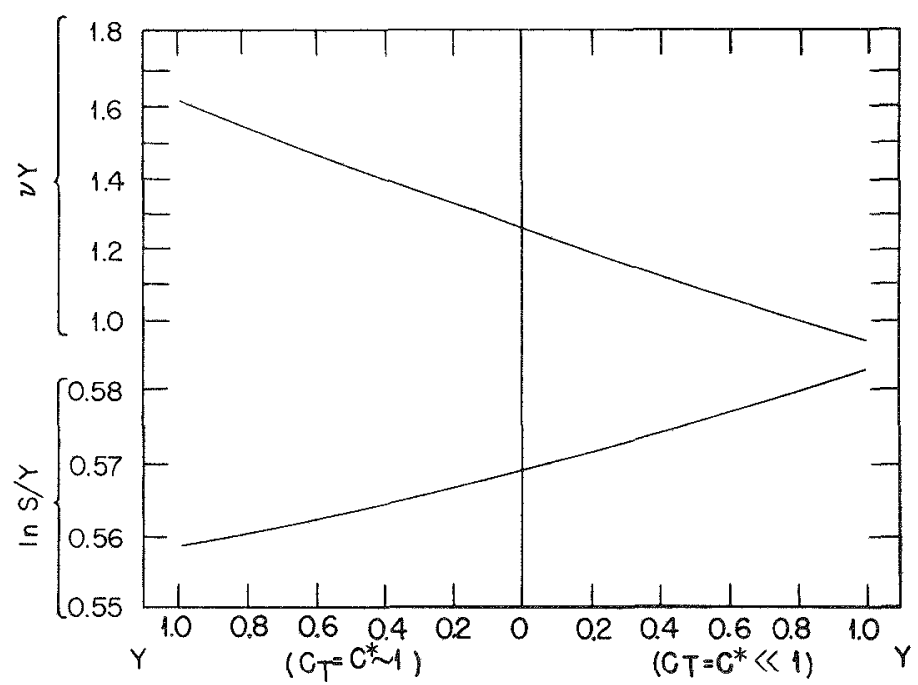

Fig. 14.5-Curves of $\mathrm{In} \mathrm{S} / \mathrm{Y}$ and $\nu \mathrm{Y}$ as functions of $\mathrm{c}_{\mathrm{T}}=\mathrm{e}^{*}$ for optimum performance in the case of a single column or the top stage of a pyramid. Curves for high concentrations of the desired isotope are shown on the left, and curves for low concentrations are shown on the right. 
For the case $\mathrm{c}_{\mathrm{T}} \ll \mathrm{c}^{*}$, it is found that

$$
S=\frac{e^{Y}+Y-1}{1+Y-e^{-Y}}
$$

which can be replaced in the range $0 \leq \mathrm{Y} \leq 1$ by the more convenient expression

$$
\frac{\ln S}{Y}=0.5000+0.0102 Y^{2}
$$

and also

$$
\nu=\frac{\mathrm{c}_{\mathrm{T}}}{\mathrm{c}^{*}} \frac{\mathrm{Y}}{\mathrm{e}^{\mathrm{Y}}+\mathrm{Y}-1}
$$

In this case, $\ln \mathrm{S} / \mathrm{Y}$ is very nearly equal to $1 / 2$, as was the case in the ideal pyramid. The ratio $\nu /\left(c_{\mathrm{T}} / \mathrm{c}^{*}\right)$ is plotted in Fig. 14.6 as a function of $\mathrm{Y}$.

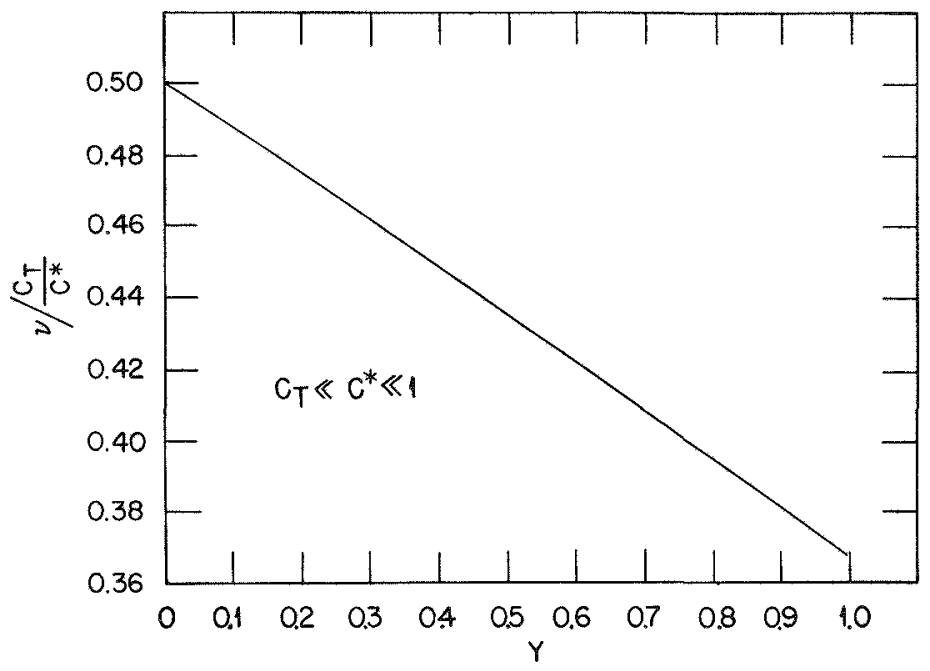

Fig. 14.6-These curves are for optimum performance in the case of a column near the bottom of a pyramid where $c_{T} \ll c^{*} \ll 1, c_{T}$ being the desired isotope concentration at the top of the column and $c^{*}$ that at the top of the pyramid.

By means of the information presented graphically in Figs. 14.3 and 14.4 , the optimum concentration and value of $\nu$ for each stage of a pyramid can be determined, starting from the top and working down 
stage by stage. For the case in which all the stages consist of columns with the same value of $Y$, the results of such calculations are given in Fig. 14.7. In this figure, curves will be found giving the ratio of the concentration at the bottom of each stage to the concentration at the top

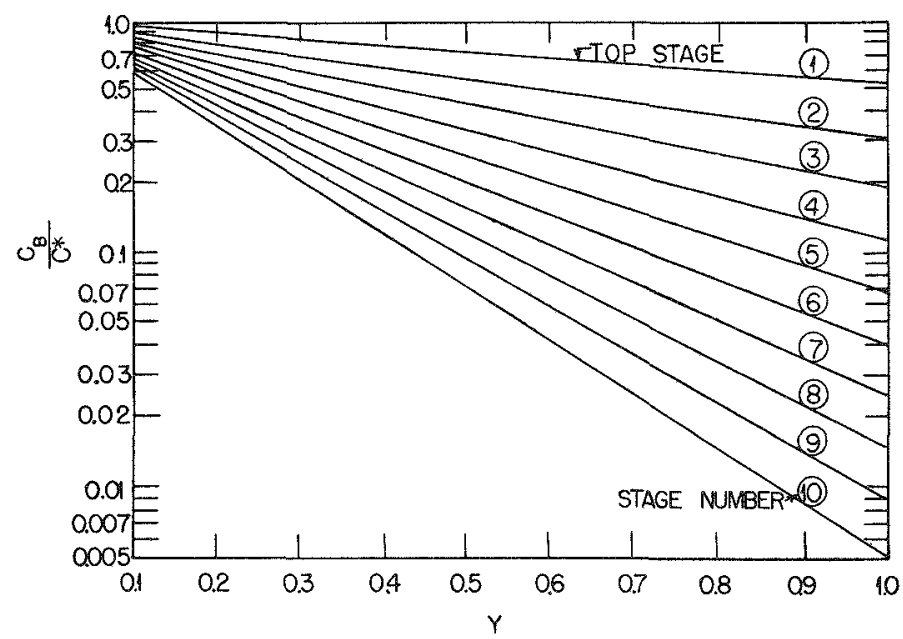

Fig. 14.7-The ratio of the concentration at the bottom of a stage, $c_{B}$, to that at the top of the pyramid, $\mathrm{c}^{*}$, as a function of $\mathrm{Y}$. The stages are numbered down from the top. This is for the case of low concentrations of the desired isotope with the pyramid operating at optimum performance.

of the highest stage, taken as stage 1. Using this ratio for the lowest stage and the concentration of material fed in at the bottom of this stage, it is possible to find the concentration at the top of the pyramid and, from this, the actual concentrations at the various stages.

Since the total upward flow of fluid must be the same at every stage of the pyramid, the number of columns per stage varies inversely as $\nu$ if all the columns have the same value of $H$. On this basis, Fig. 14.8 gives the number of columns at various stages corresponding to one column in the top stage (No. 1).

To get the optimum product rate from each column of the top stage, let $\mathrm{X}$ be the time constant of the column

$$
\mathrm{X}=\frac{\mathrm{M}}{\mathrm{HY}}
$$

where $\mathrm{M}$ is the material holdup in the column. Then

$$
\mathrm{P}=\mathrm{H} \nu=\frac{\mathrm{M}}{\mathrm{X}} \frac{\nu}{\mathrm{Y}}
$$




\section{LIQUTD THERMAL DIFFUSION}

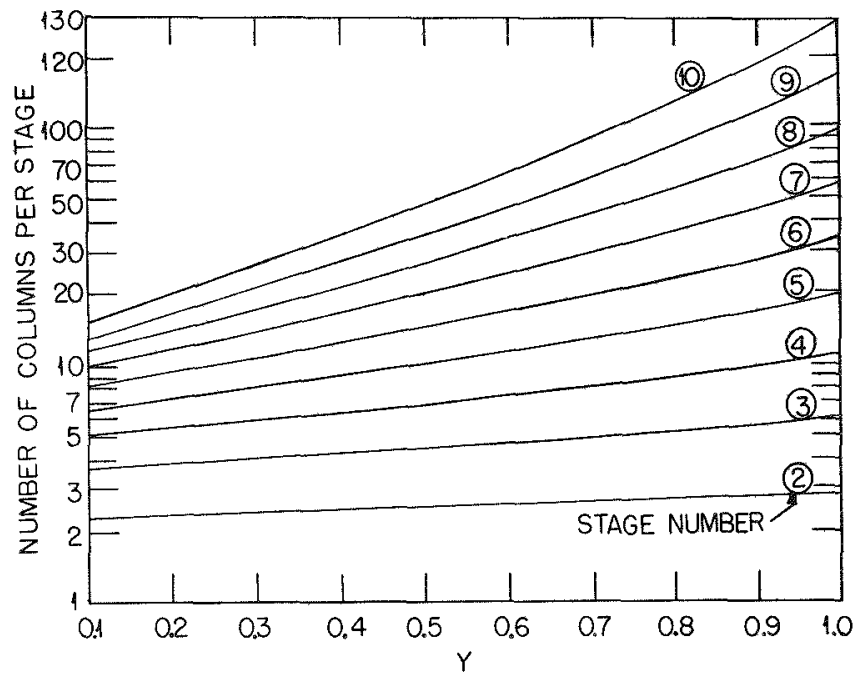

Fig. 14.8-These curves show the number of columns in each stage of the pyramid per column in the top stage as a function of $\mathrm{Y}$. The stages are numbered down from the top stage, which is No. 1. This is for the case of low concentrations of the desired isotope and optimum performance of the pyramid.

Figure 14.9 gives $\nu / \mathrm{Y}$ as a function of $\mathrm{Y}$ for the top stage $\left(\mathrm{c}_{\mathrm{T}}=\mathrm{c}^{*}\right)$. From this function and from a knowledge of $\mathrm{M}$ and $\mathrm{X}$, or from $\nu$ of Fig. 14.5 and a knowledge of $\mathrm{H}$, the product rate per top-stage column can be obtained.

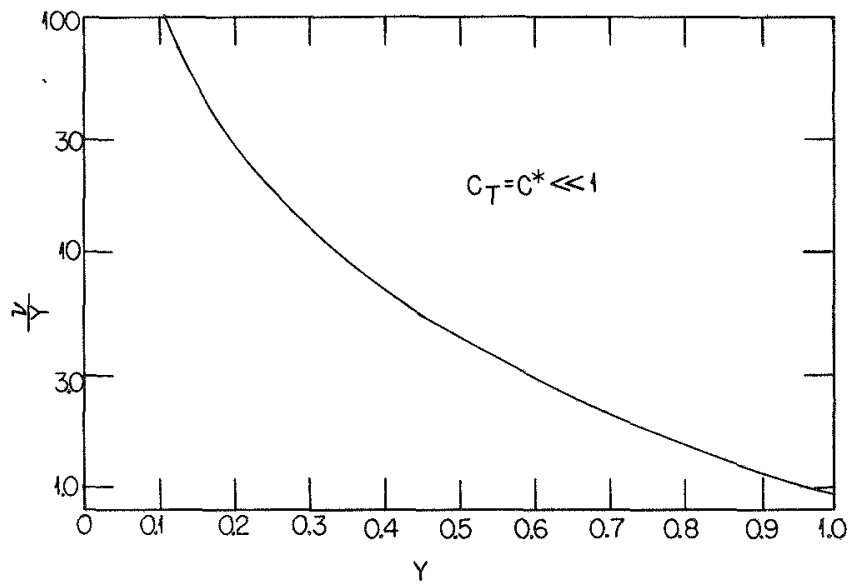

Fig. 14.9-Dependence of $\nu / Y$ on $Y$ for the top stage of a pyramid operating at optimum performance and using low concentrations of the desired isotope. 
The preceding calculations and the accompanying graphs make it possible to determine the design and operating conditions for small - pyramids, provided one is dealing with small concentrations so that the linear equation (Eq. 7 ) is valid. If the concentration is small but too large for Eq. 7 to be valid and if the separation factor is sufficiently small, Eq. 1 can be made effectively linear by replacing the slowly varying factor $1-\mathrm{c}$ by some mean value and then introducing new coefficients in place of $\alpha$ and $\nu$ to give the equation the same form as Eq. 7 .

If very high concentrations are being dealt with so that $1-c<1$, then Eqs. 11 to 13 should be used. In this case the calculations made are similar to those used for low concentrations but with negative values of $\alpha$ and $\nu$. In this way the results shown in Figs. 14.10 and 14.11 were obtained. Figure 14.10 gives $S=\left(1-c_{B}\right) /\left(1-c_{T}\right)$ as a function of $\left(1-c^{*}\right) /\left(1-c_{T}\right)$ for various values of $\mathrm{Y}$, and Fig. 14.11 gives $\nu$ as a function of the same variable. From these curves it is

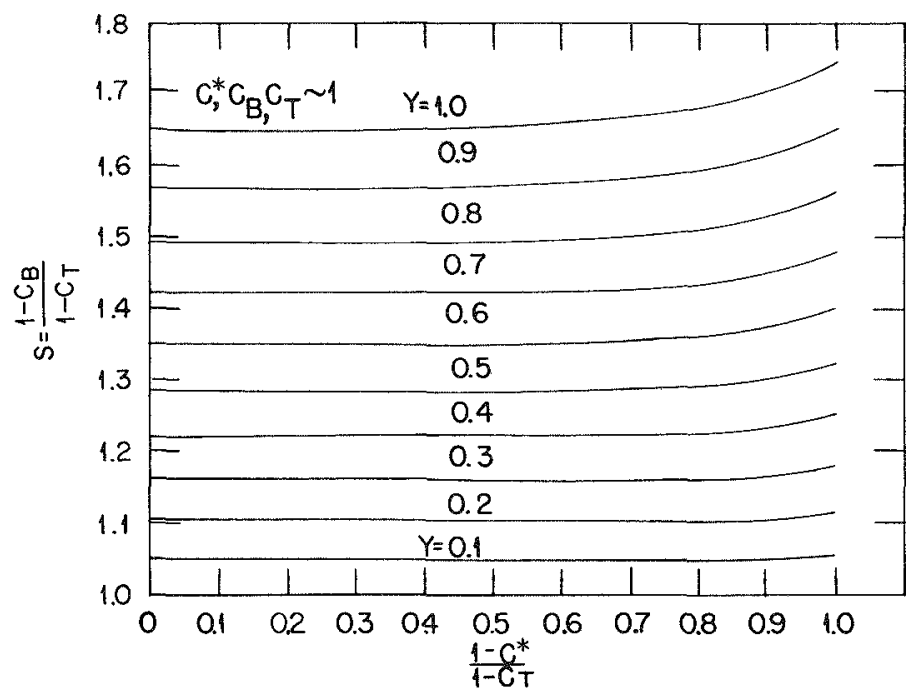

Fig. 14.10-Dependence of separation factor on concentration. These curves refer to a column operating at optimum performance as part of a pyramid. $c_{B}, c_{T}$, and $\mathrm{c}^{*}$, the concentrations of the desired is otope at the bottom of a column, at the top of the column, and at the top of the pyramid, respectively, are nearly equal to unity. Large values of the abscissa indicate that the column is near the top of the pyramid.

possible to determine the operating conditions near the top of a pyramid which is used for material of high concentration. As will be seen later, these results are also applicable to strippers. 


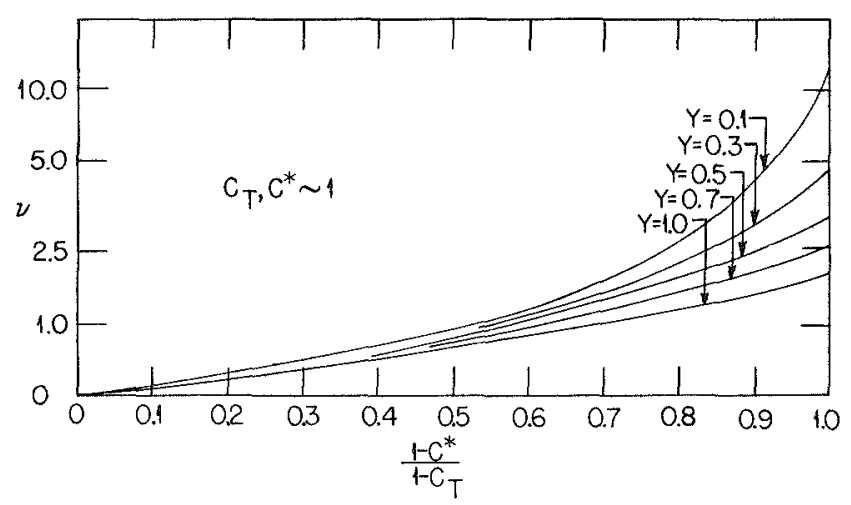

Fig. 14.11-Curves showing the generalized product rate, $\nu$, as a function of the concentrations for a column operating at optimum performance as part of a pyramid. This is for the case in which the concentration of the desired isotope is close to unity. High values of the abscissa indicate that the column is near the top of the pyramid.

If the top stage $\left(c_{T}=c^{*}\right)$ is being dealt with, then it is found that $(0 \leq \mathrm{Y} \leq 1)$

$$
\frac{\ln S}{Y}=0.5693-0.0124 Y+0.0013 Y^{2}
$$

and

$$
\nu \mathrm{Y}=1.2564+0.3392 \mathrm{Y}+0.0189 \mathrm{Y}^{2}-0.0015 \mathrm{Y}^{3}
$$

corresponding to Eqs. 37 and 38. These functions are shown in the lefthand half of Fig. 14.5.

For the case $1-c_{\mathrm{T}} \gg 1-\mathrm{c}^{*}$

$$
\mathrm{S}=\mathrm{e}^{\mathrm{Y} / 2}
$$

and

$$
\nu=\frac{1}{2}
$$


Chapter 15

\section{DESIGN AND PERFORMANCE OF SMALL PYRAMIDS}

\section{SEPARATION FACTORS}

From the calculations and graphs in Chap. 14, it is possible to design and operate a small pyramid for optimum performance. Sometimes, however, the design and operation of the pyramid are limited by the necessity of fulfilling some additional condition. For example, it may be that, with a given number of columns in the pyramid, a prescribed product rate is to be maintained and that this product rate is not the one that would have been arrived at on the basis of the criterion of optimum performance. Or it may be that the over-all separation factor for the pyramid is preassigned and is not the same as that based on the optimum-performance criterion. Such problems arise frequently in practice, and it is desirable to have a systematic procedure for solving them.

Low concentrations will be discussed here, and hence linear approximation will be used. First, number the stages, counting down from the top. Let $S_{k}$ denote the separation factor for the $k$ th stage, and let $S_{k}^{*}$ denote the separation factor between the bottom of the $\mathrm{k} t h$ stage and the top of the pyramid, so that

$$
\mathbf{s}_{\mathrm{k}}^{*}=\mathbf{s}_{1}, \mathbf{s}_{2}, \ldots, \mathrm{s}_{\mathrm{k}}
$$

From the theory of the single column, it is found that

$$
\begin{aligned}
& \frac{1}{\mathrm{~S}_{\mathrm{k}}}=\frac{\nu_{\mathrm{k}}}{1+\nu_{\mathrm{k}}} \mathrm{S}_{\mathrm{k}-1}^{*}+\frac{1-\frac{\nu_{\mathrm{k}}}{1+\nu_{\mathrm{k}}} \mathrm{S}_{\mathrm{k}-1}^{*}}{\beta_{\mathrm{k}}} \quad(\mathrm{k}=2, \ldots, \mathrm{n}) \\
& \frac{1}{\mathrm{~S}_{1}}=\frac{\nu_{1}}{1+\nu_{1}}+\frac{1}{\left(1+\nu_{1}\right) \beta_{1}} \quad(\mathrm{k}=1)
\end{aligned}
$$


where

$$
\nu_{\mathrm{k}}=\frac{\mathrm{P}}{\mathrm{HN}_{\mathrm{k}}} \quad \beta_{\mathrm{k}}=\exp \left[\mathrm{Y}\left(1+\nu_{\mathrm{k}}\right)\right]
$$

$\mathrm{n}$ is the total number of stages, $N_{k}$ is the number of columns in the $\mathrm{k}$ th stage, $\mathrm{P}$ is the product rate of the pyramid, and $\mathrm{H}$ and $\mathrm{Y}$ are the column constants, as defined previously. From Eq. 2 the result is

$$
\frac{1}{\mathrm{~S}_{\mathrm{k}}^{*}}=\frac{\nu_{\mathrm{k}}}{1+\nu_{\mathrm{k}}}+\frac{\frac{1}{\mathrm{~S}_{\mathrm{k}-1}^{*}}-\frac{\nu_{\mathrm{k}}}{1+\nu_{\mathrm{k}}}}{\beta_{\mathrm{k}}} \quad(\mathrm{k}=2, \ldots, \mathrm{n})
$$

The total number of columns is given by

$$
\mathbf{N}=\sum_{\mathrm{k}=1}^{\mathrm{n}} \mathrm{N}_{\mathrm{k}}=\frac{\mathbf{P}}{\mathrm{H} \nu_{\mathrm{an}}}
$$

where $\nu_{\text {an }}$ is defined by

$$
\frac{1}{\nu_{\mathrm{an}}}=\sum_{\mathrm{k}=1}^{\mathrm{n}} \frac{1}{\nu_{\mathrm{k}}}
$$

\section{¿. OPTIMUM-PERFORMANCE DESIGN}

A problem encountered in practice is as follows: Given a fixed number of columns, $N$, and a prescribed product, $P$, design the pyramid so that the over-all separation factor will be a maximum. In this case, on the basis of Eq. 5 , it is seen that

$$
\nu_{\text {an }}=\text { constant }
$$

or, if infinitesimal changes, $\mathrm{d} \nu_{\mathrm{k}}$, are introduced in the $\nu_{\mathrm{k}}$, it is necessary to keep

$$
\sum_{k=1}^{n} \frac{d \nu_{k}}{\nu_{k}^{2}}=0
$$

On the other hand, the necessary condition that $S^{*}=S_{n}^{*}$ be a maximum is that

$$
\mathrm{dS}=0
$$

for arbitrary $\mathrm{d} \nu_{\mathrm{k}}$ subject only to the restriction shown in Eq. 8. If Eq. 9 is expressed in terms of the $\mathrm{d} \nu_{\mathrm{k}}$, then one of the latter, say $\mathrm{d} \nu_{1}$, can be 
eliminated between this equation and Eq. 8; thus an equation is obtained in which there is no longer any restriction on any of the remaining $d v_{k}$, so that, if the whole expression is to vanish, the coefficient of each $\mathrm{d} \nu_{\mathrm{k}}$ must vanish.

Another formulation of the optimum-design problem is as follows: For a given value of $N$ and a prescribed separation factor $S_{n}^{*}=S^{*}$, the problem is to make the product rate a maximum. This means that it is necessary to keep $\mathrm{S}_{\mathrm{n}}^{*}$ fixed and make $1 / \nu_{\text {an }}$ a minimum. If infinitesimal changes $\mathrm{d} \nu_{\mathrm{k}}$ are introduced, they must now satisfy the restriction shown in Eq. 9 corresponding to $S_{n}^{*}$ constant, but for all such changes $\mathrm{Eq} .8$ must hold, as the condition that $1 / \nu_{\mathrm{a}}$ be a minimum. We are thus led to the same equations as in the previous formulation of the problem (although their interpretations are different). The same procedure for treating them can be used, and the same results are obtained.

Now carry out this procedure. For convenience, Eq. 9 is written in the form

$$
d\left(\frac{1}{S_{n}^{*}}\right)=0
$$

and, eliminating $\mathrm{d} \nu_{1}$ between this equation and Eq. 8, the result is

$$
\sum_{\mathrm{k}=2}^{\mathrm{n}}\left[\frac{\partial}{\partial \nu_{\mathrm{k}}}\left(\frac{1}{\mathrm{~S}_{\mathrm{n}}^{*}}\right)-\frac{\nu_{1}^{2}}{\nu_{\mathrm{k}}^{2}} \frac{\partial}{\partial \nu_{1}}\left(\frac{1}{\mathrm{~S}_{\mathrm{n}}^{*}}\right)\right] \mathrm{d} \nu_{\mathrm{k}}=0
$$

Since $\mathrm{d} \nu_{2}, \ldots, \mathrm{d} \nu_{\mathrm{k}}$ can be taken arbitrarily, the system of equations is

$$
\frac{\partial}{\partial \nu_{\mathrm{k}}}\left(\frac{1}{\mathrm{~S}_{\mathrm{n}}^{*}}\right)-\frac{\nu_{1}^{2}}{\nu_{\mathrm{k}}^{2}} \frac{\partial}{\partial \nu_{1}}\left(\frac{1}{\mathrm{~S}_{\mathrm{n}}^{*}}\right)=0 \quad(\mathrm{k}=2, \ldots, \mathrm{n})
$$

Now, from Eq. 4 it is seen that

$$
\begin{aligned}
& \frac{\partial}{\partial \nu_{\mathrm{k}}}\left(\frac{1}{\mathrm{~S}_{\mathrm{k}}^{*}}\right)=\frac{1}{\left(1+\nu_{\mathrm{k}}\right)^{2}}\left(1-\frac{1}{\beta_{\mathrm{k}}}\right)-\frac{\mathrm{Y}}{\beta_{\mathrm{k}}}\left(\frac{1}{\mathrm{~S}_{\mathrm{k}-1}^{*}}-\frac{\nu_{\mathrm{k}}}{1+\nu_{\mathrm{k}}}\right) \quad(\mathrm{k}>1) \\
& \frac{\partial}{\partial \nu_{\mathrm{j}}}\left(\frac{1}{\mathrm{~S}_{\mathrm{k}}^{*}}\right)=0 \quad(\mathrm{j}>\mathrm{k}) \\
& \frac{\partial}{\partial \nu_{\mathrm{j}}}\left(\frac{1}{\mathrm{~S}_{\mathrm{k}}^{*}}\right)=\frac{1}{\beta_{\mathrm{j}+1}, \ldots, \beta_{\mathrm{k}}} \frac{\partial}{\partial \nu_{\mathrm{j}}}\left(\frac{1}{\mathrm{~S}_{\mathrm{j}}^{*}}\right) \quad(\mathrm{j}<\mathrm{k}) \\
& \frac{\partial}{\partial \nu_{1}}\left(\frac{1}{S_{\mathrm{k}}^{*}}\right)=\frac{1}{\beta_{2}, \ldots, \beta_{\mathrm{k}}}\left[\frac{1}{\left(1+\nu_{1}\right)^{2}}\left(1-\frac{1}{\beta_{1}}\right)-\frac{Y}{\beta_{1}\left(1+\nu_{1}\right)}\right]
\end{aligned}
$$




\section{LIQUID THERMAL DIF FUSION}

Making use of Eq. $12 \mathrm{c}$, it is found that Eq. 11 can be written

$$
\frac{\partial}{\partial \nu_{\mathrm{k}}}\left(\frac{1}{\mathrm{~S}_{\mathrm{k}}^{*}}\right)-\frac{\nu_{\mathrm{l}}^{2}}{\nu_{\mathrm{k}}^{2}} \frac{\partial}{\partial \nu_{1}}\left(\frac{1}{\mathrm{~S}_{\mathrm{k}}^{*}}\right)=0 \quad(\mathrm{k}=2, \ldots, \mathrm{n})
$$

From this it is evident that the condition to be satisfied at each stage is independent of the stages below it. This is convenient since it is thus possible to carry out the calculations by starting from the top and working down step by step as far as desired.

By the use of Eqs. $12 \mathrm{a}$ and $12 \mathrm{~d}$ in Eq. 13, equations are found which can be put into the form

$$
\begin{aligned}
\beta_{\mathrm{k}}-1=\mathrm{Y}\left[\frac{\left(1+\nu_{\mathrm{k}}\right)^{2}}{\mathrm{~S}_{\mathrm{k}-1}^{*}}-\nu_{\mathrm{k}}\left(1+\nu_{\mathrm{k}}\right)\right. & \left.-\frac{\nu_{1}^{2}\left(1+\nu_{\mathrm{k}}\right)^{2}}{\nu_{\mathrm{k}}^{2}\left(1+\nu_{1}\right)} \frac{1}{\beta_{1}, \ldots, \beta_{\mathrm{k}-1}}\right] \\
& +\frac{\nu_{1}^{2}\left(1+\nu_{\mathrm{k}}\right)^{2}}{\nu_{\mathrm{k}}^{2}\left(1+\nu_{1}\right)^{2}} \frac{\beta_{1}-1}{\beta_{1}, \ldots, \beta_{\mathrm{k}-1}}(\mathrm{k}>2)
\end{aligned}
$$

and

$$
\begin{aligned}
\beta_{2}-1=\left[\frac{\nu_{1}\left(1+\nu_{2}\right)}{\nu_{2}\left(1+\nu_{1}\right)}\right]^{2}\left(1-\frac{1}{\beta_{1}}\right) & \\
& -\frac{\mathrm{Y}\left(1+\nu_{2}\right)\left(\nu_{1}-\nu_{2}\right)}{1+\nu_{1}}\left[\frac{\left(1+\nu_{2}\right)\left(\nu_{1}+\nu_{2}\right)}{\beta_{1} \nu_{2}^{2}}-1\right]
\end{aligned}
$$

The limiting cases are of interest. If $\nu_{1} \rightarrow 0$, then all the $\nu_{k} \rightarrow 0$, and, if $q_{\mathrm{k}}=\nu_{1} / \nu_{\mathrm{k}}$, we get in the limit

$$
q_{k}^{2}=\frac{e^{k Y}-\exp [(k-1) Y]-Y}{e^{Y}-Y-1}
$$

For $\mathrm{k}=2$

$$
q_{2}^{2}=\frac{e^{2 Y}-e^{Y}-Y}{e^{Y}-Y-1}
$$

On the other hand, if $\nu_{1} \rightarrow \infty$, it is found that the other $\nu_{\mathbf{k}}$ 's remain finite, and Eq. 14 becomes

$$
\beta_{\mathrm{k}}-1=\mathrm{Y}\left[\frac{\left(1+\nu_{\mathrm{k}}\right)^{2}}{\mathrm{~S}_{\mathrm{k}-1}^{*}}-\nu_{\mathrm{k}}\left(1+\nu_{\mathrm{k}}\right)\right]+\frac{\left(\frac{1+\nu_{\mathrm{k}}}{\nu_{\mathrm{k}}}\right)^{2}}{\beta_{2}, \ldots, \beta_{\mathrm{k}-1}} \quad(\mathrm{k}>2)
$$


whereas for $k=2$ the result is

$$
\beta_{2}-1=Y\left(1+\nu_{2}\right)+\left(\frac{1+\nu_{2}}{\nu_{2}}\right)^{2}
$$

Some calculations have been carried out on the basis of the preceding equations. Various values of $\nu_{1}$ were taken, and the equations were solved numerically for $\nu_{2}$ and $\nu_{3}$. From these, $\mathbf{S}_{1}^{*}=\mathbf{S}_{1}, \mathbf{S}_{2}^{*}, \mathbf{S}_{3}^{*}, \nu_{\mathrm{a} 2}$, and $\nu_{\mathrm{a} 3}$ were calculated. Figures 15.1 to 15.5 show $\mathrm{S} *$ as a function of $\nu_{\text {an }}$ for one, two, and three stages, each figure referring to a different value of $\mathrm{Y}$ from 0.4 to 0.8 . The $\mathrm{x}$ 's represent the end points of the curves for two and three stages and correspond to $\nu_{1}=\infty$. It will be seen that the curves meet tangentially. Figures 15.6 and 15.7 show $1 / \nu_{1}$ and $1 / \nu_{2}$ as functions of $1 / \nu_{a 2}$ for the two-stage pyramid for various values of $Y$. Figures 15.8 to 15.10 show $1 / \nu_{1}, 1 / \nu_{2}$, and $1 / \nu_{3}$ as functions of $1 / \nu_{23}$ for the three-stage pyramid. It will be recalled that $\nu_{\text {an }}$ is given by Eq. 5 in terms of $\mathrm{N}, \mathrm{P}$, and $\mathrm{H}$, and $\mathrm{N}_{\mathrm{k}}$ is given by Eq. 3 in terms of $\nu_{\mathrm{k}}, \mathbf{P}$, and $\mathrm{H}$.

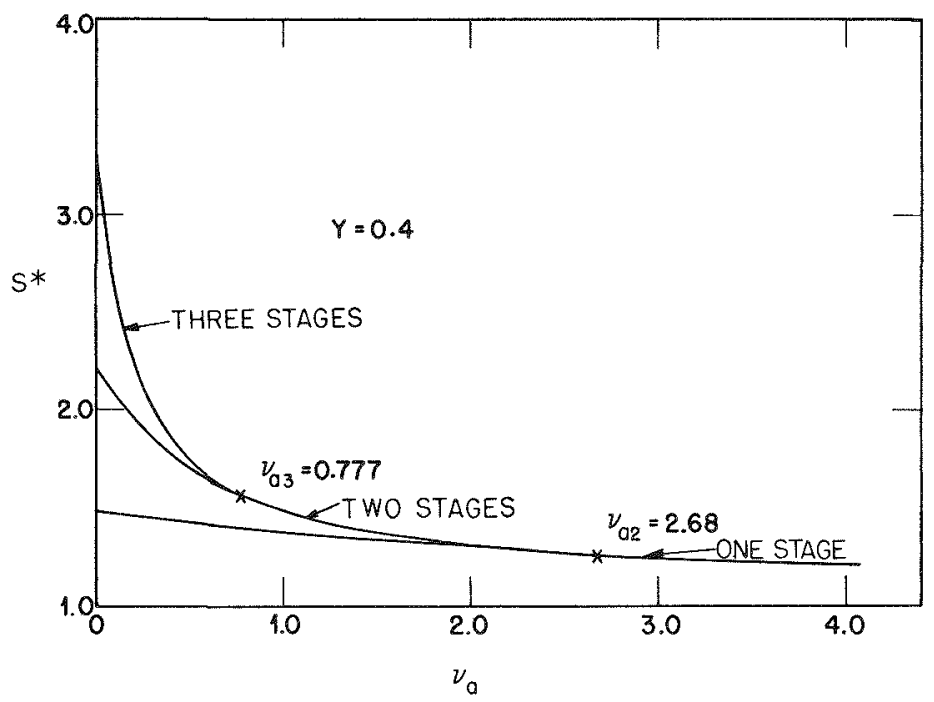

Fig. 15.1-Optimum design of a small pyramid for columns having $\mathrm{Y}=0.4$. If a separation factor less than 1.26 is desired, a single stage is best. If a separation factor between 1.26 and 1.57 is desired, two stages should be employed. 


\section{LIQUID THERMAL DIFFUSION}

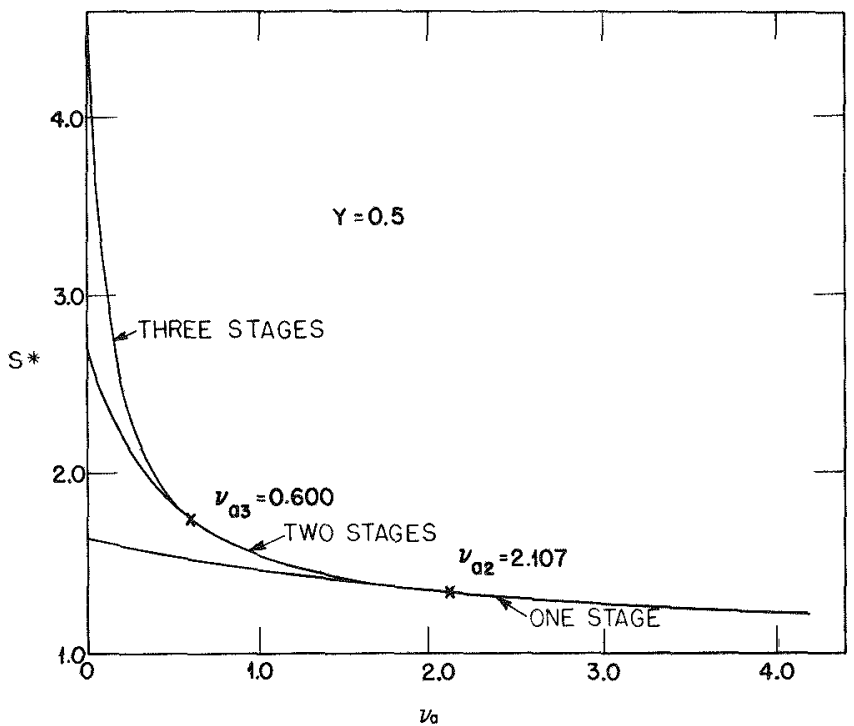

Fig. 15.2-Optimum design of a small pyramid for columns having $Y=0.5$. If a separation factor less than 1.34 is desired, a single stage is best. If a separation factor between 1.34 and 1.75 is desired, two stages should be employed.

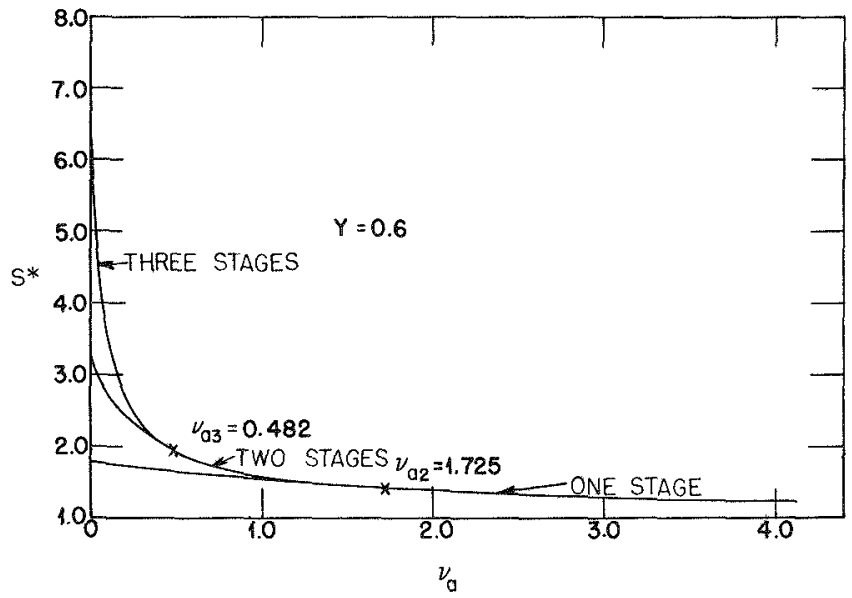

Fig. 15.3-Optimum design of a small pyramid for columns having $Y=0.6$. If a separation factor less than 1.42 is desired, a single stage is best. If a separation factor between 1.42 and 1.95 is desired, two stages should be employed. 


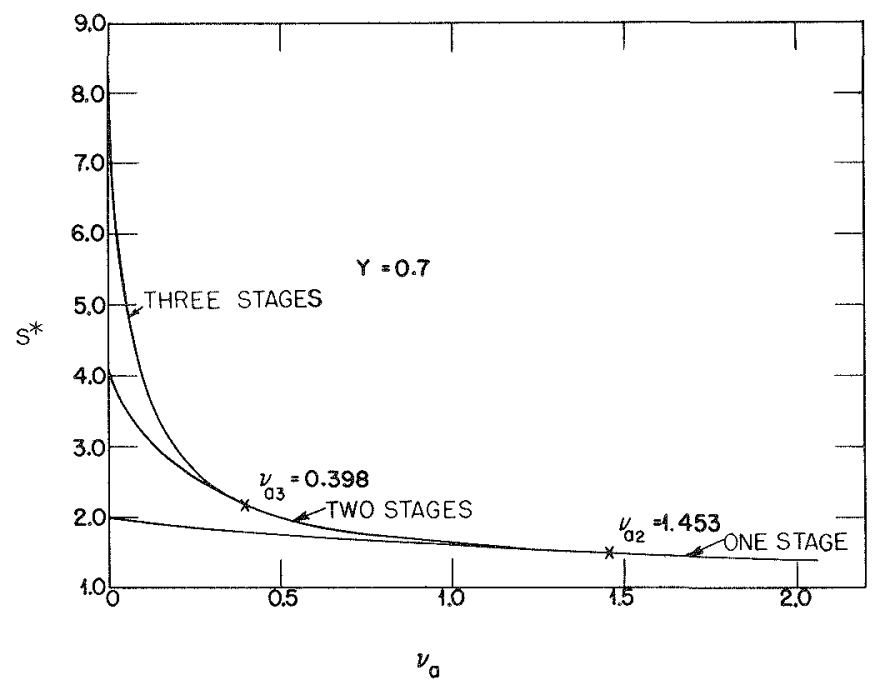

Fig. 15.4-Optimum design of a small pyramid for columns having $Y=0.7$. If a separation factor less than 1.50 is desired, a single stage is best. If a separation factor between 1.50 and 2.17 is desired, two stages should be employed.

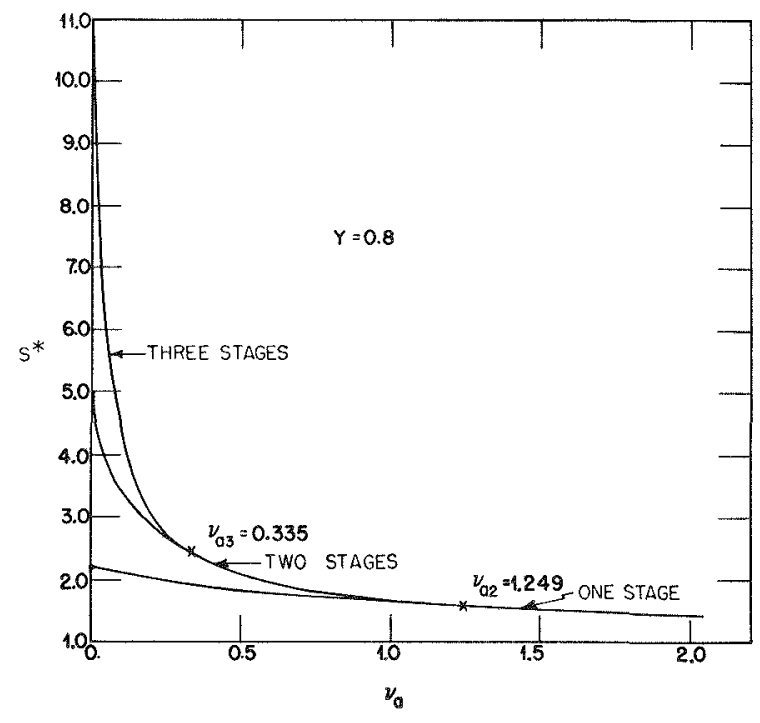

Fig. 15.5-Optimum design of a small pyramid for columns having $Y=0.8$. If a separation factor less than 1.58 is desired, a single stage is best. If a separation factor between 1.58 and 2.43 is desired, two stages should be employed. 


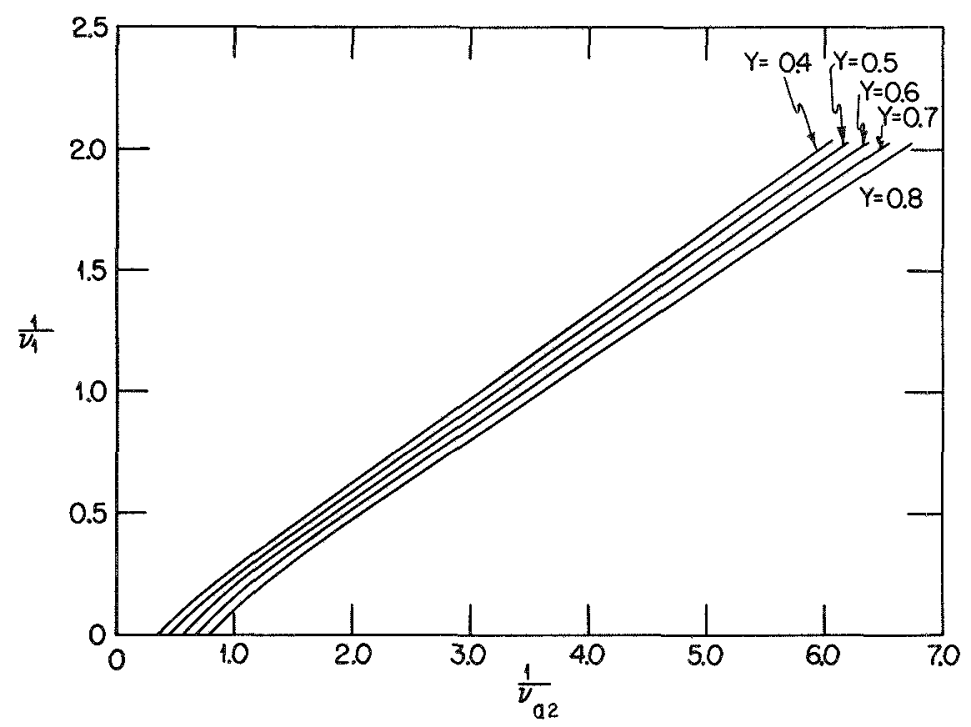

Fig. 15.6-Optimum design of a two-stage pyramid. The curves assist in the choice of the proper number of columns for each stage (see text).

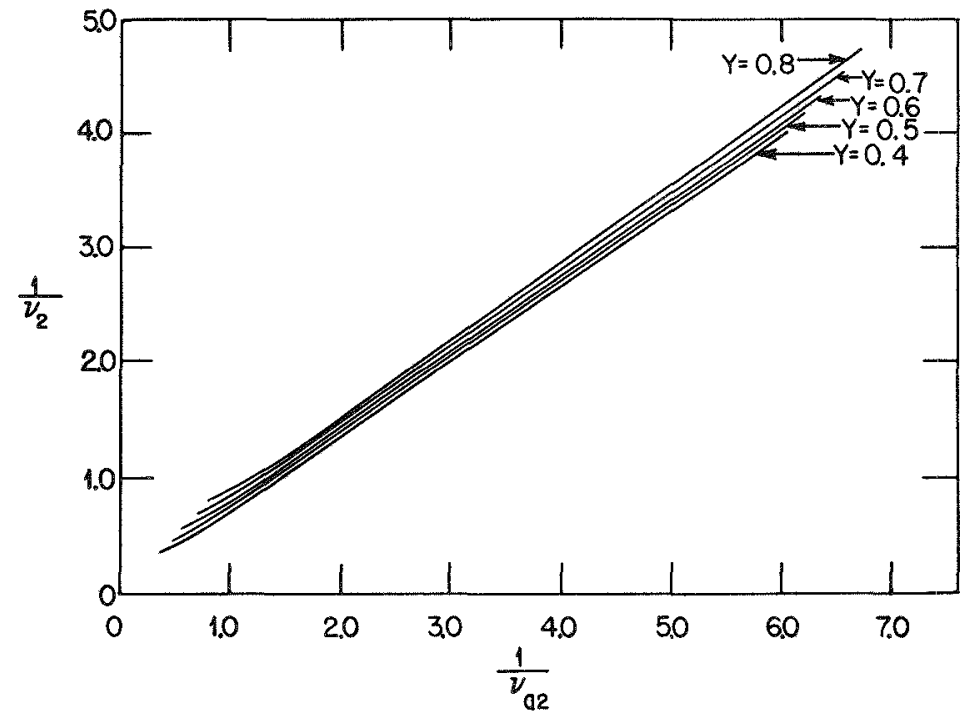

Fig. 15.7-Optimum design of a two-stage pyramid. The curves assist in the choice of the proper number of columns for each stage (see text). 


\section{DESIGN AND PERFORMANCE OF SMALL PYRAMIDS}

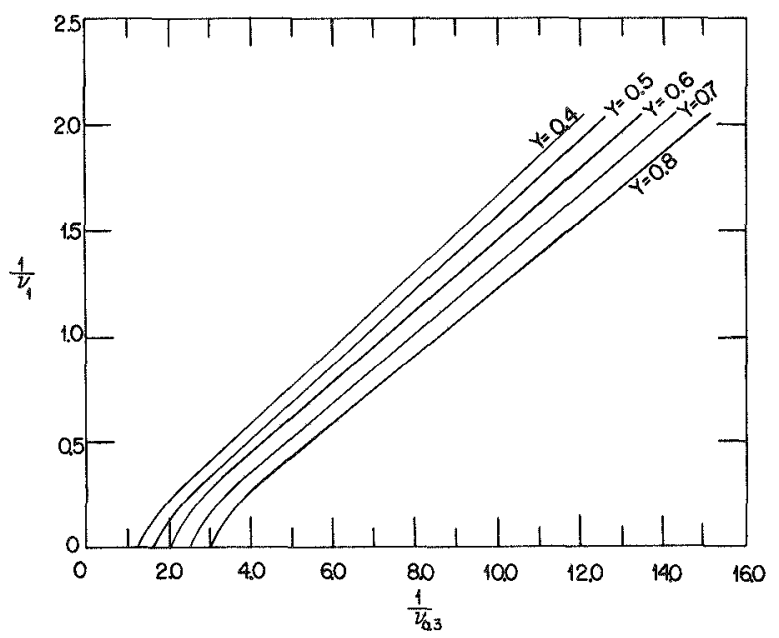

Fig. 15.8-Optimum design of a three-stage pyramid. The curves assist in the choice of the proper number of columns for each stage (see text).

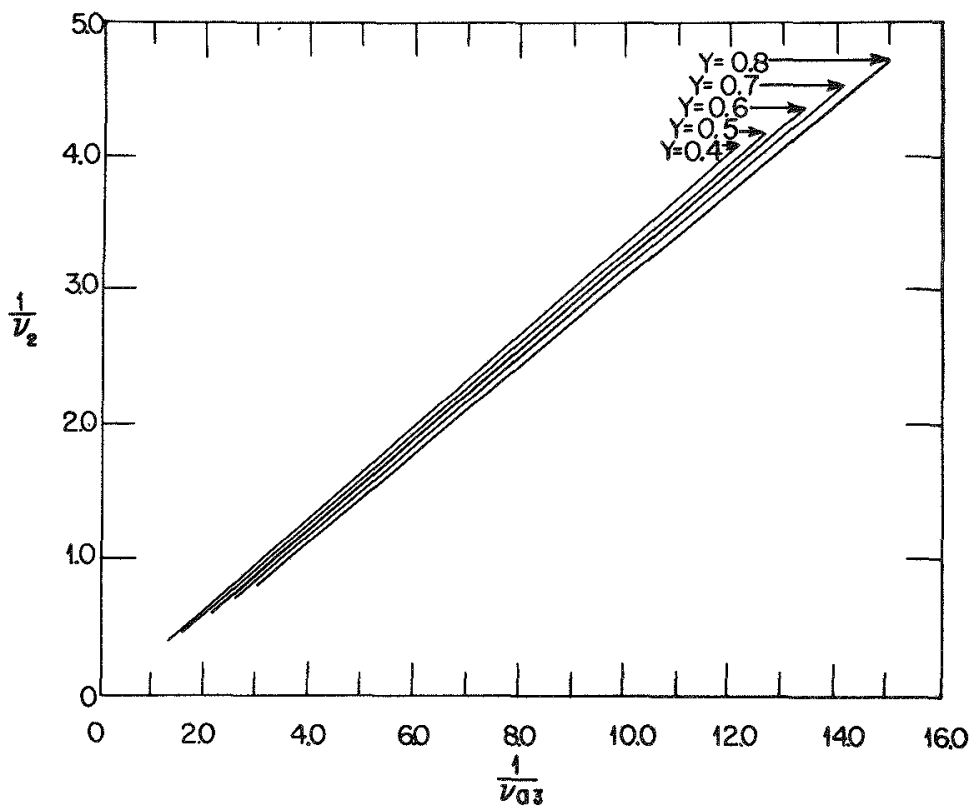

Fig. 15.9-Optimum design of a three-stage pyramid. The curves assist in the choice of the proper number of columns for each stage (see text). 


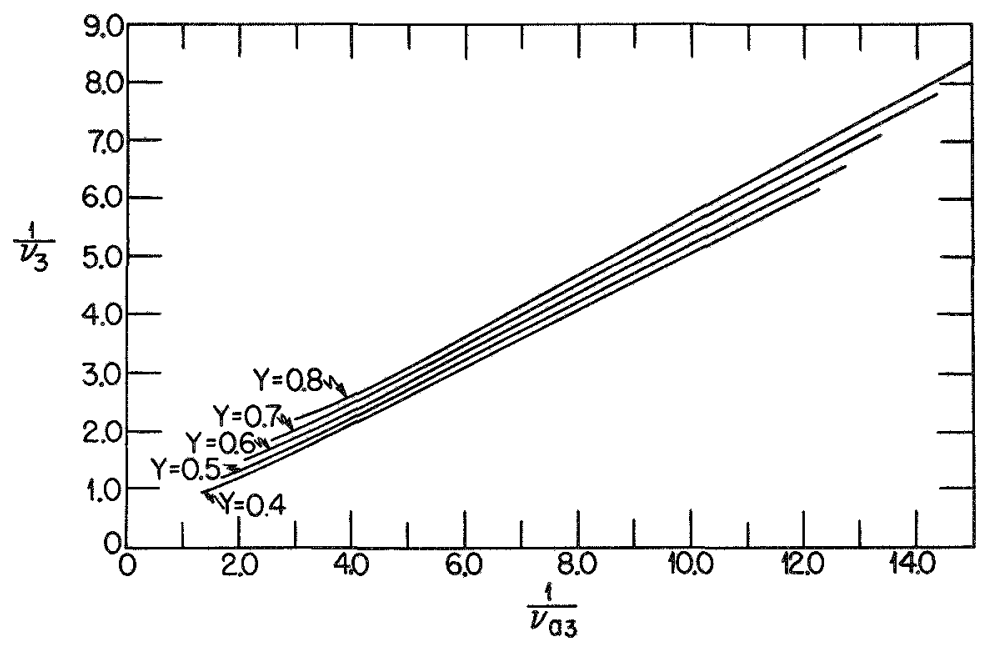

Fig. 15.10-Optimum design of a three-stage pyramid. The curves assist in the choice of the proper number of columns for each stage (see text).

\section{COMPARISON OF PERFORMANCE}

For a given value of $\nu_{\text {an }}$, as determined by the given values of $\mathrm{N}, \mathrm{P}$, and $\mathrm{H}$, the procedure of the previous section gives the best distribution of the columns among the various stages. With this "best" distribution, the separative efficiency will be a function of $\nu_{\mathrm{an}}$. Since only linear approximation is being dealt with here, the separative efficiency is written

$$
E=\frac{4 P}{N H Y}\left(S^{*}-1-\ln S^{*}\right)=\frac{4 \nu_{a}}{Y}\left(S^{*}-1-\ln S^{*}\right)
$$

Figure 15.11 shows $\mathrm{E}$ as a function of $\nu_{\mathrm{a}}$ for one, two, and three stages and for $\mathrm{Y}=0.6$, as a typical case. For a given number of stages, $\mathrm{E}$ as a function of $\nu_{\mathrm{a}}$ has a maximum. An interesting feature of the curves is that the point at which the curves for different numbers of stages meet lies close to the maximum of the curve with the smaller number of stages. In other words, if one starts out with a pyramid of a certain number of stages and gradually increases the number of columns (keeping the ratios of the numbers in the various stages so as to conform to the criterion for optimum performance developed here), a point is reached at which the separative efficiency is a maximum. Any further increase in the number of columns then results in a lowering of separative efficiency unless another stage is added to the pyramid. If 
another stage is added and one continues to satisfy the optimumperformance criterion, then the new curve for $E$ starts out at a value - very slightly lower than the previous maximum but rises rapidly to a new, and appreciably higher, maximum.

It will be seen that there is a definite advantage in having more than one stage. For the range of values of $\mathrm{Y}$ considered here $(0.4$ to 0.8$)$, the separative efficiency is about 80 per cent for a single stage, whereas

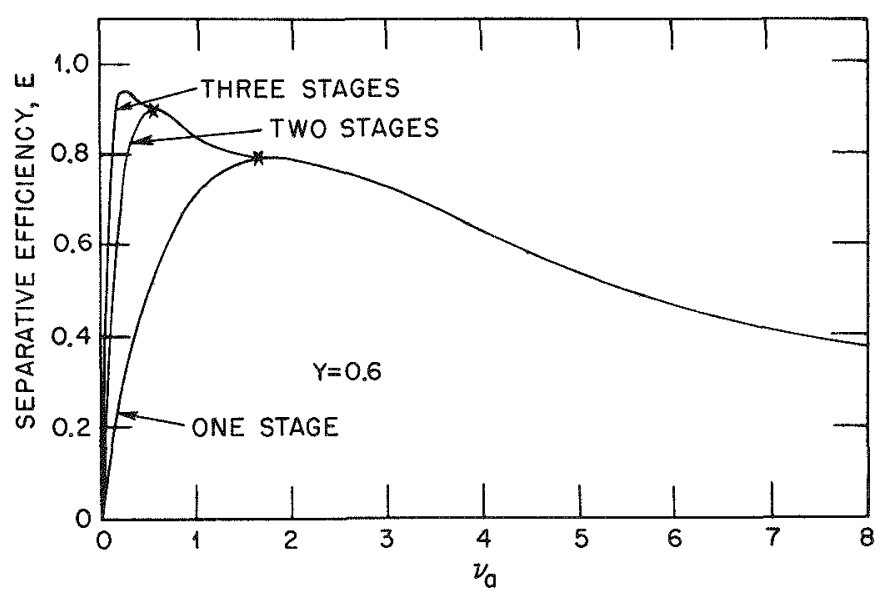

Fig. 15.11-Separative efficiency as a function of the generalized pyramid product rate for the optimum designs presented in the previous figures of this chapter.

for two stages it is over 90 per cent. Going from two to three stages leads to a further, although smaller, improvement. Above three stages the improvement due to the addition of a stage will be still smaller.

\section{OPERATING TIME}

A question of practical importance is that of the time required for the pyramid, initially filled with low-concentration material, to reach the distribution of concentration at which it can be put into operation, i.e., the steady-state product can be withdrawn.

Lengthy calculations are necessary to get this time accurately. An approximate value can be obtained fairly readily, however, by the method used in the discussion of the continuous pyramid (Chap. 12): First, the time required for the pyramid to reproduce its holdup of excess light constitutent is found. 
For the $\mathrm{k}$ th stage, the concentration, $\mathrm{c}_{\mathrm{k}}$, a distance $\mathrm{z}$ up from the bottom of a column is given by

$$
\mathrm{c}_{\mathrm{k}}=\frac{\nu_{\mathrm{k}} \mathrm{c}^{*}}{1+\nu_{\mathrm{k}}}+\left(\mathrm{c}_{\mathrm{Bk}}-\frac{\nu_{\mathrm{k}} \mathrm{c}^{*}}{1+\nu_{\mathrm{k}}}\right) \exp \left[\left(1+\nu_{\mathrm{k}}\right) \alpha \mathrm{z}\right]
$$

where $c^{*}$ is the concentration at the top of the pyramid, and $c_{\mathrm{Bk}}$ is the concentration at the bottom of the $\mathrm{k} t h$ stage. The average value, $\mathrm{c}_{\mathrm{k}}$, for a column of length $L$ is given by

$$
\overline{\mathrm{c}}_{\mathrm{k}}=\frac{1}{\mathrm{~L}} \int_{0}^{\mathrm{L}} \mathrm{c}_{\mathrm{k}} \mathrm{dz}
$$

and, on the basis of Eq. 21, this is found to be

$$
\bar{c}_{k}=\frac{\nu_{k} c^{*}}{1+\nu_{k}}+\left(c_{B k}-\frac{\nu_{k} c^{*}}{1+\nu_{k}}\right) \frac{\exp \left[\left(1+\nu_{k}\right) Y\right]-1}{\left(1+\nu_{k}\right) Y}
$$

The net light-material holdup is given by

$$
M \sum_{k}^{n} N_{k}\left(\bar{c}_{k}-c_{0}\right)
$$

where $M$ is the total holdup of material in one column, $n$ is the number of stages, and $c_{0}$ is the initial concentration. The excess light material in the product per unit time is $\mathrm{P}\left(\mathrm{c}^{*}-\mathrm{c}_{0}\right)$. Hence, the operating time (or relaxation time), $T_{n}$, is given by

$$
T_{n}=\frac{M \sum_{k=1}^{n} N_{k}\left(\bar{c}_{k}-c_{0}\right)}{P\left(c^{*}-c_{0}\right)}
$$

If Eq. 23 is used and $\mathrm{N}_{\mathrm{k}}=\mathrm{P} / \mathrm{H} \nu_{\mathrm{k}}$, it is found that

$$
\mathrm{T}_{n}=\frac{\mathrm{M}}{\mathrm{H}\left(\mathrm{c}^{*}-\mathrm{c}_{0}\right)} \sum_{\mathrm{k}=1}^{\mathrm{n}}\left[\frac{\mathrm{c}^{*}}{1+\nu_{\mathrm{k}}}-\frac{\mathrm{c}_{0}}{\nu_{\mathrm{k}}}+\left(\frac{\mathrm{c}_{\mathrm{Bk}}}{\nu_{\mathrm{k}}}-\frac{\mathrm{c}^{*}}{1+\nu_{\mathrm{k}}}\right) \frac{\beta_{\mathrm{k}}-1}{\left(1+\nu_{\mathrm{k}}\right)}\right]
$$

Setting

$$
\frac{c^{*}}{c_{0}}=S_{n}^{*} \quad \frac{c_{B k}}{c_{0}}=\frac{S_{n}^{*}}{S_{k}^{*}}
$$

the result is

$$
\mathrm{T}_{\mathrm{n}}=\frac{\mathrm{M} \mathrm{S}_{\mathrm{n}}^{*}}{\mathrm{H}\left(\mathrm{S}_{\mathrm{n}}^{*}-1\right)} \sum_{\mathrm{k}=1}^{\mathrm{n}}\left[\frac{1}{1+\nu_{\mathrm{k}}}-\frac{1}{\mathrm{~S}_{\mathrm{n}}^{*} \nu_{\mathrm{k}}}+\left(\frac{1}{S_{\mathrm{k}}^{*} \nu_{\mathrm{k}}}-\frac{1}{1+\nu_{\mathrm{k}}}\right) \frac{\beta_{\mathrm{k}}-1}{\left(1+\nu_{\mathrm{k}}\right) \mathbf{Y}}\right]
$$




\section{DESIGN AND PERFORMANCE OF SMALL PYRAMIDS}

Making use of the time constant, $x$, given by

$$
\mathrm{X}=\frac{\mathrm{M}}{\mathrm{HY}}
$$

this can be written finally as

$$
\frac{T_{n}}{X}=\frac{S_{n}^{*}}{S_{n}^{*}-1} \sum_{k=1}^{k}\left[Y\left(\frac{1}{1+\nu_{k}}-\frac{1}{S_{n}^{*} \nu_{k}}\right)+\left(\frac{1}{S_{k}^{*} \nu_{k}}-\frac{1}{1+\nu_{k}}\right) \frac{\beta_{k}-1}{1+\nu_{k}}\right]
$$

For the case $n=1$, this expression can be reduced to the form

$$
\frac{T_{1}}{X}=\frac{1}{\nu_{1}}\left(\frac{1}{1+\nu_{1}}-\frac{Y}{\beta_{1}-1}\right)
$$

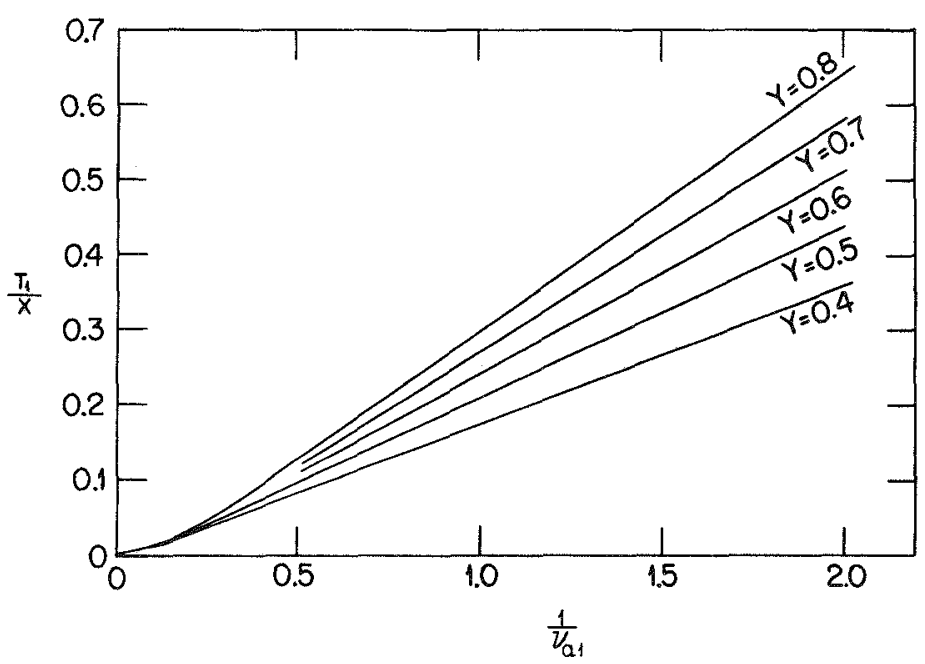

Fig. 15.12-Time $\left(T_{1}\right)$ necessary to reach steady-state operating conditions for a one-stage pyramid as a function of the reciprocal of the generalized product rate.

For pyramids designed for optimum performance, as in Sec. 2, calculations have been carried out for one, two, and three stages, and the results are presented as graphs in Figs. 15.12 to 15.14 , where $T / X$ is given as a function of $\nu_{\mathrm{a}}$, for values of $\mathrm{Y}$ from 0.4 to 0.8 . 


\section{LIQUID THERMAL DIFFUSION}

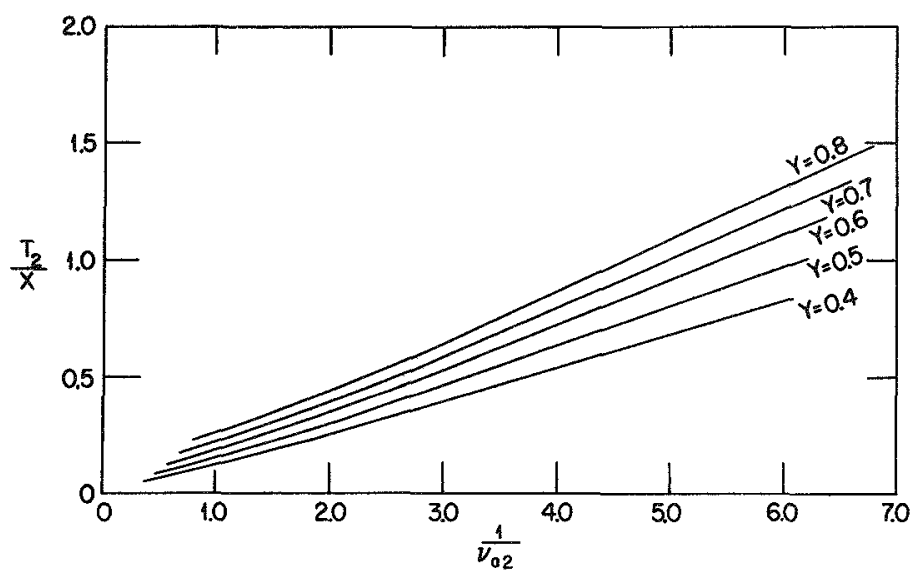

Fig. 15.13-Time $\left(\mathrm{T}_{2}\right)$ necessary to reach steady-state operating conditions for a two-stage pyramid as a function of the reciprocal of the generalized product rate.

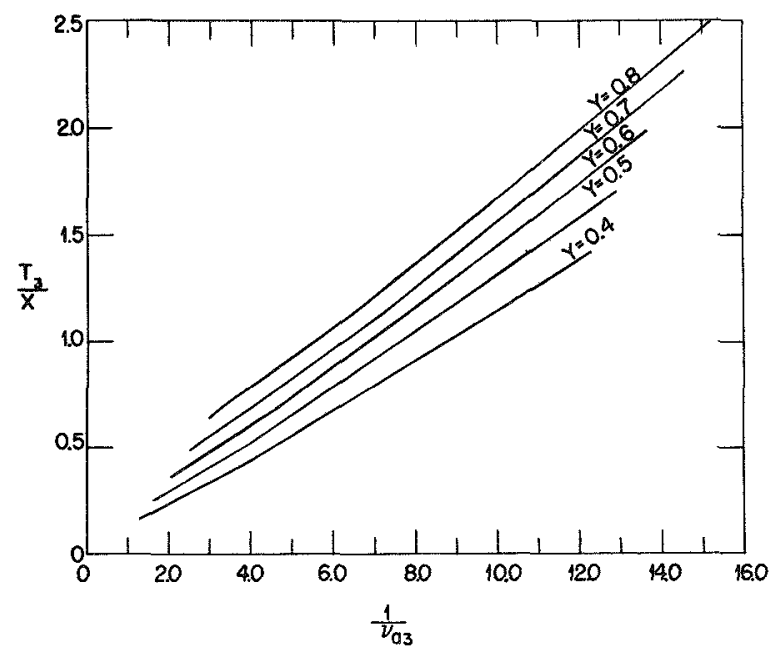

Fig. 15.14-Time $\left(\mathrm{T}_{3}\right)$ necessary to reach steady-state operating conditions for a three-stage pyramid as a function of the reciprocal of the generalized product rate. 
Chapter 16

\section{APPROXIMATE TREATMENT OF SMALL PYRAMIDS APPROACHING EQUILIBRIUM}

\section{METHOD}

The case of a single column approaching equilibrium can be treated by setting up and solving a partial differential equation with suitable boundary conditions. If the concentrations involved are small, the equation is linear and can usually be solved by standard methods. The corresponding case of a pyramid with several stages, however, is much more difficult because it involves a number of partial differential equa tions with interrelated boundary conditions. The solution of such a problem is, in general, a very laborious task. Frequently, however, it is desirable to get an approximate result without lengthy calculations. This chapter discusses one method of accomplishing this.

The method is based on the idea of simplifying the calculations by assuming that, within each column, the concentration at all times varies linearly with the distance up the column. By means of this assumption, a system of ordinary differential equations is obtained instead of the partial differential equations of the more exact treatment.

Consider the case of a pyramid of $m$ stages, with the bottom connected to a large reservoir, so that the concentration there remains constant. Let the number of parallel columns in the $\mathrm{k}$ th stage $(\mathrm{k}=1,2, \ldots, \mathrm{m})$, counting up from the bottom, be $\mathrm{N}_{\mathrm{k}}$. Let all the columns in the system be identical, and let $\mathrm{H}$ and $\mathrm{K}$ be the constants of a single column. Let $\mathrm{L}$ be the length and $\mathrm{M}$ the holdup of a column, and let $\mathrm{MU}_{\mathrm{k}}$ be the interstage holdup above the $\mathrm{k} t h$ stage. Let $\mathrm{c}_{0}$ be the concentration at the bottom of the first stage (this being a constant in the present case) and $c_{k}$ the concentration at the top of the $k t h$ stage. Finally, assume that, as the pyramid approaches equilibrium from an initial concentration $c_{0}$, product is removed at a constant rate $\mathbf{P}$. 
The net upward transport of light constituent at the middle of the $\mathrm{kth}$ column is, if the concentration is sufficiently small,

$$
\tau_{k}=\frac{1}{2}\left(N_{k} H+P\right)\left(c_{k}+c_{k-1}\right)-\frac{N_{k} K}{L}\left(c_{k}-c_{k-1}\right)
$$

since, on the basis of the assumption of linearity, the concentration there is $\left(c_{k}+c_{k-1}\right) / 2$, and the gradient of the concentration is $\left(c_{k}-c_{k-1}\right) / L$. In the same way, for the next stage up,

$$
\tau_{k-1}=\frac{1}{2}\left(N_{k+1} H+P\right)\left(c_{k}+c_{k+1}\right)-\frac{N_{k+1} K}{L}\left(c_{k+1}-c_{k}\right)
$$

The difference between these two, $\tau_{\mathrm{k}}-\tau_{\mathrm{k}+1}$, equals the rate at which the light constituent accumulates in the region between the middle of the $\mathrm{k} t h$ and the middle of the $(\mathrm{k}+1)$ th stage. The mass of light constituent present in this region is given by

$$
\begin{aligned}
\mathrm{W}_{\mathrm{k}}=\mathrm{N}_{\mathrm{k}}\left(\frac{\mathrm{M}}{2}\right)\left(\frac{1}{4} c_{\mathrm{k}-1}+\frac{3}{4} c_{\mathrm{k}}\right)+\mathrm{N}_{\mathrm{k}+1}\left(\frac{\mathrm{M}}{2}\right)\left(\frac{3}{4} \mathrm{c}_{\mathrm{k}}+\frac{1}{4} \mathrm{c}_{\mathrm{k}+1}\right)+M \mathrm{MU}_{\mathrm{k}} \mathrm{c}_{\mathrm{k}} \\
=\frac{\mathrm{M}}{8}\left[\mathrm{~N}_{\mathrm{k}} \mathrm{c}_{\mathrm{k}-1}+\left(3 \mathrm{~N}_{\mathrm{k}}+3 \mathrm{~N}_{\mathrm{k}+1}+8 \mathrm{U}_{\mathrm{k}}\right) \mathrm{c}_{\mathrm{k}}+\mathrm{N}_{\mathrm{k}+1} \mathrm{c}_{\mathrm{k}+1}\right]
\end{aligned}
$$

Hence

$$
\frac{\mathrm{d} \mathrm{W}_{\mathrm{k}}}{\mathrm{dt}}=\tau_{\mathrm{k}}-\tau_{\mathrm{k}+1}
$$

or

$$
\begin{aligned}
& \frac{M}{8}\left[N_{k} \frac{d c_{k-1}}{d t}+\left(3 N_{k}+3 N_{k+1}\right.\right.\left.+8 U_{k}\right) \frac{d c_{k}}{d t}+ \\
&=\left[N_{k+1} \frac{d c_{k+1}}{d t}\right] \\
&\left.+\left[\frac{K}{L}+\frac{H}{2}\right)+\frac{P}{2}\right] c_{k-1}+\left[N_{k}\left(-\frac{K}{L}+\frac{H}{2}\right)-N_{k+1}\left(\frac{K}{L}+\frac{H}{2}\right)\right] c_{k} \\
&\left.+\frac{H}{2}\right] c_{k+1}
\end{aligned}
$$

for $\mathrm{k}=1,2, \ldots, \mathrm{m}-1$.

In the case of the top stage $(k=m)$, some modification is necessary. 
In place of Eq. 4 it is necessary to have

$$
\frac{\mathrm{dW}}{\mathrm{dt}}=\tau_{\mathrm{m}}-\mathrm{Pc}_{\mathrm{m}}
$$

where now

$$
\begin{aligned}
W_{m}=N_{m}\left(\frac{M}{2}\right)\left(\frac{1}{4} c_{m-1}+\frac{3}{4} c_{m}\right) & +M U_{m} c_{m} \\
& =\frac{M}{8}\left[N_{m} c_{m-1}+\left(3 N_{m}+8 U_{m}\right) c_{m}\right]
\end{aligned}
$$

so that the equation for this case is

$$
\begin{aligned}
\frac{M}{8}\left[N_{m} \frac{d c_{m-1}}{d t}\right. & \left.+\left(3 N_{m}+8 U_{m}\right) \frac{d c_{m}}{d t}\right] \\
= & {\left[N_{m}\left(\frac{K}{L}+\frac{H}{2}\right)+\frac{P}{2}\right] c_{m-1}+\left[N_{m}\left(-\frac{K}{L}+\frac{H}{2}\right)-\frac{P}{2}\right] c_{m} }
\end{aligned}
$$

Finally, the constants $\mathrm{Y}=\mathrm{HL} / \mathrm{K}, \mathrm{X}=\mathrm{MK} / \mathrm{H}^{2} \mathrm{~L}$, and $\nu=\mathrm{P} / \mathrm{H}$ are introduced. Then Eq. 5 can be written, using a dot to denote a time derivative,

$$
\begin{aligned}
\mathrm{XY}^{2}\left[\mathrm{~N}_{\mathrm{k}} \dot{\mathrm{c}}_{\mathrm{k}-1}+\left(3 \mathrm{~N}_{\mathrm{k}}+3 \mathrm{~N}_{\mathrm{k}+1}+8 \mathrm{U}_{\mathrm{k}}\right) \dot{\mathrm{c}}_{\mathrm{k}}+\mathrm{N}_{\mathrm{k}+1} \dot{\mathrm{c}}_{\mathrm{k}+1}\right] \\
-\left[\mathrm{N}_{\mathrm{k}}(8+4 \mathrm{Y})+4 \nu \mathrm{Y}\right] \mathrm{c}_{\mathrm{k}-1}-\left[\mathrm{N}_{\mathrm{k}}(-8+4 \mathrm{Y})-\mathrm{N}_{\mathrm{k}+1}(8+4 \mathrm{Y})\right] \mathrm{c}_{\mathrm{k}} \\
-\left[\mathrm{N}_{\mathrm{k}+1}(8-4 \mathrm{Y})-4 \nu \mathrm{Y}\right] \mathrm{c}_{\mathrm{k}+1}=0
\end{aligned}
$$

and Eq. 8 can be written

$$
\begin{aligned}
\mathrm{XY}^{2}\left[\mathrm{~N}_{\mathrm{m}} \dot{\mathrm{c}}_{\mathrm{m}-1}+\left(3 \mathrm{~N}_{\mathrm{m}}+8 \mathrm{U}_{\mathrm{m}}\right) \dot{\mathrm{c}}_{\mathrm{m}}\right]- & {\left[\mathrm{N}_{\mathrm{m}}(8+4 \mathrm{Y})+4 \nu \mathrm{Y}\right] \mathrm{c}_{\mathrm{m}-1} } \\
- & {\left[\mathrm{N}_{\mathrm{m}}(-8+4 \mathrm{Y})-4 \nu \mathrm{Y}\right] \mathrm{c}_{\mathrm{m}}=0 }
\end{aligned}
$$

To solve this system of equations, first get the steady-state solution by setting all derivatives equal to zero. This solution can be obtained from Eq. 1 by setting $\tau_{\mathrm{k}}=\mathrm{Pc}_{\mathrm{m}}$. Then

$$
S_{j}^{1} \equiv \frac{c_{j}}{c_{j-1}}=\frac{1+\frac{1}{2} Y\left(1+\nu_{j}\right)}{1+\frac{1}{2} Y\left[\left(2 S_{j}^{c}-1\right) \nu_{j}-1\right]} \quad(j=1,2, \ldots, m)
$$


where

$$
\nu_{j}=\frac{\nu}{N_{i}} \quad S_{j}^{c}=\frac{c_{m}}{c_{j}}
$$

From Eq. 11, working down the pyramid from the top, all the $c_{j}$ can be expressed in terms of $c_{m}$, and, by getting also a relation between $c_{0}$ and $c_{m}$, all the $c_{j}$ can then be expressed in terms of $c_{0}$.

Next get the solutions of the homogeneous equations obtained by omitting from Eqs. 9 and 10 all terms containing $c_{0}$. To do this, write

$$
c_{j}=A_{j} \exp \left(\beta t / X Y^{2}\right) \quad(j=1,2, \ldots, m)
$$

and substitute back into the homogeneous equations. The latter now become a set of linear homogeneous equations for the $A_{j}$ with an unknown parameter $\beta$. Putting the determinant of the coefficients of the $A_{j}$ equal to zero, as the condition for the existence of a nontrivial solution, a secular equation is obtained to determine $\beta$. In general, this equation, being of the $\mathrm{m}$ th degree, will have $\mathrm{m}$ roots: $\beta_{1}, \beta_{2}, \ldots, \beta_{\mathrm{m}}$. If the $\mathrm{i} t h$ root, $\beta_{1}$, is put back into the equation, the solution for the $A$ 's is

$$
A_{j}=A_{j}^{(i)} \quad(i=1,2, \ldots, m)
$$

determined to within a common factor. If all the $\mathrm{m}$ roots are different, $m$ such independent solutions will be obtained. If some of the roots are repeated, it is possible to construct $m$ independent solutions; this case is not likely to arise, however, and will not be discussed further.

The general solution of Eqs. 9 and 10 can now be written

$$
c_{j}=c_{j}^{0}+\sum_{i=1}^{m} B_{i} A_{j}^{(i)} \exp \left(\beta_{i} t / X Y^{2}\right)
$$

where the $c_{j}^{0}$ are the steady-state solutions and the $B_{i}$ is a set of $m$ arbitrary constants. These constants are to be chosen to satisfy the initial conditions, which in the present case are given by

$$
\mathrm{t}=0 \quad \mathrm{c}_{\mathbf{j}}=\mathrm{c}_{0} \quad(\mathbf{j}=\mathbf{1}, \ldots, \mathrm{m})
$$

In this way the solution to the problem is obtained.

Other situations involving pyramids can be treated in the same way but with appropriate modifications in the details.

\section{EXAMPLES}

By way of illustration, the above method will be applied to the case of a single column, for which it is possible to make a comparison with 
the results of a more accurate calculation.

For a single column, there is only one equation, that corresponding to Eq. 10. Let $U_{m}=0$. By setting $c_{m-1}=c_{0}=0$ and dropping subscripts, except in the case of $c_{0}$, the result for Eq. 10 is

$$
3 X Y^{2} \dot{c}+(8-4 Y+4 \nu Y) c=(8+4 Y+4 \nu Y) c_{0}
$$

where $c$ refers to the top of the column.

The steady-state solution is given by

$$
\mathrm{S} \equiv \frac{\mathrm{c}}{\mathrm{c}_{0}}=\frac{1+\frac{1}{2} \mathrm{Y}(\nu+1)}{1+\frac{1}{2} \mathrm{Y}(\nu-1)}
$$

Figure 16.1 shows a graph of $\mathrm{S}$ vs. $\nu$, as given by $\mathrm{Eq} .18$ with $\mathrm{Y}=0.4$, and also a corresponding graph for the more accurate value

$$
\mathrm{S}_{\mathbf{a}}=\frac{\nu+1}{\nu+\exp [-\mathrm{Y}(\nu+1)]}
$$

It will be seen that the two agree best for small values of $\nu$.

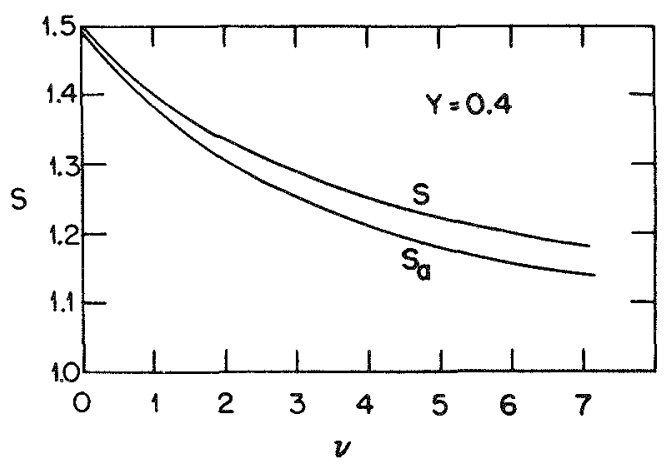

Fig. 16.1-Comparison of separation factor (S) calculated by an approximate method with the accurate value $\left(S_{a}\right)$. The case considered is steady-state operation of a single column at low concentrations of the desired isotope.

Now determine the behavior of the column as it approaches equilibrium. By omitting in Eq. 17 the term with $\mathrm{c}_{0}$ and writing

$$
\mathrm{c}=\mathrm{A} \exp \left(\beta \mathrm{t} / \mathrm{XY}^{2}\right)
$$




\section{LIQUID THERMAL DIFFUSION}

it is found that

$$
3 \beta A+[8+4 \mathbf{Y}(\nu-1)] \mathrm{A}=0
$$

whence

$$
\beta=-\frac{8}{3}\left[1+\frac{1}{2} Y(\nu-1)\right]
$$

and the general solution for $\mathrm{c}$ is

$$
c=c_{0}\left\{\frac{1+\frac{1}{2} Y(\nu+1)}{1+\frac{1}{2} Y(\nu-1)}+B \exp \left[-\frac{8}{3} \frac{1+\frac{1}{2} Y(\nu-1)}{X Y^{2}} t\right]\right\}
$$

By placing $\mathbf{t}=0, \mathbf{c}=\mathrm{c}_{0}, \mathrm{~B}$ is determined, getting finally

$$
c=c_{0}\left\{\frac{1+\frac{1}{2} Y(\nu+1)}{1+\frac{1}{2} Y(\nu-1)}-\frac{Y}{1+\frac{1}{2} Y(\nu-1)} \exp \left[-\frac{8}{3} \frac{1+\frac{1}{2} Y(\nu-1)}{X Y^{2}} t\right]\right\}
$$

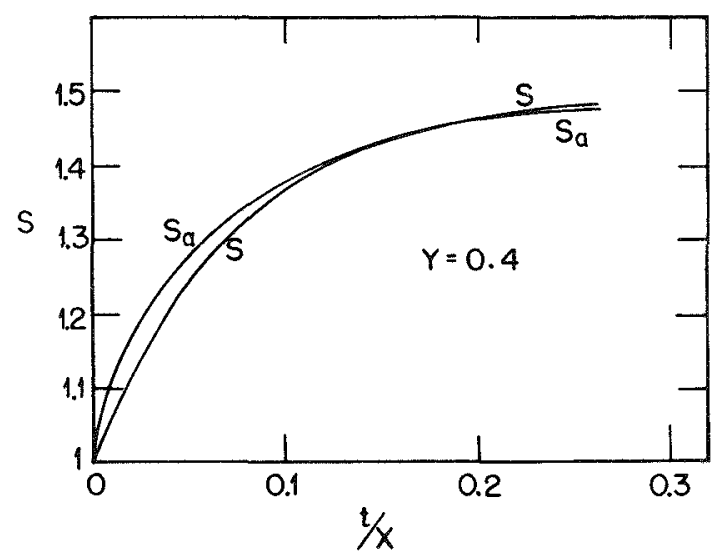

Fig. 16.2-Comparison of separation factor (S) calculated by an approximate method with the accurate value $\left(S_{2}\right)$. This refers to approach to equilibrium of a single column, closed at the top, with a reservoir at the bottom. 
In the case in which no product is removed during the process $(\nu=0)$, this becomes

$$
S=\frac{1+\frac{1}{2} Y}{1-\frac{1}{2} Y}-\frac{Y}{1-\frac{1}{2} Y} \exp \left(-\frac{8}{3} \frac{1-\frac{1}{2} Y}{X Y^{2}} t\right)
$$

Figure 16.2 shows a graph of $S$ vs. $t / X$ for the case $Y=0.4$ and also a corresponding graph for the more accurate function $S_{a}$, as determined by solving the partial differential equation for the single column. It will be seen that the agreement is best for the larger values of $t / x$.

It appears from the preceding results that the simpler method is better suited to the problem of the approach to equilibrium without product removal than to the case in which there is a finite product rate. It should be noted that it is reasonable to expect that the discrepancy between the approximate and accurate calculations will be greatest for a single column and will decrease with an increase in the number of stages in the pyramid. This is because, as the number of stages is increased, the role of any one stage becomes relatively less important and the pyramid tends toward the continuous, or infinitesimal-step, pyramid for which the approximate calculation becomes exact.

It might be mentioned parenthetically that the method discussed here can be applied to the case of a single column, but with greater accuracy than that obtained in the above example, by treating each half of the column as a separate stage with its $\mathrm{Y}$ having a value one-half that of the column. Thus, if $N_{1}=N_{2}=1$ and if $Y=0.2$, the solution is

$$
S=1.494-0.436 \exp (-13.2 t / X)-0.058 \exp (-144 t / X)
$$

which is to be compared with the expansion obtained by solving the partial differential equation for a single column

$$
S_{a}=1.492-0.415 \exp (-13.1 t / X)-0.037 \exp (-137 t / X)-\ldots
$$

Obviously, any degree of accuracy can be obtained by subdividing the column sufficiently.

As another example, take the case of a three-stage pyramid approaching equilibrium with zero product rate and attached at the bottom to an infinite reservoir. For the sake of simplicity assume that the interstage holdups are negligible. The equations for this case can be written 


$$
\begin{aligned}
& X Y^{2}\left[\left(3 N_{1}+3 N_{2}\right) \dot{c}_{1}+N_{2} \dot{c}_{2}\right]-N_{1}(8+4 Y) c_{0} \\
& +\left[N_{1}(8-4 Y)+N_{2}(8+4 Y)\right] c_{1}-N_{2}(8-4 Y) c_{2}=0 \\
& X Y^{2}\left[N_{2} \dot{c}_{1}+\left(3 N_{2}+3 N_{3}\right) \dot{c}_{2}+N_{3} \dot{c}_{3}\right]-N_{2}(8+4 Y) c_{1} \\
& +\left[N_{2}(8-4 Y)+N_{3}(8+4 Y)\right] c_{2}-N_{3}(8-4 Y) c_{3}=0
\end{aligned}
$$

To make the problem specific, take $N_{1}=9, N_{2}=5$, and $N_{3}=2$. Then the preceding equations become

$$
\left.\begin{array}{l}
X Y^{2}\left(42 \dot{c}_{1}+5 \dot{c}_{2}\right)-(72+36 Y) c_{0}+(112-16 Y) c_{1}-(40-20 Y) c_{2}=0 \\
X Y^{2}\left(5 \dot{c}_{1}+21 \dot{c}_{2}+2 \dot{c}_{3}\right)-(40+20 Y) c_{1}+(56-12 Y) c_{2} \\
X Y^{2}\left(2 \dot{c}_{2}+6 \dot{c}_{3}\right)-(16+8 Y) c_{2}+(16-8 Y) c_{3}=0
\end{array}\right\}
$$

If $s_{j}=c_{j} / c_{0}$, it follows from the above that at equilibrium

$$
S_{1}=\frac{1+\frac{Y}{2}}{1-\frac{Y}{2}} \quad S_{2}=S_{1}^{2} \quad S_{3}=S_{1}^{3}
$$

To get the "transient terms" in the solution, delete the terms in the equations containing $\mathrm{c}_{0}$ and write temporarily

$c_{1}=A_{1} \exp \left(\beta t / X Y^{2}\right) \quad c_{2}=A_{2} \exp \beta t / X Y^{2} \quad c_{3}=A_{3} \exp \beta t / X Y^{2}$

The equations become

$$
\left.\begin{array}{l}
(42 \beta+112-16 \mathrm{Y}) \mathrm{A}_{1}+(5 \beta-40+20 \mathrm{Y}) \mathrm{A}_{2}=0 \\
(5 \beta-40-20 \mathrm{Y}) \mathrm{A}_{1}+(21 \beta+56-12 \mathrm{Y}) \mathrm{A}_{2}+(2 \beta-16+8 \mathrm{Y}) \mathrm{A}_{3}=0 \\
(2 \beta-16-8 \mathrm{Y}) \mathrm{A}_{2}+(6 \beta+16-8 \mathrm{Y}) \mathrm{A}_{3}=0
\end{array}\right\}
$$

Hence the secular equation for $\beta$ is

$$
\left|\begin{array}{ccc}
42 \beta+112-16 \mathrm{Y} & 5 \beta-40+20 \mathrm{Y} & 0 \\
5 \beta-40-20 \mathrm{Y} & 21 \beta+56-12 \mathrm{Y} & 2 \beta-16+8 \mathrm{Y} \\
0 & 2 \beta-16-8 \mathrm{Y} & 6 \beta+16-8 \mathrm{Y}
\end{array}\right|=0
$$


This represents a cubic equation for $\beta$. If one takes $Y=0.4$, then the roots are

$$
\beta_{1}=0.3549 \quad \beta_{2}=2.335 \quad \beta_{3}=5.722
$$

Substituting these three values successively into the system of Eqq. $30 \mathrm{a}, \mathrm{b}$, and $\mathrm{c}$, three independent solutions for the A's are found:

$$
\left.\begin{array}{lll}
\beta=\beta_{1} & \mathrm{~A}_{2}=2.685 \mathrm{~A}_{1} & \mathrm{~A}_{3}=5.011 \mathrm{~A}_{1} \\
\beta=\beta_{2} & \mathrm{~A}_{2}=0.1722 \mathrm{~A}_{1} & \mathrm{~A}_{3}=3.395 \mathrm{~A}_{1} \\
\beta=\beta_{3} & \mathrm{~A}_{2}=2.223 \mathrm{~A}_{1} & \mathrm{~A}_{3}=3.164 \mathrm{~A}_{1}
\end{array}\right\}
$$

Hence the general solution, with appropriate equilibrium values, is given by

$$
\left.\begin{array}{rl}
S_{1}=1.5+B_{1} \exp \beta_{1} t / X Y^{2}+B_{2} \exp \beta_{2} t / X Y^{2}+B_{3} \exp \beta_{3} t / X Y^{2} \\
S_{2}=2.25+2.685 B_{1} \exp \beta_{1} t / X Y^{2}+0.1722 B_{2} \exp \beta_{2} t / X Y^{2} \\
-2.223 B_{3} \exp \beta_{3} t / X Y^{2} \\
S_{3}=3.375+5.011 B_{1} \exp \beta_{1} t / X Y^{2}-3.395 B_{2} \exp \beta_{2} t / X Y^{2} \\
+3.164 B_{3} \exp \beta_{3} t / X Y^{2}
\end{array}\right\}
$$

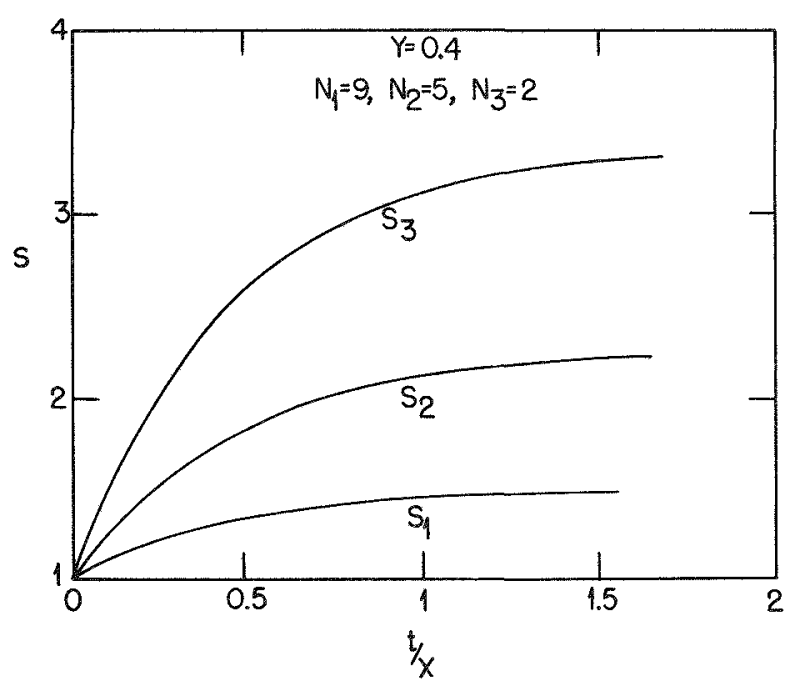

Fig. 16.3-Approach to equilibrium of a three-stage pyramid as calculated by the approximate method. 


\section{LIQUID THERMAL DIF FUSION}

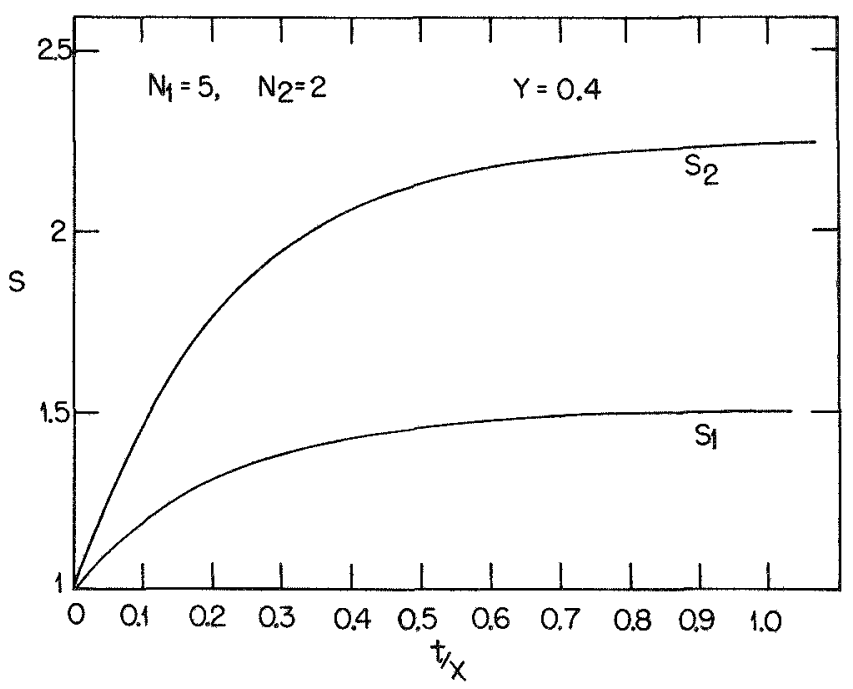

Fig. 16.4-Approach to equilibrium of a two-stage pyramid as calculated by the approximate method.

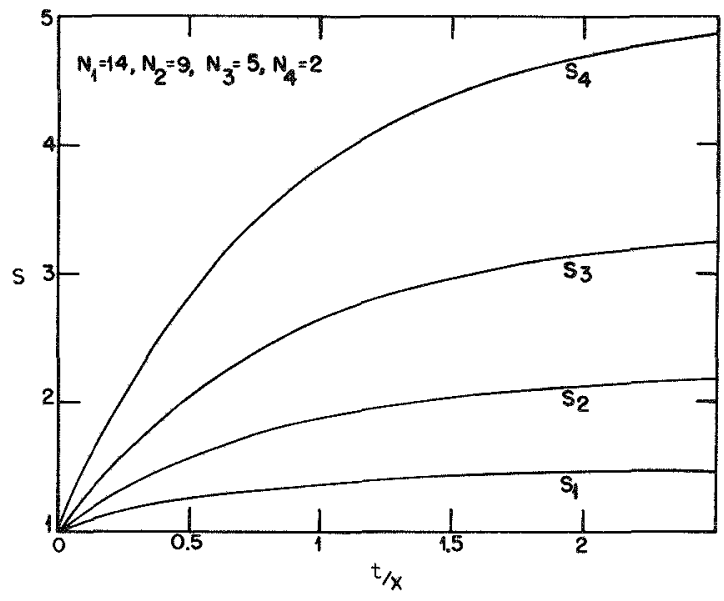

Fig. 16,5-Approach to equilibrium of a four-stage pyramid as calculated by the approximate method. 
where $B_{1}, B_{2}$, and $B_{3}$ are arbitrary constants. To get the solution which has $S_{1}=S_{2}=S_{3}=1$ for $t=0$, the constants $B_{1}, B_{2}$, and $B_{3}$ are determined from the relations

$$
\left.\begin{array}{l}
\mathrm{B}_{1}+\mathrm{B}_{2}+\mathrm{B}_{3}=-0.5 \\
2.685 \mathrm{~B}_{1}+0.1722 \mathrm{~B}_{2}-2.223 \mathrm{~B}_{3}=-1.25 \\
5.011 \mathrm{~B}_{1}-3.395 \mathrm{~B}_{2}+3.164 \mathrm{~B}_{3}=-2.375
\end{array}\right\}
$$

which give

$$
\mathrm{B}_{1}=-0.475 \quad \mathrm{~B}_{2}=-0.0128 \quad \mathrm{~B}_{3}=-0.0123
$$

so that, finally, the solution of the problem is given by

$$
\left.\begin{array}{rl}
S_{1}=1.5-0.475 \exp (-2.22 t / X)-0.013 & \exp (-14.6 \mathrm{t} / \mathrm{X}) \\
& -0.012 \exp (-35.8 \mathrm{t} / \mathrm{X}) \\
\mathrm{S}_{2}=2.25-1.275 \exp (-2.22 \mathrm{t} / \mathrm{X})-0.002 \exp (-14.6 \mathrm{t} / \mathrm{X}) \\
+0.027 \exp (-35.8 \mathrm{t} / \mathrm{X}) \\
\mathrm{S}_{3}=3.375-2.380 \exp (-2.22 \mathrm{t} / \mathrm{X})+0.044 \exp (-14.6 \mathrm{t} / \mathrm{X}) \\
-0.039 \exp (-35.8 \mathrm{t} / \mathrm{X})
\end{array}\right\}
$$

Graphs of $S_{1}, S_{2}$, and $S_{3}$ as functions of $t / X$ are given in Fig. 16.3. Figure 16.4 presents corresponding graphs for a pyramid of two stages and Fig. 16.5 for one of four stages. 


\section{THE STRIPPER SECTION}

\section{GENERAL CONSIDERATIONS}

In the previous chapters the discussion of pyramids is concerned with rectifiers, or enrichers. Frequently, however, it is desirable to have a stripper section connected to the bottom of the rectifying pyramid. This stripper can be thought of as a pyramid, or a single stage of columns, operated at a negative $Y, i_{\text {. }}$. , with the input at the top and the output, or product, removed from the bottom. The purpose of using the stripper can be twofold: (1) to remove a certain fraction of the light constituent from the working substance before the latter is discarded and (2) to maintain the "neutral point," i.e., the point where the concentration is the same as that of normal material, at a fixed place, namely, at the point of input to the pyramid.

The subscript $r$ will be used to denote quantities referring to the rectifier and $s$ to denote those referring to the stripper. Let $c_{r}$ denote the output concentration of the rectifier (for convenience, omit here the previously used asterisk), $\mathrm{c}_{0}$ the input concentration, and $\mathrm{c}_{\mathrm{s}}$ the concentration of the stripper output, or rejected material. Similarly, let $P_{r}$ denote the product rate, $P_{0}$ the rate of input of normal material, and $P_{s}$ the rate of output of the stripped material. Then, at steady operation, two equations can be written representing the conservation of the working substance and of the light constituent, respectively, i.e.,

$$
\begin{aligned}
& \mathbf{P}_{0}=\mathbf{P}_{\mathbf{r}}+\mathbf{P}_{\mathrm{S}} \\
& \mathbf{P}_{0} \mathbf{c}_{0}=\mathbf{P}_{\mathbf{r}} \mathbf{c}_{\mathbf{r}}+\mathbf{P}_{\mathrm{S}} \mathbf{c}_{\mathrm{S}}
\end{aligned}
$$

If the concentrations are all prescribed, then these equations can be solved for $P_{0}$ and $P_{S}$, e.g.,

$$
P_{0}=\frac{c_{x}-c_{s}}{c_{0}-c_{s}} P_{r}
$$




$$
P_{S}=\frac{c_{r}-c_{0}}{c_{0}-c_{s}} P_{r}
$$

If only $c_{0}, c_{r}$, and $P_{r}$ are fixed, then $P_{0}$ and $P_{S}$ will depend on the choice of $c_{S}$, the concentration of the waste material. The latter will generally be determined by economic considerations.

The stripper can be treated mathematically in either of two ways:

1. Each column can be treated in the way described in the preceding chapters, but with $\mathbf{P}$ assumed to be negative, so that raw material is supplied at the top of the column or group of columns and product is removed at the bottom. It is convenient in this case to measure $\mathrm{z}$ down from the top, rather than up from the bottom of a column, i.e., $z$ is replaced by $-\mathrm{z}$ and $\mathrm{L}$ by $-\mathrm{L}$ in the various formulas. Likewise, $\mathrm{P}$ is replaced by $-\mathrm{P}$ and $\tau$ by $-\tau$ in order to deal with positive quantities.

2. Each stripper column should be thought of simply as a column with a negative value for the column constant $H$, so that $H$ is replaced by $-\mathrm{H}$. This amounts to looking at the column "upside down" and leads to the same results as the first method.

It can be readily verified that the same expression is obtained by either of the above methods for the net rate of transport of light constituent

$$
\tau=\mathrm{Pc}-\mathrm{H} \mathrm{c}(1-\mathrm{c})-\mathrm{K} \frac{\partial \mathrm{c}}{\partial \mathrm{z}}
$$

It will be recalled that it is possible to write

$$
\tau=\mathbf{P c}^{*}
$$

where $c^{*}$ is the concentration of the product (in this case that which is rejected) and, as usual, $P$ is the product rate per column in a given stage. If the case is considered where $c \ll 1$, which is certainly appropriate for the stripper, then Eq. 5 can be written as a differential equation for $\mathrm{c}$; if $\alpha=\mathrm{H} / \mathrm{K}$ and $\nu=\mathrm{P} / \mathrm{H}$,

$$
\frac{d c}{d z}+\alpha(1-\nu) c+\alpha \nu c^{*}=0
$$

Letting $c(0)=c_{T}$ and $c(L)=c_{B}$, the solution of this equation is

$$
c=\frac{\nu c^{*}}{\nu-1}+\left(c_{\mathrm{T}}-\frac{\nu c^{*}}{\nu-1}\right) \exp [\alpha(\nu-1) z]
$$


so that

$$
c_{\mathrm{B}}=\frac{\nu \mathrm{c}^{*}}{\nu-1}+\left(\mathrm{c}_{\mathrm{T}}-\frac{\nu \mathrm{c}^{*}}{\nu-1}\right) \exp [(\nu-1) \mathrm{Y}]
$$

with $\mathbf{Y}=\alpha \mathbf{L}$. If

$$
S=\frac{c_{T}}{c_{B}} \quad S^{c}=\frac{c_{B}}{c^{*}}
$$

then from Eq. 8

$$
\mathbf{S}=\frac{1}{(\nu-1) \mathbf{S}^{\mathbf{c}}}\left\{\nu+\left[(\nu-1) \mathbf{S}^{c}-\nu\right] \exp [-(\nu-1) \mathrm{Y}]\right\}
$$

so that, in a pyramid with a given distribution of columns, it is possible to get the separation factor by starting from the output stage and applying Eq. 11 to each stage in succession. In particular, for the output stage $\left(S^{C}=1\right)$, it is found that

$$
\mathrm{S}=\frac{\nu-\exp [-(\nu-1) \mathrm{Y}]}{\nu-1}
$$

In addition to Eqs. 11 and 12, involving quantities referring to the individual columns of the stripper section (the subscript $\mathbf{s}$ has been omitted for simplicity), it is also necessary to satisfy Eqs. 1 and 2. The concentration $c_{s}$ in these equations is given by

$$
\mathrm{c}_{\mathrm{S}}=\frac{\mathrm{c}_{0}}{\mathrm{~S} \text { 荌 }}
$$

where $S_{S}^{*}$ is the product of all the separation factors of the stripper stages, whereas $\mathrm{P}_{\mathrm{S}}$ is given by the product of $\nu \mathrm{H}$ and the number of columns in any one stage of the stripper. Now, if Eqs. 1 and 2 are replaced by Eqs. 3 and 4, it is evident that one condition determines $P_{0}$, the rate at which raw material is to be fed into the system at the neutral point, whereas the other condition fixes $\mathbb{P}_{\mathbf{S}}$.

The method of solution will depend on the manner in which the problem is formulated. In some cases it may be necessary to solve simultaneously Eq. 4 and the set of equations represented by Eqs. 11 and 12; this can be done by graphical methods in complicated cases.

Usually only a small fraction of the total number of columns will be used for the stripper; therefore, the question of design for optimum performance is not so important in this case. If, however, it is desired 


\section{THE STRIPPER SECTION}

to design a stripper for optimum performance, it can be done on the basis of the ideas discussed in the preceding chapters. For example, Figs. 14.10 and 14.11 in Chap. 14, which were calculated for a rectifier working at very high concentrations, also apply to a stripper at low concentrations (if $\mathrm{c}$ and $\mathrm{c}^{\prime}=1-\mathrm{c}$ are interchanged). These graphs can be used to work stage by stage, starting from the output stage, in order to get the optimum separation factor for each stage and the corresponding value of $\nu$. Equation 4 can then be satisfied by choosing the proper number of columns for each stage, i.e., by taking in the $k t h$ stage $\mathrm{N}_{\mathrm{k}}$ columns given by

$$
\mathbf{N}_{\mathrm{k}}=\frac{\mathbf{P}_{\mathrm{S}}}{\mathrm{H} \nu_{\mathrm{k}}}
$$

where $\nu_{\mathrm{k}}$ is the value of $\nu$ for the $\mathrm{k} t h$ stage as obtained from considerations of optimum performance, whereas $P_{S}$ is given by Eq. 4, with $c_{S}$ determined by Eq. 13.

\section{SINGLE-STAGE STRIPPER}

An interesting case to consider is the one in which the stripper consists of only a single stage. Such an arrangement is likely to be used where the maintenance of a fixed neutral point is more important than the degree to which the material is stripped before being discarded. If the value of $S^{*}$ for the rectifier is denoted by $S_{r}$ and that for the stripper by $S_{S}$, then $E q .4$ can be replaced by

$$
P_{S}=\frac{S_{r}-1}{1-\frac{1}{S_{S}}} p_{r}
$$

so that

$$
1-\frac{1}{S_{S}}=\left(S_{r}-1\right) P_{r} / H \nu_{S} N_{S}
$$

where $\nu_{\mathrm{S}}$ is the value of $\nu$ for each stripper column and $\mathrm{N}_{\mathrm{S}}$ is the total number of such columns.

On the other hand, from Eq. 12, if $\mathrm{s}$ is added as a subscript, the result is

$$
\mathrm{S}_{\mathrm{S}}=\frac{\nu_{\mathrm{S}}-\exp \left[-\left(\nu_{\mathrm{S}}-1\right) \mathrm{Y}\right]}{\nu_{\mathrm{S}}-1}
$$


By eliminating $S_{S}$ between Eqs. 16 and 17, it is found that

$$
\frac{\left(\mathrm{S}_{\mathrm{r}}-1\right) \mathbf{P}_{\mathrm{r}}}{H N_{\mathrm{S}}}=\frac{\nu_{\mathrm{S}}\left\{1-\exp \left[-\left(\nu_{\mathrm{S}}-1\right) \mathrm{Y}\right]\right\}}{\nu_{\mathrm{S}}-\exp \left[-\left(\nu_{\mathrm{S}}-1\right) \mathrm{Y}\right]}
$$

If the right-hand side of Eq. 18 is denoted by W, then $W$ as a function of $\nu_{\mathrm{S}}$ for a given value of $\mathrm{Y}$ is a function that vanishes for $\nu_{\mathrm{S}}=0$ and then increases monotonically to unity as $\nu_{\mathrm{S}}$ tends to infinity. From this it is evident that

$$
\mathrm{N}_{\mathrm{S}} \geq\left(\mathrm{S}_{\mathrm{r}}-1\right) \mathrm{P}_{\mathrm{r}} / \mathrm{H}
$$

so that there is a lower limit to the number of columns required in the stripper to maintain a fixed neutral point. Actually, $\mathrm{N}_{\mathrm{S}}$ must be appreciably greater than the limit given by Eq. 19 to avoid the necessity of feeding material through the stripper at a very high rate.

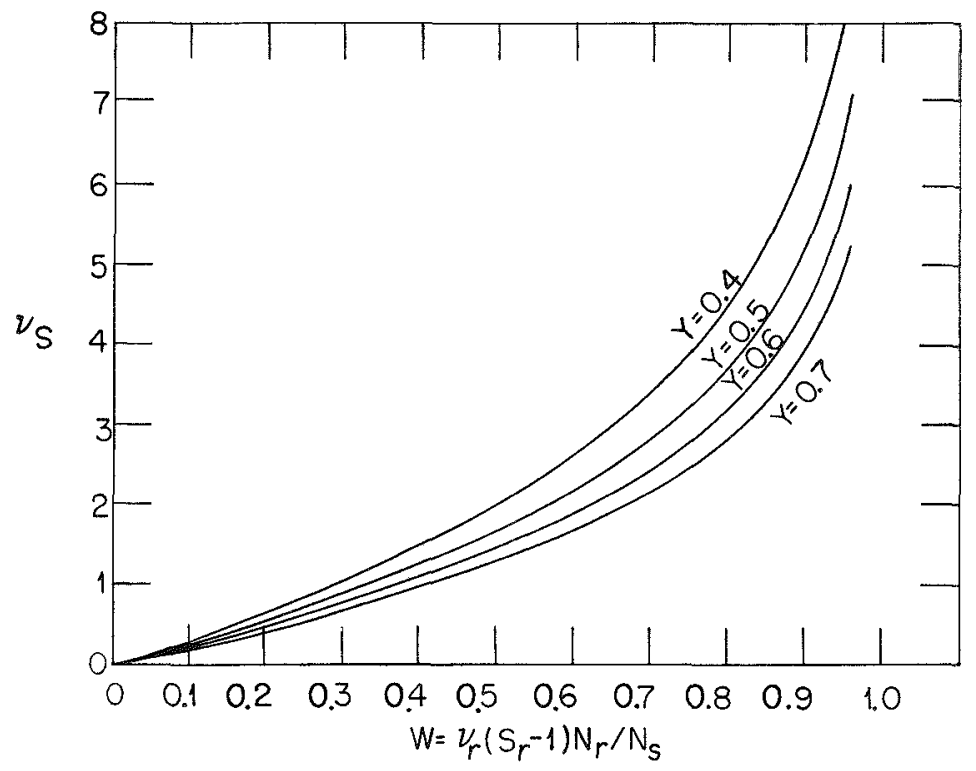

Fig. 17.1 - Stripper withdrawal rate $\left(\nu_{\mathrm{s}}\right)$ necessary to maintain steady-state operation when the product withdrawal rate is $\nu_{\Sigma}$ and the separation factor of the rectifier section is $S_{r}$. The number of columns in the rectifier and stripper stages is given by $N_{r}$ and $N_{s}$, respectively.

If the value chosen for $\mathrm{N}_{\mathrm{S}}$ satisfies $\mathrm{Eq} .19$, then from $\mathrm{Eq} .18$ the corresponding value of $\nu_{\mathrm{S}}$ can be determined. Figure 17.1 shows some curves of $\nu_{S}$ as a function of $\mathrm{W}=\left(\mathrm{S}_{\mathrm{r}}-1\right) \mathrm{P}_{\mathrm{r}} / \mathrm{HN} \mathrm{N}_{\mathrm{S}}$ for several values of 
Y. After $\nu_{\mathrm{S}}$ has been determined, Eq. 17 can be used to get $\mathbf{S}_{\mathrm{S}}$. Some curves of $\mathbf{S}_{\mathrm{S}}$ vs. $\nu_{\mathrm{S}}$ are given in Fig. 17.2.

For a stripper section of more than one stage, a similar procedure can be carried out; however, the calculations are more laborious.

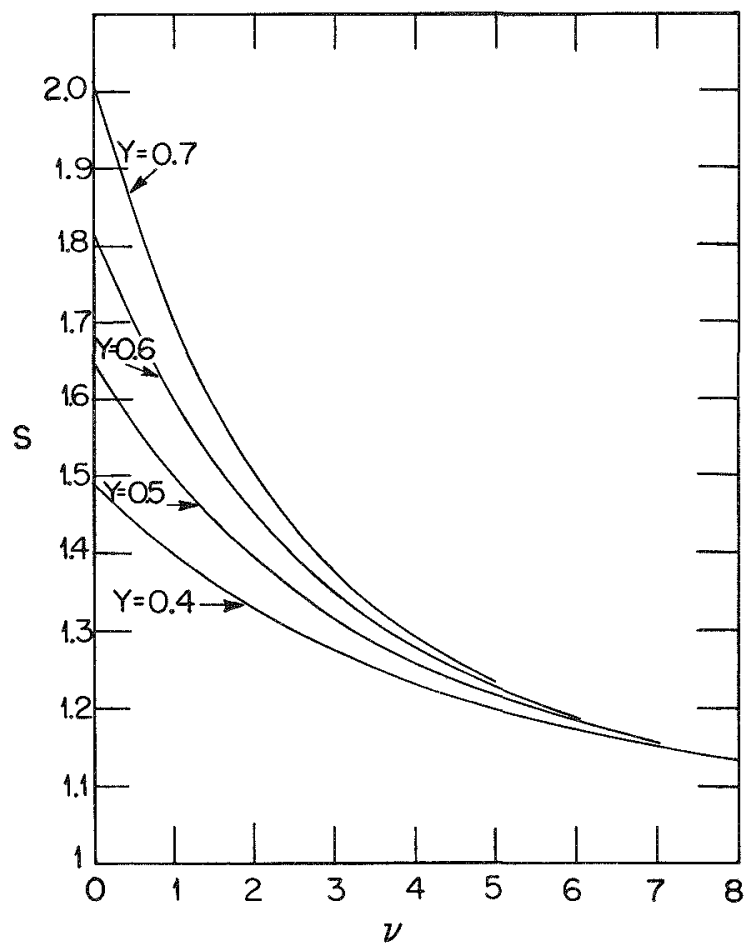

Fig. 17.2-Dependence of separation factor, $\mathrm{S}$, on generalized product rate, $\nu$, for single-stage stripper with various values of $\mathrm{Y}$. 
Chapter 18

\section{NONUNIFORM COLUMNS IN PARALLEL OPERATION}

\section{GENERAL TREATMENT}

The purpose of this chapter is to consider the behavior of a group of columns operated in parallel, taking into account possible differences in the properties of the columns and their product rates.

Each column is characterized under steady flow by the column constants $H$ and $K$, its length $L$ and mass $M$, and the product rate $P$. The constants, $H$ and $K$, can be calculated from measured values of the equilibrium separation factor $S_{e}$ and the time constant $X$ by the relations

$$
\mathrm{H}=\frac{\mathrm{M}}{\mathrm{X} \ln \mathrm{S}_{\mathrm{e}}}
$$

and

$$
K=\frac{M L}{X\left(\ln S_{e}\right)^{2}}
$$

The product rate, $\mathbf{P}$, of course, can be made to have any arbitrary value by a suitable choice of auxiliary equipment.

The steady operation of a group of $n$ columns in parallel will be considered, representing a particular stage of a pyramid, and subscripts will be used to distinguish quantities referring to the various columns in this group. Let $\tau$ denote the total transport of light constituent in one column. Then, for the $\mathrm{k}$ th column, if the concentration is sufficiently low, it is possible to write

$$
\tau_{k}=\left(H_{k}+P_{k}\right) c_{k}-K_{k} \frac{d c_{k}}{d z}(k=1, \ldots, n)
$$

where $\mathrm{z}$ is the distance measured up the column. If $\mathrm{c}^{*}$ is the concen- 
tration at the top of the pyramid, where the product is withdrawn, then there exists the relation

$$
\sum_{k=1}^{n} \tau_{k}=c^{*} \sum_{k=1}^{n} P_{k}
$$

"Parallel" operation means that the tops of all the columns are connected and that their bottoms are also all connected. Hence for the $\mathrm{k}$ th column the boundary conditions are

$$
\begin{array}{ll}
c_{k}=c_{B} & (\mathrm{z}=0) \\
c_{k}=c_{T} & (\mathrm{z}=L)
\end{array}
$$

where $c_{B}$ and $c_{T}$ are the concentrations at the bottom and top of the stage, respectively, these quantities being taken to be the same for all the columns.

Integrating Eq. 3 in order to satisfy Eq. 5 a, the result is

$$
c_{k}=c_{B} e^{\partial_{k} z}-\frac{\tau_{k}}{H_{k}+P_{k}}\left(e^{\partial z}-1\right)
$$

where

$$
\partial_{\mathrm{k}}=\frac{\mathrm{H}_{\mathrm{k}}+\mathbf{P}_{\mathrm{k}}}{\mathrm{K}_{\mathrm{k}}}
$$

For $\mathrm{z}=\mathrm{L}_{\mathrm{k}}$,

$$
c_{T}=c_{B} e^{\partial_{k} L_{k}}-\frac{\tau_{k}}{H_{k}+P_{k}}\left(e^{\partial_{k} L_{k}}-1\right)
$$

Let

$$
\beta_{\mathrm{k}}=\mathrm{e}^{\partial_{\mathrm{k}}} \mathrm{I}_{\mathrm{k}} \quad \phi_{\mathrm{k}}=\frac{\mathrm{H}_{\mathrm{k}}+\mathrm{P}_{\mathrm{k}}}{\beta_{\mathrm{k}}-1}
$$

Then, from Eq. 8,

$$
\tau_{\mathrm{k}}=\phi_{\mathrm{k}}\left(\mathrm{c}_{\mathrm{B}} \beta_{\mathrm{k}}-\mathrm{c}_{\mathrm{T}}\right)
$$

Substituting this expression into Eq. 4, gives

$$
\mathrm{c}_{\mathrm{B}} \sum_{\mathrm{k}=1}^{\mathrm{n}} \phi_{\mathrm{k}} \beta_{\mathrm{k}}=\mathrm{c}_{\mathrm{T}} \sum_{\mathrm{k}=1}^{\mathrm{n}} \phi_{\mathrm{k}}=\mathrm{c}^{*} \sum_{\mathrm{k}=1}^{\mathrm{n}} \mathrm{p}_{\mathrm{k}}
$$




\section{LIQUID THERMAL DIFFUSION}

so that

$$
\begin{aligned}
& c_{T}=\frac{c_{B} \sum_{k=1}^{n} \phi_{k} \beta_{k}-c^{*} \sum_{k=1}^{n} p_{k}}{\sum_{k=1}^{n} \phi_{k} \beta_{k}} \\
& c_{B}=\frac{c_{T} \sum_{k=1}^{n} \phi_{k}+c^{*} \sum_{k=1}^{n} p_{k}}{\sum_{k=1}^{n} \phi_{k} \beta_{k}}
\end{aligned}
$$

From Eqs. 10 and $12 \mathrm{a}$ or $12 \mathrm{~b}$,

$$
\tau_{1}=\phi_{1} \frac{\mathbf{c}_{\mathrm{B}} \sum_{\mathrm{k}=1} \phi_{\mathrm{k}}\left(\beta_{1}-\beta_{\mathrm{k}}\right)+\mathbf{c}^{*} \sum_{\mathrm{k}=1}^{\mathrm{n}} \mathbf{P}_{\mathbf{k}}}{\sum_{\mathrm{k}=1}^{\mathrm{n}} \phi_{\mathrm{k}}}
$$

or

$$
\tau_{1}=\phi_{1} \frac{c_{\mathrm{T}} \sum_{\mathrm{k}=1}^{\mathrm{n}} \phi_{\mathrm{k}}\left(\beta_{1}-\beta_{\mathrm{k}}\right)+\mathrm{c}^{*} \beta_{1} \sum_{\mathrm{k}=1}^{\mathrm{n}} \mathbf{P}_{\mathrm{k}}}{\sum_{\mathrm{k}=1}^{\mathrm{n}} \phi_{\mathrm{k}} \beta_{\mathrm{k}}}
$$

If the separation factors are introduced,

$$
S_{p}=\frac{c_{T}}{c_{B}} \quad S^{*}=\frac{c^{*}}{c_{B}} \quad S^{c}=\frac{c^{*}}{c_{T}}=\frac{S^{*}}{S}
$$

then from Eqs. 12a or 12b the following is obtained:

$$
S_{p}=\frac{\sum_{k=1}^{n} \phi_{k} \beta_{k}-S^{*} \sum_{k=1}^{n} P_{k}}{\sum_{k=1}^{n} \phi_{k}}
$$

or

$$
S_{p}=\frac{\sum_{k=1}^{n} \phi_{k} \beta_{k}}{\sum_{k=1}^{n} \phi_{k}+S^{c} \sum_{k=1}^{n} P_{k}}
$$

Of these two expressions, Eq. $15 \mathrm{~b}$ is generally the more useful since, in investigating a pyramid stage by stage, one generally starts at the 
top and works down, so that at each stage $\mathrm{S}^{\mathrm{c}}$, the separation factor for all the higher stages, is known and $S^{*}$ is not known. Suppose then that $a$ value of $S^{c}$ is given. If only the $k$ th column had been present above, its separation factor would have been $S_{k}$, given, according to $\mathrm{Eq} .15 \mathrm{~b}$, by

$$
S_{k}=\frac{\left(H_{k}+P_{k}\right) \beta_{k}}{H_{k}+P_{k}+S^{c} P_{k}\left(\beta_{k}-1\right)}
$$

or if

$$
\nu_{\mathrm{k}}=\frac{\mathrm{p}_{\mathrm{k}}}{\mathrm{H}_{\mathrm{k}}}
$$

then

$$
\mathrm{S}_{\mathrm{k}}=\frac{\left(1+\nu_{\mathrm{k}}\right) \beta_{\mathrm{k}}}{1+\nu_{\mathrm{k}}+\mathrm{S}^{\mathrm{c}} \nu_{\mathrm{k}}\left(\beta_{\mathrm{k}}-1\right)}
$$

From this it is found that

$$
\beta_{\mathrm{k}}=\frac{1-\left(\mathrm{S}^{\mathrm{c}}-1\right) \nu_{\mathrm{k}}}{\frac{1}{S_{\mathrm{k}}}\left(1+\nu_{\mathrm{k}}\right)-\mathrm{S}^{\mathrm{c}} \nu_{\mathrm{k}}}
$$

and

$$
\phi_{\mathrm{k}}=\frac{\frac{1}{\mathrm{~S}_{\mathrm{k}}}\left(1+\nu_{\mathrm{k}}\right)-\mathrm{S}^{\mathrm{c}} \nu_{\mathrm{k}}}{1-\frac{1}{\mathrm{~S}_{\mathrm{k}}}}
$$

By substituting these expressions into Eq. $15 \mathrm{~b}$, it is found that

$$
S_{p}=\frac{\sum_{k=1}^{n} H_{k}\left[1-\left(S^{c}-1\right) \nu_{k}\right] S_{k} /\left(S_{k}-1\right)}{\sum_{k=1}^{n} H_{k}\left[1-\left(S^{c}-1\right) \nu_{k}\right] /\left(S_{k}-1\right)}=\frac{\sum_{k=1}^{n} \phi_{k} \beta_{k}}{\sum_{k=1}^{n}\left(\phi_{k} \beta_{k} / S_{k}\right)}
$$

In particular, if a pyramid consisting of only a single stage is being dealt with or if the group of columns is the top stage of a pyramid, then $\mathrm{Sc}^{\mathrm{c}}=1$ and

$$
S_{p}=\frac{\sum_{k=1}^{n} \frac{H_{k} S_{k}}{S_{k}-1}}{\sum_{k=1}^{n} \frac{H_{k}}{S_{k}-1}}
$$




\section{LIQUID THERMAL DIFFUSION}

so that $S_{p}$ is a mean value of the $S^{\prime} s$ of the individual columns with a weighting factor of $\mathrm{H}_{k} /\left(\mathrm{S}_{\mathrm{k}}-1\right)$.

Having expressed $S_{p}$ in a convenient form, return to the expression for $\tau_{i}$ given by $\mathrm{Eq} .13 \mathrm{~b}$ and see whether it also can be simplified. First, write Eq. 10 or $\mathrm{Eq} .13 \mathrm{~b}$ in the form

$$
\tau_{\mathrm{i}}=\phi_{\mathrm{i}} \mathrm{c}_{\mathrm{T}}\left(\frac{\beta_{\mathrm{i}}}{\mathrm{S}_{\mathrm{p}}}-1\right)
$$

If, now, Eqs. 19 and 20 are used, this can be written

$$
\tau_{i}=\frac{\mathbf{c}_{\mathrm{B}} \mathbf{H}_{\mathbf{i}}}{1-\frac{1}{\mathbf{S}_{\mathrm{i}}}}\left[\left(1+\nu_{i}\right)\left(1-\frac{\mathrm{S}_{\mathrm{p}}}{\mathrm{S}_{\mathrm{i}}}\right)+\nu_{i} \mathbf{S}^{\mathrm{c}}\left(\mathrm{S}_{\mathrm{p}}-1\right)\right]
$$

The transport in each column can be regarded as being made up of two parts:

$$
\tau_{\dot{1}}=\tau_{i}^{0}+\tau_{i}^{\prime}
$$

where the first term on the right is the "normal" transport given by

$$
\tau_{i}^{0}=\mathrm{c}^{*} \mathbf{P}_{\mathfrak{i}}
$$

and the second term is the "circulatory" transport since, from Eq. 4, it follows that

$$
\sum_{i=1}^{n} \tau_{\mathrm{i}}^{\prime}=0
$$

It follows readily from Eq. 24 that

$$
\tau_{1}^{\prime}=\tau_{i}-\mathbf{c}^{*} \mathbf{P}_{\mathrm{i}}=\frac{\mathbf{c}_{\mathrm{B}} \mathbf{H}_{\mathrm{i}}\left(\mathbf{S}_{\mathrm{i}}-\mathbf{S}_{\mathrm{p}}\right)\left[1-\nu_{\mathrm{i}}\left(\mathrm{S}^{\mathrm{c}}-1\right)\right]}{\mathrm{S}_{\mathrm{i}}-1}
$$

In the special case $\mathrm{S}^{\mathrm{C}}=1$ (only one stage or the top stage of a pyramid),

$$
\tau_{i}=c_{T}\left[P_{i}+\frac{H_{i}\left(S_{i}-S_{p}\right)}{S_{p}\left(S_{i}-1\right)}\right]=c_{T}\left[P_{i}+H_{i} \frac{\frac{1}{S_{p}}-\frac{1}{S_{i}}}{1-\frac{1}{S_{i}}}\right]
$$

Finally, it is instructive to compare Eq. 22 with the expression for the separation factor, $S_{m}$, which would be obtained if all the columns 
were operated independently and their products were mixed together. Clearly, one would have

$$
S_{m}=\frac{\sum_{k=1}^{n} S_{k} P_{k}}{\sum_{k=1}^{n} P_{k}}
$$

which involves a weighting factor $\left(\mathrm{P}_{\mathrm{k}}=\mathrm{H}_{\mathrm{k}} \nu_{\mathrm{k}}\right)$ that is, in general, quite different from the corresponding weighting factor in Eq. 22.

\section{AVERAGE PROPERTIES}

Now compare Eq. $15 \mathrm{~b}$ with the corresponding equation which would exist if all the columns were identical and were operated at the same product rate. In the latter case, if the constants of any one column were written without any subscripts,

$$
\mathrm{S}=\frac{\phi \beta}{\phi+\mathrm{S}^{\mathrm{c}} \mathbf{P}}
$$

In making the comparison, naturally it is taken that

$$
P=\frac{1}{n} \sum_{k=1}^{n} P_{k}
$$

Hence, for Eqs. 31 and $15 \mathrm{~b}$ to be equivalent,

$$
\begin{aligned}
& \phi=\frac{H+P}{\beta-1}=\frac{1}{n} \sum_{k=1}^{n} \frac{H_{k}+P_{k}}{\beta_{k}-1} \\
& \phi \beta=\frac{\beta(H+P)}{\beta-1}=\frac{1}{n} \sum_{k=1}^{n} \frac{\left(H_{k}+P_{k}\right) \beta_{k}}{\beta_{k}-1}
\end{aligned}
$$

By subtracting Eq. 33 from Eq. 34, the result is

$$
H+P=\frac{1}{n} \sum_{k=1}^{n}\left(H_{k}+P_{k}\right)
$$

whence, on the basis of Eq. 32,

$$
H=\frac{1}{n} \sum_{k=1}^{n} H_{k}
$$


The average $H$ is just the arithmetic mean, or, in other words, the H's of parallel columns combine additively.

To get $\mathrm{K}$, use Eq. 33 and write

$$
\frac{1}{\beta-1}=\frac{1}{n(H+P)} \sum_{k=1}^{n} \frac{H_{k}+P_{k}}{\beta_{k}-1}
$$

From this, the following is obtained:

$$
K=\frac{(H+P) L}{\ln \beta}=\frac{(H+P) L}{\ln \left[1+\frac{n(H+P)}{\sum_{k=1}^{n} \frac{H_{k}+P_{k}}{\beta_{k}-1}}\right]}
$$

\section{EXAMPLES OF COLUMNS}

Let us restrict ourselves here to a single-stage system, so that $\mathrm{S}^{\mathrm{c}}=1$, and assume that the group consists of only two columns. If it is further assumed that $\mathrm{H}_{1}=\mathrm{H}_{2}$, then $\mathrm{Eq}$. 22 reduces to

$$
S_{p}=\frac{\frac{S_{1}}{S_{1}-1}+\frac{S_{2}}{S_{2}-1}}{\frac{1}{S_{1}-1}+\frac{1}{S_{2}-1}}
$$

If there is a family of curves of $\mathrm{S}$ vs. $\nu$ for a single column, it is possible to read from it the values of $S_{1}$ and $S_{2}$ for any $\nu_{1}$ and $\nu_{2}$ and to $o b-$ tain $S_{p}$ from Eq. 38 .

From Eqs. 26 and 29 the circulatory transport can be obtained:

$$
\tau_{1}^{\prime}=-\tau_{2}^{\prime}=c_{T} \frac{H_{1}\left(S_{1}-S_{p}\right)}{S_{p}\left(S_{1}-1\right)}
$$

The equivalent product rate is $\tau_{1}^{\prime} / \mathrm{c} T$.

Graphs for the case considered here are presented in Fig. 18.1. $\mathrm{H}_{1}=\mathrm{H}_{2}$, with the further simplification $\mathbf{P}_{1}=\mathbf{P}_{2}$. The two columns are characterized by $Y_{1}=\ln S_{e 1}=0.35$ and $Y_{2}=\ln S_{e 2}=0.15$. Figure 18.1 shows $\mathrm{S}_{1}, \mathrm{~S}_{2}, \mathrm{~S}_{\mathrm{m}}$, and $\mathrm{S}_{\mathrm{p}}$ as functions of $\nu_{1}=\nu_{2}=\nu$, so that the performance of the columns can be compared both singly and together. Figure 18.1 also includes a curve of $\tau_{1}^{\prime} / \mathrm{H}_{1} \mathrm{c}_{\mathrm{T}}$ as a function of $\nu$ to show the relation between the circulatory transport and the product rate. 


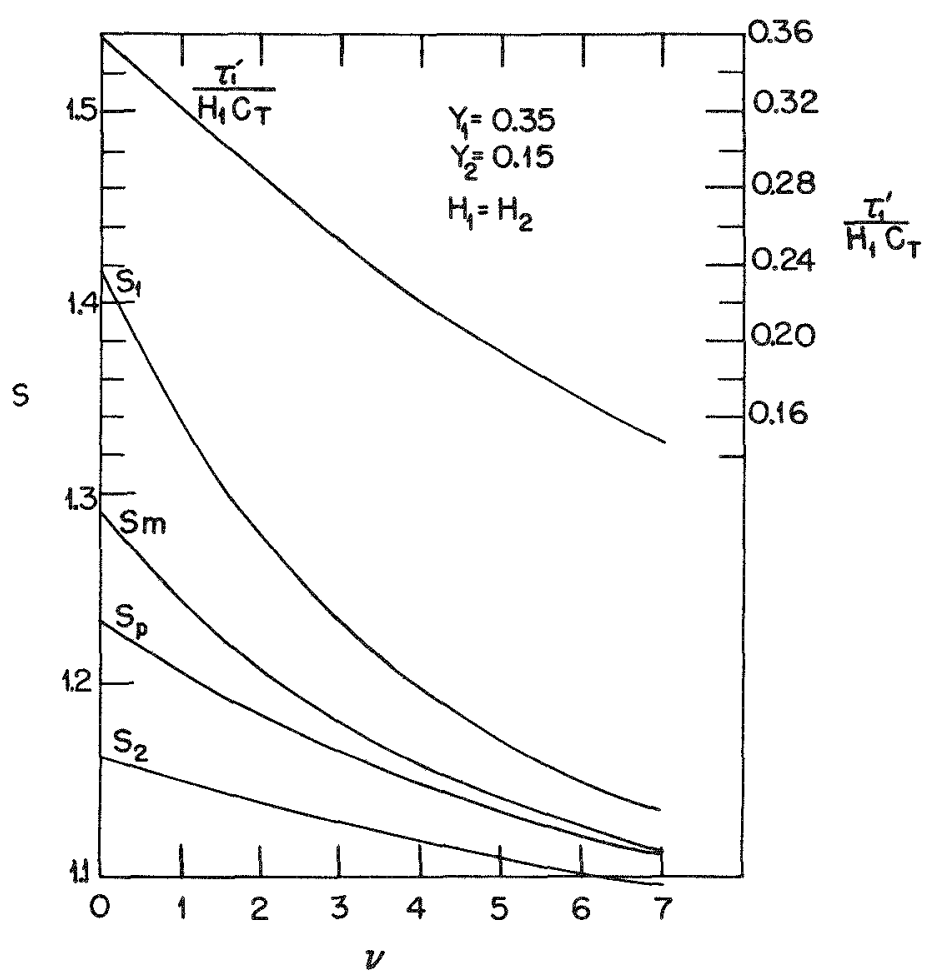

Fig. 18.1-Effect of using combinations of inhomogeneous columns on separation factor of product. $S_{1}$ refers to the performance of the good column ( $Y=$ $0.35)$, and $S_{2}$ refers to the bad column $(Y=0.15)$. $S_{m}$ and $S_{p}$ refer to the products obtained when the columns are connected together for mixed product and for parallel operation. $r_{1}^{\prime}$ represents the circulatory transport rate in the latter case.

Figure 18.1 also shows that $S_{p}$ is less than $S_{m}$, as was to be expected from the presence of the weighting factor, $1 /\left(S_{k}-1\right)$, in the former since this weights the poorer column more heavily. Suppose it is required to find $\nu$ for $S=1.26$. From the graph it is found that it is impossible to obtain this value in parallel operation. In independent operation $\left(S_{m}=1.26\right)$, it is found that $\nu=0.6$. On the other hand, if $S_{1}=$ 1.26, then $\nu=2.3$. It follows then that a single good column $\left(Y_{1}=0.35\right)$ will produce about twice as much product as the good one and poor one $\left(\mathrm{Y}_{2}=0.15\right)$ together. Suppose, next, that it is required to find $\nu$ for $\mathbf{S}=$ 1.22. From the graph it is found that for parallel operation $\nu=0.5$, approximately. On the other hand, if $S_{1}=1.22$, then $\nu=3.3$. Hence the good column alone produces more than three times as much product as the good one and poor one in parallel. 
It can be seen then that the presence of the poor column reduces efficiency both because of the fuel consumption associated with its operation and because of an actual decrease in the product rate. Although it is true that the examples given represent somewhat extreme cases of difference in the properties of two columns, such differences can occur in practice. However, even with smaller differences in the column constants, the same tendency will be found: a decrease in efficiency if the two columns are operated together, particularly if they are operated in parallel.

The conclusion to be drawn from the preceding is very clear:

Given a group of columns operating in parallel, it is important to weed out the poor ones since this will increase the efficiency of the group. 


\section{APPENDIXES}


$+$

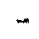

-

$-$<smiles>[3H]</smiles> 


\section{Appendix A \\ CRITICAL TEMPERATURE MEASUREMENT OF URANIUM HEXAFLUORIDE}

W. E. Whybrew, J. H. Tayman, and P. N. Kokulis

In determining the critical temperature of many substances, it is possible to use the visual method, observing the phenomenon of the actual disappearance of the meniscus of the liquid-gas demarcation line. This method is based on the fact that, as the temperature of a liquid approaches the critical temperature, the density of the liquid approaches that of the saturated vapor. It was first successfully used with carbon disulfide by Cagniard de la Tour. The principle of the method is simple: A liquid is placed in a sealed tube, and the temperature is gradually raised above the critical. It may be necessary to try this experiment a number of times to determine the exact amount of material needed to give the critical pressure and temperature with the meniscus about halfway up the tube. When the proper amount has been determined, the material is placed in the glass tube and sealed off. The temperature is slowly raised until the area around the meniscus becomes hazy, and the meniscus suddenly disappears, leaving the tube filled with a uniform fog. The pressure at which this occurs is known as the "critical pressure."

A second method was devised in 1931 by Bond and Williams. A metal container, approximately half filled with liquid and supported at a small inclination to the horizontal, on a knife-edge, was used. A wire supporting the lower end was attached to the beam of a balance. The tube was placed in a heating jacket, and the temperature was raised above the critical point. The balance was adjusted after time had been allowed for the material in the container to become uniform in density. The temperature was then allowed to drop slowly until the fluid separated into two phases. The liquid then ran down the tube, deflecting the beam balance. The temperature at which this occurred was the critical temperature. 
The method used by the present authors in their first experiments was a variation of the early visual procedure. Since the substance being investigated was corrosive to glass, the visual method was modified by the use of a metal container, which was viewed by means of an $x-r a y$ apparatus and a fluorescent screen. The screen showed the tube and the liquid as a dark shadow, with a lighter shadow for the gas phase.

A copper tube, $3 / 8$ in. in outside diameter and $5 \mathrm{in}$. long with a $1 / 32$-in. wall, was used. A 3 -ft length of $1 / 8$-in. - O.D. nickel tubing with a 0.060 in. bore was silver-soldered into the lower end of the tube. The nickel tubing was attached to a reservoir made of nickel with a heavy wall and having a $50-\mathrm{ml}$ capacity. The reservoir, the $3 \mathrm{mt}$ length of nickel tubing, and the critical-point tube were wound separately with heating elements of nichrome wire so that the temperature of each could be varied independently. The reservoir was below the critical-point tube and contained the amount of $\mathrm{UF}_{6}$ required to keep the material over the needed range of temperature and pressure in the critical-point tube by varying the temperature of the reservoir. An iron-constantan thermocouple was silver-soldered to the center of the critical-point tube, a type $K$ potentiometer being used as the temperature-indicating instrument. The cold junction was kept at $0^{\circ} \mathrm{C}$ by means of crushed ice in a thermos bottle. The thermocouple was calibrated by standard tin, which melts within $1^{\circ} \mathrm{C}$ of the critical point being determined.

The apparatus was arranged as follows: The $\mathrm{x}$-ray machine was set up, adequately protected on all sides by lead shields. The critical-point tube, in front of a lead plate that had a $3 / 16$-in. wide by 4 -in. long slit, was placed about $1 \mathrm{ft}$ in front of the $\mathrm{x}$-ray tube. Next there was a fluorescent screen and then two plates of lead glass to protect the observer. By varying the voltage on the $x$-ray machine, it was found that the meniscus could be seen better at higher voltages. Hence the voltage used was $120 \mathrm{kv}$, the limit for this machine. The principal limitation on the accuracy of this experiment was that, near the critical point where the meniscus disappeared, the contrast between liquid and vapor was exceedingly faint. However, two observers taking turns could check themselves and each other. The experiment was repeated several times, the critical temperature being approached both from above and from below. From the results obtained by this experiment, the critical temperature arrived at was $232.7 \pm 1.0^{\circ} \mathrm{C}$.

In order to increase the accuracy and reliability of the data, a later set of experiments was run. A higher voltage $\mathrm{x}$-ray machine was used in order to produce a sharper change in intensity at the meniscus. The apparatus used was modified somewhat from that used in the visual determinations. A copper tube, $1 / 2$ in. in outside diameter and 5 in. long with a $1 / 32$-in. wall, was used. The lower reservoir, which was previously used to adjust the amount of $\mathrm{UF}_{6}$ in the tube, was eliminated. In- 
stead, a few trials disclosed the amount of $U F_{6}$ required to keep the meniscus from disappearing at the bottom or top before the critical temperature was reached. With a critical-point tube having a measured volume of $15 \mathrm{ml}$, it was found that $22 \mathrm{~g}$ of $\mathrm{UF}_{6}$ was the correct amount. Preliminary trials were run using a fluorescent screen; then pictures were made on x-ray film, and prints of these are shown in Fig. A.1.

The meniscus could be seen faintly at $232.4^{\circ} \mathrm{C}$, and it could not be seen at $232.8^{\circ} \mathrm{C}$. Hence the critical temperature was taken to be the average of these two temperatures, or $232.6^{\circ} \mathrm{C}$. This is $0.1^{\circ} \mathrm{C}$ lower than the value obtained by the visual method. To judge from the amount of $\mathrm{UF}_{6}$ in the tube and its volume, the critical density should be close to $22 / 15$, or $1.47 \mathrm{~g} / \mathrm{ml}$.
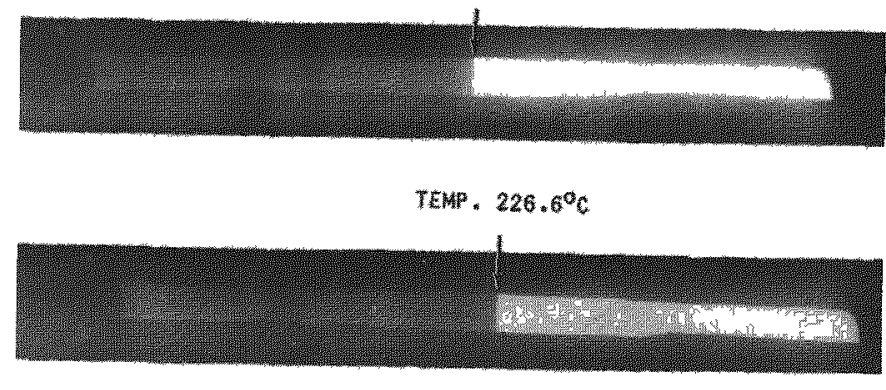

TEMP. $229.9^{\circ} \mathrm{C}$

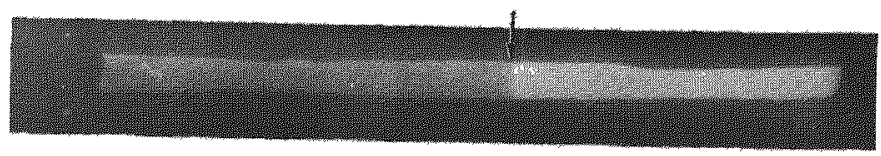

TEMP. 23: ${ }^{4} 0_{6}$

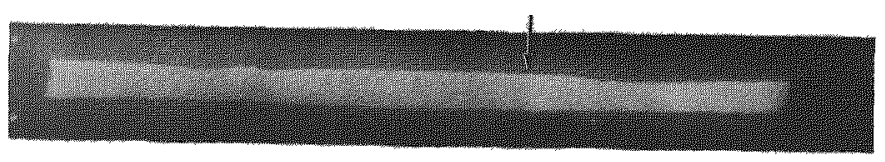

TENP. $232.44^{\circ} \mathrm{C}$

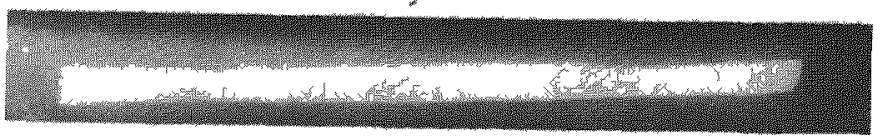

TEMP. $232.8^{\circ} 6$

Fig. A.1-X-ray photographs of a tube containing $\mathrm{UF}_{6}$ at temperatures approaching critical. Near the critical point the density of the gas phase approaches that of the liquid. The critical temperature of $U_{6} F_{6}$ lies between 232.4 and $232.8^{\circ} \mathrm{C}$. 
Appendix B

\title{
PRESSURE-TEMPERATURE-VOLUME CHARACTERISTICS OF URANIUM HEXAFLUORIDE
}

\author{
G. Y. Brokaw
}

In connection with both the experimental and the plant procedures, it was highly desirable to have accurate data on pressure-temperaturevolume characteristics, e.g., for predicting the pressures that occur during transfer operations, as well as for routine plant operations. Consequently, a set of measurements was carried out to determine these characteristics as well as the critical constants.

\section{B.1 APPARATUS}

Two 3000-psi beryllium-copper gauges were calibrated on a deadweight tester, and then they were attached to a $1904-\mathrm{ml}$ nickel reservoir that was 16 in. long and 3 in. in diameter, with $1 / 4$-in.-thick walls. Variable temperature was provided by a heating element and measured by two thermometers, which were located at the middle and at one end of the reservoir.

\section{B.2 PROCEDURE}

After thorough "conditioning," a suitable amount of $\mathrm{UF}_{6}$ was introduced into the apparatus. The equipment was cooled and evacuated of air.

The temperature was then gradually increased, and the correspond ing pressure was observed. On reaching maximum temperature, the container was cooled, and the pressure during the cooling phase was observed. By the removal of some $\mathrm{UF}_{6}$, a similar curve could be obtained at a different density.

The first curve was obtained by permitting the temperature to remain at equilibrium for about $2 \mathrm{hr}$ at each point. It was then found that 
10 to 15 min per point, with a rise of 1 volt (usually 7 to $8^{\circ} \mathrm{C}$ ) per point on the heater, gave a curve that exactly coincided with the first curve. Therefore, the speed of obtaining points within the limits employed did not alter the results.

A dead-weight calibration of the gauges after the experiment showed that a weighted average of the readings would fall within experimental error. Because 3000 -psi gauges were used, readings below 200 psi were not considered sufficiently precise for recording.

The thermometers were calibrated to $250^{\circ} \mathrm{C}$, using a National Bureau of Standards thermometer. The calibration corrections were small $\left(<1^{\circ} \mathrm{C}\right)$.

Corrections to $\rho$, due to change in the volume of the storage chamber with variations in temperature and pressure, amount to 0.005 or less in the vicinity of the critical point, and their effect is well within experimental error. The correction approaches 0.01 at 1500 psi and temperatures above $200^{\circ} \mathrm{C}$, and it approaches 0.027 at $3000 \mathrm{psi}$ and temperatures of $200^{\circ} \mathrm{C}$ or more. Because of the insignificance of these corrections relative to the purpose of the report, their magnitudes only are noted.

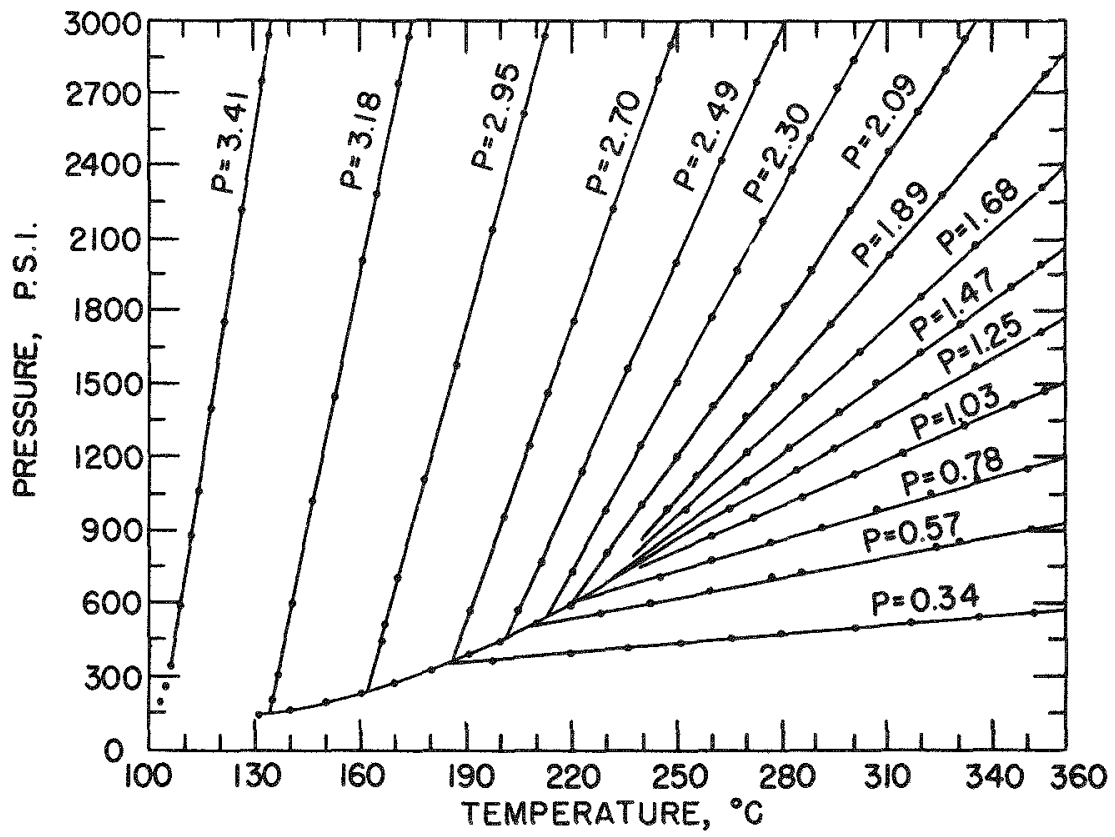

Fig. B.1-Pressure-temperature curve for $\mathrm{UF}_{6}$ at various densities. Gauge pressure vs. temperature $\left({ }^{\circ} \mathrm{C}\right)$ is plotted. 


\section{B.3 RESULTS}

The direct results of the measurements are plotted in Fig. B.1 in the form of curves showing pressure vs. temperature for various values of the density. The points plotted were chosen at random from the experimental data, approximately 1 of every 2 measured on the straight portions and 1 of every 20 on the vapor-pressure curve. A total of 447 points was determined, from which those shown in Fig. B.1 were selected without discrimination.

By the use of values read from experimental graphs, it was possible to obtain a number of other graphs.

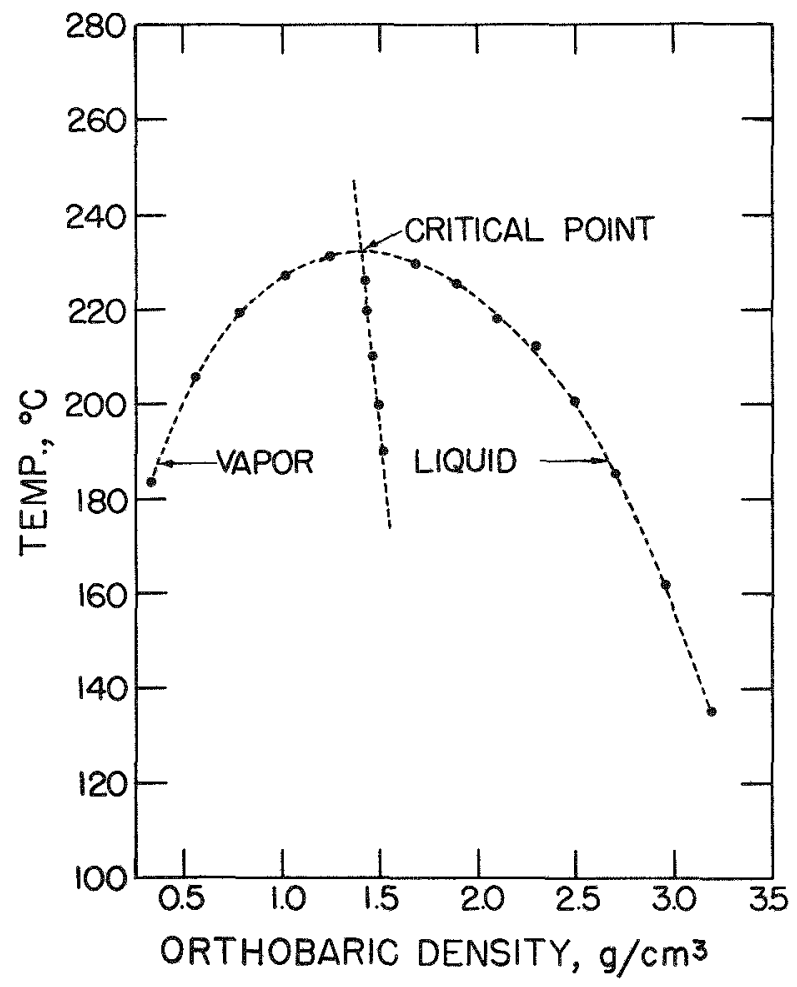

Fig. B.2-Orthobaric density of $\mathrm{UF}_{6}$. The straight line represents the average of liquid and vapor densities. The intersection of the straight line with the curve provides a simple way to determine the critical density.

Figure B.2 gives curves of the orthobaric densities of liquid and vapor as functions of the temperature. It also includes a curve of the mean of the two, which is found to be very nearly a straight line (the 


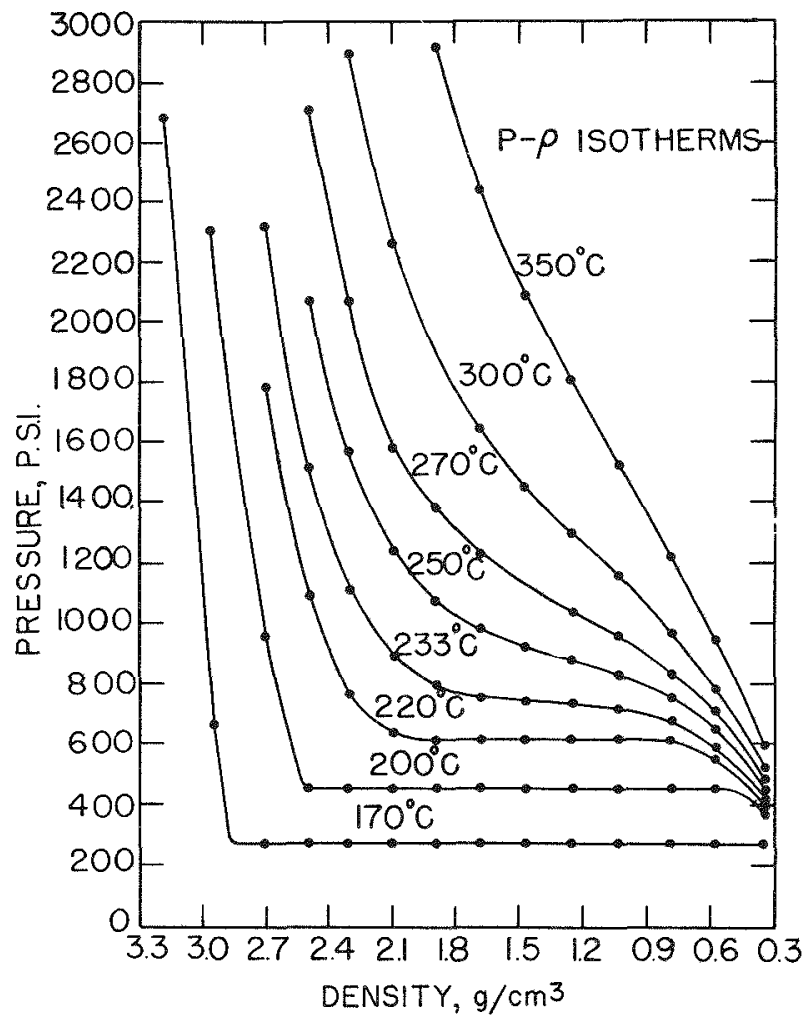

Fig. B.3-Pressure-density curves for $U_{6}$.

law of rectilinear diameters). The critical temperature is at the point where the curves for the liquid and vapor join.

Figure B. 3 consists of a family of isotherms, showing the dependence of the density, $\rho$, on the pressure, $P$, at various temperatures.

On the basis of the earlier measurements of critical temperature by means of $x$ rays and from the curves in Fig. B.2, the critical temperature was taken to be $232.5^{\circ} \mathrm{C}$. From the curve of mean density shown in Fig. B.2, the critical density at this temperature is $\rho_{\mathrm{c}}=1.41 \mathrm{~g} / \mathrm{cm}^{3}$, and the critical molar volume is $\mathrm{V}_{\mathrm{c}}=0.250$ liter. 


\title{
Appendix C \\ VISCOSITY OF LIQUID URANIUM HEXAFLUORIDE
}

\author{
W. N. Blatt
}

The viscosity was measured by flowing $\mathrm{UF}_{6}$ through a tubing of known length and diameter. The pressure to drive the material came from a thermal syphon. The rate of flow was measured by heating the material to a constant temperature and extracting the heat in a calorimeter bath. Variations in pressure could be effected by connecting a container of $\mathrm{UF}_{6}$ to the system and adjusting the temperature of the container.

Table C.1 gives the values of the viscosity at various temperatures and pressures, calculated on the basis of Poiseuille's formula.

$\mathrm{K}$. Cohen, using an expression for the viscosity, $\mu$,

$$
\mu=\mathrm{A} \exp \left(\Delta \mathrm{F}^{*}-\mathrm{P} \Delta \mathrm{V}^{*}\right) / \mathrm{RT}
$$

based on the theory of the liquid state, fitted the constants empirically to the data given in Table C.1 and obtained the following values:

$$
\begin{aligned}
A & =1.67 \times 10^{-3} \text { poise } \\
\Delta \mathrm{F}^{*} & =1100 \mathrm{cal} / \mathrm{mole} \\
\Delta \mathrm{V}^{*} & =28 \mathrm{~cm}^{3}
\end{aligned}
$$

Table C.1 - VALUES OF VISCOSITY AT VARIOUS TEMPERATURES AND PRESSURES

\begin{tabular}{ccc}
\hline $\begin{array}{c}\text { Viscosity, } \\
\text { millipoises }\end{array}$ & $\begin{array}{c}\text { Temperature, } \\
{ }^{\circ} \mathrm{C}\end{array}$ & $\begin{array}{c}\text { Pressure, } \\
\text { psi }\end{array}$ \\
\hline 10.35 & 75.8 & 3000 \\
6.89 & 153.5 & 3200 \\
5.52 & 248.0 & 3000 \\
5.05 & 250.0 & 1000 \\
7.88 & 74.6 & 374 \\
6.68 & 153.0 & 400 \\
\hline
\end{tabular}




\section{VISCOSITY OF LIQUID URANIUM HEXAFLUORDE}

$R$ being the gas constant. It follows that Cohen's formula can be written

$$
\mu=1.67 \times 10^{-3} \exp (554-0.023 P) / \mathrm{T}
$$

where $T$ is in degrees Kelvin and $P$ is in pounds per square inch. 


\title{
Appendix D \\ MEASUREMENT OF DIFFUSION COE F FICIENT OF URANIUM HEXAFLUORIDIS
}

\author{
N. Rosen and W. E. Whybrew
}

Since the ordinary diffusion coefficient plays an important role in determining column behavior, an experiment was carried out to measure this coefficient. The idea on which the measurement was based was rather simple: The two halves of a long narrow tube were filled with material having two different concentrations of light constituent, and diffusion was allowed to take place for a definite period of time with the tube kept in a constant-temperature bath. From the change in the mean concentration in each half of the tube, as determined by means of a mass spectroscope, the diffusion coefficient could be calculated. In carrying out this idea, however, certain difficulties had to be overcome; in particular, precautions had to be taken to avoid appreciable convection, which, if present, could mask the effect of diffusion.

In addition to the practical value of the measurement described here, it is believed that the work also has a certain amount of scientific interest. The diffusion coefficient measured is the coefficient for the diffusion of one isotope (the lighter one) into the other. In the present case, however, the isotopes concerned differ in mass by such a small percentage that the coefficient is essentially that of self-diffusion.

\section{D.1 EXPERIMENTAL WORK}

The tubes used for the diffusion experiment were made from $1 / 8$-in. O.D. and 0.06-in. 1.D. nickel tubing cut into 6-in. lengths, narrow tubing being used in order to reduce convection currents. Two such tubes, connected by means of a close-fitting nickel sleeve (5/16 in. in outside diameter and $1 \frac{1}{2}$ in. long) and Lunkenheimer fittings, formed the "sample tube,"

At the beginning of the experiment, the two halves of each sample tube were filled with material having two different concentrations of 
- $\quad U^{235}$. During this operation it was necessary to prevent air pockets from being left in the tube. The tube to be filled was connected to a small container, in the form of a closed copper tube $(1 / 4 \mathrm{in}$. in outside diameter, $3 / 16 \mathrm{in}$. in inside diameter, and $4 \mathrm{in}$. long), containing about $8 \mathrm{~g}$ of $\mathrm{UF}_{\mathrm{g}}$. To get rid of air in the system, the container was heated until about $3 \mathrm{~g}$ of material had passed through the tube and escaped from its open end, whereupon the open end was quickly crimped and welded. Both the tube and the container were heated to about $200^{\circ} \mathrm{C}$ to render the material highly fluid. The tube was then immersed in a water bath having a temperature of about $70^{\circ} \mathrm{C}$ and was kept there for about $3 \mathrm{~min}$, and then dry ice was applied to the junction of the tube and the container to freeze the material there. It was found that, if the tube was disconnected, weighed, connected again to the container, heated to drive out the material, and refilled as before while immersed in the $70^{\circ} \mathrm{C}$ bath, the weight of material in the tube was substantially the same as after the first filling; therefore, this method of filling gave essentially reproducible results.

In the same way, the mate to this tube was filled from another small chamber containing material of a different concentration. When both tubes were ready, they were disconnected from the containers, and, after it was verified that the material filling each tube was flush with the opening, the tubes were fitted into the nickel sleeve so that the open ends were in contact, and the Lunkenheimer fittings were made tight. Four sample tubes were made up in this way.

The two ends of each sample tube were bent into arcs about $4 \mathrm{in}$. in length and $4 \mathrm{in}$. in radius, both in the same plane, in order to form a wide U-shaped figure. One purpose for using this shape was to maintain a continuous column of liquid in the sample tube during the diffusion process, the sample tube being kept in the constant-temperature bath in a vertical plane with the nickel sleeve at the bottom; therefore, if any vapor formed, it would collect at the ends of the tube. Another reason for using this shape was that, when the sample tube was put into the constant-temperature bath, during the approach to temperature equilibrium the material at the bottom of the tube was cooler than that at the top because of the difference in wall thickness, and thus convection was kept down. A thin wire was fastened between the two ends of the sample tube to facilitate handling it.

The constant-temperature bath, in which the samples were kept, consisted of a cylindrical copper vessel, about $12 \mathrm{in}$. in diameter and $10 \mathrm{in}$. high, enclosed in a Masonite box lined with $3 \mathrm{in}$. of cork. The vessel was covered with a copper lid suspended by chains from an insulating cover containing a 3 -in. layer of Celotex. The stirrer motor was mounted on a brass plate resting on the insulating cover and separated from it by a 1-in. layer of sponge rubber to reduce vibration. 
The stirrer was of the perforated-cylinder type and was attached to the end of a vertical shaft extending down from the motor through suitable openings into the bath. For the bath liquid, Prestone was used because of its comparatively low vapor pressure. The main heating for the bath was provided by a copper coil covering almost the entire lateral surface of the copper vessel and carrying water under forced circulation from a large commercial constant-temperature bath, which is referred to as the "auxiliary bath." Additional heating was provided by a resistance-type heating element, the voltage being controlled by a Cariac. The temperature was regulated by means of a bimetallic thermostat in the auxiliary bath, which controlled the heater, and a mercury thermostat in the main bath, which actuated the heating element through a sensitive relay. The temperature of the main bath was measured by means of a Beckmann thermometer, the readings of which could be estimated to $0.001^{\circ} \mathrm{C}$; the auxiliary bath had an ordinary mercury-inglass thermometer, the readings of which could be estimated to $0.01^{\circ} \mathrm{C}$.

To hold the sample tubes in the bath, a wooden box ( 8 in. long, 3 in. wide, and $6 \mathrm{in}$. high on the outside) with a hinged cover was made of $1 / 2$ in. stock. The box, covered with a protective paint coating, was weighted down with copper plates attached to the top and bottom and was lined with sheet copper. The inside of the box was divided into four compartments, each about $1 / 2$ in. wide, by means of vertical sheetcopper partitions extending lengthwise. The design of the box was intended to reduce fluctuations in the temperatures of the sample tubes since such fluctuations could bring about mixing.

Before the constant-temperature bath was put into service, it underwent extensive observation and adjustment. The purposes were to adjust the temperature of the heating water and the current in the heating elements in order to obtain a temperature of about $70^{\circ} \mathrm{C}$, and, at the same time, to reduce the temperature fluctuations in the bath to a minimum, and also to study the behavior of the bath temperature after adjustments had been made to assure the stability of conditions.

When it appeared that the behavior of the constant-temperature bath was reasonably reliable and that no significant improvement was to be obtained through further adjustment of the bath equipment, the diffusion run was started. The four sample tubes that were filled with material, as previously described, were placed in the four compartments of the wooden box, each sample tube being in a vertical plane, with the nickel sleeve at the bottom and the two ends, or horns, at the top and with the axis of symmetry in the vertical direction. The box was lowered gently into the bath and was allowed to fill with bath liquid. The covers of the box and of the bath were closed, and the bath was allowed to reach temperature equilibrium, which required several hours.

During the diffusion period there was a temperature oscillation in the bath with an amplitude of the order of $0.01^{\circ} \mathrm{C}$ and a period of 4 or $5 \mathrm{~min}$. 
The' corresponding variation in the temperature of the sample tubes in the box was presumably considerably less. There was also a slow drift of irregular period in the temperature, with an amplitude of approximately $0.04^{\circ} \mathrm{C}$. During the removal of a sample tube, there was a temperature drop of the order of $0.1^{\circ} \mathrm{C}$. Furthermore, on the morning of the twenty-first day, when all but one sample tube had been removed, it was discovered that, during the previous night, the thermostat of the auxiliary bath had stuck, resulting in a rise in temperature of the main bath of about $0.45^{\circ} \mathrm{C}$. This was corrected over a period of several hours, and it did not appear to have introduced any irregularity in the final results. The mean bath temperature was about $69.5^{\circ} \mathrm{C}$.

The sample tubes were removed one at a time from the bath at the end of $4,12,20$, and 28 days. The procedure for removing a sample was as follows: With the sample tube kept in its vertical position, the middle part, i.e., the nickel sleeve, was at once plunged into a dry-ice and alcohol mixture in order to freeze the liquid at the junction of the two halves before any appreciable mixing occurred there. When all the sample tubes had been taken out of the bath, the two halves of each tube were separated. The contents of each half were thoroughly mixed and were analyzed for the light constituent on the mass spectroscope. From the results of the analyses, the diffusion coefficient was calculated, as will be described in Sec. D.3.

\section{D.2 THEORY}

If a substance diffuses in a long narrow tube of uniform cross section, the differential equation governing the diffusion process is given by

$$
\frac{\partial c}{\partial t}=D \frac{\partial^{2} c}{\partial x^{2}}(0 \leq x \leq a)
$$

where $c$ is the concentration of the substance at the time $t$ and at a distance $\mathrm{x}$ from one end, $\mathrm{D}$ is the diffusion coefficient, and $\mathrm{a}$ is the length of the tube. If the tube is closed at both ends, since the diffu-

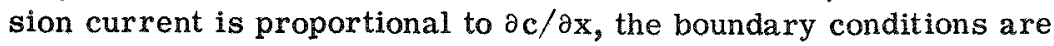

$$
\frac{\partial c}{\partial x}=0(x=0, a)
$$

Assume that initially $(t=0)$

$$
c=c_{1}^{0}\left(0 \leq x<\frac{a}{2}\right) \quad c=c_{2}^{0}\left(\frac{a}{2} \leq x \leq a\right)
$$




\section{LIQUID THERMAL DIFFUSION}

where $c_{1}^{0}$ and $c_{2}^{0}$ are constants and $c_{1}^{0}>c_{2}^{0}$. Then the solution can be expressed in the form

$c=\frac{1}{2}\left(c_{1}^{0}+c_{2}^{0}\right)+\frac{2}{\pi}\left(c_{1}^{0}-c_{2}^{0}\right) \sum_{n^{o d d}} \frac{\sin n \pi / 2 \cos n \pi x / a}{n} \exp \left[-\left(n^{2} \pi^{2} D t\right) / a^{2}\right]$

Now denote by $\overline{c_{1}}$ and $\bar{c}_{2}$ the mean values of $c$ over the two halves of the tube

$$
\overline{\mathrm{c}}_{1}=\frac{2}{\mathrm{a}} \int_{0}^{\mathrm{a} / 2} \mathrm{cdx} \quad \overline{\mathrm{c}}_{2}=\frac{2}{\mathrm{a}} \int_{0}^{\mathrm{a} / 2} \mathrm{cdx}
$$

By the use of Eq. 4, it is found that

$$
\bar{c}_{1}=\frac{1}{2}\left(c_{1}^{0}+c_{2}^{0}\right)+\frac{4}{\pi^{2}}\left(c_{1}^{0}-c_{2}^{0}\right) \sum_{n^{\text {odd }}} \frac{1}{n^{2}} \exp \left[-\left(n^{2} \pi^{2} D t\right) / a^{2}\right]
$$

and

$$
\bar{c}_{2}=\frac{1}{2}\left(c_{1}^{0}+c_{2}^{0}\right)+\frac{4}{\pi^{2}}\left(c_{2}^{0}-c_{1}^{0}\right) \sum_{n} \frac{1}{n^{2}} \exp \left[-\left(n^{2} \pi^{2} D t\right) / a^{2}\right]
$$

so that

$$
\frac{1}{2}\left(\widetilde{c}_{1}+\bar{c}_{2}\right)=\frac{1}{2}\left(c_{1}^{0}+c_{2}^{0}\right)=\vec{c}
$$

If

$$
\Delta \mathrm{c}=\overline{\mathrm{c}}_{1}-\overline{\mathrm{c}}_{2} \quad \Delta \mathrm{c}^{0}=\mathrm{c}_{1}^{0}-\mathrm{c}_{2}^{0}
$$

it follows that

$$
\frac{\Delta c}{\Delta c^{0}}=\frac{8}{\pi^{2}} \sum_{n} \frac{1}{n^{2}} \exp \left[-\left(n^{2} \pi^{2} D t\right) / a^{2}\right]
$$

If $t$ is sufficiently large so that all but the first term in the series of Eq. 9 can be neglected, which will be the case if Dt/a $\sim 0.04$ or larger, then this equation can be solved for $D$, obtaining

$$
\mathrm{D}=\frac{\mathrm{a}^{2}}{\pi^{2} \mathrm{t}} \ln \left(\frac{8}{\pi^{2}} \frac{\Delta \mathrm{c}^{0}}{\Delta \mathrm{c}}\right)
$$

which will be valid provided $\Delta c^{0} / \Delta c \sim 2$ or larger. 


\section{DIFFUSION COEFICIENT OF URANIUM HEXAFLUORIDE}

\section{D.3 DATA AND RESULTS}

The average effective length of a sample tube (corresponding to a in Sec. D.2) was $24.4 \pm 0.5 \mathrm{~cm}$, the estimated uncertainty taking account of the tapering of the bore near the crimped ends. The analyses of the concentrations initially and at various times are given in Table D.1 in the form $\Delta c / \bar{c}$. By means of Eq. 10, D was calculated for $t=12,20$,

Table D.1-DIFFUSION COEFFICIENT OF UF

\begin{tabular}{ccc}
$t$, days & $\Delta \mathrm{c} / \overline{\mathrm{c}}$ & $\begin{array}{c}\mathrm{D} \times 10^{5}, \\
\mathrm{~cm}^{2} / \mathrm{sec}\end{array}$ \\
\hline 0 & $0.577 \pm 0.010$ & \\
4 & $0.453 \pm 0.008$ & \\
12 & $0.335 \pm 0.006$ & $1.95 \pm 0.17$ \\
20 & $0.283 \pm 0.004$ & $1.76 \pm 0.11$ \\
28 & $0.211 \pm 0.004$ & $1.99 \pm 0.10$ \\
\hline
\end{tabular}

and 28 days; this equation was not valid for the case $t=4$ days. The results are included in Table $D_{0} 1$, which also indicates the uncertainties in various quantities due to uncertainties in the analyses.

The final result is taken as

$$
\mathrm{D}=(1.90 \pm 0.13) \times 10^{-5} \mathrm{~cm}^{2} / \mathrm{sec}
$$

In order to show the relation between the calculated and the measured values, in general, and in particular for the case $t=4$ days (which has not been used thus far), Fig. D.1 presents a graph of $\Delta c / \bar{c} v s . t$, as calculated from Eq. 9, using the value from Eq. 11 for D, as well as the corresponding experimental points, represented by the $x$ 's. The agreement between the experimental points and the curve, as calculated with a suitable choice of the one constant $D$, appears to be satisfactory.

\section{D.4 DISCUSSION}

It is obvious that the value of the diffusion coefficient obtained in the present work, if it is in error, is more likely to be too high than too low, because, if any disturbing factor were present that tended to bring about mixing, its effect on the concentration distribution would be more or less equivalent to that of an increase in the rate of diffusion. In fact, the experimental conditions were intended to eliminate, or at least to reduce, such disturbances; however, it is uncertain to what extent success in this matter was achieved. If such disturbances were present in 


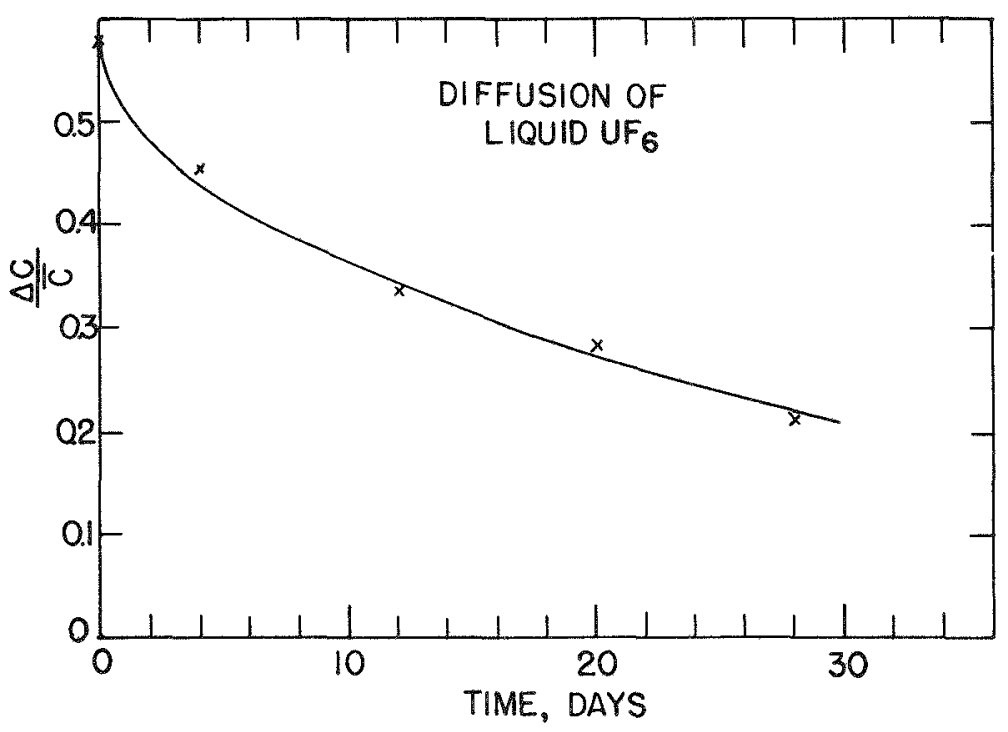

Fig. D.1-Diffusion that occurs when two samples of liquid $U_{6}$ with different concentrations of $\mathrm{U}^{235}$ are connected together. $\Delta \mathrm{c}$ is the difference in the concentration of the two samples.

the experiment, however, they must have been small since the value of the coefficient obtained was small, and hence would be expected to depend strongly on the experimental corrections; therefore, changes in these conditions should lead to marked changes in the final results. Now, before the work described here was carried out, some preliminary experiments, based on the same principle but involving a number of differences in apparatus and procedure, had been run. The preliminary experiments will not be described here; the important fact is that the final value for the diffusion coefficient obtained in those experiments turned out to agree, to within about the estimated experimental error, with that of the present work. This is a good indication that the measured value is that of the true diffusion coefficient.

It is interesting to note that Cohen, ${ }^{1}$ using an approximate formula for the diffusion coefficient of a liquid given by Powell, Roseveare, and Eyring, ${ }^{2}$ predicted a value of about $5 \times 10^{-5} \mathrm{~cm}^{2} / \mathrm{sec}$. According to the present measurements, the value at $69.5^{\circ} \mathrm{C}$ is smaller, but the order of magnitude is that predicted by Cohen. At the temperatures in the working space of a column, the mean value should be considerably higher.

\section{RE FERENCES}

1. K. Cohen, Report A-531, Feb. 4, 1943.

2. R. E. Powell, W. E. Roseveare, and H. Eyring, Ind. Eng. Chem., 33: 430 (1941). 


\section{Appendix E \\ CORROSION OF NICKEL BY URANIUM HEXAFLUORIDE AT HIGH TEMPERATURES}

In order to determine the rate of corrosion by $U F_{6}$ at high temperatures, obviously of great importance in column work, the following experiment was carried out.

Three nickel strips were each washed with carbon tetrachloride, dried, and weighed. The strips were sealed inside a welded nickel container. The container and the strips were then subjected to treatment with fluorine at $375^{\circ} \mathrm{C}$ for $2 \mathrm{hr}$. A sufficient quantity $\left(1 \frac{1}{2} \mathrm{lb}\right)$ of $\mathrm{UF}_{6}$ to give a density of $1 \mathrm{~g} / \mathrm{cm}^{3}$ was distilled into the container. The container was then heated for $1 \mathrm{hr}$ at $375^{\circ} \mathrm{C}$, the pressure being therefore about 1500 psi. The $\mathrm{UF}_{6}$ was then distilled out, and fluorine was again passed through for $1 \mathrm{hr}$ at $375^{\circ} \mathrm{C}$. The container was cooled and its

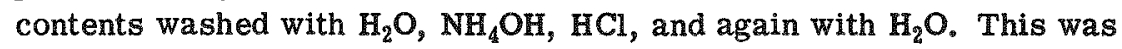
done for the purpose of removing uranyl fluoride, formed by the reaction of $\mathrm{UF}_{6}$ with nickel oxide, which was produced during the welding process. The container and its contents were dried, and fluorine was again passed through for $1 \mathrm{hr}$ at $375^{\circ} \mathrm{C}$. A sufficient quantity of $\mathrm{UF}_{6}$ was again distilled into the container to give a density of $1 \mathrm{~g} / \mathrm{cm}^{3}$. The container and its contents were then maintained at a temperature of $350^{\circ} \mathrm{C}$ for seven days. At the end of that time, the $\mathrm{UF}_{6}$ was removed by distillation, and the nickel container was cut apart. Examination of the container and the strips showed no loose uranium compound of any kind, either on the strips or in the container. The strips were found to show gains in weight of 0,1 , and $4 \mathrm{mg}$. Three other strips, treated in the same way except that they were subjected only one day to $\mathrm{UF}_{6}$ at $350^{\circ} \mathrm{C}$, showed losses in weight of 15,12 , and $10 \mathrm{mg}$. On this basis, the effect of running for six days at $350^{\circ} \mathrm{C}$ is an average increase in weight of $14 \mathrm{mg}$ per strip. Since the exposed surface area of each strip was about $1 / 3 \mathrm{sq} \mathrm{ft}$, the observed gain in weight represents $7 \mathrm{mg} / \mathrm{sq} \mathrm{ft} /$ day.

Subsequently the experiment was repeated with other strips. The changes in weight for strips exposed to $U F_{6}$ at $350^{\circ} \mathrm{C}$ for various peri- 
Table E.1-WEIGHT CHANGES IN MLLLIGRAMS FOR NICKEL STRIPS EXPOSED TO $\mathrm{UF}_{6}$

\begin{tabular}{lrrrc}
\hline & 1 day & 2 days & 7 days & 35 days \\
\hline & -9 & +2 & +4 & -5 \\
& -15 & 0 & +1.0 & -6 \\
& -13 & -15 & 0 & +13 \\
Average & -12 & -4.3 & +1.7 & +3.5 \\
\hline
\end{tabular}

ods are given in Table E.1. It should be emphasized that the data refer to different strips cut out of the same piece of nickel sheet.

It appeared from the data that there was little change in weight after two days. Since the area of each strip was about $1 / 3 \mathrm{sq} \mathrm{ft}$, the corrosion rate must have been less than $2 \mathrm{mg} / \mathrm{sq} \mathrm{ft}$, and probably less than $1 \mathrm{mg} /$ sq ft/day.

Since the nickel in the above experiments was exposed to the $\mathrm{UF}_{6}$ at a temperature appreciably higher than that to be found in a column, it was concluded that the rate of corrosion of nickel in a column would be too small to have any practical significance. 
BIBLIOGRAPHY (1940 to 1946) 
$-$

$-$

$+$ 
Bardeen, Phys. Rev., 57: 35 (1940).

Bardeen, Phys. Rev., 58: 94 (1940).

Bramley, Phys. Rev., 56: 359 (1940).

Bramley, Science, 92: 427 (1940).

Brodsky, Acta Physicochim. U.R.S.S., 13: 294 (1944).

Brodsky, Acta Physicochim. U.R.S.S., 17: 224 (1942).

Brown, Phys. Rev., 57: 242 (1940).

Brown, Phys. Rev., 58: 661 (1940).

Cacciapuoti, Nuovo cimento, (9)1: 126 (1943).

Carr, Phys. Rev., 61: 726 (1942).

Carr, J. Chem. Phys., 12: 349 (1944).

Chapman, Nature, 146: 431 (1940).

Chapman, Proc. Roy. Soc. London, 177: 38 (1940).

Chapman and Cowling, Proc. Roy. Soc. London, 179: 159 (1941).

Clusius and Dickel, Z. physik. Chem., B48: 50 (1940).

Clusius and Dickel, Naturwissenschaften, 28: 461, 711 (1940).

Clusius, Kelsch, and Waldmann, Z. physik. Chem., A189: 131 (1941).

Clusius and Kowalski, Chem. Fabrik, 304 (1940).

Clusius and Kowalski, Z. Elektrochem., 47: 81.9 (1941).

Clusius and Waldmann, Naturwissenschaften, 30: 711 (1942).

Farber and Libby, J. Chem. Phys., 8: 965 (1940).

Fleischmann, Physik. Z., 41: 14 (1940).

Fournier, Compt. rend., 215: 529 (1942).

Fournier, J. phys, radium, (8)5: 11, 45 (1944).

Fournier, J. phys. radium, (8)6: 104 (1945).

Frankel, Phys. Rev., 57: 661 (1940).

Furry, Phys. Rev., 61: 388 (1942).

Furry and Jones, Phys. Rev., 57: 561 (1940).

Furry and Jones, Phys. Rev., 69: 459 (1946).

Furth, Proc. Roy. Soc. London, 179: 461 (1942).

Gillespie and Breck, J. Chem. Phys., 9: 370 (1941).

Grew, Proc. Roy. Soc. London, 178: 390 (1941).

Grew, Nature, 150: 320 (1942).

Grew, Nature, 156: 267 (1945).

Grew, Phil. Mag., 35: 30 (1944).

Groot, Physica, 9: 699, 801 (1942).

Groot, Gorter, and Hoogenstraaten, Physica, 9: 923 (1942).

Groot, Gorter, and Hoogenstraaten, Physica, 10: 81 (1943).

Gurevich, J. Expt1. Theoret. Phys. U.S.S.R., 14: 1, 60, 121 (1944). 
Harrison, Proc. Roy. Soc. London, 181: 93 (1942).

Heath, Ibbs, and Wild, Proc. Roy. Soc. London, 178: 380 (1941).

Hellund, Phys. Rev., 57: 319, 328 (1940).

Hellund, Phys. Rev., 58: 737, 743 (1940).

Hiby and Wirtz, Physik. Z., 41: 77 (1940).

Hiby and Wirtz, Physik. Z., 44: 369 (1943).

Hireta, Bull. Chem. Soc. Japan, 16: 232, 274 (1941).

Hireta, J. Chem. Soc. Japan, 62: 392, 480 (1941).

Hveding, Tidsskr. Kjemi Bergvesen Met., 1: 110 (1941).

Jensen, Angew. Chem., 54: 405 (1941).

Jones, Phys. Rev., 58: 111 (1940).

Jones, Phys. Rev., 59: 688, 1019 (1941).

Jones and Furry, Phys. Rev., 57: 457 (1940).

Kathari and Rai, Indian J. Phys., 17: 103 (1943).

Kendell, Nature, 150: 136 (1942).

Kitagawa, J. Chem. Soc. Japan, 61: 1293 (1940).

Kitagawa and Wake, J. Chem. Soc. Japan, 62: 100 (1941).

Korsching, Naturwissenschaften, 31: 348 (1943).

Korsching and Wirtz, Ber. deut, chem. Ges., 73: 248 (1940).

Krasny-Ergen, Phys. Rev., 58: 1078 (1940).

Leaf and Wall, J. Phys. Chem., 46: 820 (1942).

Martin and Kuhn, Z. physik. Chem., A189: 219 (1941).

Meisner, Ann. phys., 39: 333 (1941).

Murin, Uspekhi Khim., 10: 671 (1941).

Murin, Compt. rend. acad. sci. U.R.S.S., 41: 291 (1943).

Murin, Compt. rend. acad. sci. U.R.S.S., 42: 386 (1944).

Murin, Doklady Akad. Nauk S.S.S.R., 42: 400 (1944).

Murin, Alkhazov, and Ratner, Bull, acad. sci. U.R.S.S., Classe sci. chim., 3-7

(1943).

Nier, Phys. Rev., 57: 40, 448, 458 (1940).

Nier and Bardeen, J. Chem. Phys., 9: 690 (1941).

Niyogi, Sci. and Culture, 7: 567 (1942).

Onsager, Phys. Rev., 57: 562 (1940).

Pollard and Watson, Phys. Rev., 58: 12 (1940).

Riehl, Z. Elektrochem., 49: 306 (1943).

Schmahl and Schewe, Z. Elektrochem., 46: 203 (1940).

Seaborg, Wahl, and Kennedy, J. Chem. Phys., 8: 639 (1940).

Shrader, Phys. Rev., 69: 439 (1946).

Simon, Phys. Rev, 60: 173 (1941).

Simon, Phys. Rev., 61: 388 (1942).

Spicer, J. Chem. Educ., 22: 593 (1945).

Steinwedel, Chemie, Die, 55: 152 (1942).

Stetter, Oesterr. Chemiker-Ztg., 45: 130 (1942).

Stier, Phys. Rev., 61: 740 (1942).

Stier, Phys. Rev., 62: 548 (1942).

Taylor, Rev. Sci. Instr., 15: 1 (1944).

Taylor and Glockler, J. Chem. Phys., 8: 843 (1940).

Taylor and Ritchie, Nature, 145: 670 (1940).

Urey, J. Wash. Acad. Sci., 30: 277 (1940). 


\section{BIBLIOGRAPHY}

Urey, J. Appl. Phys., 12: 270 (1941).

Waldmann, Z. Physik, 121: 501 (1943).

Waldmann, Naturwissenschaften, 31: 204 (1943).

- Waldmann, Naturwissenschaften, 32: 222, 223 (1944).

Wall and Holley, J. Chem. Phys., 8: 348, 949 (1940).

Watson, Phys. Rev., 57: 562, 899 (1940).

Watson, Simon, and Woernley, Phys. Rev., 62: 558 (1942).

Watson and Woernley, Phys. Rev., 63: 181, 220 (1943).

Weber, Physica, 8: 113 (1941).

Welles, Phys. Rev., 59: 920 (1941).

Westhaver and Brewer, J. Chem. Phys., 8: 314 (1940).

Wirtz, Z. Physik, 118: 510 (1941).

Wirtz, Naturwissenschaften, 31: 349, 415 (1943).

Wirtz, Physik. Z., 44: 221 (1943). 


\section{INDEX}


$-$

$-$

$-$ 


\section{INDEX}

C

Carbon isotopes, separation of, 17

Chlorine isotopes, separation of, 16

Circulation, boundary conditions for, 137-140

effect of, 137-146

to reservoir, 141-143

to storage chamber, $143-146$

Clusius-Dickel column (see Thermal diffusion column)

Column constants, 43-44, 155-156

Column imperfections, 37-38

Column operation, $39-41$

Column performance, effect of length, $57-58$

effect of pressure, 54-57

effect of temperature, 53-54

Column spacing, 50-52

effect of temperature, 53

Column structure, $36-37$

Column turbulence, 106-108

Columns, design characteristics, 29 differential equation for, 97-104 experimental studies, 43-58 geometrical irregularities in, 106-108

in pyramid (see Pyramid)

steady state in, 104-106

temperature irregularities in, 107-108

(See also Thermal diffusion column)

Columns, nonuniform, in parallel operation, 212-220

average properties of, $217-218$ examples of, 218-220

general treatment of, 212-217
Continuous pyramid (see Pyramid)

Current density in diffusion, 95-96

\section{$\mathrm{D}$}

Design, optimum performance, for continuous pyramid, $148-150$ for small pyramid, 182-190

\section{E}

Enrichment rate, $163-166$

Equilibrium, approach to, 13,16 , $44-48,89-92$

circulation effect on, 137-146

(See also Circulation)

by single column, 116-136

closed at both ends, 130-131

with finite reservoir, 127-129

general case, 133-136

with infinite reservoir, $117-126$

with infinite reservoir and finite storage chamber, 132-133

by small pyramid, 195-205

Equilibrium separation, 13-14, 16

\section{G}

General outline, 3-10

H

Historical development, prior to 1940, 11-19

1940 to $1945,20-27$ 


\section{I}

Isotope separation, carbon, 17 chlorine, 16

effect of wall spacing on, 16,23

neon, 15

potassium, 21

relation to product rate, $48-49$

sample analysis, 41-42

uranium, 22

in water solutions, effect of column length, 30

effect of salt, 32

effect of salt concentration, $29-30$

effect of spacing, 31-32

effect of temperature, $30-31$

equilibrium time, 32-33

parasitic effect of azimuthal gradients, 33-34

zinc, 18

\section{$\mathrm{N}$}

Neon isotopes, separation of, 15

Nickel, corrosion by uranium

hexafluoride, $239-240$

P

Parallel operation of nonuniform columns, 212-220

Performance criteria, 155-166

column constants, 155-156

enrichment rate, 163-166

productivity quotient $\mathrm{Q}, 156-160$

relation between $Q$ and $E, 162-163$

separative efficiency $E, 160-162$

Philadelphia pilot plant, 24-25, 26 $60,62-83$

Plant design and operation, 59-83

(See also Philadelphia pilot plant and $S-50$ plant)

Potassium isotopes, separation of, 21 Processes, thermal diffusion, basic, 11, 95-96

Product removal, 110-115
Productivity quotient, 156-160

relation to separative efficiency, 162-163

Pyramid, columns in, 84-85

equations for, 167-169

operated anywhere in pyramid, 172-180

operated singly or in top stage, 169-172

continuous, 147-154.

design for optimum performance, $148-150$

equations for, 147-148

structure, 150-153

time to put into operation, $153 \cdots 154$

operational procedure, 88-89

physical make-up, 85-88

small, in approach to equilibrium, 195-205

examples, 198-205

method, 195-198

design for optimum performance, 182-190

operating time in, 191-194

performance, comparison of, 90-92, 190-191

separation factors in, 90,92 , 181-182

stripper section for, 206-211

R

Rectifiers, approach to equilibrium, 46

$\mathrm{S}$

S-1 Committee, 23

S-50 plant, 25-27, 60-61

Separation, of isotopes (see Isotope separation)

of typical salt solutions, 13

Separation efficiency, 160-162

relation to productivity quotient, 162-163 
Separation factor, $90,92,123,125$, $129,131,134$

dependence on concentration, 179 in small pyramid, 181-182

Soret effect, 11-14

in solutions, copper sulfate, 12

dilute, 12-13

of organic compounds, 13

Steady state in columns (see Columns)

Stripper section, pyramid, 206-211

Strippers, approach to equilibrium, 47

\section{$\mathrm{T}$}

Thermal diffusion column, 14-18, $35-42$

constants, 155-156

differential equation of, 97-104

factors governing operation, 16

irregularities in, 106-108

processes in, 95-96

product removal from, 110-115

size, 23

in steady state, 104-106

Trennrohr, 15

variation of conditions in, 108-110
Transport, 16

Trennrohr column, 15

Turbulence, column, 106-108

U

Uranium hexafluoride, corrosion of nickel by, 239-240

critical temperature, measurement, 223-225

diffusion coefficient, 232-238

liquid, viscosity, 230-231

pressure-temperature-volume

characteristics, 226-229

production, 21-22

properties, $35-36$

Uranium isotopes, separation of, 22

W

Water solutions, 28-34

Z

Zinc isotopes, separation of, 18 